UNIVERSIDADE DE SÃO PAULO

FFCLRP - DEPARTAMENTO DE BIOLOGIA

PROGRAMA DE PÓS-GRADUAÇÃO EM BIOLOGIA COMPARADA

\title{
Dinâmica da regeneração natural de um cerrado stricto sensu no Nordeste do Estado de São Paulo
}

MARCO ANTONIO GOMES SOUTO

Tese apresentada à Faculdade de Filosofia, Ciências e Letras de Ribeirão Preto da USP, como parte das exigências para obtenção do título de Doutor em Ciências, Área: Biologia Comparada. 


\title{
Dinâmica da regeneração natural de um cerrado stricto sensu no Nordeste do Estado de São Paulo
}

\author{
Versão Corrigida
}

Tese apresentada à Faculdade de Filosofia, Ciências e Letras de Ribeirão Preto da USP, como parte das exigências para obtenção do título de Doutor em Ciências, Área: Biologia Comparada.

Orientador: Prof. Dr. Milton Groppo 
Autorizo a reprodução e divulgação total ou parcial deste trabalho, por qualquer meio convencional ou eletrônico, para fins de estudo e pesquisa, desde que citada a fonte.

Souto, Marco Antonio Gomes

Dinâmica da regeneração natural de um cerrado stricto sensu no Nordeste do Estado de São Paulo. Ribeirão Preto, 2017.

140 p. : il. ; $30 \mathrm{~cm}$

Tese de Doutorado, apresentada à Faculdade de Filosofia, Ciências e Letras de Ribeirão Preto/USP. Área de concentração: Biologia Comparada.

Orientador: Groppo, Milton.

1. Cerrado. 2. Stricto sensu. 3. Regeneração natural. 4. São Paulo. 5. Biodiversidade vegetal. 
SOUTO, M. A. G. Dinâmica da regeneração natural de um cerrado stricto sensu no Nordeste do Estado de São Paulo. 2017. 140 f. Tese (Doutorado em Ciências) - Faculdade de Filosofia, Ciências e Letras, Universidade de São Paulo, Ribeirão Preto, 2017.

Aprovado em: 19 de outubro de 2017.

\section{Banca Examinadora}

Prof. Dr. Milton Groppo Junior

Instituição: Universidade de São Paulo - RP

Julgamento:

Profa. Dra. Alba Regina Barbosa Araújo

Instituição: Universidade de Franca

Julgamento:

Profa. Dra. Carolina Ferreira Gomes

Instituição: Universidade de São Paulo - RP

Julgamento:

Dr. José Ricardo Barosela

Instituição: Universidade de São Paulo - RP

Julgamento:

Dra. Olga Kotchetkoff Henriques

Instituição: Prefeitura Municipal de Ribeirão Preto.

Julgamento: 


\section{AGRADECIMENTOS}

Todas as energias benéficas que me acompanharam durante todo o processo do doutorado, desde a motivação da busca até a conclusão da tese.

Minha esposa e companheira Juliana por sempre apoiar e participar de mais essa etapa da minha vida.

Minha filha Helena por, mesmo sem saber, ter paciência e aceitar as ausências de seu pai em alguns momentos.

Meus pais e toda a família pela presença e apoio irrestrito em todos os momentos.

Minha ex-orientadora, Prof ${ }^{a}$. Dr ${ }^{\text {a }}$. Silvana Aparecida Godoy, e meu atual orientador, Prof. Dr. Milton Groppo.

Ao Programa de Biologia Comparada da USP - Ribeirão Preto, todos os seus professores e seus funcionários.

Aos proprietários da Fazenda Santa Cecília pela autorização do estudo em áreas de preservação da propriedade.

Ao Ramon Santana pelo grande auxílio nas atividades de campo na etapa dos estudos florísticos.

CNPq pela bolsa de doutorado durante todo o período.

Meu muito obrigado! 
Quanto mais aumenta nosso conhecimento, mais evidente fica nossa ignorância.

John Kennedy 


\section{RESUMO}

SOUTO, M. A. G. Dinâmica da regeneração natural de um cerrado stricto sensu no Nordeste do Estado de São Paulo. 2017. 140 f. Tese (Doutorado em Ciências) - Faculdade de Filosofia, Ciências e Letras, Universidade de São Paulo, Ribeirão Preto, 2017.

A savana pode ser definida, em linhas gerais, como um ambiente com características intermediárias entre campo e floresta. Em virtude de sua grande distribuição geográfica, sendo encontrada em aproximadamente $30 \%$ das áreas com estações secas do planeta, existem cerca de 200 definições diferentes para o conceito de savana. O Cerrado brasileiro, classificado como um tipo de savana, acompanha a tendência de apresentar inúmeras definições de acordo com o autor ou região. Apesar disso, pode-se afirmar que o Cerrado é o segundo maior bioma brasileiro ocupando cerca de $21 \%$ do território nacional, distribuindo-se em grande extensão norte-sul, apresentando desde formações florestais até campos abertos. No presente estudo define-se cerrado stricto sensu como o ambiente com a presença de árvores de pequeno porte, retorcidas e com ramificações irregulares, geralmente com cascas com cortiça e folhas xeromórficas. $O$ atual estado de conservação das savanas é crítico e, especificamente no estado de São Paulo, essa situação não é diferente, sendo que os remanescentes de cerrado estão sob grandes pressões antrópicas, principalmente a pressão das atividades agrícolas que convertem a paisagem natural por meio da modificação da cobertura vegetal, comprometendo a conservação das áreas naturais, extremamente fragmentadas e alteradas. Dado o atual estado de conservação do cerrado, é fundamental o conhecimento da situação de conservação dos remanescentes e como estão ocorrendo os processos de regeneração natural dessas áreas contribui neste processo, pois para fundamentar qualquer ação de conservação, manejo ou intervenção direta as informações sobre a biodiversidade vegetal são essenciais. Assim, o objetivo deste estudo foi estudar aspectos da dinâmica da regeneração natural da vegetação de um remanescente de cerrado stricto sensu localizado no município de Patrocínio Paulista - SP. Para isso, caracterizou-se a composição do estrato adulto do remanescente, o estrato juvenil, a chuva e banco de sementes, complementando essas informações com dados fenológicos de seis espécies arbóreas, todos estudos realizados em um fragmento de cerrado stricto sensu com 100 ha localizado na Fazenda Santa Cecília, Patrocínio Paulista - SP. Os resultados obtidos indicam claramente uma diminuição da biodiversidade vegetal local, onde os estratos regenerativos representam uma amostra muito pequena do estrato adulto atual. Aumentando-se a escala temporal da análise, utilizando os resultados apresentados pelo único estudo fitossociológico realizado no mesmo fragmento no ano de 2004, essa tendência fica ainda mais evidente, reforçando os resultados encontrados no presente estudo. A composição florística do estrato regenerativo com uma diversidade muito aquém do esperado, não apresentando uma biodiversidade compatível com o esperado, indica o fracasso do processo de regeneração no fragmento analisado. O processo de diminuição da biodiversidade vegetal local, com a possível extinção de muitas espécies vegetais em médio e longo prazos, caracteriza o fragmento analisado como um escoadouro de biodiversidade. Esse processo representa um enorme risco para a biodiversidade local e regional, alterando características estruturais e relacionadas à dinâmica da área. Estudos mais detalhados precisam ser desenvolvidos com o intuito de se verificar como as ações (naturais ou antrópicas) estão afetando diferentes componentes naturais (polinizadores, dispersores, aspectos fisiológicos das espécies vegetais etc.) provocando tão rápida diminuição da biodiversidade local. A manutenção em longo prazo da cobertura vegetal de uma área depende, diretamente, da capacidade de conservação e desenvolvimento dos complexos processos relacionados à regeneração natural da comunidade e, se de alguma maneira, esses processos forem afetados, toda a dinâmica natural de uma área pode ser comprometida.

Palavras chave: cerrado, stricto sensu, regeneração natural, São Paulo, biodiversidade vegetal. 


\begin{abstract}
SOUTO, M. A. G. Dynamics of the natural regeneration of a cerrado stricto sensu in the Northeast of the State of São Paulo. 2017. 140 f. Tese (Doutorado em Ciências) - Faculdade de Filosofia, Ciências e Letras, Universidade de São Paulo, Ribeirão Preto, 2017.
\end{abstract}

The savanna can be broadly defined as an environment with intermediate characteristics between field and forest. Due to its great geographical distribution, being found in approximately $30 \%$ of the dry areas of the planet, there are about 200 different definitions for the savanna concept. The Brazilian Cerrado, classified as a type of savannah, accompanies the tendency to present numerous definitions according to the author or region. In spite of this, it can be affirmed that the Cerrado is the second largest Brazilian biome occupying about $21 \%$ of the national territory, being distributed in great north-south extension, presenting from forest formations to open fields. In the present study cerrado stricto sensu is defined as the environment with the presence of small trees, twisted and with irregular branches, usually with bark with cork and xeromorphic leaves. The current conservation status of the savannas is critical and, specifically in the state of São Paulo, this situation is not different, being that the remnants of cerrado are under great anthropic pressures, mainly the pressure of the agricultural activities that convert the natural landscape through the modification of the vegetal cover, compromising the conservation of the natural areas, extremely fragmented and altered. Given the current state of conservation of the cerrado, it is essential to know the conservation status of the remnants and to know how natural regeneration processes are taking place in these areas, since in order to substantiate any conservation action, management or direct intervention information on plant biodiversity are essential. Thus, the objective of this study was to study aspects of the dynamics of the natural regeneration of the vegetation of a remnant of cerrado stricto sensu located in the municipality of Patrocínio Paulista - SP. For this, the composition of the adult stratum of the remnant, the juvenile stratum, rainfall and seed bank were characterized, complementing this information with phenological data of six tree species, all studies carried out on a fragment of cerrado stricto sensu with 100 ha in Fazenda Santa Cecília, Patrocínio Paulista - SP. The results clearly indicate a decrease in local plant biodiversity, where the regenerative strata represent a very small sample of the current adult stratum. Increasing the time scale of the analysis, using the results presented by the only phytosociological study carried out in the same fragment in the year 2004, this trend is even more evident, reinforcing the results found in the present study. The floristic composition of the regenerative stratum with a diversity that is much lower than expected, does not present a biodiversity compatible with the expected, indicates the failure of the regeneration process in the analyzed fragment. The process of decreasing local plant biodiversity, with the possible extinction of many plant species in the medium and long term, characterizes the fragment analyzed as a drainage of biodiversity. This process poses a huge risk to local and regional biodiversity, altering structural characteristics and related to the dynamics of the area. More detailed studies have to be carried out in order to verify how natural or anthropogenic actions are affecting different natural components (pollinators, dispersers, physiological aspects of plant species, etc.), causing a rapid reduction of local biodiversity. The long-term maintenance of the vegetative cover of an area depends directly on the conservation and development capacity of the complex processes related to the natural regeneration of the community and, if in any way, these processes are affected, all the natural dynamics of an area can be compromised.

Keywords: cerrado, stricto sensu, natural regeneration, São Paulo, plant biodiversity. 


\section{LISTA DE FIGURAS}

\section{INTRODUÇÃO}

Figura 1 Mapa de distribuição do bioma Cerrado no estado de São Paulo

Figura 2 Visão geral do fragmento de cerrado stricto sensu localizado na Fazenda Santa Cecília e seu entorno.

Figura 3 Área do fragmento de cerrado stricto sensu localizado na Fazenda Santa Cecília, Patrocínio Paulista - SP e localização das 30 parcelas de coleta do fragmento

\section{CAPÍTULO I}

Figura 1 Curva cumulativa espécie-área para a área amostrada de cerrado stricto sensu da Fazenda Santa Cecília, Patrocínio Paulista - SP.

Figura 2 Classes de diâmetro $(\mathrm{cm})$ dos indivíduos da área de cerrado stricto sensu da Fazenda Santa Cecília, Patrocínio Paulista - SP.

Figura 3 Classes de altura $(\mathrm{m})$ dos indivíduos da área de cerrado stricto sensu da Fazenda Santa Cecília, Patrocínio Paulista - SP.

\section{CAPÍTULO II}

Figura 1 Curva do coletor do estrato de regeneração do cerrado stricto sensu da Fazenda Santa Cecília, com intervalo de confiança de $95 \%$.

\section{CAPÍTULO IV}

Figura 1 Normais climáticas do município de Patrocínio Paulista - SP

Figura 2 Dados climáticos do município de Patrocínio Paulista - SP.

Figura 3 Eventos fenológicos e suas respectivas intensidades mensais de Xylopia aromatica em fragmento de cerrado stricto sensu em Patrocínio Paulista SP

Figura 4 Eventos fenológicos e suas respectivas intensidades mensais de Copaifera langsdorffii em fragmento de cerrado stricto sensu em Patrocínio Paulista SP......

Figura 5 Eventos fenológicos e suas respectivas intensidades mensais de Dalbergia miscolobium em fragmento de cerrado stricto sensu em Patrocínio Paulista SP.

Figura 6 Eventos fenológicos e suas respectivas intensidades mensais de Pterodon emarginatus em fragmento de cerrado stricto sensu em Patrocínio Paulista $\mathrm{SP}$

Figura 7 Eventos fenológicos e suas respectivas intensidades mensais de Qualea grandiflora em fragmento de cerrado stricto sensu em Patrocínio Paulista SP.

Figura 8 Eventos fenológicos e suas respectivas intensidades mensais de Qualea multiflora em fragmento de cerrado stricto sensu em Patrocínio Paulista SP.

Figura 9 Diagrama de presença e ausência das fenofases nos meses de observação para seis espécies localizadas no fragmento de cerrado stricto sensu da Fazenda Santa Cecília, Patrocínio Paulista - SP...

\section{CAPÍTULO $V$}

Figura 1 Dendrograma dos índices de similaridade de Sorensen dos diferentes estratos do fragmento de cerrado stricto sensu da Fazenda Santa Cecília, Patrocínio Paulista - SP 
Figura 2 Quantidade de espécies lenhosas em diferentes estratos em fragmento de cerrado stricto sensu da Fazenda Santa Cecília, Patrocínio Paulista - SP

Figura 3 Distribuição das espécies de acordo com Taxa de Regeneração Natural (TRN)...

Figura 4 Distribuição das espécies do estrato adulto do fragmento de cerrato stricto sensu da Fazenda Santa Cecília segundo suas características (grupo ecológico e síndrome de dispersão).

Figura 5 Distribuição das espécies do estrato de regeneração do fragmento de cerrato stricto sensu da Fazenda Santa Cecília segundo suas características (grupo ecológico e síndrome de dispersão). 


\section{LISTA DE TABELAS}

\section{CAPÍTULO I}

Tabela 1 Parâmetros fitossociológicos das espécies com PAS $\geq 15 \mathrm{~cm}$, amostradas no cerrado stricto sensu na Fazenda Santa Cecília, Patrocínio Paulista, SP, em ordem decrescente de VI.

Tabela 2 Classificação quanto a síndrome de dispersão e grupo ecológico das espécies vegetais amostradas no cerrado stricto sensu na Fazenda Santa Cecília, Patrocínio Paulista, SP.

\section{CAPÍTULO II}

Tabela 1 Parâmetros fitossociológicos das espécies com PAS entre $5-15 \mathrm{~cm}$, amostradas no cerrado stricto sensu na Fazenda Santa Cecília, Patrocínio Paulista, SP, em ordem decrescente de VI.

Tabela 2 Classificação quanto a síndrome de dispersão e grupo ecológico das espécies vegetais amostradas no cerrado stricto sensu na Fazenda Santa Cecília, Patrocínio Paulista, SP.

\section{CAPÍTULO III}

Tabela 1 Espécies amostradas na chuva de sementes de fragmento de cerrado stricto sensu localizado na Fazenda Santa

Cecília.

\section{CAPÍTULO IV}

Tabela 1 Classificação quanto a síndrome de dispersão e grupo ecológico das espécies vegetais amostradas no cerrado stricto sensu na Fazenda Santa Cecília, Patrocínio Paulista, SP.

Tabela 2 Escala de intensidade dos estados fenológicos.

Tabela 3 Interpretação dos valores de correlação de Spearman, conforme Shimakura (2017).

Tabela 4 Correlações de Spearman entre temperatura e eventos fenológicos das seis espécies analisadas.

Tabela 5 Correlações de Spearman entre precipitação e eventos fenológicos das seis espécies analisadas.

\section{CAPÍTULO V}

Tabela 1 Espécies e respectivas famílias amostradas no cerrado stricto sensu na Fazenda Santa Cecília, Patrocínio Paulista SP.

Tabela 2 Características populacionais quantitativas do estrato adulto amostrado por Teixeira et al. (2004) e pelo presente estudo.

Tabela 3 Distribuição das espécies amostradas segundo suas características ecológicas em cada componente da vegetação de fragmento de cerrado stricto sensu localizado no município de Patrocínio Paulista - SP.

Tabela 4 Valores dos índices de diversidade dos estratos adulto, de regeneração, chuva de sementes do presente estudo e do estrato adulto encontrado no trabalho de Teixeira et al. (2004).

Tabela 5 Taxas de Regeneração Natural (TRN), em porcentagem, de espécies lenhosas encontradas em um fragmento de cerrado stricto sensu localizado na Fazenda Santa Cecília, Patrocínio Paulista - SP. 


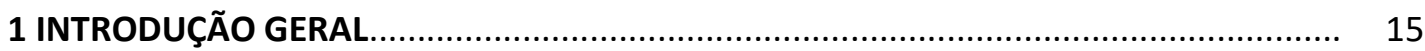

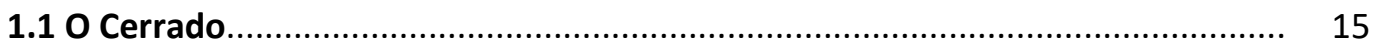

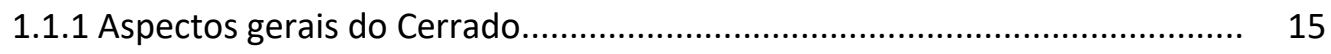

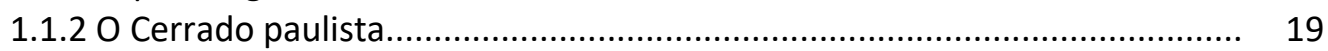

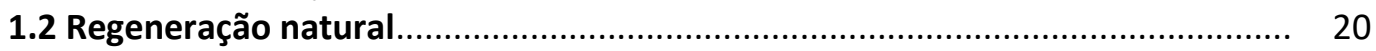

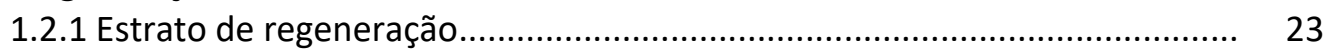

1.2.2 Chuva e banco de sementes...................................................................... 23

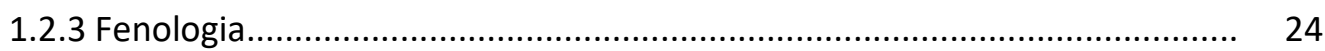

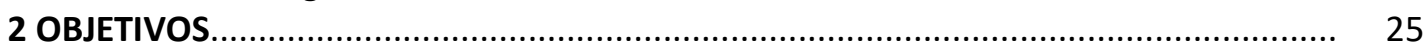

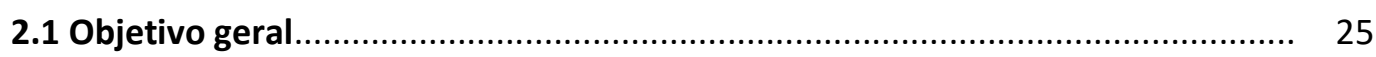

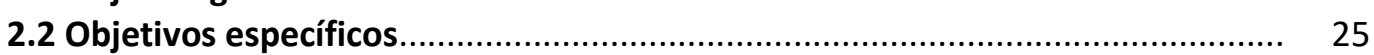

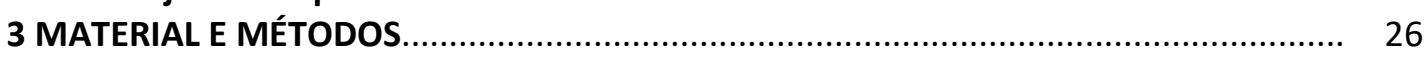

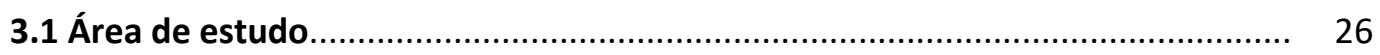

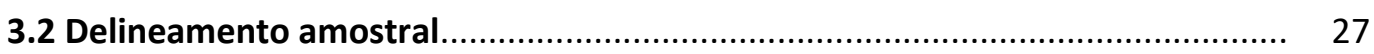

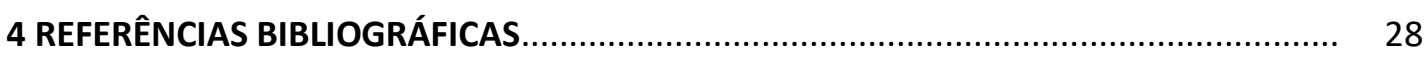

CAPÍTULO I: Estrutura e composição do estrato adulto de um remanescente de cerrado stricto sensu localizado em Patrocínio Paulista - SP...................................... 34

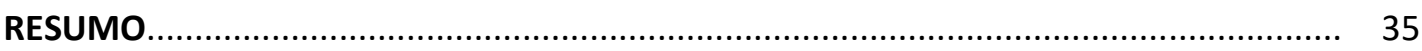

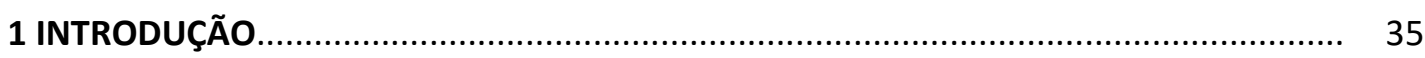

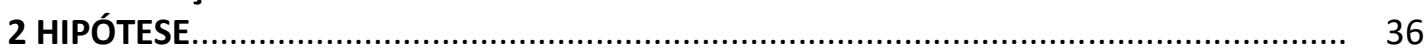

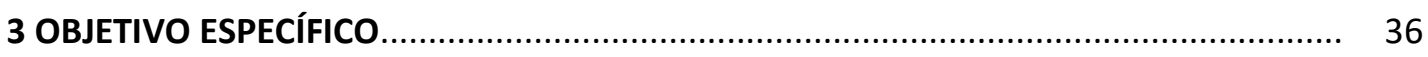

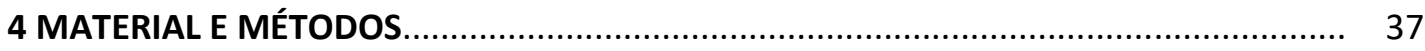

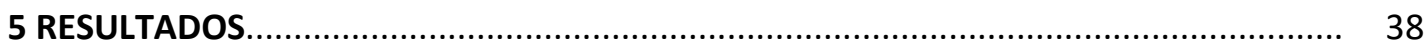

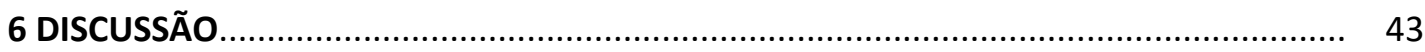

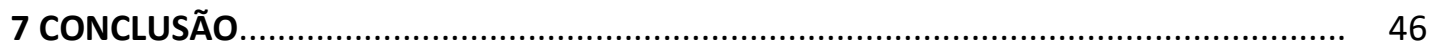

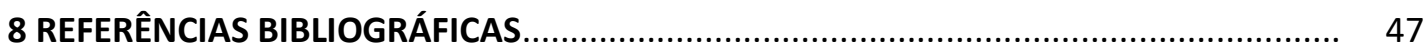

CAPÍTULO II: Estrutura e composição do estrato de regeneração de um remanescente de cerrado stricto sensu localizado em Patrocínio Paulista - SP........... 53

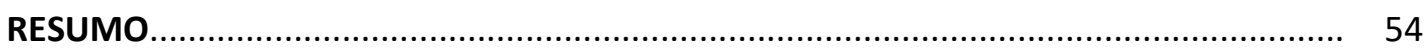

1 INTRODUÇÃO

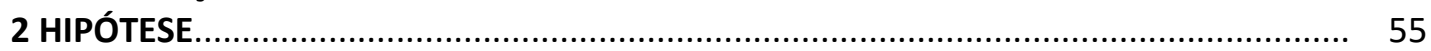

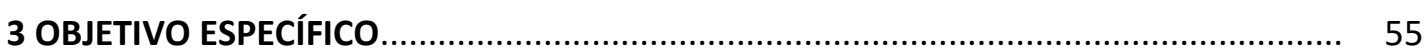

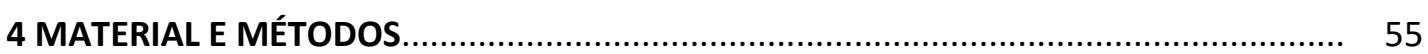

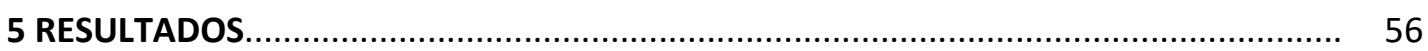

6 DISCUSSÃO

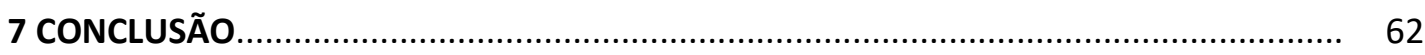

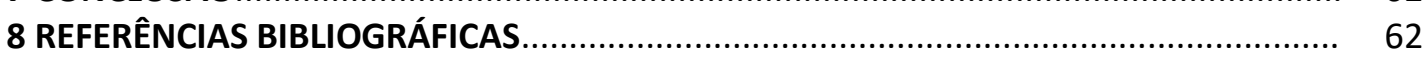

CAPÍTULO III: Chuva e banco de sementes de um remanescente de cerrado stricto

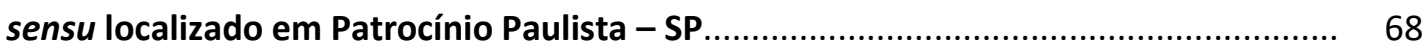

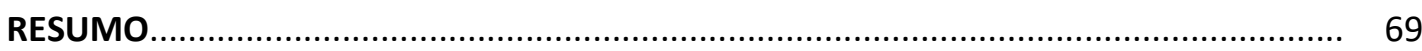

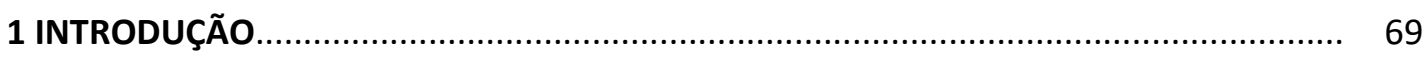

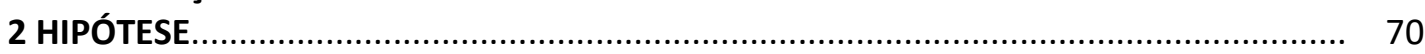

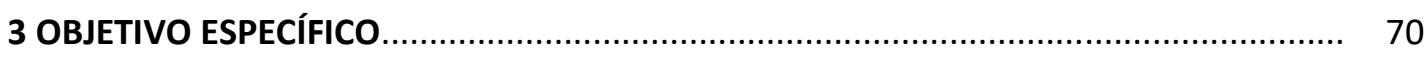

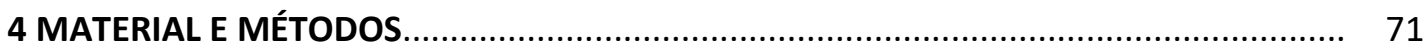

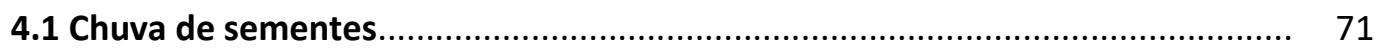

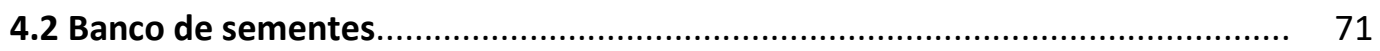

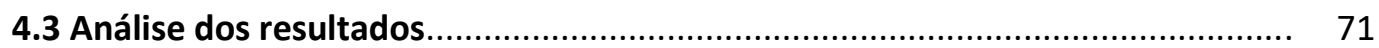


5 RESULTADOS

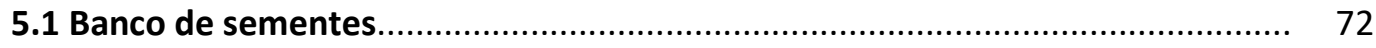

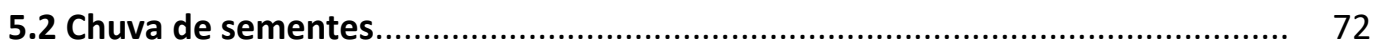

6 DISCUSSÃO

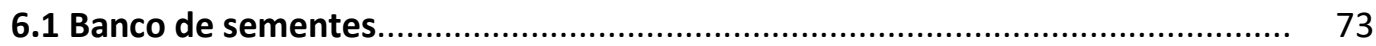

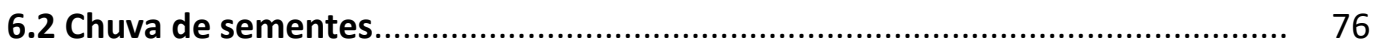

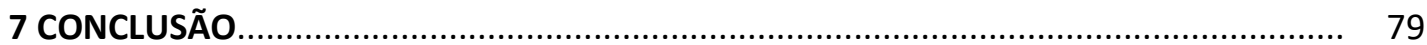

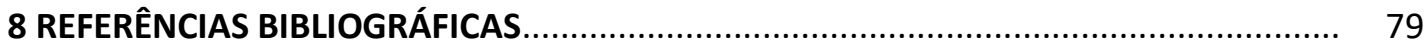

CAPÍTULO IV: Fenologia de seis espécies arbóreas em um remanescente de cerrado stricto sensu localizado em Patrocínio Paulista - SP..................................................... 85

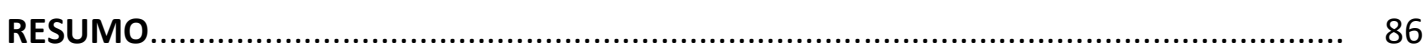

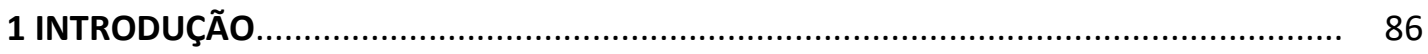

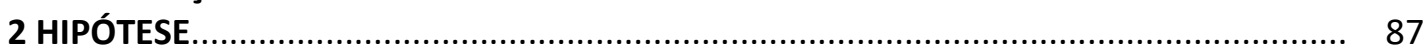

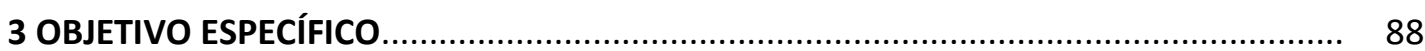

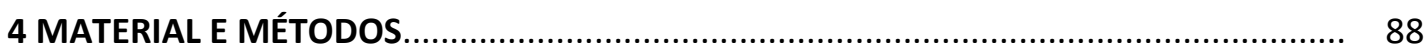

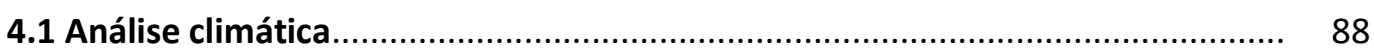

4.2 Espécies estudadas............................................................................... 88

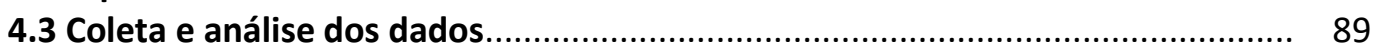

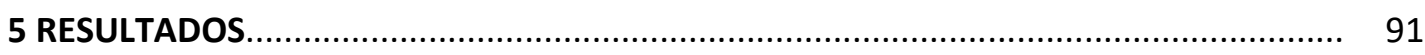

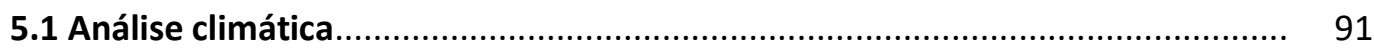

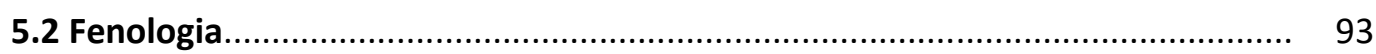

5.2.1 Xylopia aromatica (Lam.) Mart. ............................................................... 93

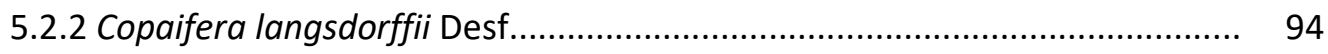

5.2.3 Dalbergia miscolobium Benth............................................................... 94

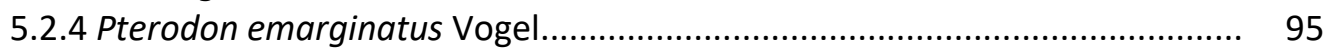

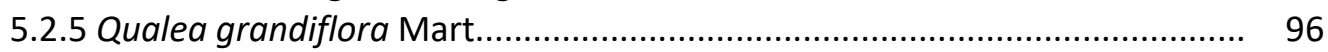

5.2.6 Qualea multiflora Mart.................................................................................. 9

5.3 Índice de Correlação de Spearman.............................................................. 98

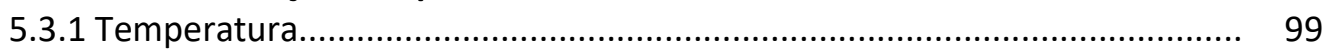

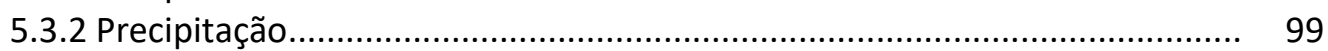

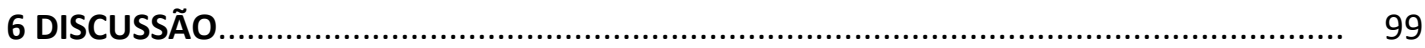

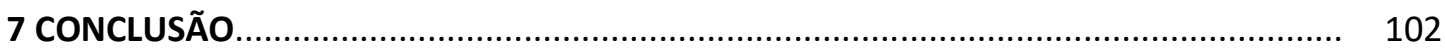

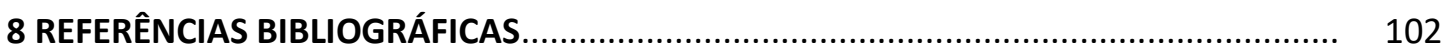

CAPÍTULO V: Dinâmica de regeneração de um remanescente de cerrado stricto sensu localizado em Patrocínio Paulista - SP .............................................................. 107

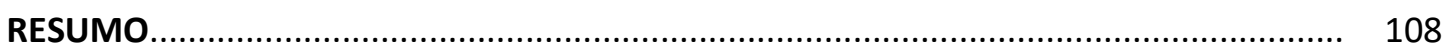

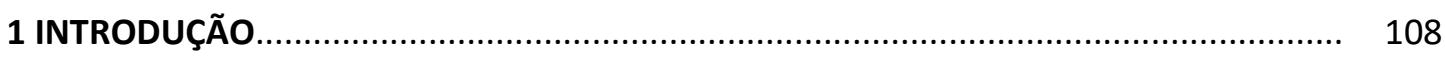

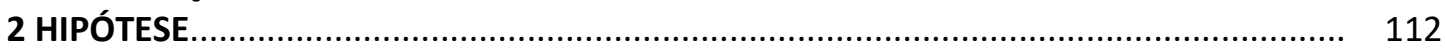

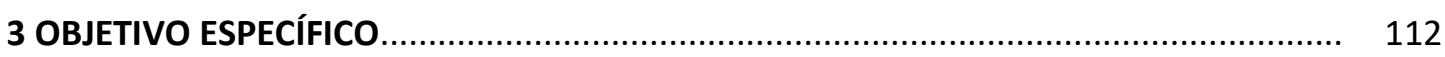

4 MATERIAL E MÉTODOS....................................................................... 112

4.1 Similaridade florística entre estratos...................................................... 112

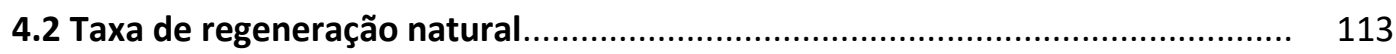

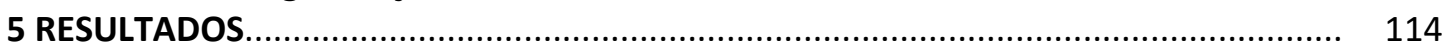

5.1 Similaridade florística entre estratos........................................................... 114

5.2 Taxa de Regeneração Natural (TRN) ........................................................ 121

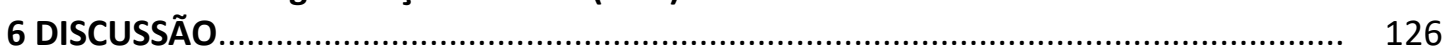

6.1 Comparação entre estratos adultos: Teixeira et al. (2004) e presente estudo... 127

6.2 Comparação entre estrato adulto do presente estudo e estrato de regeneração..................................................................................................... 130

6.3 Comparação entre estrato de regeneração e chuva de sementes...................... 132 


\section{INTRODUÇÃO GERAL}

\subsection{Cerrado}

\subsubsection{Aspectos gerais do Cerrado}

Atualmente, a definição de savana, tratando-se do domínio fitogeográfico mundial, é muito controversa devido, principalmente, a grande quantidade de definições baseadas em conceitos diversos (Walter et al., 2008). Savanas podem ser encontradas em diferentes latitudes de todos os continentes do mundo, sendo que em cada região são adotados critérios de definição, nem sempre claros e distintos, causando muitas confusões conceituais e práticas. Essa enorme diversidade de tratamento torna muito extensa a literatura disponível, dificultando comparações, análises e definição de fatores influentes em nível mundial. Isto não provoca, apenas, desdobramentos acadêmicos, dificultando ou impossibilitando comparações diretas (Eiten, 1986), mas também influencia diversas questões práticas relacionadas à medidas e aspectos conservacionistas, além da definição de políticas de defesa dessas áreas.

De forma geral, savana é aceita como uma paisagem que apresenta características intermediárias entre campo e floresta, possuindo um estrato de gramíneas, que pode ser contínuo ou não, e árvores e arbustos em quantidades variáveis, sendo essa a definição mais ampla da formação fisionômica.

A definição mais recente de savana foi apresentada por Mistry (2000) e inclui aspectos temporais e funcionais, dando uma abordagem mais atual à definição. $\mathrm{O}$ autor afirma que as savanas são "ecossistemas dinâmicos determinados pela umidade e nutrientes disponíveis para as plantas, pelo fogo e pela herbivoria, a diferentes escalas espaciais e temporais". Além dessas duas definições, Walter et al. (2008) apresentam mais 10 definições para o conceito de savana e ressaltam que podem existir cerca de 200 definições para o conceito, considerandose as posições dos diversos autores que se dedicam ao tema.

Como bioma, as savanas são encontradas em cerca de 30\% das áreas terrestres do planeta (Mistry, 2000), sendo que em áreas tropicais essa taxa de cobertura pode alcançar $40 \%$, distribuídos em áreas extremamente diversificadas, tanto em relevo quanto em tipo de solo (Cole, 1986; Collinson, 1988). Os principais aspectos ambientais que influenciam a distribuição das savanas são o clima e o solo (Cole, 1986), mas outros fatores não podem ser ignorados, como a hidrologia, a geomorfologia e o fogo. Adicionalmente, não se pode ignorar a ação humana que influencia diretamente nas características das savanas, já que cerca de $20 \%$ da população mundial habita áreas de ocorrência natural do bioma (Mistry, 2000). 
Considerado um tipo de savana, o bioma brasileiro Cerrado também é alvo da falta de uniformidade das definições e da clareza de parâmetros adotados em sua definição (Ribeiro e Walter, 2008).

Segundo maior bioma brasileiro, o Cerrado ocupava, originalmente, cerca de $21 \%$ do território do Brasil (aproximadamente $2.000 .000 \mathrm{~km}^{2}$ ), área distribuída, principalmente, no Planalto Central (Motta et al., 2002) e com pequenos encraves na Amazônia e no estado do Paraná (Oliveira-Filho e Ratter, 2002). Apresentando um complexo vegetacional que engloba desde formações florestais até campos abertos, o Cerrado pode ser encontrado em altitudes que vão de $300 \mathrm{~m}$ a até $1.600 \mathrm{~m}$ em uma extensa distribuição no sentido norte-sul (Ribeiro e Walter, 2008).

De acordo com Silva et al. (2008), o clima da região do Cerrado apresenta características estacionais, sendo bem definidas as estações seca (maio-setembro) e chuvosa (outubro-abril), sendo que a precipitação média anual varia entre $600-2.000 \mathrm{~mm}$. Essa grande oscilação das chuvas é resultado, dentre outros fatores, à grande extensão latitudinal do Cerrado, assim como dos biomas limítrofes, que influenciam decisivamente nas taxas pluviométricas (Silva et al., 2008). A temperatura média anual também é influenciada por aspectos geográficos, encontrando-se médias anuais de temperatura mais elevadas na porção norte do Cerrado $\left(23^{\circ} \mathrm{C}-27^{\circ} \mathrm{C}\right)$, onde a temperatura máxima pode atingir facilmente os $36^{\circ} \mathrm{C}$. Já na região centro-sul do Cerrado a média de temperatura diminui significativamente, ficando em torno de $18^{\circ} \mathrm{C}-22^{\circ} \mathrm{C}$ e a temperatura máxima dificilmente ultrapassa $31^{\circ} \mathrm{C}$ (Silva et al., 2008).

A grande extensão do Cerrado influencia, também, nos tipos de solo encontrados em seus domínios. Segundo Reatto et al. (2008), os solos com alta fertilidade são derivados de rochas ricas em minerais ferromagnesianos (basalto, diabásio e outros). Esse tipo de rocha, em relevos mais acidentados, sofre rápido intemperismo, gerando um solo rico em nutrientes que comporta formações florestais. Em áreas onde são encontradas rochas pobres em minerais (granitos, arenitos e outros) os solos apresentam alta porosidade e baixa fertilidade, além de serem muito suscetíveis à erosão. O mesmo autor informa ainda que os solos do Cerrado não podem ser classificados apenas nessas duas categorias, já que existem áreas onde ocorre a mistura, em diferentes composições, entre os tipos de solos, resultando em solos com vários níveis de fertilidade, o que irá influenciar, diretamente, na fitofisionomia encontrada na região.

Assim como para as savanas, nos estudos sobre o Cerrado há uma falta de uniformidade nas definições utilizadas, pois diferentes autores apresentam distintos posicionamentos (Ribeiro e Walter, 2008) e isso gera grandes dificuldades e até mesmo impedimentos na comparação de estudos disponíveis na ampla literatura disponível. 
Mais recentemente, Coutinho (2006) considerou cerrado como um bioma, enquanto Batalha (2011) afirma que o cerrado é um domínio fitogeográfico com diferentes tipos vegetacionais, incluindo desde o campo aberto até densas formações florestais. Ainda não existe um consenso sobre o conceito e aceita-se que essa indefinição é resultado da constituição peculiar do cerrado que, sobre um mesmo conceito, engloba diferentes formações vegetais, indo desde o campo aberto até densas formações florestais com 30 metros de altura (Aguiar et al., 2004).

Com todas essas indefinições e variantes em suas definições básicas, estima-se que existam cerca de 11.400 espécies de angiospermas para o Cerrado e uma taxa de endemismo das plantas vasculares de 36\% (Forzza et al., 2010). Grande parte da diversidade vegetal encontrada no Cerrado é motivada pela sua formação em mosaico de ecossistemas (Walter et al., 2008).

O fator determinante na distribuição da vegetação do cerrado tem sido alvo de controvérsia, mas em geral, alguns fatores são considerados relevantes: clima, tipo de solo, disponibilidade hídrica e de nutrientes do solo, topografia, latitude, profundidade do lençol freático e intervenção antrópica (Ribeiro e Walter, 2008). Todos esses fatores constroem uma intrincada relação, sendo necessária a análise integrada de tais fatores.

Segundo o sistema de classificação da vegetação adotado por Ribeiro e Walter (2008), pode-se reconhecer cerca de 25 fitofisionomias diferentes no Cerrado, classificadas em três categorias: formação florestal, savânicas e campestres.

Nas formações florestais de Cerrado percebe-se expressiva presença de espécies arbóreas e formação de dossel contínuo, podendo ou não estarem associadas a corpos hídricos superficiais. As formações florestais podem ser classificadas em: Mata de Galeria (Inundável ou Não Inundável), Mata Seca (Sempre-Verde, Semidecídua, Decídua) e Cerradão (Mesotrófico ou Distrófico).

As formações savânicas formam o grupo mais diverso fisionomicamente. Caracterizamse pela presença de espécies arbóreas em diferentes densidades (sem a formação de um dossel contínuo) e de um estrato arbustivo-herbáceo. Possui quatro fitofisionomias principais: Parque de Cerrado, Cerrado sentido restrito (Cerrado Denso, Cerrado Típico, Cerrado Ralo ou Cerrado Rupestre), Palmeiral (Babaçual, Buritizal, Guerobal ou Macaubal) e Vereda.

As formações campestres são caracterizadas pela ausência de espécies arbóreas que, quando presentes, apresentam indivíduos pouco desenvolvidos, e um estrato arbustivoherbáceo bem desenvolvido. A principal característica fisionômica que diferencia os tipos de formação campestre é a densidade de indivíduos arbustivos. As três fitofisionomias que 
podem ser classificadas como formação campestre são: Campo Sujo (Seco, Úmido, Murundus), Campo Limpo (Seco, Úmido, Murundus) e Campo Rupestre.

É importante ressaltar que a biodiversidade encontrada atualmente no Cerrado também possui relação com o seu histórico de formação (Ledru, 2002). A área central do Cerrado localiza-se no Planalto Central brasileiro e limita-se com quase todos os biomas do Brasil, exceto os campos sulinos e os ecossistemas costeiros e marinhos. De forma descontínua, existem porções de cerrado na Amazônia, na Caatinga e na Mata Atlântica, sendo que estes remanescentes são vestígios do processo histórico sofrido pelo Cerrado, que apresentou episódios de expansão e retração que responderam, basicamente, às mudanças climáticas (Aguiar et al., 2004). Durante os períodos secos, o cerrado expandiu ocupando áreas com formações florestais e durante os períodos úmidos a floresta ocupou áreas de Cerrado. As características atuais do Cerrado são resultado de um "clima intermediário", conforme relatam os autores acima citados.

Mas apesar de sua importância ecológica e natural, cerca de $80 \%$ da área original do Cerrado já foi alterada de alguma forma (Myers et al., 2000), principalmente pelas atividades antrópicas.

Diversos autores estudam os motivos que levam à descaracterização e a situação atual de conservação do Cerrado (Klink e Moreira, 2002; Machado et al., 2004; Alho, 2005; Felfili et al., 2005; Ribeiro et al., 2005; Ratter et al., 2006). Essas pesquisam mostram que em cerca de meio século as atividades antrópicas ocorrentes no Cerrado, originalmente criações extensivas de gado com baixíssimo impacto ambiental, tornaram-se altamente impactantes e transformadoras da cobertura vegetal, com a inclusão de pastagens com gramíneas africanas, agricultura mecanizada e ocupações urbanas, alterando totalmente a paisagem original (Machado et al., 2004).

Em todo o mundo, as áreas de savana sofrem intensa exploração humana, principalmente atividades agropecuárias. Isso se deve, dentre outros fatores, à pequena importância cultural, biológica e ecológica destinada aos domínios de vegetação não florestal, sendo que no Brasil, essa situação não é diferente. De acordo com Barros (2009), o Cerrado tornou-se uma alternativa legitimada por lei, ou pela sua ausência, a exploração de áreas florestais, como a Mata Atlântica ou Amazônia, para a expansão agrícola ou plantios florestais. Dessa forma, a intensa alteração da cobertura natural fragmentou intensamente a biota natural, inserindo-a em uma matriz severamente antropizada. Assim, ainda de acordo com Barros (2009), análises mais detalhadas indicam que cerca de $50 \%$ da área original de Cerrado brasileiro está totalmente alterada, sendo considerada como não-Cerrado, 17\% está 
severamente antropizada, outros $17 \%$ seriam áreas com níveis mais baixos de antropização e apenas $16 \%$ podem ser consideradas áreas de Cerrado não antropizado.

\subsubsection{O Cerrado paulista}

Quando comparada com a situação do Cerrado nacional, o cerrado paulista se mostra ainda mais impactado, pois no estado, originalmente, o cerrado que ocupava 14\% da área (São Paulo, 1997), atualmente encontra-se em menos de 1\% da área do estado. Essa área atual está completamente fragmentada em pequenas porções cercadas por pastagens, áreas agrícolas e urbanas. Destes remanescentes, a área localizada no nordeste do estado de São Paulo foi considerada pelo Ministério do Meio Ambiente (MMA, 2007) como uma área de alta prioridade para a conservação e recuperação do Cerrado no Brasil.

No Estado merece destaque a pressão exercida pelas culturas agrícolas, principalmente a cana-de-açúcar que está, gradativamente, substituindo a já fragmentada vegetação do cerrado (Durigan et al., 2004; Kronka et al., 2005). Importante destacar que a agricultura constitui uma forte pressão antrópica em todo o Cerrado brasileiro e, nessa análise, as principais culturas são a soja e o milho.

Uma grande ameaça para os biomas nacionais são as queimadas de origem antrópica, prática adotada amplamente em zonas rurais. Entretanto, no estado de São Paulo os incêndios de origem antrópica não constituem uma ameaça ao cerrado em virtude de uma lei que proíbe o seu uso em áreas naturais. Durigan et al. (2007) afirmam que diversos estudos não identificaram evidências de fogo em cerca de $80 \%$ das áreas de cerrado analisadas nos últimos anos.

Após a promulgação do Decreto 750 (Brasil, 1993), que dispõem sobre atividades exploratórias diretas da Mata Atlântica, destacando-se o desmatamento, houve um severo aumento dos impactos antrópicos diretos sobre o cerrado e áreas ecotonais. Áreas de cerrado, por estarem totalmente desprotegidas em âmbito legal, tornaram-se alternativa direta para a exploração agropecuária, intensificando a conversão dessas áreas naturais (Figura 1). Dessa forma, Pivello (2005) afirma que o desmatamento, o fogo e espécies vegetais exóticas invasoras são as principais ameaças à biodiversidade do cerrado, sendo que estes impactos podem ser diretos ou indiretos, já que as mudanças no uso da terra no entorno de áreas naturais acarretam em diversas consequências, sendo que tais aspectos ainda não foram totalmente elucidados. 
Figura 1 - Mapa de distribuição do bioma Cerrado no estado de São Paulo. Fonte: Siqueira e Durigan (2007). A: distribuição original do Cerrado no estado de SP. B: remanescentes de Cerrado no estado de São Paulo.
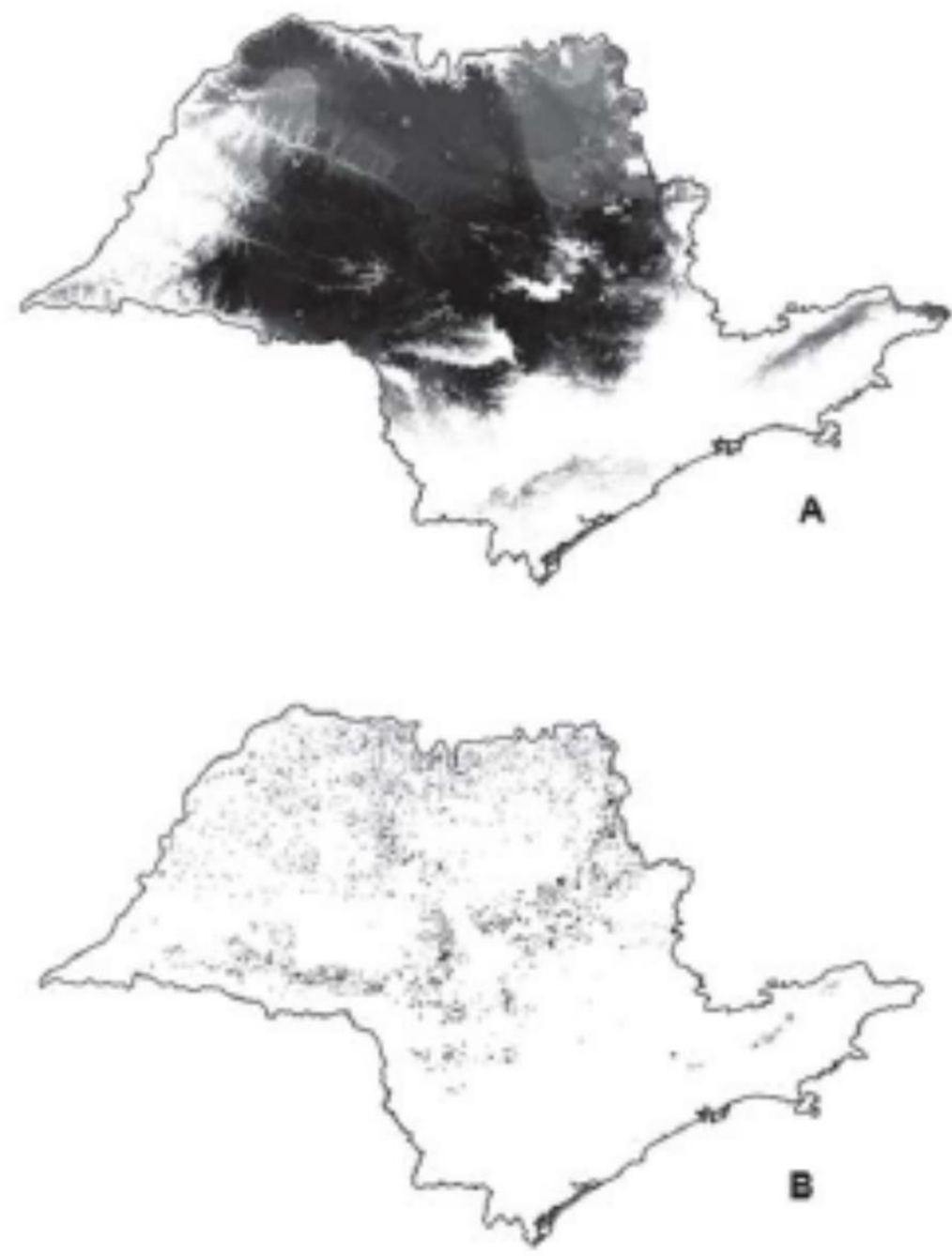

\subsection{Regeneração natural}

A abordagem científica sobre sucessão teve início no final do século XIX, mas foi apenas em 1916 que Clements (apud Kershaw \& Looney, 1985) consolidou essa área de estudo, sendo que suas ideias perduraram até a metade do século XX. Clements acreditava que o processo sucessional era totalmente ordenado e, assim, previsível, onde as mudanças estruturais e na composição refletiriam o processo de maturação de determinada comunidade vegetal. A vegetação clímax, isto é, a situação de equilíbrio da comunidade vegetal, onde não são notadas grandes modificações, seria definida apenas pelo clima local.

Em 1926, Gleason (apud Kershaw \& Looney, 1985) critica o determinismo defendido por Clements, afirmando que as comunidades vegetais são formadas por acaso, sendo resultado 
da combinação de espécies com demandas ambientais semelhantes. Alguns anos depois, em 1935, Tansley fez oposição à ideia de monoclímax de Clements, considerando outras características ambientais como influenciadoras no processo de sucessão, como o tipo de solo e posição topográfica.

No final da década de 60 do século XX, Margalef (1968) e Odum (1969), incrementam a definição de sucessão, afirmando que este processo ocorre por meio do aumento da complexidade dos ecossistemas, angariando mais níveis tróficos (e a formação de redes tróficas) e uma maior biodiversidade, até que o sistema alcance uma máxima biomassa e diversidade. Apenas a partir da década de 70 assume-se que os ecossistemas estão continuamente em estado de equilíbrio dinâmico, ou seja, não há uma única situação de equilíbrio entre a vegetação e o clima, pois existem diversos outros fatores (micro e macro fatores) que influenciam nas características dos ecossistemas, assumindo-se a importância dos distúrbios frequentes (como a criação de micro sítios, por exemplo) e oscilações de médio e longo prazo (regime de chuvas, por exemplo) de fatores que influenciam, diretamente, as características naturais dos ecossistemas (Glenn-Lewin et al., 1992; Orlóci, 1993).

Atualmente, o processo sucessional pode ser classificado em dois tipos:

1. Sucessão primária: processo que ocorre em substrato recém exposto, ou seja, não há solo desenvolvido ou indícios de vegetação prévia, como matéria orgânica ou propágulos, que deverão ter sua origem externa ao local. Como exemplo pode-se citar o processo ocorrente em áreas atingidas por derramamento de lava vulcânica, afloramentos rochosos ou dunas.

2. Sucessão secundária: processo ocorrente em áreas previamente ocupadas por vegetação nativa onde, após algum distúrbio, ocorre a substituição da cobertura vegetal removida através de legado biológico próprio. Alguns autores, como Orlóci (1993), utilizam o conceito de "regeneração" pois entendem que a vegetação, não necessariamente, voltará a apresentar as mesmas características presentes antes do distúrbio. A regeneração ocorre em áreas exploradas e abandonadas, após queimadas ou derrubadas etc.

Assim, nos casos de regeneração natural, as características dos distúrbios são fundamentais para se compreender, em linhas gerais, os resultados provocados. De acordo com Glenn-Lewin et al. (1992) os distúrbios possuem implicações em três dimensões (espaço, tempo e magnitude), sendo que, dependendo da característica de cada uma dessas dimensões, avaliadas separadamente ou em sinergia, os resultados serão extremamente diversos.

Dado o atual estado de conservação do cerrado, é fundamental o conhecimento da situação dos remanescentes subsidiando ações conservacionistas e de recuperação (Teixeira et 
al., 2004). E para isso é fundamental conhecer os aspectos relacionados à dinâmica de regeneração do bioma e suas fitofisionomias.

A dinâmica da regeneração natural de uma formação vegetal é influenciada por vários fatores (bióticos e abióticos, intrínsecos e extrínsecos) que são fundamentais para a compreensão dos principais processos da dinâmica florestal (Lieberman, 1996). Os principais processos envolvidos na regeneração florestal são os propágulos oriundos da dispersão, do banco de sementes ou de plântulas e da reprodução vegetativa (Whitmore, 1996; Rodrigues et al., 2004). Cada um desses processos contribui diferentemente de acordo com a fitofisionomia e grau de conservação do remanescente analisado (Brown e Lugo, 1990; Guariguata e Ostertag, 2001).

As primeiras fases do ciclo de vida vegetal, representadas pela semente e plântula, são as mais vulneráveis, apresentando alta mortalidade (Harper, 1977), e são fundamentais para manter o tamanho das populações vegetais. Assim, a sobrevivência nessa fase afeta a abundância e distribuição dos indivíduos adultos de uma espécie, assim como a composição e estrutura da comunidade (Harper, 1977). São vários fatores que influenciam na abundância e riqueza de plântulas e indivíduos jovens de espécies arbóreas, sendo os principais: disponibilidade de luz, padrão de produção e dispersão de sementes, e ação de predadores de sementes e plântulas (Denslow e Guzman, 2000; Scariot, 2000).

Já se compreende quais processos contribuem para a regeneração florestal após um distúrbio natural, merecendo destaque a contribuição das árvores remanescentes (produção de sementes e/ou rebrotamento), recrutamento de plântulas pré-existentes (banco de plântulas) e recrutamento de sementes (banco de sementes do solo e/ou chuva de sementes) (Whitmore, 1991). Entretanto, em áreas antropizadas, tais fatores podem sofrer diferentes graus de perturbação e sua contribuição no processo regenerativo pode ser alterado.

Apesar de sua importância para a compreensão da regeneração natural, estudos que abordam o estrato de regeneração são relativamente pouco comuns (Benítez-Malvido, 1998; Metzger, 1998; Scariot, 1999; Benítez-Malvido e Martínez-Ramos, 2003; Lieberman, 1996; Mesquita et al., 2001;), devido às dificuldades intrínsecas de pesquisas nessa área.

Apesar de sua complexidade, informações relacionadas aos aspectos da regeneração natural de todos os biomas são extremamente necessárias, destacando-se aqueles que sofrem significativos impactos antrópicos, pois dados relativos à manutenção da biodiversidade vegetal são aplicados na conservação, manejo e recuperação de áreas antropizadas (Guariguata et al., 1997). 


\subsubsection{Estrato de regeneração}

O estrato de regeneração é formado por indivíduos vegetais com altura igual ou superior a um metro, pois estes indivíduos já são considerados plenamente estabelecidos, superando a pressão seletiva imposta pelas condições ambientais nas fases anteriores do desenvolvimento (Felfili et al., 2000).

O estudo do estrato de regeneração fornece um panorama sobre o comportamento da comunidade vegetal, possibilitando asserções sobre o comportamento e desenvolvimento florestal. Isso é possível pois assume-se que há uma íntima relação entre o número de indivíduos e composição do estrato de regeneração e o estrato adulto de um futuro próximo (Mendes, 2002).

A análise do estrato de regeneração permite vislumbrar padrões de substituição de espécies ou alterações na comunidade florestal (Guariguata e Ostertag, 2001). Assim, comparar a composição florística do estrato de regeneração com o estrato adulto permite determinar aspectos importantes sobre a dinâmica da comunidade (Mendes, 2002). Isto ocorre pois, devido ao longo ciclo de vida de muitas espécies arbóreas, as comunidades podem manter uma elevada diversidade, mas esta não é autossustentável. Sabe-se que para manter a diversidade elevada ao longo do tempo é fundamental que os indivíduos adultos completem seu ciclo reprodutivo com sucesso (Guariguata e Ostertag, 2001). Assim, o estudo do estrato de regeneração é importante pois auxilia na compreensão dos resultados dos impactos antrópicos em remanescentes florestais, fornecendo importantes informações sobre a dinâmica sucessional em determinada área.

\subsubsection{Chuva e banco de sementes}

Pode-se entender o conceito banco de sementes como as sementes viáveis presentes no solo de uma área que, quando germinadas, poderão substituir os indivíduos vegetais adultos que morrem por causas naturais ou antrópicas (Roberts, 1981; Baker, 1989). Assim, o banco de sementes do solo pode ser considerado um depósito de sementes de muitas espécies, autóctones e alóctones, destacando-se as espécies pioneiras (Araújo et al., 2001).

A viabilidade das sementes no banco é extremamente variável (Murdoch e Ellis, 1992), sendo relevantes, neste processo, características genéticas e fisiológicas da espécie, como a viabilidade e período de dormência, além de características ambientais, como temperatura, luz, disponibilidade hídrica e ocorrência de fogo, e fatores bióticos, tal como a predação das sementes e a presença de patógenos (Baskin e Baskin, 2001; Mallik, 2008). Outra importante característica do banco de sementes é a sua origem. O banco de sementes pode ser formado por sementes produzidas localmente, também chamadas de autóctones, e as sementes 
alóctones, isto é, provenientes de outras áreas e que são transportadas por diferentes síndromes de dispersão (Martínez-Ramos e Soto-Castro, 1993). As sementes presentes no banco de sementes chegam até a área pelo processo de chuva de sementes, que pode transportar sementes da própria área ou de áreas muito distantes (Hall e Swaine, 1980), de acordo com a síndrome de dispersão da espécie (Melo et al., 2006).

Importante destacar que vários fatores influenciam nas características do banco de semente, como o bioma estudado, o histórico da área e a profundidade de coleta (Garwood, 1989).

O banco de sementes está envolvido em processos fundamentais da dinâmica florestal, natural ou após distúrbios, como a colonização e estabelecimento dos indivíduos vegetais e a manutenção da diversidade de espécies (Garwood, 1989; Grombone-Guaratini e Rodrigues, 2002).

Em ambientes tropicais, a principal fonte de regeneração das espécies vegetais ocorre via chuva de sementes (Benítez-Malvido e Martinez-Ramos, 2003). A chegada das sementes inicia outra etapa da regeneração natural: o estabelecimento e desenvolvimento dos indivíduos. As alterações estruturais e florísticas são derivadas, diretamente, da chegada de sementes no território (Clark et al., 1999; Hardesty e Parker, 2002), sendo que a dispersão de sementes é evento decisório na chuva de sementes. Por sua vez, a chuva de sementes é influenciada diretamente pelo tamanho das sementes e agentes dispersores. As principais síndromes de dispersão presentes em uma comunidade vegetal fornecem importantes informações ecológicas, como a estrutura da vegetação, o estádio sucessional e o grau de conservação. Assim, estudar a chuva de sementes de uma área natural permite a compreensão de importantes processos ocorrentes naquela área, destacando-se os processos relacionados à regeneração da vegetação natural e na composição da comunidade vegetal (Hardesty e Parker 2002).

Dada a sua importância, alterações nos processos envolvidos na chuva de sementes podem gerar uma limitação de propágulos em determinadas áreas, dificultando ou modificando componentes fundamentais no processo de regeneração natural (Muller-Landau et al., 2002).

\subsubsection{Fenologia}

A fenologia tem como objeto o estudo do ciclo de vida dos seres vivos, identificando fases e/ou padrões repetitivos ao longo do tempo, possibilitando a compreensão mais ampla de eventos reprodutivos ou vegetativos, fatores importantes na dinâmica florestal (Morellato, 1995). 
O conhecimento gerado pelos estudos fenológicos tem diversas aplicações, indo desde aspectos ecológicos básicos das espécies estudadas, implicações sobre produtividade e organização da comunidade vegetal, até auxiliar na tomada de decisões relacionadas ao manejo sustentável das espécies e biomas (Mariot et al., 2003).

Além das características genéticas da espécie, aspectos climáticos tem influência direta sobre a sua fenologia, influenciando em diversos aspectos, como a época de ocorrência dos eventos reprodutivos e a intensidade desses eventos, assim como a sua duração e periodicidade (Ferraz et al., 1999). Dentre estes aspectos climáticos, pode-se destacar a importância da temperatura e da precipitação (Morellato e Leitão Filho, 1990).

O acompanhamento das variações fenológicas fornece importantes informações sobre o ciclo de vida de uma espécie vegetal, indicando as principais fases vegetativas e reprodutivas (floração e frutificação). Esse acompanhamento também permite visualizar importantes relações ecológicas da região, como a polinização e dispersão de sementes, possibilitando uma abordagem relacionada à fauna local (Morellato e Leitão Filho, 1990) e também aos processos básicos relacionados à regeneração natural (Morellato e Leitão-Filho, 1996).

Relacionar as diferentes fenofases dos organismos com as condições climáticas e ambientais fornecem um importante indicativo de como tais condições estão afetando as espécies e/ou indivíduos (Mariot et al., 2003).

Assim, os estudos fenológicos são importantes pois fornecem muitas informações relevantes em diferentes níveis, saindo do indivíduo e chegando até à comunidade. Estas informações também são importantes em áreas aplicadas, como a conservação e preservação de habitats, a exploração sustentável e recuperação de áreas degradadas (Morellato e Leitão Filho, 1990).

\section{OBJETIVOS}

\subsection{Objetivo geral}

Estudar aspectos da dinâmica da regeneração natural da vegetação de um remanescente de Cerrado stricto sensu localizado no município de Patrocínio Paulista - SP.

\subsection{Objetivos específicos}

- Caracterizar o estrato adulto de um remanescente de cerrado stricto sensu localizado no município de Patrocínio Paulista - SP; 
- Comparar as características fitossociológicas do estrato adulto com estudo realizado no mesmo fragmento dez anos antes;

- Conhecer a composição do estrato de regeneração do fragmento de cerrado e comparar com o estrato adulto;

- Avaliar a composição da chuva de sementes e verificar a relevância do banco de sementes na regeneração natural do fragmento de cerrado estudado;

- Acompanhar a fenologia de seis espécies lenhosas de cerrado, relacionando as fenofases com fatores climáticos;

- Relacionar os vários componentes estruturais da vegetação do fragmento analisado (estrato adulto, estrato de regeneração, banco de sementes, chuva de sementes e fenologia) em um contexto de dinâmica da regeneração natural.

\section{MATERIAL E MÉTODOS}

\section{1 Área de estudo}

No presente estudo será adotada a abordagem de Batalha (2011), em que o autor considera a palavra Cerrado (com inicial maiúscula) como associada ao domínio fitogeográfico do Cerrado. Dentro deste domínio, o cerrado (com inicial minúscula) ou cerrado sensu lato que engloba os diferentes tipos vegetacionais (do campo limpo até o cerradão); e cerrado sensu stricto como uma das fisionomias savânicas do cerrado sensu lato. A definição de cerrado sensu stricto adotada no presente estudo é aquela apresentada por Ribeiro e Walter (2008), que indica a presença de árvores de pequeno porte, retorcidas e com ramificações irregulares, geralmente com cascas com cortiça e folhas xeromórficas; os arbustos apresentam-se espalhados.

O estudo foi realizado em uma área de cerrado stricto sensu com uma área total de 100 há conservada pelos proprietários da Fazenda Santa Cecília, município de Patrocínio Paulista SP. O remanescente apresenta significativo grau de ação antrópica no seu entorno, limitandose com áreas de cultivo de cana-de-açúcar a oeste e norte, por um remanescente com 100 ha de Floresta Estacional Semidecidual ao sul e por outras áreas de cerrado a leste, formando um remanescente contíguo com cerca de 400 ha (Figura 2). A área é caracterizada pela presença de solo arenoso e profundo, clima estacional, um dossel com altura média de 10 metros e uma composição florística relativamente repetitiva (Teixeira et al., 2004). 
Figura 2 - Visão geral do fragmento de cerrado stricto sensu localizado na Fazenda Santa Cecília e seu entorno. Fonte: elaborada pelo autor.

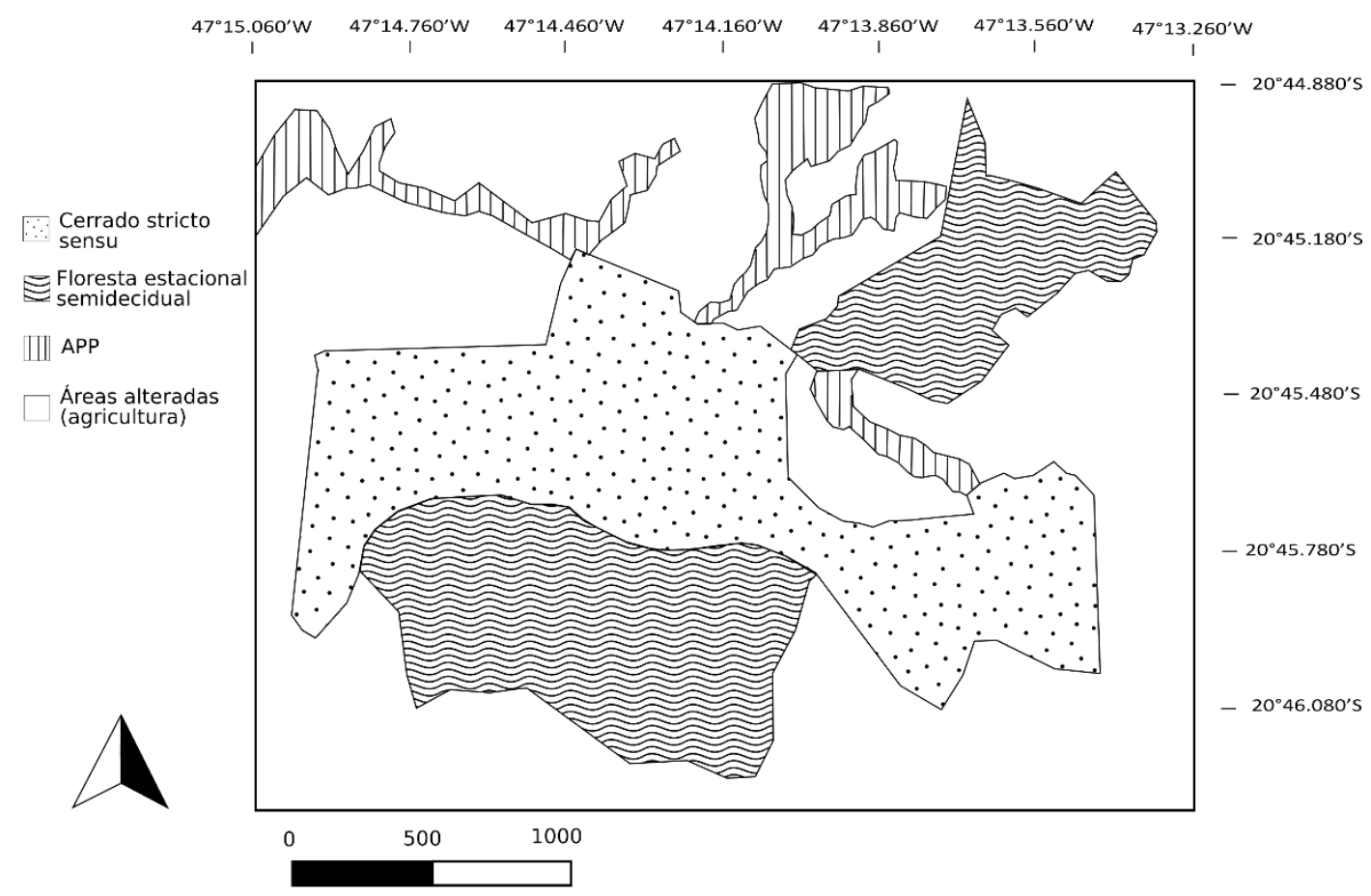

De acordo com Siqueira e Durigan (2007), no estado de São Paulo a distribuição em mosaico de áreas de cerrado e floresta estacional semidecidual é bastante recorrente, com ênfase para o extremo nordeste do estado (Fapesp, 2017), localização geográfica do município de Patrocínio Paulista. Esse mosaico é resultado, de acordo com Oliveira-Filho e Ratter (2002), da fertilidade dos solos, pois áreas que apresentam solos mais férteis apresentam uma cobertura de floresta estacional semidecídua, enquanto em áreas com solo mais pobre o cerrado é predominante. Essa afirmação pode ser confirmada pelo estudo de Araújo (2006) que analisou o solo da área de cerrado e floresta estacional da Fazenda Santa Cecília.

De acordo com a classificação de Köppen, o clima na região é tipo Cwb (mesotérmico úmido de altitude) nas áreas mais altas do relevo e Cwa (mesotérmico úmido) nas áreas mais baixas. Há a presença de duas estações bem definidas, sendo um verão caracterizado por altas temperaturas e alta pluviosidade (outubro a março) e um inverno com baixas temperaturas e baixas taxas de pluviosidade (abril a setembro) (Teixeira et al., 2004).

\subsection{Delineamento amostral}

Para a coleta de dados foram demarcadas aleatoriamente 30 parcelas de $10 \times 10 \mathrm{~m}$, totalizando uma área de amostragem de $3.000 \mathrm{~m}^{2}$ distribuídas na área conforme a Figura 3. A localização das parcelas de amostragem foi definida por meio de sorteio das coordenadas de 
latitude e longitude no mapa da área de estudo, no qual foi plotada uma grade com células de $100 \mathrm{~m}^{2}$. Para a elaboração do mapa foi utilizado o software QGis 2.0.1 (QGis, 2014).

Figura 3 - área de coleta do fragmento de cerrado stricto sensu localizado na Fazenda Santa Cecília, Patrocínio Paulista - SP.

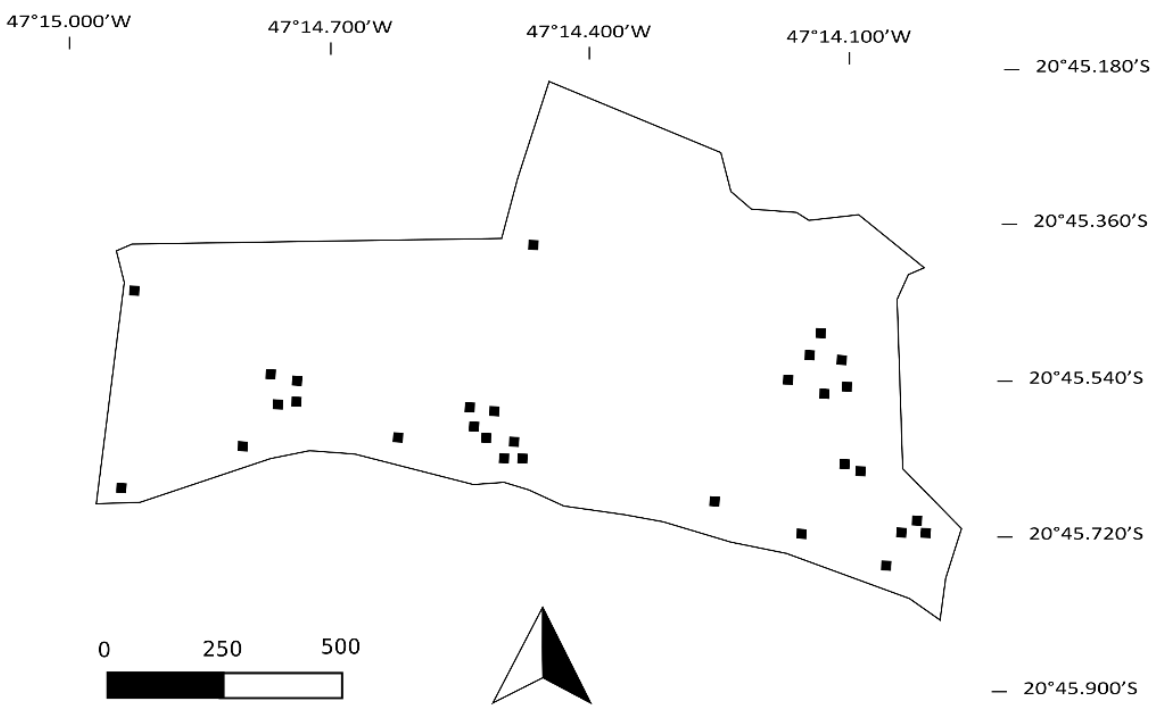

\section{REFERÊNCIAS BIBLIOGRÁFICAS}

AGUIAR, L. M. S.; MACHADO, R. B.; MARINHO-FILHO, J. 2004. A Diversidade Biológica do Cerrado. In: AGUIAR, L. M. S.; CAMARGO, A. J. A. (Ed). Cerrado: ecologia e caracterização. Brasília: EMBRAPA. p. 17-40.

ALHO, C. J. R. 2005. Desafios para a conservação do Cerrado, em face das atuais tendências de uso e ocupação. In: SCARIOT, A.; SOUSASILVA, J. C.; FELFILI, J. M. (Org.). Cerrado: ecologia, biodiversidade e conservação. Brasília: Ministério do Meio Ambiente, p.367-381.

ARAÚJO, M. M.; OlIVEIRA, F. A.; VIEIRA, I. C. G.; BARROS, P. L. C. E LIMA, C. A. T. 2001. Densidade e composição florística do banco de sementes do solo de florestas sucessionais na região do Baixo Rio Guamá, Amazônia Oriental. Scientia Forestalis 59, 115-130.

ARAÚJO, A. R. B. Fatores edáficos condicionantes da distribuição das espécies arbóreas em remanescentes de floresta estacional semidecidual e cerrado. 2006. 117 p. Tese (Doutorado em Agronomia - Produção Vegetal - Faculdade de Ciências Agrárias e Veterinárias, UNESP, Jaboticabal. 2001.

BAKER, H. G. 1989. Some Aspects of the Natural History of Seed Banks. In: LECK, M. A.; PARKER, T. V.; SIMPSON, R. L. Ecology of Soil Seed Banks. New York: Academic Press. p.9-21.

BARROS, F. S. 2009. A ação do homem no processo de destruição do cerrado. Disponível em: <http://www.soscerrado.com/html/acao.pdf>. Acesso em: 10 abr. 2017. 
BASKIN, C. C.; BASKIN, J. M. 2001. Germination ecology of seeds in the persistent seed bank. In: BASKIN, C. C.; BASKIN, J. M. Seeds: ecology, biogeography and evolution. San Diego: Academic Press. p.133-164.

BATALHA, M. A. 2011. O cerrado não é um bioma. Biota Neotropica 11 (1), 21-24.

BENÍTEZ-MALVIDO, J. 1998. Impact of forest fragmentation on seedling abundance in a tropical rain forest. Conservation Biology 12, 380-389.

BENÍTEZ-MALVIDO, J.; MARTÍNEZ-RAMOS, M. 2003. Impact of forest fragmentation on understory plant species richness in Amazonia. Conservation Biology 17, 389-400.

BRASIL, DECRETO No 750, DE 10 DE FEVEREIRO DE 1993. Dispõe sobre o corte, a exploração e a supressão de vegetação primária ou nos estágios avançado e médio de regeneração da Mata Atlântica, e dá outras providências. Diário Oficial da União, Brasília, DF, p. 1801, 11 fev., 1993. Seção 1.

BROWN, S.; LUGO, A. E. 1990. Tropical secondary forests. Journal of Tropical Ecology 6, 1-32.

CLARK, J. S.; SILMAN, M.; KERN, R.; MACKLIN, E. E HILLERISLAMBERS, J. 1999. Seed dispersal near and far: patterns across temperate and tropical forests. Ecology 80, 1475-1494.

COLE, M. M. 1986. The savannas: biogeography and geobotany. Academic Press: London, 438 p.

COLLINSON, A. S. 1988. Introduction to world vegetation. 2 ed. Unwin Hyman Ltd.: London, 325 p.

COUTINHO, L. M. 2006. O conceito de bioma. Acta Botanica Brasilica 20 (1), 13-23.

DENSLOW, J. S. e GUZMAN, S. 2000. Variation in stand structure, light and seedling abundance across a tropical moist forest chronosequence. Journal of Vegetation Science 11, 201-212.

DURIGAN, G.; FRANCO, G. A. D. C.; SIQUEIRA, M. F. 2004. A vegetação dos remanescentes de Cerrado no Estado de São Paulo. In: BITENCOURT, M. D.; MENDONÇA, R. R. (Org.). Viabilidade da conservação dos remanescentes de Cerrado no Estado de São Paulo. São Paulo: Annablume, p. 29-56.

DURIGAN, G.; SIQUEIRA, M. F.; FRANCO, G. A. D. C. 2007. Threats to the Cerrado remnants of the state of São Paulo, Scientia Agricola (4), 355-363.

EITEN, G. 1986. The use of the term "savanna". Tropical Ecology 27 (1), 10-23.

FAPESP. Atlas 2.1 Sinbiota - CRIA. Disponível em: <http://sinbiota.biota.org.br/atlas/>. Acesso em: 10 abr. 2017.

FELFILI, J. M.; RIBEIRO, J. F.; FAGG, C. W.; MACHADO, J. W. B. 2000. Recuperação de matas de galeria. Planaltina: Embrapa Cerrados, $46 \mathrm{p}$. 
FELFILI, J. M.; SOUSA-SILVA, J. C.; SCARIOT, A. 2005. Biodiversidade, ecologia e conservação do Cerrado: avanços do conhecimento. In: SCARIOT, A.; SOUSA-SILVA, J. C.; FELFILI, J. M. (Org.). Cerrado: ecologia, biodiversidade e conservação. Brasília: Ministério do Meio Ambiente. p. 25-44.

FERRAZ, D. K.; ARTES, R.; MANTOVANI, W.; MAGALHÃES, L. M. 1999. Fenologia de árvores em fragmento de mata em São Paulo, SP. Revista Brasileira de Biologia 59 (2), 305-317.

FORZZA, R.C. (org.), et al. 2010. Catálogo de plantas e fungos do Brasil [online]. Rio de Janeiro: Andrea Jakobsson Estúdio: Instituto de Pesquisa Jardim Botânico do Rio de Janeiro. 828 p. Disponível em: <http://static.scielo.org/scielobooks/x5x7v/pdf/forzza9788560035090.pdf>.

GARWOOD, N. C. 1989. Tropical soil seed banks: a review. In: LECK, M.A.; PARKER, T.; SIMPSON, R.L. Ecology soil seed bank. San Diego: Academic Press, p. 149-209.

GLENN-LEWIN, D. C.; PEET, R. K.; VEBLEN, T. T. 1992. Plant Succession; theory and prediction. London: Chapman e Hall, $352 \mathrm{p}$.

GROMBONE-GUARATINI, M. T.; RODRIGUES R. R. 2002. Seed bank and seed rain in a seasonal semi-deciduos forest in south-eastern Brazil. Journal of Tropical Ecology 18, 759-774.

GUARIGUATA, M. R.; CHAZDON, R. L.; DENSLOW, J. S.; DUPUY, J. M.; ANDERSON, L. 1997. Structure and floristics of secondary and old-growth forest stands in lowland Costa Rica. Plant Ecology 132, 107-120.

GUARIGUATA, M. R.; OSTERTAG, R. 2001. Neotropical secondary succession: changes in structural and functional characteristics. Forest Ecology Management 148, 185-206.

HALL, J. B.; SWAINE, M. D. 1980. Seed Stocks in Ghanaian Forest Soils. Biotropica 12, 256-263.

HARDESTY, B. D. E PARKER, V. T. 2002. Community seed rain patterns and a comparison to adult community structure in a West African tropical forest. Plant Ecology 164, 49-64.

HARPER, J. L. 1977. Population biology of plants. London: Academic Press, 892 p.

KERSHAW, K. A.; LOONEY, J. H. 1985. Quantitative and dynamic plant ecology. 3 ed. Caulfield: Edward Arnold, $282 \mathrm{pp}$.

KLINK, C. A.; MOREIRA, A. 2002. Past and current human occupation, and land use. In: OLIVEIRA, P.S.; MARQUIS, R.J. (Ed.). Ecology and natural history of a Neotropical Savanna. New York: Columbia University Press, p. 69-88.

KRONKA, F. J. N.; NALON, M. A.; MATSUKUMA, C. K.; KANASHIRO, M. M.; YWANE, M. S. S.; PAVÃO, M.; DURIGAN, G.; LIMA, L. M. P. R.; GUILLAUMON, J. R.; BAITELLO, J. B.; BORGO, S. C.; MANETTI, L. A.; BARRADAS, A. M. F.; FUKUDA, J. C.; SHIDA, C. N.; MONTEIRO, C. H. B.; PONTINHA, A. A. S.; ANDRADE, G. G.; BARBOSA, O.; SOARES, A. P. 2005. Inventário florestal da vegetação natural do estado de São Paulo. São Paulo: Secretaria do Meio Ambiente, 200 p. 
LEDRU, M. P. Late quaternary history and evolution of the Cerrados as revealed by palynological records. 2002. In: OLIVEIRA, P.S.; MARQUIS, R.J. (Eds). The Cerrados of Brazil: ecology and natural history of a neotropical savanna. New York: Columbia University Press, p. 33-50.

LIEBERMAN, D. 1996. Demography of tropical tree seedlings: a review. In: WAINE, M.D. The ecology of tropical forest tree seedlings. Paris: UNESCO and Parthenon Publishing Group, p. 131-138.

MACHADO, R. B.; RAMOS NETO, M. B.; PEREIRA, P. G. P.; CALDAS, E. F.; GONÇALVES, D. A.; SANTOS, N. S.; TABOR, K.; STEININGER, M. 2004. Estimativas de perda da área do Cerrado brasileiro. Disponível em: <http://cmbbc.cpac.embrapa.br/RelatDesmatamCerrado\%20ClBrasil \%20JUL2004.pdf>. Acesso em: 22 fev. 2017.

MALLIK, A. U. 2008. Allelopathy in forested ecosystems. In: ZENG, R. S., MALLIK, A. U.; LUO, S. M. Allelopathy in sustainable agriculture and forestry. New York: Springer, p. 363-386.

MMA, MINISTÉRIO DO MEIO AMBIENTE. 2007. Áreas prioritárias para a conservação, uso sustentável e repartição de benefícios da biodiversidade brasileira: Atualização - Portaria MMA № 09, de 23 de janeiro de 2007. Brasília: MMA, 300 p.

MARGALEF, R. 1968. Perspectives in Ecological Theory. Chicago: University of Chicago Press, $111 \mathrm{p}$.

MARIOT, A.; MANTOVANI, A.; REIS, M. S. 2003. Uso e conservação de Piper cernuum Vell. (Piperaceae) na Mata Atlântica: fenologia reprodutiva e dispersão de sementes. Revista Brasileira de Plantas Medicinais 5 (2), 1-10.

MARTÍNEZ-RAMOS, M.; SOTO-CASTRO, A.1993. Seed rain and advanced regeneration in a tropical rain forest. In: FLEMING, T. H.; ESTRADA, A. Frugivory and seed dispersal: ecological and evolutionary aspects. Boston: Kluwer Academic Publishers, p. 299-318.

MELO, F. P. L., DIRZO, R., TABARELLI, M. 2006. Biased seed rain in forest edges: Evidence from the Brazilian Atlantic forest. Biological Conservation 132, 50-60.

MENDES, S. 2002. Comparação entre os estratos arbóreo e de regeneração na mata de galeria da Estação Ecológica do Panga, Uberlândia-MG. Dissertação de Mestrado: UFU, 76 p.

MESQUITA, R. C. G.; ICKES, K.; GANADE, G.; WILLIAMSON, G. B. 2001. Alternative successional pathways in the Amazon Basin. Journal of Ecology 89, 528-537.

METZGER, J. P. Changements de la structure du paysage et richesse spécifique des fragments forestiers dans le Sud-Est du Brésil. 1998. Sciences de la vie 321, 319-333.

MISTRY, J. 2000. World savannas: ecology and human use. Harlow: Prentice-Hall, 344 p.

MORELLATO, L. P. C. 1995. As estações do ano na floresta. In: LEITÃO FILHO, H. F.; MORELLATO, L. P. C. Ecologia e preservação de uma floresta tropical urbana: Reserva de Santa Genebra. Campinas: UNICAMP, p. 187-192. 
MORELLATO, L. P. C.; LEITÃO-FILHO, H. F. 1990. Estratégias fenológicas de espécies arbóreas em floresta mesófila na Serra do Japi, Jundiaí, São Paulo. Revista Brasileira de Biologia 50 (1), 163-173.

MORELLATO, L. P. C.; LEITÃO-FILHO, H. F. 1996. Reproductive phenology of climbers in a Southeasthern Brazilian forest. Biotropica 28, 180-191.

MOTTA, P. E. F.; CURI, N.; FRANZMEIER, D. P. 2002. Relation of Soils and Geomorphic Surfaces in the Brazilian Cerrado. In: OLIVEIRA, P. S.; MARQUIS, R. J. The Cerrados of Brazil: ecology and natural history of a neotropical savanna. New York: Columbia University Press, p.13-32.

MULLER-LANDAU, H. C.; WRIGHT, S. J.; CALDERÓN, O.; HUBBELL, S. P.; FOSTER, R. B. 2002. Assessing recruitment limitation: concepts, methods and case-studies from a Tropical Forest. In: LEVEY, D. J.; SILVA, W. R.; GALETTI, M. Seed dispersal and frugivory: ecology, evolution and conservation. Oxfordshire: CABI Plublishing, p. 35-53.

MURDOCH, A. J.; ELLIS, R. H. 1992. Longevity, Viability and Dormancy. In: FENNER, M. Seeds: the ecology of regeneration in plant communities. Wallingford: CAB International, p.193229.

MYeRS, N.; MITTERMEIER, R. A.; MITTERMEIER, C. G.; FONSECA, G. A. B.; KENT, J. 2000. Biodiversity hotspots for conservation priorities. Nature 403, p. 853-858.

ODUM, E. P. 1969. The strategy of ecosystem development. Science 164, p. 262-270.

OLIVEIRA-FILHO, A. T.; RATTER, J. A. 2002. Vegetation Physiognomies and Woody Flora of the Cerrado Biome. In: OLIVEIRA, P. S.; MARQUIS, R. J. The Cerrados of Brazil: ecology and natural history of a neotropical savanna. New York: Columbia University Press, p. 91-120.

ORLÓCI, L. 1993. Conjectures and scenarios in recovery study. Coenoses 8, 141-148.

PIVELLO, V. R. 2005. Manejo de fragmentos de Cerrado: princípios para a conservação da biodiversidade. In: SCARIOT, A.; SILVA, J. C. S.; FELFILI, J. M. (Org.). Cerrado: ecologia, biodiversidade e conservação. Brasília: Ministério do Meio Ambiente, p. 401-413.

QGIS Development Team, 2014. QGIS Geographic Information System. Open Source Geospatial Foundation Project. Disponível em: <http://www.qgis.org/>. Acesso em: 10 jan. 2014.

RATTER, J. A.; BRIDGEWATER, S.; RIBEIRO, J. F. 2006. Biodiversity patterns of the woody vegetation of the Brazilian Cerrado. In: PENNINGTON, T.; GWILYM, P. L.; RATTER, J. A. (Org.). Neotropical Savannas and dry forests: diversity, biogeography and conservation. Boca Raton: Taylor e Francis, p. 31-66.

REATTO, A.; CORREIA, J. R.; SPERA, S. T.; MARTINS, E. S. 2008. Solos do Bioma Cerrado: Aspectos pedológicos. In: SANO, S. M.; ALMEIDA, S. P.; RIBEIRO, J. F. (Ed). Cerrado: ecologia e flora. Brasília: EMBRAPA, p. 109-149.

RIBEIRO, J. F.; BRIDGEWATER, S.; RATTER, J. A.; SOUSA-SILVA, J. C. 2005. Ocupação do bioma Cerrado e conservação da sua diversidade vegetal. In: SCARIOT, A.; SOUSA-SILVA, J. C.; FELFILI, J. M. (Org.). Cerrado: ecologia, biodiversidade e conservação. Brasília: Ministério do Meio Ambiente, p. 383-399. 
RIBEIRO, J. F.; WALTER, B. M. T. 2008. As Principais Fitofisionomias do Bioma Cerrado. In: SANO, S. M.; ALMEIDA, S. P.; RIBEIRO, J. F. (Ed). Cerrado: ecologia e flora. Brasília: EMBRAPA, p. 153-212.

ROBERTS, H. A. 1981. Seed banks in the soil. Cambridge: Academic Press, 55 p.

RODRIGUES, R. R.; TORRES, R. B.; MATTHES, L. A. F.; PENHA, A. S. 2004. Tree species sprouting from root buds in a semideciduous forest affected by fires. Brazilian Archives of Biology and Technology 47 (1), 127-133.

SÃO PAULO. 1997. Cerrado: Bases para a conservação e uso sustentável das áreas de Cerrado do Estado de São Paulo. São Paulo: SEMA, $184 \mathrm{p}$.

SCARIOT, A. 1999. Forest fragmentation effects on palm diversity in central Amazonia. Journal of Ecology 87, 66-76.

SCARIOT, A. 2000. Seedling mortality by litterfall in Amazonian forest fragments. Biotropica 32, 662-669.

SILVA, F. A. M.; ASSAD, E. D.; EVANGELISTA, B. A. 2008. Caracterização Climática do Bioma Cerrado. In: SANO, S. M.; ALMEIDA, S. P.; RIBEIRO, J. F. (Ed). Cerrado: ecologia e flora. Brasília: EMBRAPA, p. 71-88.

SIQUEIRA, M. F.; DURIGAN, G. 2007. Modelagem da distribuição geográfica de espécies lenhosas de cerrado no estado de São Paulo. Revista Brasileira de Botânica 30 (2), 233-243.

TANSLEY, A. G. 1935. The use and abuse of vegetational concepts and terms. Ecology 16, 284307.

TEIXEIRA, M. I. J. G.; ARAUJO, A. R. B.; VALERI, S. V.; RODRIGUES, R. R. 2004. Florística e fitossociologia de área de Cerrado s.s. no município de Patrocínio Paulista, nordeste do estado de São Paulo. Bragantia 63 (1), 1-11.

WALTER, B. M. T.; CARVALHO, A. M.; RIBEIRO, J. F. 2008. O conceito de savana e de seu componente Cerrado. In: SANO, S. M; ALMEIDA, S. P.; RIBEIRO, J. F. (Eds). Cerrado: ecologia e flora. Brasília: EMBRAPA, p. 19-45.

WHITMORE, T. C. 1991. Tropical rain forest dynamics and its implications for management. In: Rain forest regeneration and management. Gómez-Pompa, A.; Whitmore, T.C.; Hadley, M. (Eds). Paris: UNESCO e Parthenon Publishing Group, p. 67-89.

WHITMORE, T. C. 1996. A review of some aspects of tropical rain forest seedling ecology with suggestions for further inquiry. In: SWAINE, M.D. The ecology of tropical forest tree seedlings. Paris: UNESCO e Parthenon Publishing Group, p. 3-39. 


\section{CAPÍTULO I}

Estrutura e composição do estrato adulto de um remanescente de cerrado stricto sensu localizado em Patrocínio Paulista - SP 


\section{RESUMO}

O Cerrado é o segundo maior bioma brasileiro ocupando cerca de $21 \%$ do território. Atualmente, $80 \%$ da sua área está degradada por ações antrópicas, restando no estado de São Paulo cerca de $1 \%$. O objetivo dessa pesquisa foi caracterizar a estrutura de um remanescente de cerrado stricto sensu localizado em Patrocínio Paulista - SP. Em 100 ha foram demarcadas 30 parcelas amostrando-se todos os indivíduos com PAS $\geq 15 \mathrm{~cm}$. Para as análises dos dados utilizou-se os programas Fitopac 2.0 e Mata Nativa 2. Foram amostrados 729 indivíduos, sendo 93 mortos, e identificadas 44 espécies pertencentes a 24 famílias. As famílias mais ricas foram Fabaceae, Vochysiaceae e Styracaceae e as com maior número de indivíduos foram Vochysiaceae, Annonaceae e Fabaceae. A diversidade é baixa como indicam os índices Shannon e Weaver e Pielou. A distribuição diamétrica resultou na forma de um "J" invertido, com um grande número de indivíduos nas classes de menor diâmetro. A estrutura vertical indicou uma ocupação expressiva do estrato médio (80\%). Os resultados corroboram a fisionomia de um cerrado s.s. denso, com baixa diversidade, alto número de mortos e expressiva dominância de poucas espécies tanto na estrutura horizontal como na vertical, evidenciando problemas de conservação no remanescente.

Palavras-chave: florística, fitossociologia, diversidade vegetal.

\section{INTRODUÇÃO}

Os estudos fitossociológicos são fundamentais para se conhecer as características principais de uma formação vegetal. Além da lista de espécies presentes, busca-se informações sobre suas relações interespecíficas, sua disposição e como se apresentam no processo de sucessão natural (Rodrigues e Pires, 1988). A complexidade na interpretação dos dados obtidos por estudos desse tipo é devida, dentre outros fatores, à grande quantidade de fatores influentes no processo, como os climáticos, bióticos, abióticos e antrópicos, que resultam em muitas formações ecológicas distintas (Longhi, 1980). Assim, é essencial conhecer a composição e estrutura da vegetação de determinada área, por meio de dados e características quantitativos e qualitativos, possibilitando diversas interpretações e utilizações dessas informações (Alencar, 1988).

O Cerrado, considerado o segundo maior bioma brasileiro, originalmente ocupava cerca de $21 \%$ do território do Brasil, distribuído, principalmente, no Planalto Central (Motta et al., 2002). No estado de São Paulo o Cerrado ocupava cerca de $14 \%$ da área total do estado (São Paulo, 1997), mas essa área foi reduzida drasticamente, para pouco menos de $1 \%$ (Kronka et al., 2005). Outro ponto extremamente preocupante para a conservação do Cerrado paulista é decorrente da extrema fragmentação das áreas remanescentes e seu isolamento por áreas antropizadas, como pastos, culturas agrícolas e áreas urbanizadas (Durigan et al., 2007). Em relação à diversidade vegetal, o acúmulo de dados sobre a flora brasileira nos últimos anos permitiu registrar 11.384 espécies de angiospermas para o Cerrado (Forzza et al., 2010), número bem mais expressivo que as estimativas anteriores entre 7.000 (Shepherd, 2000) e 
10.000 (Myers et al., 2000), com uma taxa de endemismo em torno de 36\%, bem maior que a da Amazônia, domínio fitogeográfico com o qual se equipara em riqueza de espécies (Myers et al., 2000).

A maioria dos estudos no cerrado paulista foi realizada em áreas centrais do estado (Eiten, 1963; Toledo Filho et al., 1984; Pagano et al., 1989; Leitão Filho, 1992, Durigan et al., 1994; Batalha et al., 1997) sendo que poucos trabalhos abordaram o bioma na região nordeste do estado de São Paulo (Sasaki e Mello-Silva, 2008; Teixeira et al., 2004), transição entre o cerrado paulista, o mineiro e do planalto central (Durigan et al., 2003). Apesar dessa região ser classificada pelo Ministério do Meio Ambiente como prioridade máxima de conservação (MMA, 2007), é uma das regiões com maior índice de desmatamento no estado de São Paulo nos últimos 30 anos (Kronka et al., 1998).

Apesar de ser considerado um dos 25 hotsposts mundiais, cerca de $80 \%$ da área original do Cerrado já foi degradada por ações antrópicas (Myers et al., 2000). Machado et al. (2004) afirmam que $55 \%$ da área original do Cerrado já foi totalmente desmatada. Considerando-se o estado de São Paulo resta cerca de 1\% de Cerrado com características originais (Durigan et al., 2011), em remanescentes altamente fragmentados e antropizados por atividades agropecuárias.

Este estudo foi realizado em uma região de cerrado stricto sensu localizado no extremo nordeste do estado de São Paulo, área carente de estudos científicos aprofundados e relevante no contexto ecológico por se tratar de área de transição do bioma Cerrado.

\section{HIPÓTESES}

a) A estrutura e composição florística do estrato adulto do remanescente de cerrado stricto sensu da Fazenda Santa Cecília, Patrocínio Paulista - SP, são semelhantes àquelas encontradas em outros fragmentos de cerrado stricto sensu paulistas.

b) Por se tratar de área sem atividades antrópicas diretas, como extração de madeira ou fogo, por aproximadamente 70 anos, suas características (florística e estrutura) correspondem a áreas conservadas.

\section{OBJETIVO ESPECÍFICO}

Caracterizar a estrutura de um remanescente de cerrado stricto sensu localizado na Fazenda Santa Cecília, município de Patrocínio Paulista - SP, visando avaliar a estrutura e diversidade da comunidade vegetal. 


\section{MATERIAL E MÉTODOS}

Em uma área amostral de $3.000 \mathrm{~m}^{2}$, durante o ano de 2014, foram amostrados todos os indivíduos com PAS (Perímetro à Altura do Solo) igual ou superior a $15 \mathrm{~cm}$. A medida do perímetro à altura do solo diminui incorreções devidas a perfilhamentos, que são muito comuns em espécies do cerrado (Marimon Júnior e Haridasan, 2005; Neri, 2005).

A suficiência amostral foi verificada com a análise da curva do coletor construída por meio do estimador Jackknife de primeira ordem com intervalo de confiança de $95 \%$. Os cálculos foram realizados utilizando o software Estimates (Colwell, 2013) sendo o gráfico construído no aplicativo Statistica 13.

Para cada indivíduo amostrado os dados anotados foram: perímetro, medido com fita métrica, e a altura estimada. Todos os indivíduos amostrados foram numerados e plaqueados, sendo que a identificação foi realizada utilizando-se literatura especializada e consultas a especialistas.

A análise do levantamento fitossociológico foi realizada com o software Fitopac 2.0 (Shepherd, 2009) utilizando-se os seguintes parâmetros: densidade relativa, frequência relativa, dominância relativa por área (calculada a partir da área basal de cada indivíduo arbóreo) e índice do valor de importância e de cobertura (Müller-Dombois e Ellenberg, 1974). Para as medidas de diversidade foram utilizados o índice de diversidade de Shannon e Weaver, índice de concentração de Simpson e o índice de equabilidade de Pielou (Magurran, 1988). Com o intuito de descrever detalhadamente a estrutura da vegetação, também foram incluídos os resultados da área basal total, indicador da densidade que se relaciona com o volume, e densidade total absoluta (número total de indivíduos de uma área).

A análise da distribuição diamétrica, da estrutura vertical e da distribuição espacial dos indivíduos amostrados foi feita utilizando-se o software Mata Nativa 2 (Cientec, 2006). Para a distribuição diamétrica foram elaborados histogramas considerando classes fixas de $4,0 \mathrm{~cm}$. A distribuição dos indivíduos na estrutura vertical considerou classes fixas de 3,0 m de altura. 0 índice utilizado para a distribuição espacial foi Payandeh (Payandeh, 1970) comparado aos de MacGuinnes e Fracker e Brischle (Barros e Machado, 1984).

Todas as espécies amostradas foram classificadas de acordo com a sua síndrome de dispersão de sementes (autocoria, barocoria ou zoocoria) e seu grupo ecológico (pioneira, secundária inicial, secundária tardia e sub-bosque) com auxílio de bibliografia especializada. 


\section{RESULTADOS}

$\mathrm{Na}$ área de estudo foram amostrados 729 indivíduos distribuídos em 44 espécies, 34 gêneros e 24 famílias (Tabela 1). As famílias mais ricas foram Fabaceae (12 espécies) Vochysiaceae (4 espécies) e Styracaceae (3 espécies) que representaram 43,1\% das espécies registradas. As famílias com maior número de indivíduos foram Vochysiaceae (236), Annonaceae (233) e Fabaceae (84) que somaram $75,8 \%$ do total de indivíduos amostrados. Dezessete famílias foram representadas por apenas uma espécie, totalizando 70,8\%, o que corrobora outras investigações para o cerrado (Felfili et al. 2002; Fidelis e Godoy 2003; Aquino et al. 2007; Güntzel et al. 2011).

Tabela 1 - Parâmetros fitossociológicos das espécies com PAS $\geq 15 \mathrm{~cm}$, amostradas no cerrado stricto sensu na Fazenda Santa Cecília, Patrocínio Paulista, SP, em ordem decrescente de VI. NI: número de indivíduos por espécie; DR: Densidade Relativa (\%); FR: Frequência Relativa; DoR: Dominância Relativa (\%); VI: Valor de Importância; VC: Valor de Cobertura.

\begin{tabular}{lllllll}
\hline Espécie & NI & DR & FR & DoR & VI & VC \\
\hline Qualea grandiflora & 119 & 16,32 & 9,76 & 22,26 & 48,34 & 38,58 \\
Xylopia aromatica & 163 & 22,36 & 11,38 & 11,38 & 45,12 & 33,74 \\
Qualea jundiahy & 96 & 13,17 & 8,54 & 12,62 & 34,32 & 25,78 \\
Morta & 93 & 12,76 & 11,38 & 9,50 & 33,64 & 22,26 \\
Xylopia sericea & 70 & 9,60 & 8,94 & 4,99 & 23,53 & 14,59 \\
Pterodon emarginatus & 25 & 3,43 & 4,47 & 12,74 & 20,64 & 16,17 \\
Copaifera langsdorffii & 22 & 3,02 & 5,69 & 6,16 & 14,87 & 9,18 \\
Dalbergia miscolobium & 15 & 2,06 & 4,88 & 4,66 & 11,60 & 6,72 \\
Virola sebifera & 16 & 2,19 & 3,25 & 1,50 & 6,95 & 3,70 \\
Qualea multiflora & 12 & 1,65 & 2,44 & 2,75 & 6,84 & 4,40 \\
Miconia albicans & 11 & 1,51 & 2,03 & 0,59 & 4,13 & 2,10 \\
Qualea parviflora & 9 & 1,23 & 1,22 & 1,32 & 3,78 & 2,56 \\
Bowdichia virgilioides & 6 & 0,82 & 2,03 & 0,28 & 3,13 & 1,10 \\
Ouratea spectabilis & 5 & 0,69 & 2,03 & 0,41 & 3,13 & 1,09 \\
Aspidosperma tomentosum & 6 & 0,82 & 1,63 & 0,49 & 2,94 & 1,31 \\
Dimorphandra mollis & 6 & 0,82 & 1,63 & 0,46 & 2,91 & 1,28 \\
Ocotea corymbosa & 4 & 0,55 & 1,63 & 0,42 & 2,60 & 0,97 \\
Styrax camporum & 3 & 0,41 & 1,22 & 0,89 & 2,52 & 1,30 \\
Tapirira guianensis & 4 & 0,55 & 1,22 & 0,60 & 2,37 & 1,15 \\
Caryocar brasiliense & 4 & 0,55 & 1,22 & 0,47 & 2,24 & 1,02 \\
Pera glabrata & 3 & 0,41 & 0,81 & 0,99 & 2,21 & 1,40 \\
Styrax ferrugineus & 3 & 0,41 & 1,22 & 0,46 & 2,09 & 0,87 \\
Ocotea pulchella & 4 & 0,55 & 0,81 & 0,28 & 1,65 & 0,83 \\
Hirtella glandulosa & 2 & 0,27 & 0,81 & 0,47 & 1,56 & 0,75 \\
Myrcia lasiantha & 3 & 0,41 & 0,81 & 0,15 & 1,37 & 0,56 \\
Styrax pohlii & 1 & 0,14 & 0,41 & 0,80 & 1,34 & 0,93 \\
Diospyros hispida & 2 & 0,27 & 0,81 & 0,23 & 1,32 & 0,51 \\
Pterocarpus violaceus & 2 & 0,27 & 0,81 & 0,19 & 1,28 & 0,46 \\
\hline & & & & & & continua...
\end{tabular}




\begin{tabular}{lllllll}
\hline Espécie & NI & DR & FR & DoR & VI & VC \\
\hline Senna rugosa & 3 & 0,41 & 0,41 & 0,45 & 1,27 & 0,87 \\
Clusia sp & 2 & 0,27 & 0,41 & 0,07 & 0,75 & 0,34 \\
Erythroxylum suberosum & 1 & 0,14 & 0,41 & 0,16 & 0,70 & 0,29 \\
Guapira noxia & 1 & 0,14 & 0,41 & 0,12 & 0,66 & 0,25 \\
Cupania vernalis & 1 & 0,14 & 0,41 & 0,10 & 0,65 & 0,24 \\
Alibertia sessilis & 1 & 0,14 & 0,41 & 0,10 & 0,65 & 0,24 \\
Eriotheca gracilipes & 1 & 0,14 & 0,41 & 0,09 & 0,63 & 0,23 \\
Acosmium dasycarpum & 1 & 0,14 & 0,41 & 0,07 & 0,62 & 0,21 \\
Brosimum gaudichaudii & 1 & 0,14 & 0,41 & 0,07 & 0,61 & 0,20 \\
Myrsine guianensis & 1 & 0,14 & 0,41 & 0,06 & 0,61 & 0,20 \\
Acosmium subelegans & 1 & 0,14 & 0,41 & 0,06 & 0,61 & 0,20 \\
Cordiera sessilis & 1 & 0,14 & 0,41 & 0,05 & 0,60 & 0,19 \\
Myrcia variabilis & 1 & 0,14 & 0,41 & 0,04 & 0,58 & 0,18 \\
Stryphnodendron polyphyllum & 1 & 0,14 & 0,41 & 0,03 & 0,58 & 0,17 \\
Byrsonima intermedia & 1 & 0,14 & 0,41 & 0,03 & 0,58 & 0,17 \\
Stryphnodendron adstringens & 1 & 0,14 & 0,41 & 0,02 & 0,57 & 0,16 \\
Andira humilis & 1 & 0,14 & 0,41 & 0,03 & 0,57 & 0,16 \\
\hline TOTAL & 729 & 100 & 100 & 100 & 300 & 200 \\
\hline
\end{tabular}

Pela análise da curva do coletor elaborada (Figura 1) assume-se uma suficiência amostral a partir da parcela 23, apesar de não atingida uma clara assíntota.

Figura 1 - Curva cumulativa espécie-área para a área amostrada de cerrado stricto sensu da Fazenda Santa Cecília, Patrocínio Paulista - SP.

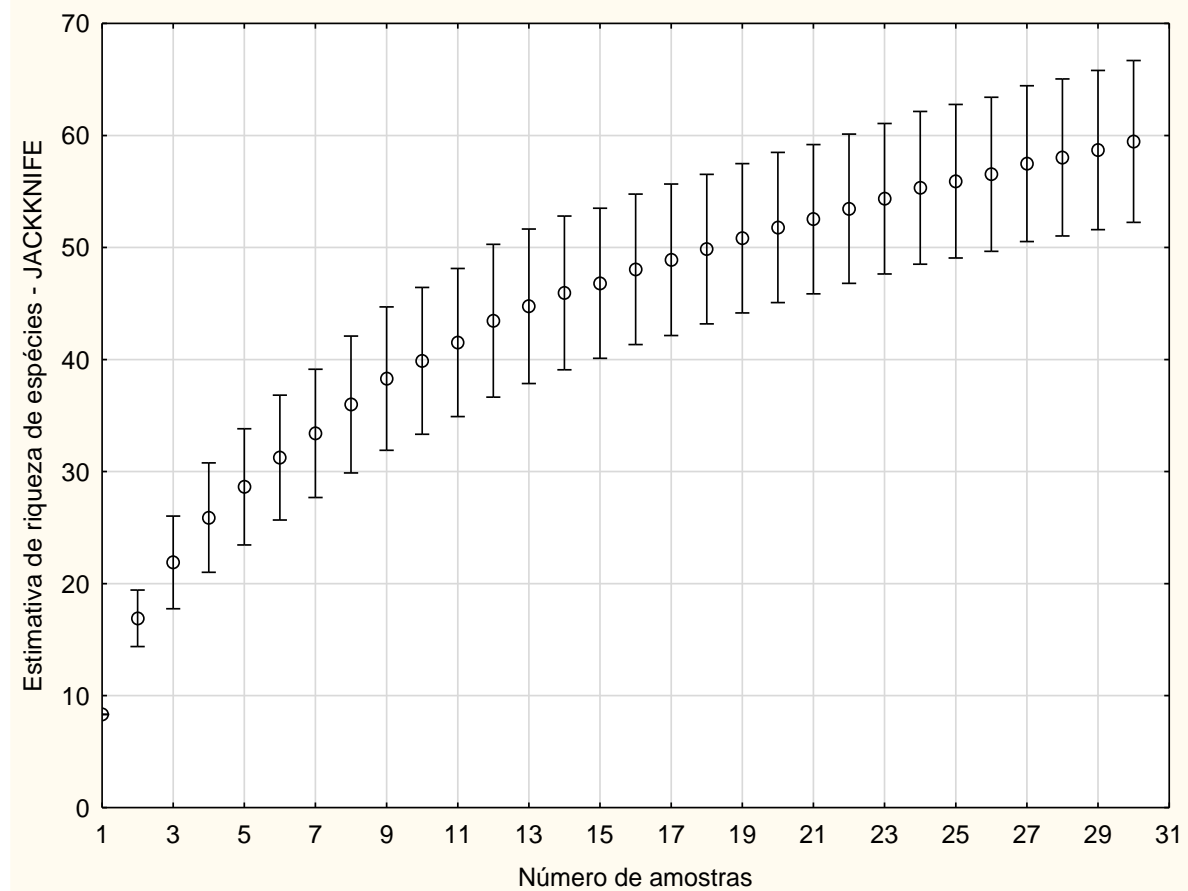

A Área Basal Total (ABT) foi de 7,7127 $\mathrm{m}^{2}$ e a Densidade Total Absoluta foi de 2.430 ind.ha ${ }^{-1}$, dados maiores do que aqueles verificados em outras áreas de cerrado stricto sensu 
(Teixeira e Rodrigues 2006; Durigan et al. 2002) onde foi considerado apenas o componente arbóreo. Entretanto, estes dados devem ser analisados com certa cautela, pois os critérios de inclusão variam de acordo com a pesquisa, tornando difícil uma comparação direta. Outros resultados do presente estudo apontam para uma baixa diversidade $\left(H^{\prime}=2,54\right.$ nats/ind; equabilidade $=0,67 ;$ Simpson $=0,88$ ).

A Figura 2 indica uma distribuição de classes de diâmetro dos indivíduos na forma de um "J" invertido, com 382 indivíduos (52,4\%) formando a classe com menor diâmetro (4,8-8,7 $\mathrm{cm}$ ), sendo que apenas quatro espécies (Q. grandiflora, $X$. aromatica, $Q$. jundiahy e $X$. sericea), mais a categoria de mortas, contribuem com 309 indivíduos (80,9\%).

Figura 2 - Classes de diâmetro $(\mathrm{cm})$ dos indivíduos da área de cerrado stricto sensu da Fazenda Santa Cecília, Patrocínio Paulista-SP.

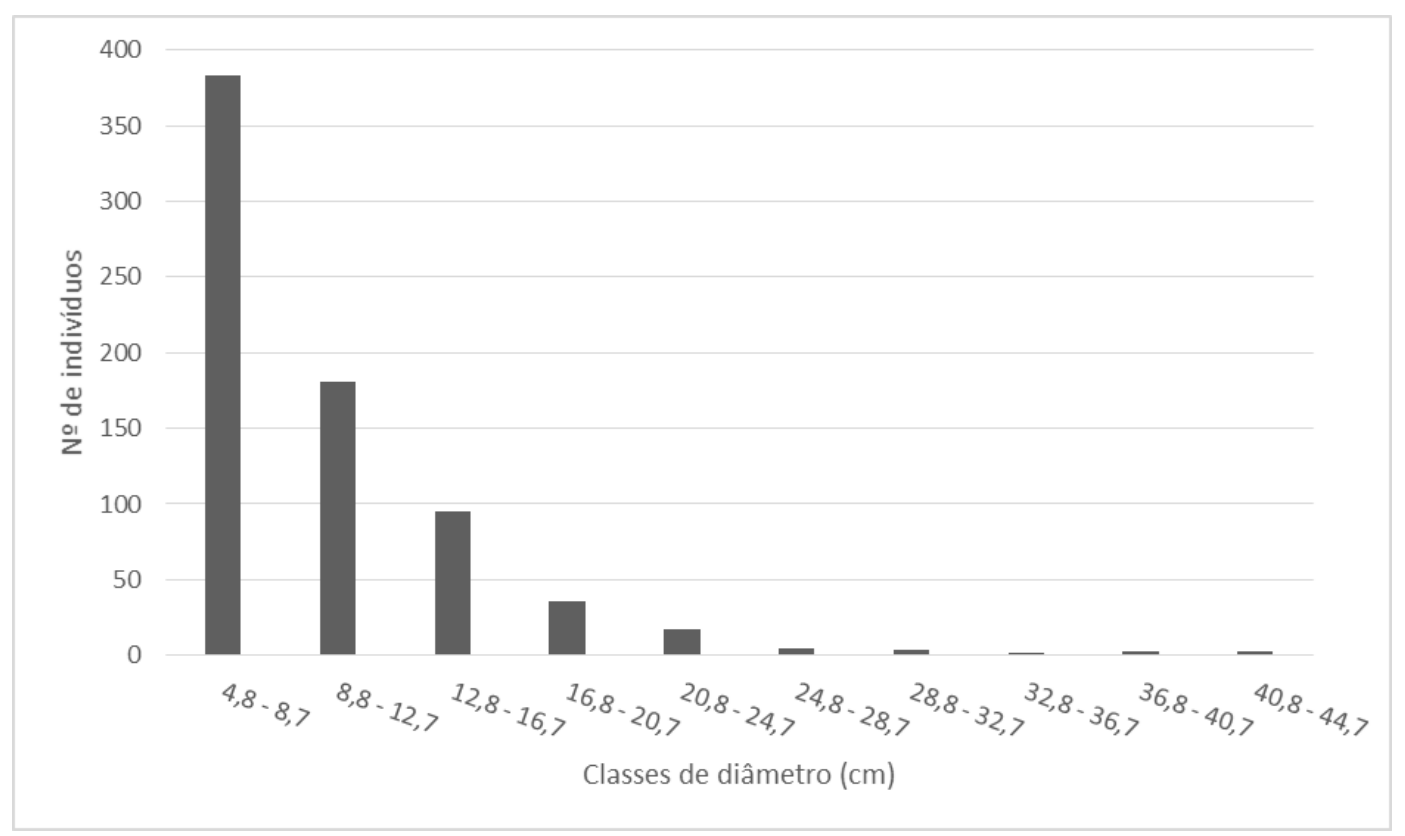

A estrutura vertical (Figura 3) apresenta a maioria dos indivíduos (345) na classe formada por indivíduos entre quatro e seis metros de altura, perfazendo $47,3 \%$ da amostra. Similar ao observado na distribuição diamétrica, X. aromatica, Q. grandiflora, Q. jundiahy, categoria de mortas e $X$. sericea representam $73,5 \%$ dos indivíduos no estrato. Ainda, considerando as 10 espécies de maior $\mathrm{VI}$, no estrato inferior (alturas inferiores a 3,0 m) figuram apenas mortas, $Q$. grandiflora, $X$. aromatica e $X$. sericea. No estrato superior (alturas superiores a 10,0 m) predominam Qualea grandiflora, Qualea jundiahy e Xylopia aromatica $(51,3 \%)$.

$\mathrm{Na}$ área amostrada, foram encontradas 24 espécies (54,5\%) com distribuição não agrupada (aleatória), 16 (36,4\%) com distribuição agrupada e quatro $(9,1 \%)$ com tendência ao 
agrupamento sem confirmação por outros índices como o de MacGuinnes e Fracker e Brischle. As espécies com maior índice de agregação foram Qualea parviflora, Qualea grandiflora, Qualea jundiahy, Pterodon emarginatus e Xylopia aromatica.

Com relação à síndrome de dispersão encontrou-se 27 espécies zoocóricas (62,8\%), 12 anemocóricas (27,9\%) e 4 autocóricas (9,3\%). Quando analisados os grupos ecológicos, verificou-se que as espécies pioneiras totalizaram 9 espécies $(20,9 \%)$, as secundárias iniciais 10 espécies (23,3\%), as secundárias tardias 16 espécies (37,3\%), as clímax 2 espécies $(4,6 \%)$ e as de sub-bosque $6(13,9 \%)$ (Tabela 2$)$.

Figura 3 - Classes de altura $(\mathrm{m})$ dos indivíduos da área de cerrado stricto sensu da Fazenda Santa Cecília, Patrocínio Paulista-SP.

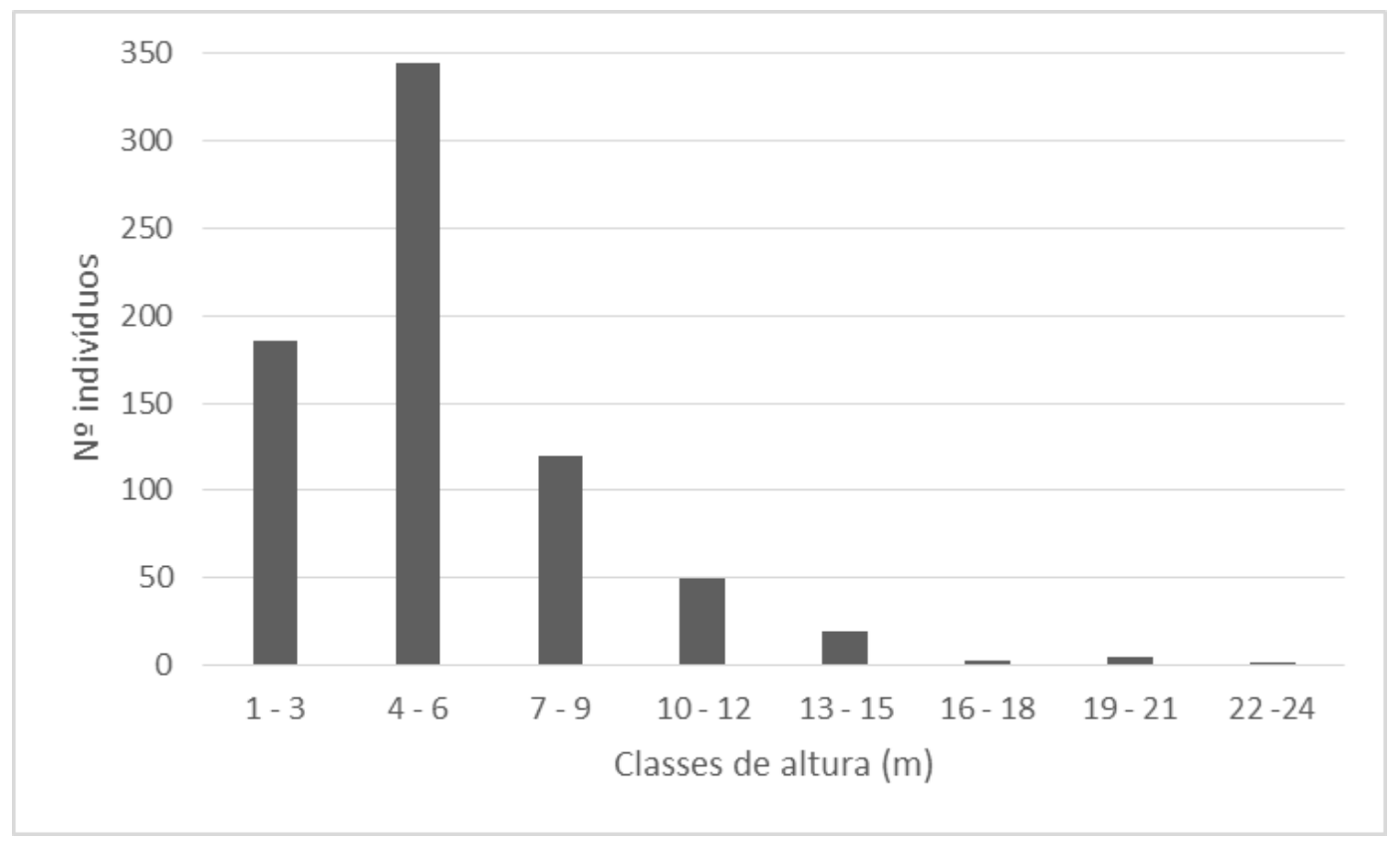

Tabela 2 - Classificação quanto a síndrome de dispersão e grupo ecológico das espécies vegetais amostradas no cerrado stricto sensu na Fazenda Santa Cecília, Patrocínio Paulista, SP. SD: síndrome de dispersão; ZOO: zoocórica; ANE: anemocórica, AUT: autocórica; GE: grupo ecológico; P: pioneira, SI: secundário inicial, ST: secundária tardia, C: clímax; SB: sub-bosque.

\begin{tabular}{|c|c|c|}
\hline FAMÍLIA / Espécie & SD & GE \\
\hline ANACARDIACEAE & & \\
\hline $\begin{array}{l}\text { Tapirira guianensis Aubl. } \\
\text { ANNONACEAE }\end{array}$ & ZOO & ST \\
\hline Xylopia aromatica (Lam.) Mart. & ZOO & $P$ \\
\hline $\begin{array}{l}\text { Xylopia sericea A.St.-Hil. } \\
\text { APOCYNACEAE }\end{array}$ & ZOO & SI \\
\hline $\begin{array}{l}\text { Aspidosperma tomentosum Mart. } \\
\text { CARYOCARACEAE }\end{array}$ & ANE & C \\
\hline Caryocar brasiliense A.St.-Hil. & ZOO & ST \\
\hline
\end{tabular}




\begin{tabular}{|c|c|c|}
\hline FAMÍLIA / Espécie & SD & GE \\
\hline \multicolumn{3}{|l|}{ CHRYSOBALANACEAE } \\
\hline Hirtella glandulosa Spreng. & ZOO & $\mathrm{C}$ \\
\hline \multicolumn{3}{|l|}{ CLUSIACEAE } \\
\hline Clusia sp & - & - \\
\hline \multicolumn{3}{|l|}{ EBENACEAE } \\
\hline Diospyros hispida A.DC. & ZOO & $\mathrm{SI}$ \\
\hline \multicolumn{3}{|l|}{ ERYTHROXYLACAEAE } \\
\hline Erythroxylum suberosum A.St.-Hil. & ZOO & SB \\
\hline \multicolumn{3}{|l|}{ FABACEAE } \\
\hline Acosmium dasycarpum (Vogel) Yakovlev & ANE & $\mathrm{SI}$ \\
\hline Acosmium subelegans (Mohlenbr.) & ANE & $P$ \\
\hline Andira humilis Mart. ex Benth. & ZOO & SB \\
\hline Bowdichia virgilioides Kunth & AUT & ST \\
\hline Copaifera langsdorffii Desf. & ZOo & ST \\
\hline Dalbergia miscolobium Benth. & ANE & $P$ \\
\hline Dimorphandra mollis Benth. & ANE & $P$ \\
\hline Pterocarpus violaceus Vogel & ANE & $\mathrm{SI}$ \\
\hline Pterodon emarginatus Vogel & ANE & $\mathrm{SI}$ \\
\hline Senna rugosa (G. Don) H.S.Irwin e Barneby & AUT & SB \\
\hline Stryphnodendron adstringens (Mart.) Coville & AUT & ST \\
\hline Stryphnodendron polyphyllum Mart. & AUT & $\mathrm{SI}$ \\
\hline \multicolumn{3}{|l|}{ LAURACEAE } \\
\hline Ocotea corymbosa (Meisn.) Mez & ZOO & ST \\
\hline Ocotea pulchella (Nees e Mart.) Mez & ZOO & ST \\
\hline \multicolumn{3}{|l|}{ MALPIGHIACEAE } \\
\hline Byrsonima intermedia A. Juss. & ZOO & SB \\
\hline \multicolumn{3}{|l|}{ MALVACEAE } \\
\hline Eriotheca gracilipes (K.Schum.) A.Robyns & ANE & $\mathrm{SI}$ \\
\hline \multicolumn{3}{|l|}{ MELASTOMATACEAE } \\
\hline Miconia albicans (Sw.) Steud. & ZOO & SB \\
\hline \multicolumn{3}{|l|}{ MORACEAE } \\
\hline Brosimum gaudichaudii Trécul & ZOO & $P$ \\
\hline \multicolumn{3}{|l|}{ MYRISTICACEAE } \\
\hline Virola sebifera Aubl. & ZOO & $P$ \\
\hline \multicolumn{3}{|l|}{ MYRTACEAE } \\
\hline Myrcia lasiantha DC. & ZOO & ST \\
\hline Myrcia variabilis (Mart.) ex DC. & ZOO & ST \\
\hline \multicolumn{3}{|l|}{ NYCTAGINACEAE } \\
\hline Guapira noxia (Netto) Lundell & ZOO & $\mathrm{SI}$ \\
\hline \multicolumn{3}{|l|}{ OCHNACEAE } \\
\hline Ouratea spectabilis (Mart. ex Engl.) Engl. & ZOO & ST \\
\hline \multicolumn{3}{|l|}{ PERACEAE } \\
\hline Pera glabrata (Schott) Poepp. ex Baill. & ZOO & $P$ \\
\hline \multicolumn{3}{|l|}{ PRIMULACEAE } \\
\hline Myrsine guianensis (Aubl.) Kuntz & ZO० & $P$ \\
\hline \multicolumn{3}{|l|}{ RUBIACEAE } \\
\hline Alibertia sessilis (Cham.) K. Schum. & ZOO & SB \\
\hline Cordiera sessilis (Vell.) Kuntze & ZOO & $\mathrm{SI}$ \\
\hline
\end{tabular}




\begin{tabular}{lcc}
\hline FAMíLIA / Espécie & SD & GE \\
\hline $\begin{array}{l}\text { SAPINDACEAE } \\
\text { Cupania vernalis Cambess }\end{array}$ & ZOO & SI \\
STYRACACEAE & & \\
Styrax camporum Pohl & ZOO & ST \\
Styrax ferrugineus Nees e Mart. & ZOO & ST \\
Styrax pohlii A.DC. & ZOO & ST \\
VOCHYSIACEAE & & \\
Qualea grandiflora Mart. & ANE & P \\
Qualea jundiahy Warm. & ANE & ST \\
Qualea multiflora Mart. & ANE & ST \\
Qualea parviflora Mart. & ANE & ST \\
\hline
\end{tabular}

\section{DISCUSSÃO}

A curva do coletor obtida não apresentou uma nítida estabilização, o que não indica um baixo esforço amostral, pois Müeller-Dombois e Ellemberg (1974) afirmam que em biomas tropicais o número de espécies amostradas aumenta à medida que se aumenta o tamanho da amostra, não havendo um ponto de estabilização quando se trata o número de espécies (Schilling e Batista 2008). Assim, por motivos práticos, a amostragem pode ser interrompida quando não há um acréscimo significativo de espécies com o aumento da área amostral (Mueller-Dombois e Ellemberg, 1974; Schilling e Batista, 2008), fato constatado neste estudo.

Muitas pesquisas em áreas de cerrado indicam Fabaceae como uma das principais famílias na composição da comunidade vegetal, com elevado número de espécies amostradas e valor de importância (Felfili et al., 1993; Felfili e Silva Júnior, 1993; Rizzini, 1997; Silva et al., 2002; Weiser e Godoy, 2001), destacando-se na estrutura e dinâmica dessas comunidades.

Outra família de elevada importância em áreas de Cerrado é Vochysiaceae, apresentando alta riqueza e número elevado de indivíduos (Felfili et al., 1993; Costa e Araújo, 2001; Silva et al., 2002; Balduíno et al., 2005). Haridasan (2000) propõe que uma explicação para a destacada importância pode ser o fato das espécies serem acumuladoras de alumínio, o que, como para Fabaceae, confere uma vantagem competitiva em solos com alta acidez. No presente estudo, Vochysiaceae representou 9,1\% das espécies e 32,4\% dos indivíduos amostrados. A expressiva abundância de Qualea grandiflora (16,3\% do total de indivíduos amostrados) contribuiu para a representatividade da família. Para outros parâmetros fitossociológicos analisados a espécie também se destacou, como Dominância Relativa, VI e VC. Espécies de Qualea, principalmente Q. grandiflora e Q. parviflora, contribuem decisivamente para a alta importância da família Vochysiaceae em áreas de Cerrado (Ratter et al., 1997; Ratter et al., 2003), destacando-se áreas de Cerrado localizadas no Planalto Central 
Brasileiro (Heringer et al., 1977), indicando que o gênero está presente na flora de várias áreas de Cerrado em todo o Brasil.

Das 44 espécies amostradas, apenas quatro espécies totalizam 41,5\% da Freqüência Relativa (FR) (Qualea grandiflora, Xylopia aromatica, Qualea jundiahy e Xylopia sericea). A constatação alinha-se ao padrão de diversidade observado para outras comunidades vegetais em que há poucas espécies, amplamente distribuídas na área, e espécies raras ou pouco frequentes que ocupam menor espaço (Andrade et al., 2002; Medeiros et al., 2008).

Xylopia é considerado um gênero comum nos cerrados paulistas por vários autores, com destaque em pesquisas florísticas há mais de 20 anos (Ratter et al., 1997; Rizzini, 1997). Investigações mais recentes no Mato Grosso do Sul (Güntzel et al., 2011), em São Paulo (Gimenez e Godoy, 2007) e em Minas Gerais (Saporetti Jr et al., 2003) também destacaram a dominância e abundância de espécies de Xylopia, com destaque para $X$. aromatica. A expressiva abundância de espécies do gênero pode indicar intensa pressão antrópica na área, com alterações na dinâmica natural do remanescente (Cardoso-Leite et al., 2004).

É importante destacar o grande número de indivíduos mortos (93). Eles perfazem o quarto maior VI, foram encontrados em 28 das 30 parcelas amostradas, são responsáveis por 12,7\% da Densidade Relativa e estão distribuídos de modo aleatório, não formando agregados na área investigada. Segundo alguns autores (Aquino et al., 2007; Eiten, 1994; Felfili e Silva Júnior, 1993), a grande quantidade de indivíduos mortos reflete a ocorrência de perturbações recentes na área, como fogo, presença de gado e outras atividades antrópicas. Em contrapartida, outros autores afirmam que, no cerrado, é comum o grande número de indivíduos mortos (Furley e Ratter, 1988; Pagano et al., 1989).

Embora o histórico relatado por pessoas da Fazenda descarte atividades antrópicas impactantes há muitas décadas, os dados indicam o contrário. A alta quantidade de mortas e seu padrão de distribuição constituem evidências de eventos impactantes contínuos e disseminados por toda a área. Aventa-se a hipótese de que o tamanho do fragmento, a matriz em que está inserido e consequentemente o seu isolamento, influências indiretas exercidas pela pressão humana, possam ser os complicantes para a sua conservação, modificando as suas características naturais, como propuseram Pivello e Coutinho (1996) para os remanescentes de cerrado.

A riqueza encontrada para a área pode ser considerada baixa, pois estudos realizados em outras áreas de cerrado stricto sensu indicam valores de $\mathrm{H}^{\prime}$ entre 3,0 e 3,7 (Felfili et al., 1997; Costa e Araújo, 2001; Felfili e Silva Júnior, 2001; Meira Neto e Saporetti Jr, 2002; Assunção e Felfili, 2004). Dados semelhantes ao encontrado foram verificados em fragmentos de Cerrado com áreas pequenas (Ishara et al., 2008) ou altamente antropizados, com episódios 
de incêndios frequentes (Durigan et al., 1994). Alguns autores (Felfili et al., 2000; Moreira, 2000) afirmam que a ocorrência de queimadas seria responsável pela extinção local de algumas espécies. Entretanto, relatos da inexistência de episódios de incêndios nos últimos 70 anos e a relativa abundância de espécies sensíveis ao fogo como Copaifera langsdorfii e Miconia albicans (Felfili et al., 1997; Moreira, 2000; Ishara et al., 2008) reforçam que o fogo não deve ser a explicação para a diminuição da riqueza.

É importante destacar que a distribuição na forma de "J" invertido, encontrada na análise da distribuição diamétrica, tem sido obtida para comunidades de cerrado, conforme apontam Uhlmann et al. (1998), Fidelis e Godoy (2003), Assunção e Felfili (2004); Costa et al. (2010). Segundo Assunção e Felfili (2004), isto decorre da presença maciça de indivíduos jovens, ainda em estabelecimento, ou como ressaltaram Silva Júnior e Silva (1988) também pelo menor porte que muitas espécies de cerrado apresentam.

Os resultados da análise da estrutura vertical corroboram a fisionomia de um cerrado stricto sensu denso (Ribeiro e Walter, 2008), com predomínio de indivíduos com alturas entre 4 e $6 \mathrm{~m}$ e poucos arbóreos de grande porte, emergindo desse estrato. Dentre as espécies emergentes destacam-se indivíduos de Pterodon emarginatus, com alturas entre 18-25m, Dalbergia miscolobium com 20 m e Copaifera langsdorffii, com 18 m de altura.

O padrão de distribuição observado difere do relatado em outros trabalhos que afirmam ter encontrado distribuição agregada como a mais frequente (Hay et al., 2000; Resende et al., 2003; Souza e Coimbra, 2005). A distribuição espacial das espécies pode ser influenciada por fatores bióticos e abióticos (Fortin et al., 2002). Para Hutchings (1997), o fogo, patógenos, dispersores e micro habitats influenciam na distribuição espacial das espécies vegetais. Coutinho (2006) destaca a importância dos aspectos edáficos e das relações fitossociológicas.

Ludwing e Reynolds (1988) destacam a influência dos modos de dispersão na distribuição espacial das espécies vegetais. Para as espécies anemocóricas seria esperada uma distribuição de diásporos ao acaso, enquanto espécies zoocóricas ou barocóricas têm maior probabilidade de distribuição agregada (Bernasol e Lima-Ribeiro, 2010). Na presente análise, quatro das cinco espécies com maior índice de agregação são anemocóricas, não corroborando o padrão descrito pelos autores.

Dentre as características abióticas, a luminosidade poderia provocar uma concentração de indivíduos, mas os dados são inconclusivos, já que as cinco espécies com maior índice de agregação podem ser classificadas desde pioneiras (por exemplo, Xylopia aromatica) até secundárias tardias (Qualea parviflora). Além disso, como ressaltam Camilotti 
et al. (2011), no cerrado stricto sensu a luminosidade não é um fator relevante para este contexto, devendo ser considerada apenas para áreas florestais.

Acrescentando-se à análise o padrão de distribuição aleatória apresentado pela categoria das mortas, parece mais apropriado inferir que as populações analisadas estão se estruturando espacialmente sob a influência de diversos fatores impactantes, diretos e indiretos, uma vez que a área é parte de uma matriz de Cerrado altamente alterada por atividades antrópicas em seu entorno. Tais impactos estariam influenciando o estabelecimento das plântulas e o recrutamento dos indivíduos (Barbour et. al., 1987) e também provocando a morte de indivíduos adultos.

\section{CONCLUSÃO}

Este trabalho mostra a caracterização florística e estrutural de um cerrado stricto sensu denso, com uma expressiva abundância de indivíduos nas menores classes de diâmetro e que ocupam o estrato médio, com alturas entre 3 a $9 \mathrm{~m}$. Algumas constatações merecem destaque, tais como a baixa diversidade e a dominância de poucas espécies, incluindo a categoria de mortas, tanto na estrutura horizontal como na vertical. Considerando que a distribuição diamétrica informa sobre a dinâmica de reposição de indivíduos, a maciça ocupação por apenas quatro espécies, as mesmas que dominam também o estrato médio na ocupação vertical, não oferece previsões otimistas quanto ao aumento da diversidade, regeneração e manutenção do remanescente. No mesmo sentido apontam os dados sobre a distribuição espacial dos indivíduos, que indicam forte agrupamento dessas espécies. Outro indicativo alarmante é o alto número de plantas adultas mortas, em pé, que têm destacada importância na estrutura horizontal e vertical e uma ocorrência generalizada na área, descartando a hipótese de um evento único desastroso e reforçando a existência de eventos impactantes contínuos na área como um todo. O conjunto de dados obtidos indica que a área está sob impacto, a despeito do histórico verbal disponível sobre a ausência de intervenções antrópicas diretas há muitos anos. Portanto, ressalta-se a necessidade de outras investigações,

tanto de histórico como sobre outros aspectos da dinâmica de regeneração, para a compreensão das causas dos problemas de conservação verificados no remanescente.

Dessa forma, as hipóteses iniciais deste estudo foram refutadas, já que foram identificadas alterações significativas na composição e estrutura do estrato adulto do fragmento de cerrado analisado. 


\section{REFERÊNCIAS BIBLIOGRÁFICAS}

ALENCAR, J. C. 1988. Metodologia para análise de vegetação. In: Encontro sobre inventários na Amazônia. Manaus: Anais. p. 19.

ANDRADE, L. A. Z.; FELFILI, M. J.; VIOLATTI, L. 2002. Fitossociologia de uma área de cerrado denso na RECOR-IBGE, Brasília-DF. Acta Botanica Brasilica 16 (2), 225-240.

AQUINO, F. G.; WALTER, B. M. T.; RIBEIRO, J. F. 2007. Woody community dynamics in two fragments of cerrado stricto sensu over a seven-year period (1995-2002), MA, Brazil. Revista Brasileira de Botânica 30 (1), 113-121.

ASSUNÇÃO, S. L.; FELFILI, J. M. 2004. Fitossociologia de um fragmento de cerrado sensu stricto na APA de Paranoá, DF, Brasil. Acta Botanica Brasilica 18 (4), 903-910.

BALDUÍNO, A. P. C.; SOUZA, A. L.; NETO, J. A. A. M.; SILVA, A. F.; SILVA JÚNIOR, M. C. 2005. Fitossociologia e análise comparativa de composição florística do Cerrado na Floana de Paraopeba-MG. Revista Árvore 29 (1), 25-34.

BARBOUR, M. G.; BURK, J. H.; PITTS, W. D. 1987. Terrestrial Plant Ecology. Benjamim/Cummings: Menlo-Park. 604 p.

BATALHA, M. A.; ARAGAKI, S.; MANTOVANI, W. 1997. Florística do cerrado em Emas (Pirassununga, SP). Boletim de Botânica da Universidade de São Paulo 16, 49-64.

BARROS, P. L. C.; MACHADO, S. S. Aplicação de índice de dispersão em espécies de florestas tropicais da Amazônia Brasileira. Curitiba: FUPEF, 1984, 44p.

BERNASOL, W. P.; LIMA-RIBEIRO, M. S. 2010. Estrutura espacial e diamétrica de espécies arbóreas e seus condicionantes em um fragmento de cerrado sentido restrito no sudoeste goiano. Hoehnea 37 (2), 181-198.

CAMILOTTI, D. C.; PAGOTTO, T. C. S.; ARAÚJO, A. C. 2011. Análise da vegetação arbórea de um remanescente de Cerradão em Bandeirantes, Mato Grosso do Sul, Brasil. Iheringia 66 (1), 31-46.

CARDOSO-LEITE, E.; COVRE, T. B.; OMETtO, R. G.; CAVALCANTI, D. C.; PAGANI, M. I. 2004. Fitossociologia e caracterização sucessional de um fragmento de mata ciliar em Rio Claro/SP, como subsídio à recuperação da área. Revista do Instituto Florestal 16 (1), 3141.

CIENTEC. 2006. Mata Nativa 2. Viçosa: Cientec Ltda., Universidade Federal de Viçosa.

COLWELL, R. K. 2013. EstimateS: Statistical estimation of species richness and shared species from samples. Version 9. Disponível em: <http://viceroy.eeb.uconn.edu/estimates/estimatespages/EstimateSRegistration.ht m>. Acesso em: 25 fev. 2017.

COSTA, A. A.; ARAÚJO, G. M. 2001. Comparação da vegetação arbórea de cerradão e de cerrado na Reserva do Panga, Uberlândia, Minas Gerais. Acta Botanica Brasilica 15 (1), 6372. 
COSTA, C. P.; CUNHA, C. N.; COSTA, S. C. 2010. Characterization of the flora and structure of the shrub-tree layer in a cerrado area in Pantanal do Poconé, MT. Biota Neotropica 10 (3), 61-73.

COUTINHO, L. M. 2006. O conceito de bioma. Acta Botanica Brasilica 20 (1), 13-23.

DURIGAN, G.; LEITÃO FILHO, H. F.; RODRIGUES, R. R. 1994. Phytosociology and structure of a frequently burnt cerrado vegetation in SE- Brazil. Flora 189, 153-160.

DURIGAN, G.; NISHIKAWA, D. L. L.; ROCHA, E.; SILVEIRA, E. R.; PULITANO, F. M.; REGALADO, L. B.; CARVALHAES, M. A.; PARANAGUÁ, P. A.; RANIERI, V. E. L. 2002. Caracterização de dois estratos da vegetação em uma área de cerrado no município de Brotas, SP, Brasil. Acta Botanica Brasilica 16 (3), 251-262.

DURIGAN, G., SIQUEIRA, M. F., FRANCO, G. A. D. C., BRIDGEWATER, S.; RATTER, J. A. 2003. The vegetation of priority areas for cerrado conservation in São Paulo State, Brazil. Edinburgh Journal of Botany 60, p. 217-241.

DURIGAN, G.; SIQUEIRA, M. F.; FRANCO, G. A. D. C. 2007. Threats to the Cerrado remnants of the state of São Paulo, Scientia Agricola (4), 355-363.

DURIGAN, G.; MELO, A. C. G.; MAX, J. C. M.; BOAS, O. V.; CONTIERI, W. A.; RAMOS, V. S. 2011. Manual de recuperação da vegetação de Cerrado. São Paulo: CETESB. 23 p.

EITEN, G. 1963. Habitat flora of fazenda Campininha, São Paulo, Brazil. In: FERRI, M. G. (Coord). I Simpósio sobre o cerrado. São Paulo: EDUSP, p. 179-231.

EITEN, G. 1994. Vegetação do cerrado. In: PINTO, M. N. (Ed.). Cerrado: caracterização, ocupação e perspectivas. 2.ed. Brasília: SEMATEC, p. 17-73.

FELFILI, J. M.; SILVA JÚNIOR, M. C. 1993. A comparative study of cerrado (stricto sensu) vegetation in Central Brazil. Journal of Tropical Ecology 9, 277-289.

FELFILI, J. M.; SILVA JÚNIOR, M. C.; REZENDE, A. V.; MACHADO, J. W. B.; WALTER, B. M. T.; SILVA, P. E. N.; HAY, J. D. 1993. Análise comparativa da florística e fitossociologia da vegetação arbórea do cerrado sensu stricto na Chapada Pratinha, DF-Brasil. Acta Botanica Brasilica 6 (1), 27-46.

FELFILI, J. M.; SILVA JÚNIOR, M. C.; NOGUEIRA, P. E; WALTER, B. M. T. W.; SILVA, M. A., ENCINAS, J. I. 1997. Comparação florística e fitossociológica do cerrado nas Chapadas Pratinha e dos Veadeiros. In: Leite, L; Saito, C. (eds). Contribuição ao conhecimento ecológico do cerrado. Brasília: UnB, p. 6-11.

FELFILI, J. M.; REZENDE, A. V.; SILVA JÚNIOR, M. C.; SILVA, M. A. 2000. Changes in the floristic composition of cerrado sensu stricto in Brazil over a nine-year period. Journal of Tropical Ecology 16, 579-590.

FELFILI, J. M.; SILVA JÚNIOR, M. C. 2001. Biogeografia do Bioma Cerrado: estudo fitofisionômico na Chapada do Espigão Mestre do São Francisco. Brasília: UNB, 152 p. 
FELFILI, J. M.; NOGUEIRA, P. E.; SILVA-JÚNIOR, M. C.; MARIMON, B. S.; DELITTI, W. B. C. 2002. Composição florística e fitossociologia do cerrado sentido restrito no município de Água Boa MT. Acta Botanica Brasilica 16 (1), 103-112.

FIDELIS, A. T.; GODOY, S. A. P. 2003. Estrutura de um cerrado stricto sensu na gleba Cerrado Pé-de-Gigante, Santa Rita do Passa Quatro, SP. Acta Botanica Brasilica 17 (4), 531-539.

FORTIN, M. J.; DALE, M. R. T.; HOEF, J. 2002. Spatial analysis in ecology. In: EL-SHAARAWI, A.H.; PIEGORSCH, W.W. (Ed.). Encyclopedia of Environmetrics. Chichester: John Wiley e Sons, p. 2051-2058.

FORZZA, R.C. (org.), et al. 2010. Catálogo de plantas e fungos do Brasil [online]. Rio de Janeiro: Andrea Jakobsson Estúdio: Instituto de Pesquisa Jardim Botânico do Rio de Janeiro. 828 p. Disponível em: <http://static.scielo.org/scielobooks/x5x7v/pdf/forzza9788560035090.pdf>.

FURLEY, P.; RATTER, J. 1988. Soil resources and plant communities of the central Brazilian cerrado and their development. Journal of Biogeography 15, 97-108.

GIMENEZ, V. M. M.; GODOY, S. A. P. 2007. Diversidade da Vegetação Regenerante de um Cerrado após Plantio de Exóticas em Luiz Antônio (SP). Revista Brasileira de Biociências 5 (2), 729-731.

GÜNTZEL, A. M.; DIAS, N. R.; COERTJENS, C. M.; SILVA, G. C.; VIEIRA, E. A. 2011. Análise fitossociológica de um remanescente de vegetação na microbacia do Córrego Criminoso (Bacia do Rio Taquari, Coxim, MS, Brasil): subsídios para a recomposição da vegetação. Acta Botanica Brasilica 25 (3), 586-592.

HARIDASAN, M. 2000. Nutrição mineral das plantas nativas do Cerrado: grupos funcionais. In: CAVALCANTI, T.B.; WALTER, B.M.T. (Org.). Tópicos atuais em botânica: palestras convidadas. Brasília: Embrapa, p.159-164.

HAY, J. D.; BIZERRIL, M. X.; CALOURO, A. M.; COSTA, E. M. N.; FERREIRA, A. A.; GASTAL, M. L. A.; GOES JUNIOR, C. D.; MANZAN, D. J.; MARTINS, C. R.; MONTEIRO, J. M. G.; OLIVEIRA, S. S.; RODRIGUES, M. C. M.; SEYFFARTH, J. A. S.; WALTER, B. M. T. 2000. Comparação do padrão da distribuição espacial em escalas diferentes de espécies nativas do cerrado, em Brasília, DF. Revista Brasileira de Botânica 23 (3), 341-347.

HERINGER, E. P.; BARROSO, G. M.; RIZZO, J. A.; RIZZINI, C. T. 1977. A flora do Cerrado. In: FERRI, M.G. (coord.). IV Simpósio sobre o cerrado. São Paulo: Ed. Itatiaia, p. 211-232.

HUTCHINGS, M. J. 1997. The structure of plant populations. In: CRAWLEY, M.J. (Ed.). Plant Ecology. Oxford: Blackwell Science, p. 325-358.

ISHARA, K. L.; DÉSTRO, G. F. G.; MAIMONI-RODELLA, R. C. S.; YANAGIZAWA, Y. A. N. P. 2008. Composição florística de remanescente de cerrado sensu stricto em Botucatu, SP. Revista Brasileira de Botânica 31 (4), 575-586. 
KRONKA, F. J. N.; NALON, M. A.; MATSUKUMA, C. K.; KANASHIRO, M. M.; YWANE, M. S. S.; PAVÃO, M.; DURIGAN, G.; LIMA, L. M. P. R.; GUILLAUMON, J. R.; BAITELLO, J. B.; BORGO, S. C.; MANETTI, L. A.; BARRADAS, A. M. F.; FUKUDA, J. C.; SHIDA, C. N.; MONTEIRO, C. H. B.; PONTINHA, A. A. S.; ANDRADE, G. G.; BARBOSA, O.; SOARES, A. P. 2005. Inventário florestal da vegetação natural do estado de São Paulo. São Paulo: Secretaria do Meio Ambiente, 200 p.

LEITÃO-FILHO, H. F. 1992. A flora arbórea da Serra do Japi. In: MORELLATO, L. P. C. (Ed.). História natural da Serra do Japi. Campinas: UNICAMP, p. 40-62.

LONGHI, S. J. 1980. A estrutura de uma floresta natural de Araucaria angustifolia (Bert.) O. Ktze, no sul do Brasil. 198 p. Dissertação de Mestrado em Engenharia Florestal. Setor de Ciências Agrárias, Universidade Federal do Paraná, Curitiba, PR, 198 p.

LUDWING, J. A.; REYNOLDS, J. F. 1988. Statistical ecology: a primer on methods and computing. New York: John Wiley e Sons, $337 \mathrm{p}$.

MACHADO, R. B.; RAMOS NETO, M. B.; PEREIRA, P.; CALDAS, E.; GONÇALVES, D.; SANTOS, N.; TABOR, K.; STEININGER, M. 2004. Estimativas de perda da área do Cerrado brasileiro. Brasília: Conservation International do Brasil, 23 p.

MAGURRAN, A. E. 1988. Ecological diversity and its measurement. New Jersey: Princeton University Press, $179 \mathrm{p}$.

MARIMON JÚNIOR, B. H.; HARIDASAN, M. 2005. Comparação da vegetação arbórea e características edáficas de um cerradão e um cerrado sensu stricto em áreas adjacentes em solos distróficos no leste de Mato Grosso, Brasil. Acta Botanica Brasílica 19 (4), 913 926.

MEDEIROS, M. B.; WALTER, B. M. T.; SILVA, G. P. 2008. Fitossociologia do cerrado stricto sensu no município de Carolina, MA, Brasil. CERNE 14 (4), 285-294.

MEIRA NETO, J. A. A.; SAPORETTI JÚNIOR, A. W. 2002. Composição florística em cerrado no Parque Nacional da Serra do Cipó, MG. Revista Árvore 26 (5), 645-648.

MOREIRA, A. G. 2000. Effects of fire protection on savanna structure in Central Brazil. Journal of Biogeography 27, 1021-1029.

MOTTA, P. E. F.; CURI, N.; FRANZMEIER, D. P. 2002. Relation of Soils and Geomorphic Surfaces in the Brazilian Cerrado. In: OLIVEIRA, P.S.; MARQUIS, R.J. The Cerrados of Brazil: ecology and natural history of a neotropical savanna. New York: Columbia University Press, p.1332.

MUELLER-DOMBOIS, D.; ELLENBERG, H. 1974. Aims and methods of vegetation ecology. New York: John Wiley e Sons, $547 \mathrm{p}$.

MYeRS, N.; MITTERMEIER, R. A.; MITTERMEIER, C. G.; FONSECA, G. A. B.; KENT, J. 2000. Biodiversity hotspots for conservation priorities. Nature 403, 853-858.

NERI, A. V. 2005. Regeneração de espécies nativas lenhosas sob plantio de Eucalyptus em área de Cerrado na Floresta Nacional de Paraopeba, MG, Brasil. Acta Botanica Brasilica 19 (2), 369-376. 
PAGANO, S. N. 1989. Produção de folhedo em mata mesófila semidecídua no município de Rio Claro, SP. Revista Brasileira de Biologia, 49 (3), 633-639.

PAYANDEH, B. 1970. Comparison of method for assessing spatial distribuition of trees. Forest Science 16, 312-317.

PIVELLO, V. R.; COUTINHO, L. M. 1996. A qualitative successional model to assist in the management of Brazilian cerrados. Forest Ecology and Management 87 (1), 127-138.

RATTER, J. A.; RIBEIRO, J. F.; BRIDGEWATER, S. 1997. The Brazilian cerrado vegetation and threats to its biodiversity. Annals of Botany 80 (3), 223-230.

RATTER, J. A.; BRIDGEWATER, S.; RIBEIRO, J. F. 2003. Analysis of the floristic composition of the Brazilian cerrado vegetation: comparison of the woody vegetation of 376 areas. Edinburgh Journal of Botany 60, 57-109.

RESENDE, J. C. F.; KLINK, C. A.; SCHIAVINI, I. 2003. Spatial hererogeneity and its influence on Copaifera langsdorffii Desf. (Caesalpiniaceae). Brazilian Archives of Biology and Technology 46, 405-414.

RIBEIRO, J. F.; WALTER, B. M. T. 2008. As principais fitofisionomias do bioma Cerrado. In: SANO, S.M.; ALMEIDA, S.P.; RIBEIRO, J.F. (Ed). Cerrado: ecologia e flora. Brasília: EMBRAPA, p. 153-212.

RIZZINI, C. T. 1997. Tratado de fitogeografia do Brasil. Rio de Janeiro: Âmbito Cultural Edições Ltda., $747 \mathrm{p.}$

RODRIGUES, W. A., PIRES, J. M. 1988. Inventário fitossociológico. In: Encontro sobre inventários florísticos na Amazônia. Manaus: Anais. p. 5.

SÃO PAULO. 1997. Cerrado: bases para a conservação e uso sustentável das áreas de Cerrado do Estado de São Paulo. São Paulo: SEMA, 184 p.

SAPORETTI JR., A. W.; MEIRA NETO, J. A. A.; ALMADO, R. P. 2003. Fitossociologia de cerrado sensu stricto no município de Abaeté - MG. Revista Árvore 27 (3), 413-419.

SASAKI, D.; MELLO-SILVA, R. 2008. Levantamento florístico no cerrado de Pedregulho, SP, Brasil. Acta Botanica Brasilica 22 (1), p.187-202.

SCHILLING, A. C.; BATISTA, J. L. F. 2008. Curva de acumulação de espécies e suficiência amostral em Florestas Tropicais. Revista Brasileira de Botânica 31 (1), 179-187.

SHEPHERD, G. J. 2000. Conhecimento e diversidade de plantas terrestres do Brasil. Brasília: UnB, $53 \mathrm{p}$.

SHEPHERD, G. J. 2009. Fitopac v. 2.0. Universidade Estadual de Campinas, Campinas.

SILVA JÚNIOR, M. C.; SILVA, A. F. 1988. Distribuição dos diâmetros dos troncos das espécies mais importantes do cerrado na Estação Florestal de Experimentação de Paraopeba (EFLEX), MG. Acta Botanica Brasilica 2 (1-2), 107-126. 
SILVA, L. O.; COSTA, D. A.; ESPÍRITO SANTO FILHO, K.; FERREIRA, H. D.; BRANDÃO, D. 2002. Levantamento florístico e fitossociológico em duas áreas de cerrado sensu stricto no Parque Estadual da Serra de Caldas Novas, Goiás. Acta Botanica Brasilica 16 (2), 43-53.

SOUZA, J. P.; COIMBRA, F. G. 2005. Estrutura populacional e distribuição espacial de Qualea parviflora Mart. em um Cerrado sensu stricto. Bioscience Journal 21, 65-70.

TEIXEIRA, A. P.; RODRIGUES, R. R. 2006. Análise florística e estrutural do componente arbustivo-arbóreo de uma floresta de galeria no Município de Cristais Paulista, SP, Brasil. Acta Botanica Brasilica 20 (4), 803-813.

TEIXEIRA, M. I. J. G.; ARAÚJO, A. R. B.; VALERI, S. V.; RODRIGUES, R. R. 2004. Florística e fitossociologia de área de Cerrado s.s. no município de Patrocínio Paulista, nordeste do estado de São Paulo. Bragantia 63 (1), 1-11.

TOLEDO FILHO, D. V. Composição florística e estrutura fitossociológica da vegetação de cerrado no município de Luis Antônio (SP). 1984. 173 p. Dissertação (Mestrado em Biologia Vegetal) - Departamento de Biologia Vegetal, UNICAMP, Campinas. 1984.

UHLMANN, A.; GALVÃO, F.; SILVA, S. M. 1998. Análise da estrutura de duas unidades fitofisionômicas de savana (cerrado) no sul do Brasil. Acta Botanica Brasilica 12 (3), 211247.

WEISER, V. L.; GODOY, S. A. P. 2001. Florística em um hectare de cerrado stricto sensu na ARIECerrado Pé-de-Gigante, Santa Rita do Passa Quatro, SP. Acta Botanica Brasilica 15 (2), 201-212. 


\section{CAPÍTULO II}

Estrutura e composição do estrato de regeneração de um remanescente de cerrado stricto sensu localizado em Patrocínio Paulista - SP 


\section{RESUMO}

Apesar de sua extensa área original no Brasil, o Cerrado já foi severamente degradado, com a conversão de áreas naturais e fragmentação, gerando remanescentes em diferentes estados de conservação. Esses impactos acarretam em modificações nos diversos componentes da comunidade vegetal, destacando-se o estrato de regeneração. Dessa forma, os objetivos desse estudo foram (i) caracterizar a estrutura do estrato regenerativo de um remanescente de cerrado stricto sensu localizado na Fazenda Santa Cecília, município de Patrocínio Paulista - SP e (ii) verificar a similaridade entre a composição do estrato de regeneração e adulto do fragmento. Para isso foi realizado um levantamento florístico em 120 parcelas de $2 \times 2 \mathrm{~m}$ distribuídas aleatoriamente em um fragmento de cerrado stricto sensu durante dois anos, amostrando todos os indivíduos com PAS entre $5-15 \mathrm{~cm}$. A similaridade com o estrato adulto foi verificada utilizando-se o Índice de Jaccard. Foram identificados 214 indivíduos distribuídos em 17 espécies. O Índice de Shannon obtido foi 2,272 e o Índice de Similaridade de Jaccard foi $40 \%$. Os resultados apontam para uma diversidade muito baixa, tanto em comparação com outros estudos quanto com o estrato adulto. Vários estudos afirmam que tais modificações podem ser motivadas pelas pressões antrópicas presentes nos remanescentes, sendo que um monitoramento dos padrões de regeneração assim como estudos complementares são necessários para se identificar os motivos dessa intensa diminuição da diversidade vegetal local.

Palavras-chave: estrato de regeneração, fitossociologia, diminuição da biodiversidade.

\section{INTRODUÇÃO}

O cerrado paulista, que ocupava cerca de $14 \%$ da área total do estado (São Paulo, 1997), nos últimos 30 anos sofreu uma drástica redução dessa área, restando pouco menos de 1\% (Kronka et al., 2005), sendo que estas áreas remanescentes estão espalhadas em pequenos fragmentos isolados por uma matriz antrópica (Durigan et al., 2007).

Essa intensa degradação causada pela remoção de áreas naturais e fragmentação de remanescentes interfere em muitos processos ecológicos das comunidades vegetais, dentre eles a dinâmica de reposição de indivíduos e espécies por meio da formação do estrato de regeneração. A maior parte dos estudos sobre o estrato regenerativo de cerrado foram realizados na região central do Brasil (Amaral et al., 2015; Gonzaga et al., 2013; Matos, 1994; Medeiros et al., 2007; Oliveira e Felfili, 2005) e nenhum estudo desse tipo foi realizado em áreas de cerrado do extremo nordeste paulista. Assim, é importante expandir esses estudos para outras áreas do bioma, incluindo áreas de transição como, por exemplo, entre o cerrado paulista, o mineiro e do planalto central.

Alguns autores (Martinez-Ramos, 1991; Felfili et al., 2000) assumem que o estrato regenerativo de uma comunidade vegetal é composto de indivíduos que já ultrapassaram o período crítico de mortalidade, definido para as comunidades arbóreas como os indivíduos com altura igual ou superior a um metro (Felfili et al., 2000), que já superaram as pressões de seleção natural do ambiente. 
Informações sobre este estrato de regeneração são fundamentais pois ele mantem a estabilidade e a continuidade da flora de um local, mesmo depois de remoção parcial ou total do estrato adulto, causada por ações naturais ou antrópicas (Pereira, 2009). Assim, conhecer a composição do estrato de regeneração permite fazer considerações a respeito do potencial regenerativo de um ecossistema, indicando possíveis alterações na sua estrutura ou composição (Guariguata e Ostertag, 2001) ao longo do tempo e possibilitando uma maior compreensão sobre a manutenção da diversidade, estabilidade e dinâmica da comunidade (Felfili et al., 1997). Apesar dessa importância, são poucas as pesquisas sobre o estrato de regeneração de cerrado sensu stricto.

\section{HIPÓTESE}

O estrato juvenil tem uma composição semelhante àquela encontrada no estrato adulto, indicando a adequada manutenção dos processos ecológicos relacionados ao ciclo de vida das diversas espécies arbóreas presentes na área.

\section{OBJETIVOS ESPECÍFICOS}

Caracterizar a estrutura e diversidade vegetal do estrato regenerativo de um remanescente de cerrado stricto sensu localizado na Fazenda Santa Cecília, município de Patrocínio Paulista - SP.

\section{MATERIAL E MÉTODOS}

Nas 30 parcelas utilizadas para o levantamento florístico do estrato adulto foram plotadas 4 subparcelas de $2 \times 2 \mathrm{~m}$, uma em cada vértice, totalizando 120 parcelas de amostragem do estrato de regeneração.

Em cada subparcela, todos os indivíduos lenhosos com perímetro a altura do solo entre 5 - $15 \mathrm{~cm}$ foram amostrados em quatro ocasiões (setembro de 2014-2015 e março de 2015-2016), adaptando o método apresentado por Medeiros et al. (2007). A coleta de dados realizada em quatro ocasiões distintas diminui a influência das variações temporais no recrutamento dos indivíduos, sendo que em cada etapa de coleta foram amostradas 30 parcelas. 
A suficiência amostral foi verificada utilizando-se o software EstimateS (Colwell, 2013) e o gráfico foi construído com o software Statistica 13. Para a construção do gráfico foi utilizado o estimador Jackknife de primeira ordem com intervalo de confiança de 95\%.

Para cada indivíduo amostrado os dados coletados foram: perímetro, medido com fita métrica, e a altura estimada. A identificação das espécies foi realizada em campo e as mesmas foram agrupadas em famílias de acordo com Flora do Brasil (2016).

A análise do levantamento fitossociológico foi realizada com o software Fitopac 2.0 (Shepherd 2009) utilizando-se os seguintes parâmetros: densidade relativa; frequência relativa; dominância relativa por área (calculada a partir da área basal de cada indivíduo arbóreo); índice do valor de importância e de cobertura (Mueller-Dombois e Ellenberg, 1974). Para as medidas de diversidade foram utilizados o índice de diversidade de Shannon e Weaver, índice de concentração de Simpson e o índice de equabilidade de Pielou (Magurran, 1988). Com o intuito de descrever detalhadamente a estrutura da vegetação, também foram incluídos os resultados da área basal total e densidade total absoluta.

Com o intuito de caracterizar mais detalhadamente as espécies amostradas foi realizada a sua classificação conforme a síndrome de dispersão de sementes (autocoria, barocoria ou zoocoria) e grupo ecológico (pioneira, secundária inicial, secundária tardia e sub-bosque) utilizando-se bibliografia especializada.

\section{RESULTADOS}

Pela análise da curva do coletor elaborada (Figura 1) assume-se uma suficiência amostral a partir da parcela 60, apesar de não atingida uma clara assíntota.

Na área de estudo foram amostrados 214 indivíduos distribuídos em 17 espécies, 16 gêneros e 9 famílias (Tabela 1). As famílias mais ricas foram Fabaceae (6 espécies) Annonaceae ( 2 espécies), Vochysiaceae ( 2 espécies) e Styracaceae ( 2 espécies) que representaram 66,6\% das espécies registradas. As famílias com maior número de indivíduos foram Annonaceae (64), Melastomataceae (44), Myristicaceae (26) e Vochysiaceae (20), que somaram 71,9\% do total de indivíduos amostrados. Seis famílias foram representadas por apenas uma espécie, totalizando $54,4 \%$.

A Área Basal Total foi de $0,156 \mathrm{~m}^{2}$ e a Densidade Total Absoluta foi de 4.458 ind.ha-1. Outros resultados do presente estudo apontam para uma baixa diversidade $\left(H^{\prime}=2,272\right.$; equabilidade $=0,786$; Simpson $=0,876$ ). 
Figura 1 - Curva do coletor do estrato de regeneração do cerrado stricto sensu da Fazenda Santa Cecília, com intervalo de confiança de 95\%.

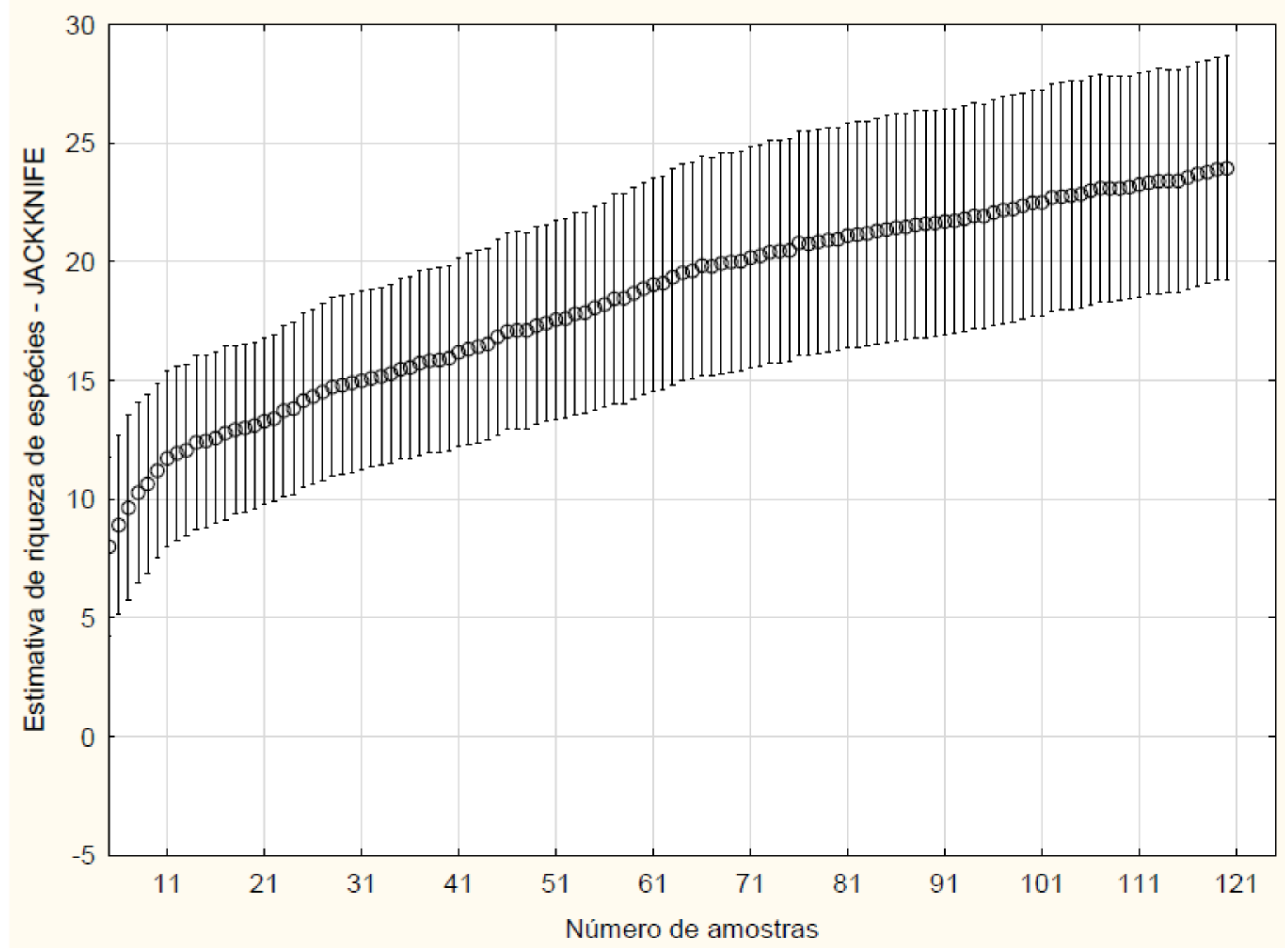

Tabela 1 - Parâmetros fitossociológicos das espécies com PAS entre 5 - 15cm, amostradas no cerrado stricto sensu na Fazenda Santa Cecília, Patrocínio Paulista, SP, em ordem decrescente de VI. NI: número de indivíduos por espécie; DR: Densidade Relativa (\%); FR: Frequência Relativa; DoR: Dominância Relativa (\%); VI: Valor de Importância; VC: Valor de Cobertura.

\begin{tabular}{lllllll}
\hline \multicolumn{1}{c}{ Espécie } & NI & DR & FR & DoR & VI & VC \\
\hline Miconia albicans & 44 & 20,56 & 20,00 & 22,72 & 63,28 & 43,28 \\
Xylopia aromatica & 38 & 17,76 & 17,78 & 18,11 & 53,65 & 35,87 \\
Xylopia sericea & 26 & 12,15 & 11,11 & 11,78 & 35,04 & 23,93 \\
Virola sebifera & 26 & 12,15 & 11,67 & 10,62 & 34,44 & 22,77 \\
morta & 22 & 10,28 & 9,44 & 9,87 & 29,59 & 20,15 \\
Qualea grandiflora & 19 & 8,88 & 8,89 & 11,51 & 29,28 & 20,39 \\
Copaifera langsdorffii & 11 & 5,14 & 6,11 & 4,99 & 16,24 & 10,13 \\
Styrax ferrugineus & 9 & 4,21 & 5,00 & 2,11 & 11,31 & 6,31 \\
Pterodon emarginatus & 7 & 3,27 & 3,33 & 4,19 & 10,79 & 7,46 \\
Dalbergia miscolobium & 2 & 0,93 & 1,11 & 0,98 & 3,02 & 1,91 \\
Andira humilis & 2 & 0,93 & 1,11 & 0,67 & 2,71 & 1,60 \\
Hirtella glandulosa & 2 & 0,93 & 1,11 & 0,5 & 2,54 & 1,43 \\
Senna rugosa & 1 & 0,47 & 0,56 & 0,52 & 1,54 & 0,98 \\
Qualea parviflora & 1 & 0,47 & 0,56 & 0,37 & 1,39 & 0,83 \\
Ocotea corymbosa & 1 & 0,47 & 0,56 & 0,31 & 1,34 & 0,78 \\
Cupania vernalis & 1 & 0,47 & 0,56 & 0,29 & 1,31 & 0,76 \\
Acosmium dasycarpum & 1 & 0,47 & 0,56 & 0,24 & 1,27 & 0,71 \\
Styrax pohlii & 1 & 0,47 & 0,56 & 0,22 & 1,24 & 0,69 \\
\hline TOTAL & 214 & 100 & 100 & 100 & 300 & 200 \\
\hline
\end{tabular}


Conforme indica a Tabela 2, a distribuição das espécies quanto a sua síndrome de dispersão foi: 11 espécies zoocóricas (64,7\%), 5 espécies anemocóricas (29,4\%) e 1 espécie autocórica (5,9\%). Com relação ao grupo ecológico, as espécies distribuíram-se da seguinte forma: 4 espécies pioneiras (23,5\%), 4 espécies secundária inicial (23,5\%), 5 espécies secundária tardia (29,5\%), 1 espécie clímax (5,9\%) e 3 espécies de sub-bosque $(17,6 \%)$.

Tabela 2 - Classificação quanto a síndrome de dispersão e grupo ecológico das espécies vegetais amostradas no cerrado stricto sensu na Fazenda Santa Cecília, Patrocínio Paulista, SP. SD: síndrome de dispersão; ZOO: zoocórica; ANE: anemocórica, AUT: autocórica; GE: grupo ecológico; P: pioneira, SI: secundário inicial, ST: secundária tardia, C: clímax; SB: sub-bosque.

\begin{tabular}{lcc}
\hline \multicolumn{1}{c}{ FAMÍLIA / Espécie } & SD & GE \\
\hline ANNONACEAE & & \\
Xylopia aromatica (Lam.) Mart. & ZOO & P \\
Xylopia sericea A.St.-Hil. & ZOO & SI \\
CHRYSOBALANACEAE & & \\
Hirtella glandulosa Spreng. & ZOO & C \\
FABACEAE & & \\
Acosmium dasycarpum (Vogel) Yakovlev & ANE & SI \\
$\begin{array}{l}\text { Andira humilis Mart. ex Benth. } \\
\text { Copaifera langsdorffii Desf. }\end{array}$ & ZOO & SB \\
Dalbergia miscolobium Benth. & ZOO & ST \\
$\begin{array}{l}\text { Pterodon emarginatus Vogel } \\
\text { Senna rugosa (G. Don) H.S.Irwin e Barneby }\end{array}$ & ANE & P \\
LAURACEAE & AUT & SB \\
Ocotea corymbosa (Meisn.) Mez & & \\
MELASTOMATACEAE & ZOO & ST \\
Miconia albicans (Sw.) Steud. & & \\
MYRISTICACEAE & ZOO & SB \\
Virola sebifera Aubl. & & \\
SAPINDACEAE & ZOO & P \\
Cupania vernalis Cambess & & \\
STYRACACEAE & ZOO & SI \\
Styrax camporum Pohl & & \\
Styrax ferrugineus Nees e Mart. & ZOO & ST \\
VOCHYSIACEAE & ZOO & ST \\
$\begin{array}{l}\text { Qualea grandiflora Mart. } \\
\text { Qualea parviflora Mart. }\end{array}$ & ANE & P \\
\hline & ANE & ST \\
\hline
\end{tabular}

\section{DISCUSSÃO}

Vários estudos sobre análise temporal do bioma Cerrado no estado de São Paulo (Klink e Moreira, 2002; Machado et al., 2004; Felfili et al., 2005; Pivello, 2005; Ribeiro et al., 2005; Ratter et al., 2006) apontaram diferentes ritmos de degradação ambiental na composição da 
flora dos remanescentes. Entretanto, estes estudos analisaram apenas o estrato adulto ao longo do tempo, sendo que poucos estudos analisaram o estrato de regeneração do Cerrado.

A riqueza e equabilidade encontradas são consideradas muito baixas quando comparada com outros estudos. Estes baixos índices são justificados pela grande abundância de indivíduos de duas espécies: Miconia albicans e Xylopia aromatica que, quando somadas, correspondem a $38,3 \%$ do total de indivíduos. É fundamental ressaltar que, devido à escassez de estudos sobre o estrato regenerativo do cerrado, a comparação dos resultados fitossociológicos deve ser realizada com bastante cautela, pois os limites de inclusão e tamanho amostral variam muito.

Comparando-se o Índice de Shannon encontrado no presente estudo com outros estudos realizados no estrato regenerativo de cerrado em áreas com plantio de eucalipto, ou seja, altamente alteradas, constata-se que, realmente, a área estudada apresenta uma riqueza extremamente baixa para este estrato. Os estudos consultados apresentaram índices de diversidade entre 2,49 - 3,34 (Neri et al., 2005; Saporetti Jr. et al., 2003a; Calegario et al., 1993). Quando a comparação é feita com áreas naturais de cerrado stricto sensu, a disparidade dos resultados é ainda maior, pois os valores do índice de Shannon para o estrato de regeneração em áreas naturais de cerrado variam entre 3,16-3,73 (Felfili et al., 1997; Felfili e Imaña-Encinas, 2001; Meira Neto e Saporetti Jr., 2002; Felfili et al., 2002; Saporetti Jr. et al., 2003b).

Assim, apesar de uma grande variação nos valores de diversidade encontrados e nas diferentes condições ambientais de cada área analisada em outras pesquisas, o presente estudo apresentou valor de diversidade inferior aqueles encontrados em áreas altamente modificadas como, por exemplo, áreas com estrato adulto composto por espécies do gênero Eucalyptus. Vale ressaltar que, de acordo com Tabarelli e Mantovani (1999), Werneck et al. (2000) e Rosa e Schiavini (2006), a comparação dos índices de diversidade entre diferentes estudos do estrato regenerativo de cerrado deve ser realizado com grande cautela, pois além das peculiaridades naturais das diferentes formações do cerrado, outras características precisam ser consideradas, como o critério de inclusão dos indivíduos, a área total amostrada e o seu grau de alteração, pois estes são fatores que influenciam diretamente na diversidade da comunidade vegetal.

Vale et al. (2009) indica que o baixo valor do Índice de Diversidade de Shannon encontrado pode ser justificado pela pressão antrópica na área estudada, pois estes impactos modificaram as características ambientais da área e favoreceram poucas espécies tolerantes à alta luminosidade. Essa explicação não se aplica integralmente ao presente estudo, pois as 
espécies amostradas são representantes de diferentes grupos ecológicos (pioneiras, secundária inicial, secundária tardia, clímax e sub-bosque).

Ainda tratando sobre o IVI, apesar de não ser considerada uma espécie, destaca-se a categoria das mortas que apresentam o quinto maior índice. A grande quantidade de indivíduos mortos, espalhados por todo o fragmento, sugerem eventos impactantes diretos e indiretos na comunidade, o que estaria prejudicando o recrutamento de novos indivíduos (Barbour et. al., 1987).

Alguns autores, como Oliveira e Silva (1993) e Hoffmann (1999), afirmam que as características reprodutivas das espécies vegetais contribuem fortemente para a estrutura das populações de uma comunidade vegetal, pois espécies com propagação vegetativa, devido ao seu alto potencial de crescimento populacional, poderiam dominar o estrato de regeneração. Outros autores (Ferri, 1961; Rizzini, 1971; Oliveira e Silva, 1993; Nardoto et al., 1998; Kanegae et al., 2000; Braz et al., 2000), afirmam que para o cerrado, a propagação vegetativa estaria presente em um grande número de espécies lenhosas. Entretanto, analisando-se as quatro espécies com maior número de indivíduos amostrado, nenhuma possui propagação vegetativa (Miranda-Melo et al., 2007; Souza et al., 2015; Rios e Ribeiro, 2014). Dessa forma, o tipo de propagação das principais espécies amostradas não justifica a sua dominância.

Oliveira-Filho et al. (1997) e Schiavini et al. (2001) afirmam que as condições ambientais influenciam, decisivamente, no estabelecimento de indivíduos de espécies vegetais. Assim, o atual estrato adulto seria reflexo das condições ambientais de períodos mais antigos que teriam influenciado no estabelecimento dos atuais indivíduos adultos (Gonzaga et al., 2013). Com a mudança das condições ambientais devido à inúmeros fatores, destacandose os fatores antrópicos, os indivíduos do estrato de regeneração estariam sob influência de um novo grupo de fatores, determinando, dessa forma, um novo conjunto de espécies regenerantes (Oliveira e Felfili, 2005). Desta forma, devido à sua plasticidade, as condições ambientais atuais ou de um passado recente atuariam decisivamente, na estrutura e composição do estrato de regeneração. Schiavini et al. (2001) também destaca a importância de aspectos fenológicos, destacando a produção de sementes ao longo dos anos como fator decisivo para a formação do estrato de regeneração.

Os distúrbios provocados pelo fogo no estrato regenerativo poderia ser uma possível explicação para a baixa diversidade encontrada, pois ele afeta, diretamente, o recrutamento de espécies lenhosas (Oliveira e Silva, 1993; Hoffmann, 1998; Felfili et al., 2000; Braz et al., 2000) podendo ter excluído plântulas e/ou indivíduos jovens de espécies pouco abundantes na área ou com eventos reprodutivos com longos intervalos (Gouveia e Felfili, 1998). Hoffmann (1996) verificou o impacto do fogo no estabelecimento de plântulas e constatou que em áreas 
com episódios de queimada recente houve uma diminuição do número de plântulas. Em áreas com ausência de fogo há pelo menos dois anos, o estrato de regeneração apresentou uma composição muito semelhante ao de áreas preservadas, isto é, sem eventos de fogo. Essa rápida recomposição se deve à algumas características da fisiologia das espécies, como alta capacidade de rebrota, grande desenvolvimento do sistema radicular com acúmulo de reservas, rápido desenvolvimento da parte aérea (Oliveira e Silva, 1993; Matos, 1994; Hoffmann, 1998; Braz et al., 2000). Entretanto, o fogo também não pode ser aceito como uma explicação plausível para a pequena quantidade de espécies amostradas neste estudo, pois segundo os proprietários da área, não foram registradas queimadas no fragmento nos últimos 70 anos.

Tratando-se sobre as síndromes de dispersão, a espécie com maior número de indivíduos amostrado, Miconia albicans, assim como as outras três espécies com maior IVI (Xylopia aromatica, X. sericeae e Virola sebifera) possuem sementes dispersadas por aves (Marcondes-Machado, 2002). Apesar de diversos autores afirmarem que a zoocoria é a síndrome de dispersão mais comum entre as espécies de cerrado (Gottsberger e SilberbauerGottsberger, 1983; Weiser e Godoy, 2001; Vieira et al., 2002), outros autores (Neri et al., 2005) afirmam que as espécies zoocóricas são mais comuns em áreas de borda dos fragmentos, devido à maior comunidade dispersora neste ambiente. Assim, a grande quantidade de indivíduos dessas espécies espalhadas por todo o fragmento poderia indicar um desequilíbrio nos fatores abióticos, aumentando, assim, a área de abrangência dos Efeitos de Borda que, segundo Lovejoy et al. (1986), são modificações de condições bióticas e abióticas em áreas próximas às bordas de um fragmento florestal que apresentam relação com a distância da borda.

Em uma comunidade florestal, uma população de espécie arbórea apenas consegue se manter caso tenha uma grande quantidade de indivíduos no estrato de regeneração, já que a maior parte destes indivíduos não atingirá a fase adulta (Salles e Schiavini, 2007; Amaral et al., 2015). Quando isso não ocorre, a morte dos indivíduos adultos significará a extinção local destas espécies devido à ausência de indivíduos jovens em fase de recrutamento, resultando em significativas mudanças na composição florística.

Dessa forma, pode-se entender que o dossel de uma floresta é formado por um equilíbrio dinâmico em um processo natural de desenvolvimento, morte e substituição dos indivíduos arbóreos (Fonseca e Rodrigues, 2000). Assim, é comum que uma comunidade florestal sofra pequenas mudanças graduais em sua composição florística ao longo dos anos, seguindo o processo de sucessão natural. Este trabalho apresenta evidências de que os níveis 
de perturbação antrópica no entorno estão prejudicando diretamente, e de forma muito acelerada, o processo de regeneração natural na área de estudo.

Para subsidiar racionalmente ações de conservação e manejo de áreas fragmentadas frente às crescentes pressões antrópicas, é fundamental conhecer de forma mais detalhada os processos ecológicos, como por exemplo a dinâmica da regeneração natural desses ambientes alterados (Pereira et al., 2001).

\section{CONCLUSÃO}

Os resultados permitem afirmar que o estrato de regeneração do fragmento de cerrado analisado possui uma diversidade vegetal muito baixa, com dominância de duas espécies: Miconia albicans e Xylopia aromatica. A análise de similaridade com o estrato adulto indica uma intensa diminuição da biodiversidade em um intervalo de tempo curto, já que não foi encontrada uma diversidade e quantidade de indivíduos adequadas para realizar a substituição natural dos indivíduos. No atual estágio e com os dados coletados não é possível afirmar com exatidão os fatores motivadores da diminuição da diversidade verificada.

De acordo com os resultados obtidos, a hipótese inicial, que considera a semelhança na composição entre o estrato adulto e juvenil, pode ser refutada.

Assim, sugere-se novos estudos e um monitoramento na área, tanto do estrato adulto quanto o de regeneração, analisando a sua dinâmica e buscando tendências, assim como explicações para a grande flutuação do número de espécies. Dessa forma, será possível determinar medidas de manejo adequadas, evitando-se a possível extinção local de diversas espécies nativas importantes do cerrado.

\section{REFERÊNCIAS BIBLIOGRÁFICAS}

AMARAL, C. S.; AMARAL, W. G.; PEREIRA, I. M.; OliVEIRA, P. A.; MACHADO, V. M. 2015. Comparação florístico estrutural dos estratos adultos e regenerantes em área minerada de campo rupestre, Diamantina, MG. CERNE 21 (2), 183-190.

BARBOUR, M. G.; BURK, J. H.; PITTS, W. D. 1987. Terrestrial Plant Ecology. Benjamim/ Cummings: Menlo-Park. 604 p.

BRAZ, V. S.; KANEGAE, M. F.; FRANCO, A. C. 2000. Estabelecimento e desenvolvimento de Dalbergia miscolobium Benth, em duas fitofisionomias típicas dos cerrados do Brasil Central. Acta Botanica Brasilica 14, 27-35.

CALEGARIO, N.; SOUZA, A. L.; MARANGON, L. C.; SILVA, A.F. 1993. Parâmetros florísticos e fitossociológicos da regeneração natural de espécies arbóreas nativas no sub-bosque de povoamentos de Eucalyptus. Revista Árvore 17 (1), 16-29. 
COLWELL, R. K. 2013. EstimateS: Statitical estimation of species richness and shared species from samples. Version 9. Disponível em: <purl.oclc.org/estimates>. Acesso em: 02 de jul. 2016.

DURIGAN, G.; SIQUEIRA, M. F.; FRANCO, G. A. D. C. 2007. Threats to the Cerrado remnants of the state of São Paulo. Scientia Agricola 64 (4), 355-363.

EMBRAPA. 2013. Sistema brasileiro de classificação de solos. 3ed. Brasília. 353 p.

FELFILI, J. M.; SILVA-JÚNIOR, M. C.; REZENDE, A. V.; NOGUEIRA, P. E.; WALTER, B. M. T.; SILVA, M. A.; ENCINAS, J. I. 1997. Comparação florística e fitossociológica do cerrado nas chapadas Pratinha e dos Veadeiros. In: LEITE, L.; SAITO, C.H. (Eds.). Contribuição ao conhecimento ecológico do Cerrado. Brasília: UnB, p. 6-11.

FELFILI, J. M.; RIBEIRO, J. F.; FAGG, C. W.; MACHADO, J. W. B. 2000. Recuperação de matas de galeria. Planaltina: Embrapa Cerrados, 46 p.

FELFILI, J. M.; REZENDE, A. V.; SILVA JÚNIOR, M. C.; SILVA, M. A. 2000. Changes in the floristic composition of cerrado sensu stricto in Brazil over nine-year period. Journal of Tropical Ecology 16, 579-590.

FELFILI, J. M.; IMAÑA-ENCINAS, J. 2001. Suficiência da amostragem no cerrado sensu stricto das quatro áreas estudadas na Chapada do Espigão Mestre do São Francisco. In: FELFILI, J. M.; SILVA-JÚNIOR, M. C. (Orgs.). Biogeografia do Bioma Cerrado: estudo fitofisionômico na Chapada do Espigão Mestre do São Francisco. Brasília: UnB, p. 31-35.

FELFILI, J. M.; NOGUEIRA, P. E.; SILVA JÚNIOR, M. C.; MARIMON, B. S.; DELITTI, W. B. C. 2002. Composição florística e fotossociologia do cerrado sentido restrito no município de Água Boa, MT. Acta Botanica Brasilica 16 (1), 103-112.

FELFILI, M. F.; CARVALHO, F. A.; HAIDAR, R. F. 2005. Manual para o monitoramento de parcelas permanentes nos biomas Cerrado e Pantanal. Brasília: UnB, 55 p.

FERRI, M. G. 1961. Aspects of soil-water-plant relationships in conection with some Brazilian types of vegetation. In: UNESCO. Tropical soils and vegetation: proceedings of the Abidjan Symposium, p. 103-109.

FLORA DO BRASIL 2020 - em construção. Jardim Botânico do Rio de Janeiro. Disponível em: <http://floradobrasil.jbrj.gov.br/ >. Acesso em: 14 mar. 2016.

FONSECA, R. C. B.; RODRIGUES, R. R. 2000. Análise estrutural e aspectos do mosaico sucessional de uma floresta semidecídua em Botucatu, SP. Scientia Forestalis 57, 27-43.

GONZAGA, A. P. D.; PINTO, J. R. R.; MACHADO, E. L. M.; FELFILI, J. M. 2013. Similaridade florística entre estratos da vegetação em quatro Florestas Estacionais Deciduais na bacia do Rio São Francisco. Rodriguésia 64 (1), 11-19.

GOUVEIA, G. P.; FELFILI, J. M. 1998. Fenologia de comunidades de cerrado e de mata de galeria no Brasil Central. Revista Árvore 22 (4), 443-450.

GUARIGUATA, M. R.; OSTERTAG, R. 2001. Neotropical secondary forest succession: changes in structural and functional characteristics. Forest Ecology and Management 148, 185-206. 
GOTTSBERGER, G.; SILBERBAUER-GOTTSBERGER, I. 1983. Dispersal and distribution in the Cerrado vegetation of Brazil. Sonderbd Naturwiss ver Hamburg 7, 315-352.

HOFFMANN, W. A. 1996. The effects of fire and cover on seedling establishment in a neotropical savanna. Journal of Ecology 84, 383-393.

HOFFMANN, W. A. 1998. Post-burn reproduction of woody plants in a neotropical savanna: the relative importance of sexual and vegetative reproduction. Journal of Applied Ecology 35, 422-433.

HOFFMANN, W. A. 1999. Fire and population dynamics of woody plants in a neotropical savanna: matrix model. Ecology 80, 1354-1369.

KANEGAE, M. F.; BRAZ, V. S.; FRANCO, A. C. 2000. Efeitos da seca sazonal e disponibilidade de luz na sobrevivência e crescimento de Bowdichia virgilioides em duas fitofisionomias típicas dos cerrados do Brasil Central. Revista Brasileira de Botânica 23, 459-468.

KLINK, C. A.; MOREIRA, A. G. 2002. Past and current human occupation and land-use. In: OLIVEIRA, P.S.; MARQUIS, R.J. (Eds.). 2002. The Cerrado of Brazil: ecology and natural history of a neotropical savanna. New York: Columbia University Press, p. 69-88.

KRONKA, F. J. N.; NALON, M. A.; MATSUKUMA, C. K.; KANASHIRO, M. M.; YWANE, M. S. S.; PAVÃO, M.; DURIGAN, G.; LIMA, L. M. P. R.; GUILLAUMON, J. R.; BAITELLO, J. B.; BORGO, S. C.; MANETTI, L. A.; BARRADAS, A. M. F.; FUKUDA, J. C.; SHIDA, C. N.; MONTEIRO, C. H. B.; PONTINHA, A. A. S.; ANDRADE, G. G.; BARBOSA, O.; SOARES, A. P. 2005. Inventário florestal da vegetação natural do estado de São Paulo. São Paulo: Instituto Florestal. 200 p.

LOVEJOY, T. E.; BIERREGAARD, R. O.; RYLANDS, A. B.; MALCOLM, J. R.; QUINTELA, C. E.; HARPER, L. H.; BROWN, K. S.; POWELL, A. H.; POWELL, G. V. N.; SCHUBART, H. O. R.; HAYS, M. B. 1986. Edge and other effects of isolation on Amazon forest fragments. In: SOULÉ, M. E. (Ed.). Conservation Biology: The Science of Scarcity and Diversity. Massachusetts: Sunderland, p. 257- 285.

MACHADO, R. B.; RAMOS NETO, M. B.; PEREIRA, P.; CALDAS, E.; GONÇALVES, D.; SANTOS, N.; TABOR, K.; STEININGER, M. 2004. Estimativas de perda da área do Cerrado brasileiro. Brasília: Conservation International do Brasil, $23 \mathrm{p}$.

MAGURRAN, A. E. 1988. Ecological diversity and its measurement. New Jersey: Princeton University Press, $179 \mathrm{p}$.

MARCONDES-MACHADO, L. O. 2002. Comportamento alimentar de aves em Miconia rubiginosa (Melastomataceae) em fragmeneto de Cerrado, São Paulo. Iheringia 92 (3), $97-$ 100.

MARTÍNEZ-RAMOS, M. 1991. Patrones, processos e mecanismos en la comunidad de plantulas de uma selva humeda neotropical. Tese de Doutorado, Universidad Nacional de Mexico, $142 \mathrm{p}$.

MATOS, M. R. B. 1994. Efeito do fogo sobre os regenerantes de Blepharocalyx salicifolius H. B. K. (Myrtaceae) em Cerrado aberto, Brasília, DF. Dissertação de Mestrado em Ecologia Instituto de Ciências Biológicas, Universidade de Brasília, Brasília, 98 p. 
MEDEIROS, M. M.; FELFILI, J. M.; LIBANO, A. M. 2007. Comparação florístico-estrutural dos estratos de regeneração e adulto em Cerrado sensu stricto no Brasil central. CERNE 13 (3), 291-298.

MEIRA NETO, J. A. A.; SAPORETTI-JÚNIOR, A. W. 2002. Composição florística em cerrado no Parque Nacional da Serra do Cipó, MG. Revista Árvore 26 (5), 645-648.

MESQUITA, R. D. G. 2000. Management of advanced regeneration in secondary forests of the Brazilian Amazon. Forest Ecology and Management 130 (1-3), 131-140.

MIRANDA-MELO, A. A.; MARTINS, F. R; SANTOS, F. A. M. 2007. Population structure of Xylopia aromatica (Lam.) Mart. and of Roupala montana Aubl. in "cerrado" fragments in São Paulo State. Revista Brasileira de Botânica 30 (3), 501-507.

MUELLER-DOMBOIS, D.; ELLENBERG, H. 1974. Aims and methods of vegetation ecology. New York: John Wiley e Sons, $547 \mathrm{p}$.

NARDOTO, G. B.; SOUZA, M. P.; FRANCO, A. C. 1998. Estabelecimento e padrões sazonais de produtividade de Kielmeyera coriacea (Spr.) Mart. nos cerrados do Planalto Central: efeitos do estresse hídrico e sombreamento. Revista Brasileira de Botânica 21, 313-319.

NERI, A. V.; CAMPOS, E. P.; DUARTE, T. G.; MEIRA NETO, J. A. A.; SILVA, A. F.; VALENTE, G. E. 2005. Regeneração de espécies nativas lenhosas sob plantio de Eucalyptus em área de Cerrado na Floresta Nacional de Paraopeba, MG, Brasil. Acta Botanica Brasílica 19 (2), 369-376.

OLIVEIRA, E. C. L.; FELFILI, J. M. 2005. Estrutura e dinâmica da regeneração natural de uma mata de galeria no Distrito Federal, Brasil. Acta Botanica Brasílica 19, 801-811.

OLIVEIRA, P. E.; SILVA, J. C. S. 1993. Reproductive biology of two species of Kielmeyera (Guttiferae) in the cerrados of central Brazil. Journal of Tropical Ecology 9, 67-79.

OLIVEIRA-FILHO, A. T.; MELLO, J. M.; SCOLFORO, J. R. S. 1997. Effects of past disturbance and edges on tree community structure and dynamics within a fragment of tropical semideciduous forest in southeastern Brazil over a five-year period (1987-1992). Plant Ecology 131, 45-66.

PEREIRA, I. M.; ANDRADE, L. A.; COSTA, J. R. M.; DIAS, J. M. 2001. Regeneração natural em um remanescente de Caatinga sob diferentes níveis de perturbação, no Agreste Paraibano. Acta Botânica Brasílica 15 (3), 413-426.

PEREIRA, P. S. C. 2009. Análise multitemporal do comportamento estrutural e espectral da regeneração do cerrado sensu-stricto. Dissertação de Mestrado em Análise e Modelagem de Sistemas Ambientais - Instituto de Geociências, Universidade Federal de Minas Gerais, Belo Horizonte, $90 \mathrm{p}$.

PIVELLO, V. R. 2005. Manejo de fragmentos de Cerrado: princípios para a conservação da biodiversidade. In: SCARIOT, A.; SOUSA-SILVA, J.C.; FELFILI, J.M. (Org.). Cerrado: ecologia, biodiversidade e conservação. Brasília: MMA. p. 401-413. 
RATTER, J. A.; BRIDGEWATER, S.; RIBEIRO, J. F. 2006. Biodiversity patterns of the woody vegetation of the Brazilian Cerrado. In: PENNINGTON, T.; GWILYM, P. L.; RATTER, J. A. (Org.). Neotropical Savannas and dry forests: diversity, biogeography and conservation. Boca Raton: Taylor e Francis, p. 31-66.

RIBEIRO, J. F.; BRIDGEWATER, S.; RATTER, J. A.; SOUSA-SILVA, J. C. 2005. Ocupação do bioma Cerrado e conservação da sua diversidade vegetal. In: SCARIOT, A.; SOUSA-SILVA, J. C.; FELFILI, J. M. (Org.). Cerrado: ecologia, biodiversidade e conservação. Brasília: MMA, p. 383-399.

RIOS, M. N. S.; RIBEIRO, J. F. 2014. Enraizamento de estacas de cinco espécies de mata de galeria em diferentes épocas do ano. Enciclopédia Biosfera 10 (18), 1524-1536.

RIZZINI, C. T. 1971. Aspectos ecológicos da regeneração de algumas plantas do cerrado. In: FERRI, M. G. (Ed.). III Simpósio sobre o Cerrado, p. 61-64.

ROSA, A. G.; SCHIAVINI, I. 2006. Estrutura da comunidade arbórea em um remanescente florestal urbano (Parque do Sabiá, Uberlândia, MG). Bioscience Journal 22 (1), 151-162.

SALLES, J. C.; SCHIAVINI, I. 2007. Estrutura e composição do estrato de regeneração em um fragmento florestal urbano: implicações para a dinâmica e a conservação da comunidade arbórea. Acta Botanica Brasilica 21 (1), 223-233.

SÃO PAULO. Secretaria do Meio Ambiente de São Paulo. 1997. Cerrado: bases para a conservação e uso sustentável das áreas de Cerrado do Estado de São Paulo. São Paulo: SEMA, $184 \mathrm{p}$.

SAPORETTI JR., A. W.; MEIRA NETO, J. A. A.; ALMADO, R. P. 2003a. Fitossociologia de Cerrado sensu stricto no município de Abaeté, MG. Revista Árvore 27 (3), 279-284.

SAPORETTI JR., A. W.; MEIRA NETO, J. A. A.; ALMADO, R. P. 2003b. Fitossociologia de subbosque de cerrado em talhão de Eucalyptus grandis W. Hill. Ex maiden no município de Bom Despacho, MG. Revista Árvore 27 (6), 905-910.

SCHIAVINI, I.; RESENDE, J. C. F.; AQUINO, F. G. 2001. Dinâmica de populações de espécies arbóreas em mata de galeria e mata mesófila na margem do ribeirão Panga, MG. In: RIBEIRO, J. F.; FONSECA, C. E. L. E SOUSA-SILVA, J. C. (Eds.). Cerrado: caracterização e recuperação de matas de galeria. Brasília: Embrapa Cerrados. p. 267-299.

SHEPHERD, G. J. 2000. Conhecimento e diversidade de plantas terrestres do Brasil. Brasília: DF, $53 \mathrm{p}$.

SHERMAN, G. E.; SUTTON, T. B. R.; LUTHMAN, L. Quantum GIS User Guide - Version 2. Disponível em: <www.qgis.org>. Acesso em: 10 de fevereiro de 2014.

SOUSA, S. R.; ALBUQUERQUE, L. B.; SOUSA, A. C.; PACHÊCO, B. S.; MALAQUIAS, J.; AQUINO, F. G. 2015. Enraizamento de estacas de Miconia (Melastomataceae): alternativa para produção de mudas para a restauração ecológica. Neotropical Biology and Conservation $10(3), 152-158$.

TABARELLI, M.; MANTOVANI, W. 1999. A regeneração de um floresta tropical montana após corte e queima (São Paulo - Brasil). Revista Brasileira de Biologia 59 (2), 239-250. 
VALE, V. S.; CRESPILHO, R. F.; SCHIAVINI, I. 2009. Análise da regeneração natural em uma comunidade vegetal de cerrado no Parque Victório Siquierolli, Uberlândia-MG. Bioscience Journal 25 (1), 131-145.

VIEIRA, D. L. M.; AQUINO, F. G.; BRITO, M. A.; FERNADES-BULHÃO, C.; HENRIQUES, R. P. B. 2002. Síndromes de dispersão de espécies arbustivo-arbóreas em Cerrado sensu stricto do Brasil Central e Savanas Amazônicas. Revista Brasileira de Botânica 25 (2), 215-220.

WEISER, V. L.; GODOY, S. A. P. 2001. Florística em um hectare de Cerrado stricto sensu na ARIE - Cerrado Pé-de-Gigante, Santa Rita do Passa Quatro, SP. Acta Botanica Brasilica 15 (2), 201-212.

WERNECK, M. S.; PEDRALLI, G.; KOENIG, R.; GISEKE, L. F. 2000. Florística e estrutura de três trechos de uma floresta semidecidual na Estação Ecológica do Tripuí, Ouro Preto, MG. Revista Brasileira de Botânica 23 (1), 97-106. 


\section{CAPÍTULO III}

Chuva e banco de sementes de um remanescente de cerrado stricto sensu localizado em Patrocínio

$$
\text { Paulista - SP }
$$




\section{RESUMO}

Para a manutenção adequada do processo de regeneração natural e da biodiversidade vegetal em uma área é fundamental que a produção e dispersão de sementes ocorra em quantidade adequada para o desenvolvimento de novos indivíduos, sendo que estes processos podem definir a composição florística de uma área. Em virtude da pressão antrópica em remanescentes de cerrado stricto sensu, conhecer a composição da chuva e banco de sementes permite realizar projeções sobre o processo de regeneração natural. Dessa forma, os objetivos desse trabalho foram: (i) coletar e analisar a chuva de sementes em um fragmento de cerrado stricto sensu no município de Patrocínio Paulista - SP; (ii) coletar e analisar o banco de sementes em um fragmento de cerrado stricto sensu no município de Patrocínio Paulista SP. Para o estudo da chuva de sementes foram utilizados 60 coletores localizados nas parcelas de amostragem sendo que o seu conteúdo foi amostrado mensalmente durante 20 meses. Para o estudo do banco de sementes foram coletadas no total 40 amostras compostas por 1 $\mathrm{m}^{2}$ de solo no final da estação seca e chuvosa entre os anos de 2014 e 2016, sendo que o material coletado foi colocado em casa de vegetação durante três meses. A análise dos resultados foi realizada com o software Fitopac 2.0. Na chuva de sementes foram coletadas 1.178 sementes de 8 espécies, destacando-se Miconia albicans, Xylopia aromatica e Xylopia sericeae, indicando uma baixa diversidade e a completa ausência de espécies alóctones ao fragmento. Estes resultados podem ser atribuídos às pressões antrópicas (fragmentação de habitat) que podem ter modificado processos de produção ou dispersão de sementes. De acordo com os resultados, o processo de regeneração natural do fragmento está comprometido e, caso ações de enriquecimento não sejam adotadas, haverá um intenso decréscimo na biodiversidade local em pouco tempo.

Palavras-chave: chuva de sementes, banco de sementes, regeneração natural.

\section{INTRODUÇÃO}

A manutenção de uma comunidade vegetal depende de inúmeros processos, sendo que a capacidade de regeneração natural e manutenção do equilíbrio dinâmico entre as populações são os mais básicos (Fenner, 1985; Hofgaard, 1993). Para que tais processos ocorram é fundamental que os indivíduos adultos produzam sementes viáveis em quantidade suficiente (Fenner, 1985) e que estas sementes alcancem sítios adequados para o estabelecimento de um novo indivíduo (Harper, 1977). Swaine e Whitmore (1988) afirmam que o resultado desses processos pode definir a composição e fisionomia de áreas naturais, tamanha sua importância.

A chegada de sementes em um território por meio dos mecanismos de dispersão (chuva de sementes) e as sementes depositadas no solo (banco de sementes) são importantes indicadores da capacidade de manutenção ou recuperação de uma floresta após um distúrbio (Baider et al., 1999). Logo após um distúrbio, que pode ser a abertura de uma clareira após o tombamento de uma árvore, um incêndio ou uma ação antrópica, as sementes presentes no solo serão as primeiras a germinar, de acordo com suas demandas fisiológicas, iniciando o processo de regeneração natural da área (Campos e Souza, 2003) ocorrendo, paralelamente, a 
entrada de novas sementes pela chuva de sementes (Garwood, 1989), tornando a comunidade potencialmente mais diversificada (Pérez e Santiago, 2001).

Apesar dos avanços nos estudos ecológicos das espécies vegetais do cerrado, ainda não há um consenso sobre a importância das sementes e plântulas na regeneração natural desse bioma (Hoffmann, 1996). Historicamente, é considerado que a reprodução por semente não é comum, sendo a rebrota ou perfilhamento os processos mais encontrados (Warming, 1908). Ferri (1961) e Rizzini e Herringer (1962) corroboraram essas ideias, indicando a escassez de plântulas de espécies lenhosas em áreas naturais. Apesar de alguns estudos indicarem a alta viabilidade de sementes de espécies de cerrado em ambiente controlado (Rizzini, 1971; Felippe e Silva, 1984), poucos estudos verificaram estas informações em ambientes de campo.

Devido aos intensos impactos antrópicos sofridos pelos remanescentes de cerrado é fundamental conhecer a importância e composição florística do banco e chuva de sementes, possibilitando a realização de previsões sobre o processo de regeneração que ocorre nos fragmentos (Nappo et al., 1999). E conhecer com antecipação os direcionamentos da regeneração natural de uma área permitem o planejamento de ações relacionadas à conservação da biodiversidade e manutenção de processos ecológicos básicos (Tekle e Bekele, 2000).

\section{HIPÓTESE}

O banco de sementes deve possuir uma amostra significativa das espécies arbóreas presentes na área e entorno, contribuindo de forma dedicada para a manutenção das espécies vegetais encontradas na área.

A chuva de sementes apresenta uma diversidade adequada e relacionada às espécies vegetais encontradas no fragmento de cerrado stricto sensu e entorno.

\section{OBJETIVOS ESPECÍFICOS}

- Coletar e analisar a chuva de sementes em um fragmento de cerrado stricto sensu no município de Patrocínio Paulista - SP;

- Coletar e analisar o banco de sementes em um fragmento de cerrado stricto sensu no município de Patrocínio Paulista - SP; 


\section{MATERIAL E MÉTODOS}

\subsection{Chuva de sementes}

Para o estudo da chuva de sementes em cada parcela de amostragem do fragmento de cerrado stricto sensu da Fazenda Santa Cecília foram colocados dois coletores com dimensões de $0,5 \times 0,5 \mathrm{~cm}\left(0,25 \mathrm{~m}^{2}\right)$, totalizando 60 coletores e uma área amostral de $15 \mathrm{~m}^{2}$. Os coletores foram montados com estrutura de madeira e tela de náilon de $1 \mathrm{~mm}$ com uma altura aproximada de $20 \mathrm{~cm}$ do solo.

O material depositado nos coletores foi recolhido mensalmente no período de março de 2015 até outubro de 2016, totalizando 20 meses. Todo o material presente nos coletores era coletado e colocado em sacos de papel devidamente identificados, sendo que todo o material coletado era devidamente triado e as sementes identificadas até o nível de espécie utilizando bibliografia especializada.

\subsection{Banco de sementes}

Para o estudo do banco de sementes, em cada etapa foram coletadas 10 amostras de solo de $1 \mathrm{~m}^{2}$ a uma profundidade aproximada de $15 \mathrm{~cm}$ em 10 parcelas sorteadas ao acaso. As coletas foram realizadas em setembro de 2014, março e setembro de 2015 e março de 2016, sempre no final das estações seca e chuvosa. No final do experimento foram coletadas 40 amostras de solo, sendo que cada parcela foi amostrada, no mínimo, uma vez.

Após coleta, as amostras eram acondicionadas em sacos plásticos e levadas para casa de vegetação, onde o material coletado era depositado em bandejas plásticas com regas e acompanhamento periódicos durante três meses consecutivos.

\subsection{Análise dos resultados}

A análise da coleta da chuva de sementes foi realizada com o software Fitopac 2.0 (Shepherd, 2009) utilizando-se os seguintes parâmetros: número absoluto de sementes coletadas, densidade relativa e frequência relativa. As espécies coletadas também foram classificadas quanto a sua forma de vida (arbórea ou arbustiva), síndrome de dispersão 
(autocórica, anemocórica ou zoocórica) e grupo ecológico (pioneira, secundária inicial, secundária tardia ou clímax) utilizando-se bibliografia especializada.

Para viabilizar a comparação com outros estudos de maneira mais segura, a partir do número absoluto de sementes de cada espécie foi calculado os valores relativos (número de sementes $/ \mathrm{m}^{2}$ ). Isso minimiza as influências da metodologia utilizada ou aspectos específicos de diferentes áreas de estudo.

\section{RESULTADOS}

\subsection{Banco de sementes}

Não foi registrada germinação de sementes nas amostras coletadas totalizando, assim, zero registros. Dois eventos merecem registro: o aparecimento de uma espécie de pteridófita de solo em algumas amostras (essa espécie pode ser encontrada em algumas parcelas do fragmento analisado e estruturas vegetativas, possivelmente, foram levadas nas amostras de solo) e a germinação de poucos indivíduos de espécies ruderais.

\subsection{Chuva de sementes}

$\mathrm{Na}$ avaliação da chuva de sementes durante 20 meses foram coletadas 1.178 sementes pertencentes a 8 espécies de 4 famílias (Tabela 1), destacando-se Miconia albicans, Xylopia aromatica e Xylopia sericeae, que totalizaram $77,6 \%$ do total de sementes coletadas.

Tabela 1 - Espécies amostradas na chuva de sementes de fragmento de cerrado stricto sensu localizado na Fazenda Santa Cecília. NI: número de indivíduos; DR: densidade relativa; FR: frequência relativa; VR: valor relativo (sementes $\left./ \mathrm{m}^{2}\right)$; FV: forma de vida; SD: síndrome de dispersão; ANE: anemocoria; ZOO: zoocoria; GE: grupo ecológico; P: pioneira; SI: secundária inicial; ST: secundária tardia; SB: sub-bosque.

\begin{tabular}{lccccccc}
\hline Espécie & NI & DR & FR & VR & FV & SD & GE \\
\hline $\begin{array}{l}\text { Miconia albicans (Sw.) Steud. } \\
\text { Xylopia aromatica (Lam.) }\end{array}$ & 490 & 41,60 & 8,00 & 32,6 & arbusto & ZOO & SB \\
Mart. & 24,28 & 24,00 & 19,0 & árvore & ZOO & P \\
Xylopia sericea St. Hill. & 138 & 11,71 & 12,00 & 9,2 & árvore & ZOO & SI \\
Qualea grandiflora Mart. & 82 & 6,96 & 12,00 & 5,4 & árvore & ANE & P \\
Qualea jundiahy Warm & 68 & 5,77 & 14,00 & 4,5 & árvore & ANE & ST \\
Qualea parviflora Mart. & 66 & 5,60 & 17,00 & 4,4 & árvore & ANE & ST \\
Virola sebifera Aubl. & 46 & 3,90 & 12,00 & 3,1 & árvore & ZOO & P
\end{tabular}


Com relação às famílias, Vochysiaceae apresenta uma maior quantidade de espécies (4), seguida por Annonaceae (2) e Myristicaceae e Melastomataceae (1 espécie cada). Relacionado à forma de vida, 7 espécies são arbóreas e apenas 1 arbustiva. Quanto à síndrome de dispersão, quatro espécies são zoocóricas e quatro são anemocóricas. Na classificação por grupo ecológico 3 espécies são pioneiras, 1 secundária inicial, 3 secundárias tardias e 1 de subbosque.

Os índices ecológicos indicam uma diversidade muito baixa (Índice de Shannon-Wiener - 1,609 e Índice de Simpson - 0,26) e uma concentração em poucas espécies (equabilidade $0,774)$.

\section{DISCUSSÃO}

O histórico de perturbações tem muitas implicações na sucessão florestal, pois diferentes tipos e intensidades de perturbação podem resultar em diferentes estruturas florestais. Em áreas alteradas, um dos fatores mais importantes que limitam o recrutamento de plântulas é a baixa disponibilidade de sementes, afetada pela presença e distância de manchas de floresta, que funcionariam como fontes de sementes e de agentes dispersores (Kolb, 1993; Duncan e Chapman, 1999; Holl, 1999; Cubiña e Aide, 2001; Mesquita et al., 2001).

\subsection{Banco de sementes}

O resultado obtido com o experimento do banco de sementes, apesar de improvável, pode ser debatido utilizando-se algumas hipóteses encontradas na bibliografia.

A primeira hipótese que deve ser analisada é a ocorrência de falhas metodológicas durante a coleta do banco de sementes e/ou durante o tempo do material em casa de vegetação. Entretanto, comparando-se as metodologias de coleta do material em campo e posterior acompanhamento do material em casa de vegetação adotadas neste trabalho com aquelas praticadas em outros estudos, percebe-se a sua compatibilidade, dada peculiaridades pontuais de cada pesquisa. Importante ressaltar, também, que o experimento foi repetido quatro vezes, no final das estações seca e chuvosa de dois anos consecutivos, o que dificulta a chance de falhas ou equívocos realizados em todas as etapas. 
Ainda se tratando da metodologia adotada, Oliveira Filho e Ratter (2000) afirmam que, devido a sua heterogeneidade, a quantidade de espécies encontradas no banco de sementes é diretamente proporcional à área amostral e distância entre as amostras. Quanto à área amostral deste estudo $\left(15 \mathrm{~m}^{2}\right)$ assume-se, de acordo com algumas pesquisas (Caldato et al., 1996; Gasparino et al., 2006; Nóbrega et al., 2009; Machado et al., 2013), que a mesma é adequada e pertinente para uma amostragem significante do banco de sementes presente em um fragmento de 100 ha. É importante ressaltar, também, que as amostras foram recolhidas de pontos espalhados por todo o fragmento, abrangendo toda a área amostral, com distâncias que chegavam a $1,5 \mathrm{~km}$ entre $\mathrm{si}$, aproximadamente.

Assim, considera-se improvável a hipótese de erro metodológico, já que foram seguidas as orientações da bibliografia vigente de forma adequada. Dessa forma, a possibilidade de erro metodológico, se não totalmente excluída, torna-se pouquíssimo provável.

A segunda hipótese que poderia explicar o resultado obtido é a sazonalidade. Visando minimizar influências temporais nos resultados, o experimento foi repetido em dois anos consecutivos, ao término das estações seca e chuvosa. Segundo Joly (1986) isso minimiza a influência da sazonalidade nas amostras, já que a composição do banco de sementes pode variar de acordo com as estações do ano em diferentes formações vegetais. A sazonalidade contribuiria diretamente na formação de um banco de sementes transitório, de acordo com a época da coleta e fisiologia das sementes das espécies presentes, interferindo diretamente nas espécies amostradas (Garwood, 1989; Durigan et al., 2000). Como o resultado foi o mesmo em estações do ano distintas de dois anos consecutivos, um possível efeito da sazonalidade pode ser descartado.

A terceira hipótese encontrada na bibliografia que explicaria a ausência de sementes no banco de sementes é a que aborda os efeitos da predação.

Alterações antrópicas em áreas naturais acarretam em diferentes impactos para distintas populações animais (De Walt et al., 2003), destacando-se por sua importância ecológica os dispersores e predadores de sementes, como aves e pequenos mamíferos, que desempenham funções fundamentais na regeneração florestal (Terborgh et al., 2001; Tabarelli e Peres, 2002; Alves-Costa, 2004). Um desequilíbrio que afete a densidade de predadores de sementes, tornando-a maior, pode reduzir drasticamente o banco de sementes no solo (Terborgh et al., 2001). Harper et al. (2005), Hill e Curran (2005) e Galetti et al. (2003) identificaram aumento na predação de sementes em áreas antropizadas, de borda, em comparação com áreas preservadas de diferentes fitofisionomias. 
Assim, o resultado encontrado para o experimento do banco de sementes poderia ser derivado das alterações na comunidade animal na área que estaria aumentando as populações de espécies predadoras de sementes (Siminski et al., 2004).

A quarta hipótese encontrada na bibliografia é referente à influência de fatores abióticos modificados em longo prazo que acarretariam uma série de resultados nos processos ecológicos de áreas fragmentadas. Um dos fatores abióticos de relevante interesse em áreas de cerrado é a presença do fogo, pois ele pode estimular ou destruir o banco de sementes do solo (Garcia-Nuñes et al., 2003), fato descrito por Melo et al. (2007), que indicaram uma perda de riqueza florística do banco de sementes comparando-se com o estrato adulto da mesma área em virtude da incidência de queimadas na área estudada. No entanto, de acordo com declarações dos atuais proprietários, não há registros de queimadas na área de cerrado, pelo menos, nos últimos 70 anos.

Metzger et al. (2006) afirma que algumas características abióticas encontradas em florestas secundárias, como o aumento da temperatura, a diminuição da umidade do solo e as maiores taxas de danos mecânicos poderiam aumentar a mortalidade de sementes do solo em comparação com áreas preservadas. Essas modificações de fatores abióticos são derivadas, diretamente, das alterações das características físicas do dossel, destacando-se densidade e cobertura (Guariguata e Ostertag, 2001; Williams-Linera, 2002). A área analisada no presente estudo, apesar de não sofrer intervenções antrópicas diretas como incêndios ou corte seletivo, está imersa em uma matriz altamente antropizada, o que pode conferir características de áreas secundárias.

Ainda se tratando de fatores abióticos, outros autores afirmam que a quantidade de sementes do solo em áreas de cerrado é influenciada diretamente pela sazonalidade, como já citado, destacando-se a influência da duração e intensidade das chuvas (Kemp, 1989; Costa e Araújo, 2003). De acordo com estes autores o banco de sementes do cerrado seguiria a sazonalidade climática. Entretanto, como também afirmado anteriormente, esta hipótese também pode ser descartada devido aos períodos de coletas abrangerem as épocas chuvosa e secas de dois anos consecutivos.

Outra influência plausível das alterações microclimáticas presentes no fragmento seria aquela que interfere diretamente na produção de sementes pelos indivíduos adultos presentes. Este tópico não será discutido neste momento pois trata-se de estudo apresentado no capítulo 4 da presente tese, onde serão apresentados os resultados de acompanhamento fenológico de seis espécies arbóreas. Complementarmente, é importante ressaltar a relevância dos dispersores de sementes, fato comentado anteriormente e que será melhor tratado ainda neste capítulo, na abordagem sobre a chuva de sementes. 
A última hipótese elencada para justificar o resultado obtido no experimento do banco de sementes aborda o esgotamento do banco de sementes, relacionado, também, com as modificações abióticas de longo prazo.

Pesquisas realizadas em áreas florestais alteradas (Leal-Filho, 1992; Nogueira e Nogueira, 1991; Nóbrega et al., 2009) indicam que interferências contínuas em ecossistemas florestais modificam significativamente a composição do banco de sementes com o aumento de espécies pioneiras em detrimento das espécies secundárias e clímax.

Essas perturbações contínuas, além de propiciarem a entrada de sementes de espécies exóticas, não permitem o desenvolvimento das sementes recém germinadas, aumentando a mortalidade das plântulas (Machado et al., 2013). Esse ciclo, quando repetido diversas vezes em um intervalo de tempo considerável, esgota as sementes viáveis no solo sem, contudo, oferecer condições de reposição das sementes germinadas ou mortas. Dessa forma, as sementes presentes no solo atingem uma quantidade extremamente pequena, quando não desaparecem completamente. Assim, com a ausência de propágulos viáveis, a regeneração natural da área torna-se inviável (Kageyama et al., 1989). Malavasi et al. (2005) afirmam que quando o banco de sementes atinge o estado de esgotamento, a regeneração natural depende, basicamente, do processo da chuva de sementes originada de uma fonte adjacente de propágulos.

É muito importante destacar que não necessariamente uma única explicação ou hipótese oferece subsídios completos para justificar os resultados obtidos. Deve-se analisar os fatores e justificativas de forma sinérgica, sendo que mais estudos são necessários para comprovar, ou excluir, as teorias apresentadas.

\subsection{Chuva de sementes}

O domínio de poucas espécies na chuva de sementes, refletindo uma diversidade extremamente baixa, é característica presente em alguns estudos sobre chuva de sementes em ambientes florestais, como Grombone-Guaratini e Rodrigues (2002) e Lima et al. (2008), e também em savanas (Oliveira e Moreira, 1992; Pachêco, 2014). Vale ressaltar que as três espécies mais abundantes na chuva de sementes (Miconia albicans, Xylopia aromatica e Xylopia sericea) apresentam síndrome de dispersão zoocórica e a sua alta ocorrência é decorrente das sementes originárias diretamente dos indivíduos adultos em idade reprodutiva, pois estas três espécies estão amplamente distribuídas na área analisada e, destacando-se M. albicans, possuem frutificação abundante. 
Grombone-Guaratini e Rodrigues (2002) declaram que em ambientes tropicais o banco de sementes pouco contribuiria na regeneração natural de áreas alteradas. Isso seria resultado direto de dois fatores já apresentados: a presença de fatores abióticos desfavoráveis e a curta viabilidade fisiológica das sementes de espécies tropicais (Garwood, 1983). Dessa forma, o fator determinante para a manutenção e/ou recuperação da riqueza vegetal em áreas naturais seria a chuva de sementes de espécies autóctones e alóctones, isto é, aquelas espécies presentes no fragmento e aquelas provenientes de áreas próximas pelas síndromes de dispersão de sementes.

E assim como o resultado encontrado no banco de sementes, a chuva de sementes no fragmento de cerrado amostrado também se mostrou inesperada, com resultados muito aquém dos encontrados na bibliografia pesquisada. Em outras áreas de cerrado stricto sensu os valores encontrados foram bem maiores, como em Machado et al. (2013), Lima (2015) e Macedo (2015).

A chuva de sementes de espécies autóctones está relacionada aos padrões fenológicos das espécies e indivíduos presentes no próprio fragmento, aspecto que será tratado mais detalhadamente no Capítulo 4 da presente tese. Dessa forma, agora será tratada apenas a chuva de sementes alóctone, isto é, aquela dependente, obrigatoriamente, das síndromes de dispersão, destacando-se a zoocoria. Importante destacar que as oito espécies encontradas na chuva de sementes possuem grande quantidade de indivíduos adultos espalhados por todo o fragmento, conforme dados apresentados no Capítulo 1. A ausência de sementes de espécies alóctones ao fragmento pode indicar uma pequena ação de espécies dispersoras de sementes. No entanto, este estudo não coletou dados referentes aos dispersores de sementes, recorrendo a dados da literatura para justificar os resultados obtidos.

Pozza (2002), em levantamento qualitativo da comunidade de aves realizado no fragmento de Floresta Estacional Semidecidual contíguo ao fragmento de cerrado analisado neste estudo, identificaram 173 espécies de aves, número considerado elevado para estudos do gênero. Assim, parte-se da premissa que ainda exista uma significativa comunidade de aves dispersoras no entorno. Seriam necessários estudos específicos sobre a ecologia das espécies de aves para identificar alguma característica ou comportamento que impedisse as aves de visitar o fragmento de cerrado já que não existem barreiras físicas separando-os.

Muitos estudos já identificaram um padrão de diminuição da comunidade de aves em fragmentos florestais quando comparados com áreas preservadas, destacando-se as espécies frugívoras (Bierregaard e Lovejoy, 1989; Hagan et al., 1996; Johns, 1991; Newmark, 1991; Renjifo, 1999; Cordeiro e Howe, 2003; Dennis et al., 2004) e, segundo Galetti et al. (2003), isso afeta diretamente o sucesso reprodutivo das espécies vegetais. 
A ação das aves dispersoras interfere diretamente na regeneração natural, limitando a quantidade de sementes dispersadas ou depositando as sementes em locais com pequena probabilidade de recrutamento (Schupp, 1993), como bordas ou clareiras. Dessa forma, em áreas altamente antropizadas, onde houve uma diminuição da avifauna também haverá uma redução na chuva de sementes, interferindo, diretamente, no desenvolvimento de novos indivíduos de espécies vegetais (Benitez-Malvido, 1998) resultando, em médio e longo prazo, em uma deterioração do fluxo gênico de tais espécies (Godoy e Jordano, 2001; Jordano et al., 2006). Ainda segundo Jordano et al. (2006) a função ecológica dos dispersores de sementes vai muito além do transporte de propágulos, sendo que as influências em aspectos ecológicos da comunidade são muito mais extensas.

Outra hipótese para a baixa chuva de sementes registrada e a ausência de sementes de espécies alóctones é o isolamento provocado pelo processo de fragmentação de habitat. Sabese que a fragmentação de habitats naturais altera as características abióticas desses locais, como luminosidade e umidade (Hay et al., 2000), e essas modificações podem afastar organismos dispersores de semente, com destaque para a avifauna. Alterações na comunidade de dispersores já foram verificadas em alguns estudos, como por exemplo Silva e Tabarelli (2000), Githiru et al. (2002) e Graham (2002). Assim, percebe-se a complexa rede de relacionamentos ecológicos encontrada em áreas naturais de equilíbrio muito sensível.

Sobre as síndromes de dispersão das espécies amostradas na chuva de sementes não há dados coletados suficientes para qualquer tipo de afirmação, de acordo com o reduzido número de espécies coletadas. Vale destacar que o equilíbrio entre espécies anemocóricas e zoocóricas não é característica das espécies vegetais do cerrado, sendo que muitos trabalhos afirmam a predominância de espécies com síndrome de dispersão zoocórica (Weiser e Godoy, 2001; Vieira et al., 2002).

Finalmente, comparando-se a composição da chuva de sementes e do banco de sementes pode-se constatar que há a necessidade de se investigar mais detalhadamente o processo de regeneração, pois como estudo de base, os trabalhos do banco e chuva de sementes realizado geraram mais dúvidas e possibilidades do que, realmente, apresentaram afirmações categóricas. Outros estudos identificaram um banco de sementes menor do que a chuva de semente (Rabinowitz e Rapp, 1980; Grombone-Guaratini e Rodrigues, 2001), indicando que esta característica não é totalmente inédita. Fato que merece destaque foi a total ausência de sementes viáveis no banco de sementes.

Para este caso, após a realização dos experimentos em casa de vegetação, o material coletado deveria ter sofrido outra verificação com metodologia diferente. O solo poderia ser peneirado e as sementes, se presentes, identificadas. Caso alguma semente fosse encontrada, 
derrubaria a hipótese levantada neste trabalho da não ocorrência de sementes no banco. Entretanto, levantaria outra dúvida: porque as sementes não estavam viáveis? Como afirmado anteriormente, isto demandaria esforços específicos que fogem aos objetivos iniciais deste estudo.

\section{CONCLUSÃO}

De acordo com os resultados deste estudo, pode-se afirmar que o banco de sementes do fragmento de cerrado stricto sensu analisado não contem sementes de espécies arbóreas e, dessa forma, não é capaz de sustentar etapas básicas da regeneração natural, não confirmando, assim, a hipótese inicial. Dessa forma, seriam necessárias ações de enriquecimento da biodiversidade vegetal através de técnicas que viabilizassem a manutenção da diversidade atual.

A literatura consultada declara que uma chuva de sementes com as características identificadas neste estudo é própria de ambientes perturbados, influenciados antropicamente, onde os processos ecológicos envolvidos na dispersão de sementes estariam severamente comprometidos.

Em ambientes tropicais a composição da comunidade vegetal é altamente dependente da chuva de sementes para o recrutamento de espécies lenhosas. Dessa forma, devido à baixa diversidade da chuva e banco de sementes, é recomendada atenção ao processo de regeneração natural da área, pois esse resultado pode indicar uma drástica diminuição da diversidade vegetal.

\section{REFERÊNCIAS BIBLIOGRÁFICAS}

ALVES-COSTA, C. P. 2004. Efeitos da defaunação de mamíferos herbívoros na comunidade vegetal. Tese de doutorado, Universidade Estadual de Campinas, Campinas, 120 p.

BAIDER, C.; TABARELLI, M. e MANTOVANI, W. 1999. O banco de sementes de um trecho de floresta atlântica montana (São Paulo, Brasil). Revista Brasileira de Botânica 59 (2), 319328.

BENITEZ-MALVIDO, J. 1998. Impact of forest fragmentation on seedling abundance in a tropical rain forest. Conservation Biology 12, 380-389.

BIERREGAARD, R. O.; LOVEJOY, T. E. 1989. Effects of forest fragmentation on Amazonian understory bird communities. Acta Amazonica 19, 215-241. 
CALDATO, S. L.; FLOSS, P. A.; CROCE, D. M.; LONGHI, S. J. 1996. Estudo da regeneração natural, banco de sementes e chuva de sementes na Reserva Genética Florestal de Caçador, SC. Ciência Florestal 6 (1), 27-38.

CAMPOS, J. B. e SOUZA, M. C. 2003. Potencial for natural forest regeneration from seed bank in an upper Paraná River floodplain, Brazil. Brazilian Archives of Biology and Technology 46 (4), 625-639.

CORDEIRO, N. J.; HOWE, H. F. 2001. Low recruitment of trees dispersed by animals in african forest fragments. Conservation Biology 15, 1733-1741.

COSTA, R. C.; ARAÚJO, F. S. 2003. Densidade, germinação e flora do banco de sementes no solo, no final da estação seca, em uma área de caatinga, Quixadá, CE. Acta Botânica Brasílica, 259-264.

CUBIÑA, A.; AIDE, T. M. 2001. The effect of distance from forest edge on seed rain and soil seed bank in a tropical pasture. Biotropica 33, 26-267.

DE WALT, S. J., MALIAKAL, S. K.; DENSLOW, J. S. 2003. Changes in vegetation structure and composition along a tropical forest chronosequence: implications for wildlife. Forest Ecology Management 182, 139-151.

DENNIS, A. J.; WESTCOTT, D. A.; MCKEOWN, A.; BRADFORD, M.; HARRINGTON, G. 2004. Fruit removal rates across a landscape. In: KANOWSKI, J.; CATTERALL, C. P.; DENNIS, A. J.; WESTCOTT, D. A. (Ed.). Animal-plant interactions in rainforest: conservation and restoration. Australia: Cooperative Research Centre for Tropical Rainforest Ecology and Management, p. 9-11.

DUNCAN, R. S.; CHAPMAN, C. A. 1999. Seed dispersal and potential forest succession in abandoned agriculture in tropical Africa. Journal of Applied Ecology 9, 908-1008.

DURIGAN, G.; RODRIGUES, R. R.; SCHIAVINI, I. 2000. A heterogeneidade ambiental definindo a metodologia de amostragem da floresta ciliar. In: RODRIGUES, R. R.; LEITÃO FILHO, H. F. (Ed.). Matas ciliares: conservação e recuperação. São Paulo: Universidade de São Paulo, p. 159-167.

FELIPPE, G. M.; SILVA, J. C. S. 1984. Estudos de germinação em espécies do cerrado. Revista Brasileira de Botânica 7, 157-163.

FENNER, M. 1985. Seed ecology. New York: Chapman e Hall, 151 p.

FERRI, M. G. 1961. Aspects of the soil-water-plant relationship in connexion with some Brazilian types of vegetation. In: UNESCO. Tropical Soils and Vegetation. Proceedings of the Abidjan Symposium, p.103-109.

GALETTI, M.; ALVES-COSTA, C. P; CAZETTA, E. 2003. Effects of forest fragmentation, anthropogenic edges and fruit color on the consumption of ornithocoric fruits. Biology Conservation 111, 269-273.

GARCIA-NUÑES, C.; AZOCAR, A.; SILVA, J. F. 2003. Seed production and soil seed bank in the evergreen woody species from a neotropical savanna. Journal of Tropical Ecology 17 (1), 563-576. 
GARWOOD, N. C. 1983. Seed germination in a seasonal tropical forest in Panama: a community study. Ecology Monography 53, 159-181.

GARWOOD, N. C. 1989. Tropical soil seed banks: a review. In: LECK, M. A.; PARKER, T. V.; SIMPSON, R. L. (Ed). Ecology of soil seed banks. New York: Academic Press, p. 149-210.

GASPARINO, D.; MALAVASI, U. C.; MALAVASI, M. M.; SOUZA, I. 2006. Quantificação do banco de sementes sob diferentes usos do solo em área de domínio ciliar. Revista Árvore 30 (1), 19.

GITHIRU M.; LENS, L.; BENNUR, L. A.; OGOL, C. 2002. Effects of site and fruit size on the composition of avian frugivore assemblages in a fragmented Afrotropical forest. Oikos 96, 320-330.

GRAHAM, C. 2002. Use of fruiting trees by birds in continuous forest and riparian forest remnants in Los Tuxtlas, Veracruz, Mexico. Biotropica 34, 589-597.

GODOY, J. A.; JORDANO, P. 2001. Seed dispersal by animals: exact identification of source trees with endocarp DNA microsatellites. Molecular Ecology 10, 2275-2283.

GROMBONE-GUARATINI, M. T.; RODRIGUES, R. R. 2002. Seed bank and seed rain in a seasonal semi-deciduous forest in south-eastern Brazil. Journal of Tropical Ecology 18, 759-774.

GUARIGUATA, M. R.; OSTERTAG, R. 2001. Neotropical secondary succession: changes in structural and functional characteristics. Forest Ecology Management 148, 185-206.

HAGAN, J. M.; HAEGEN, W. M. V.; MCKINLEY, P. S. 1996. The early development of forest fragmentation effects on birds. Conservation Biology 10, 188-202.

HARPER, J. L. 1977. Population biology of plants. London: Academic Press, 892 p.

HARPER, K. A.; MACDONALD, S. E.; BURTON, P. J.; CHEN, J.; BROSOFSKE, K. D.; SAUNDERS, S. C.; EUSKIRCHEN, E. S.; ROBERTS, D.; JAITEH, M. S.; ESSEN, P. 2005. Edge influence on forest structure and composition in fragmented landscapes. Conservation Biology 3, 768-782.

HAY, J. D.; BIZERRIL, M. X.; CALOURO, A. M.; COSTA, E. M. N.; FERREIRA, A. A.; GASTAL, M. L. A.; GOES JÚNIOR, C. D.; MANZAN, D. J.; MARTINS, C. R.; MONTEIRO, J. M. G.; OLIVEIRA, S. A.; RODRIGUES, M. C. M.; SEYFARTH, J. A. S.; WALTER, B. M. T. 2000. Comparação do padrão da distribuição espacial em escalas diferentes de espécies ativas do cerrado, em Brasília, DF. Revista Brasileira de Botânica 23, 341-347.

HILL, J. L.; CURRAN, P. J. 2005. Fragment shape and tree species composition in tropical forests: a landscape level investigation. African Journal Ecology 43, 35-43.

HOFFMANN, W. A. 1996. The effects off fire and cover on seedling establishment in a neotropical savanna. Journal of Ecology 84, 383-393.

HOFGAARD, A. 1993. Seed rain quantity and quality, 1984-1992, in a high altitude old-growth spruce forest, northern Sweden. New Phytologist 125, 635-640.

HOLL, K. D. 1999. Factors limiting tropical rain forest regeneration in abandoned pasture: seed rain, seed germination, microclimate and soil. Biotropica 31, 229-242. 
JOHNS, A. D. 1991. Responses of Amazonian rain forest birds to habitat modification. Journal Tropical Ecology 7, 417-437.

JOLY, C. A. 1986. Heterogeneidade ambiental e diversidade de estratégias adaptativas de espécies de mata de galeria. In: Simpósio da Academia de DE Ciências de São Paulo Perspectivas de Ecologia Teórica. São Paulo: ACIESP, p. 19-38.

JORDANO, P.; GALETTI, M.; PIZO, M. A.; SILVA, W. R. 2006. Ligando frugivoria e dispersão de sementes à Biologia da Conservação. In: ROCHA, C. F. D.; BERGALLO, H. G.; ALVES, M. A. S. S.; VAN SLUYS, M. (Org.). Biologia da Conservação: Essências. São Carlos: Editora RIMA, p. 411-436

KAGEYAMA, P. Y.; CASTRO, C. F. A.; CARPANEZZI, A. A. 1989. Implantação de matas ciliares: estratégias para auxiliar a sucessão secundária. In: Simpósio sobre mata ciliar. Campinas: Fundação Cargill. p. 130-143.

KEMP, P. R. 1989. Seed banks and vegetation processes in deserts. In: LECK, M. A.; PARKER, V.T.; SIMPSON, R. L. (Eds). Ecology of soil seed banks. New York: Academic Press. p. 257280.

LEAL-FILHO, N. Caracterização do banco de sementes de três estádios de uma sucessão vegetal na Zona da Mata de Minas Gerais. 1992. Dissertação de Mestrado em Ciências Florestais Universidade Federal de Viçosa, Viçosa, MG, 116 p.

LIMA, A. B.; RODAL, M. J. N.; SILVA, A. C. B. L. 2008. Chuva de sementes em uma área de vegetação de Caatinga no Estado de Pernambuco. Rodriguésia 59 (4), 649-658.

LIMA, A. S. 2015. Caracterização florística e estrutural e avaliação da chuva de sementes em área de cerrado sentido restrito em Brasília, DF: subsídios para conservação e recuperação. Tese de Doutorado, Universidade de Brasília, Brasília, 117 p.

MACEDO, C. F. C. 2015. Anaálise da chuva de sementes como método para restauração de um fragmento de cerrado sentido restrito. Monografia, Universidade de Brasília, Brasília, 42 p.

MACHADO, V. M.; SANTOS, J. B.; PEREIRA, I. M.; LARA. R. O.; CABRAL, C. M.; AMARAL, C. S. 2013. Avaliação do banco de sementes de uma área em processo de recuperação em cerrado campestre. Planta Daninha 31 (2), 303-312.

MALAVASI, U. C.; GASPARINO, D.; MALAVASI, M. M. 2005. Semeadura direta na recomposição vegetal de áreas ciliares: efeitos da sazonalidade, uso do solo, exclusão da predação, e profundidade na sobrevivência inicial. Semina: Ciências Agrárias 26 (4), 449-454.

MELO, A. C. G.; DURIGAN, G.; GORENSTEIN, M. R. 2007. Efeito do fogo sobre o banco de sementes em faixa de borda de Floresta Estacional Semidecidual, SP, Brasil. Acta Botanica Brasileira 21 (4), 927-934.

MESQUITA, R. C. G.; ICKES, K.; GANADE, G.; WILLIAMSON, G. B. 2001. Alternative successional pathways in the Amazon Basin. Journal of Ecology 89, 528-537.

METZGER, J. P.; ALVES, L. F.; GOULART, W.; TEIXEIRA, A. M. G.; SIMÕES, S. J. C.; CATHARINO, E. L. M. 2006. Uma área de relevante interesse biológico, porém pouco conhecida: a Reserva Florestal do Morro Grande. Biota Neotropica 6 (2), 1-33. 
NAPPO, M. E.; FONTES, M. A. L.; OLIVEIRAFILHO, A. T.1999. Suficiência amostral e análise do tamanho de parcela para o estudo da regeneração natural do sub-bosque de povoamentos homogêneos de Mimosa scabrella Benth., em área minerada, em Poços de Caldas-MG. Revista Árvore 23 (4), 443-453.

NEWMARK, W. D. 1991. Tropical forest fragmentation and the local extinction of understory birds in the East Usambara Mountains, Tanzania. Conservation Biology 5, 67-78.

NÓBREGA, A. M. F.; VALERI, S. V.; PAULA, R. C.; PAVANI, M. C. M. D.; SILVA, S. A. 2009. Banco de sementes de remanescentes naturais e de áreas reflorestadas em uma várzea do rio Mogi-Guaçu. Revista Árvore 33 (3), 403-411.

NOGUEIRA, J. C. B.; NOGUEIRA, L. T. 1991. Regeneração natural de mata ciliar na Estação Ecológica de Bauru. Revista do Instituto Florestal 3 (2), 157-162.

OLIVEIRA FILHO, A. T.; RATTER, J. A. 2000. Padrões florísticos das matas ciliares da região do cerrado e a evolução das paisagens do Brasil Central durante o quaternário tardio. In: RODRIGUES, R.R.; LEITÃO FILHO, H. F. Matas Ciliares: conservação e recuperação. São Paulo: Universidade de São Paulo, 109-124.

OLIVEIRA, P. E. A. M.; MOREIRA, A. G. 1992. Anemocoria em espécies do cerrado e de Mata de Galeria de Brasília, DF. Revista Brasileira de Botânica 15 (2), 1663-1740.

PACHÊCO, B. S. 2014. Chuva de sementes como indicador de restauração ecológica em matas ripárias do Distrito Federal. Dissertação de Mestrado em Ciências Biológicas - Universidade Estadual de Montes Claros, Montes Claros, 75p.

PÉREZ, E. M.; SANTIAGO, E. T. 2001. Dinámica estacional del banco de semillas en una sabana en los Lhanos Centro-Orientales de Venezuela. Biotropica 33 (3), 435-446.

POZZA, D. D. 2002. Composição da avifauna da Estação Ecológica de São Carlos (Brotas-SP) e reserva ambiental da Fazenda Santa Cecília (Patrocinio Paulista). Dissertação de Mestrado do Programa de Pos-Graduação em Ecologia e Recursos Naturais do Centro de Ciências Biológicas e da Saúde da Universidade de São Carlos, 103 p.

RABINOWITZ, D.; RAPP, J. K. 1980. Seed rain in a North American tall grass prairie. Journal of Applied Ecology 17, 793-802.

RENJIFO, L. M. 1999. Composition changes in a sub-Andean avifauna after long-term forest fragmentation. Conservation Biology 13, 1124-1139.

RIZZINI, C. T. 1971 Aspectos ecológicos da regeneração em algumas plantas do cerrado. In: (Ed.). FERRI, M.G. (Ed.). III Simpósio sobre o Cerrado, pp. 167-179.

RIZZINI, C. T.; HERRINGER, E. P. 1962. Studies on the underground organs of trees and shrubs from some southern Brazilian savannas. Anais da Academia Brasileira de Ciências 34, 235247.

SCHUPP, E. W. 1993. Quantity, quality and the effectiveness of seed dispersal by animals. Vegetatio 107/108, 15-29.

SHEPHERD, G. J. 2009. Fitopac v. 2.0. Universidade Estadual de Campinas, Campinas. 
SILVA, J. C.; TABARELLI, M. 2000. Tree species impoverishment and the future flora of the Atlantic forest of northeast Brazil. Nature 404, 72-74.

SIMINSKI, A.; MANTOVANI, M; REIS, M. S.; FANTINI, A. C. 2004. Sucessão florestal secundária no município de São Pedro de Alcântara, litoral de Santa Catarina: estrutura e diversidade. Ciência Florestal 14 (1), 21-33.

SWAINE, M. D.; WHITMORE, T. C. 1988. On the definition of ecological species groups in tropical rain forests. Vegetatio $75,81-86$.

TABARELLI, M.; PERES, C. A. 2002. Abiotic and vertebrate seed dispersal in the Brazilian Atlantic forest: implications for forest regeneration. Conservation Biology 106, 165-176.

TEKLE, K.; BEKELE, T. 2000. The Role of Soil Seed Banks in the Rehabilitation of Degraded Hillslopes in Southern Wello, Ethiopia. Biotropica 32 (1), 23-32.

TERBORGH, J.; LOPEZ, L.; NUÑEZ, P.; RAO, M.; SHAHABUDDIN, G.; ORIHUELA, G.; RIVREOS, M.; ASCANIO, R.; ADLER, G. H.; LAMBERT, T. D.; BALBAS, L. 2001. Ecological meltdown in predator-free forest fragments. Science 294, 1923-1926.

VIEIRA, D. L. M.; AQUINO, F. G.; BRITO, M. A.; FERNADES-BULHÃO, C.; HENRIQUES, R. P. B. 2002. Síndromes de dispersão de espécies arbustivo-arbóreas em Cerrado sensu stricto do Brasil Central e Savanas Amazônicas. Revista Brasileira de Botânica 25 (2), 215-220.

WEISER, V. L.; GODOY, S. A. P. 2001. Florística em um hectare de Cerrado stricto sensu na ARIE - Cerrado Pé-de-Gigante, Santa Rita do Passa Quatro, SP. Acta Botanica Brasilica 15 (2), 201-212.

WILLIAMS-LINERA, G. 2002. Tree species richness complementarity, disturbance and fragmentation in a Mexican tropical montane cloud forest. Biodiversity Conservation 11, 1825-1843. 


\section{CAPÍTULO IV}

Fenologia de seis espécies arbóreas em um remanescente de cerrado stricto sensu localizado em Patrocínio Paulista - SP 


\section{RESUMO}

Os estudos fenológicos têm como principal objetivo relacionar eventos biológicos dos vegetais (fenofases vegetativas e reprodutivas) com aspectos ambientais (temperatura e umidade). Essa análise possibilita verificar a participação de espécies vegetais com características ecológicas distintas nos processos relacionados à regeneração natural. Assim, os objetivos deste estudo foram: (i) acompanhar a fenologia de seis espécies lenhosas de cerrado, relacionando as fenofases e suas intensidades com fatores climáticos; (ii) analisar as implicações das fenofases e suas intensidades na contribuição da regeneração natural no fragmento analisado. As espécies selecionadas foram: Copaifera langsdorffii, Dalbergia miscolobium, Pterodon emarginatus, Qualea grandiflora, Qualea multiflora e Xylopia aromatica. Foram marcados cinco indivíduos de cada espécie localizados no fragmento de cerrado stricto sensu da Fazenda Santa Cecília que foram observados durante 18 meses consecutivos seguindo o método proposto por Fournier e Charpantier. Foi calculado o percentual de intensidade de Fournier e o coeficiente de correlação de Spearman para verificar a influência dos aspectos climáticos (temperatura e pluviosidade) nos estados fenológicos. O resultado da análise de Spearman não indicou relação entre os eventos fenológicos e fatores climáticos. Na análise fenológica, pode-se classificar as espécies observadas em dois grupos: um grupo formado por Xylopia aromatica e Qualea grandiflora, no qual as fenofases reprodutivas foram observadas durante todo o período de observação, e outro grupo formado pelas demais espécies onde as fenofases reprodutivas tiveram baixa intensidade e duração. Esse resultado pode influenciar diretamente no processo de regeneração natural do fragmento, pois a produção de sementes é evento fundamental para a manutenção das populações, atuando diretamente no recrutamento de novos indivíduos. Dessa forma, a baixa taxa de produção de sementes poderia ser considerada um gargalo demográfico na área analisada.

Palavras-chave: fenologia, fenofases, influências ambientais.

\section{INTRODUÇÃO}

A sazonalidade climática é uma das características marcantes de áreas de Cerrado (Oliveira, 2008). Desde Warming (1908), percebe-se que as mudanças na vegetação desse bioma (fenofases), como a floração ou a queda das folhas, acompanham as oscilações do clima. Assim, os estudos fenológicos buscam compreender a relação entre os diversos eventos biológicos dos vegetais e os fatores ambientais, como temperatura e pluviosidade (Lieth, 1974), contribuindo para a compreensão da dinâmica vegetacional e regeneração natural (Talora e Morellato, 2000).

Alguns aspectos básicos relacionados às fenofases vegetativas de plantas lenhosas de Cerrado relacionam-se com as adaptações voltadas para superar o estresse hídrico (Oliveira et al., 2005). Essas adaptações possibilitam, basicamente, a manutenção das folhas durante todo o ano, a produção ou a queda das folhas durante a estação seca (Franco et al., 2005; Lenza e

Klink, 2006; Oliveira, 2008), de forma a otimizar o equilíbrio hídrico do indivíduo de acordo com as características ambientais. As diferentes manifestações fenológicas de cada espécie 
indicam estratégias adaptativas diferentes a um mesmo fator condicionante (Lenza e Klink, 2006).

Os estados fenológicos reprodutivos, iniciando na floração, passando pela frutificação e culminando na dispersão de sementes, são mais diversificados nas espécies de Cerrado, podendo-se encontrar espécies em floração durante todo o ano (Batalha e Mantovani, 2000; Lenza e Klink, 2006). Alguns estudos apontam a influência de fatores abióticos, como precipitação e temperatura, para o início das fenofases reprodutivas (Fernandes-Bulhão e Figueiredo, 2002; Munhoz e Felfili, 2007; Oliveira, 2008). Oliveira (2008) também ressalta a importância da síndrome de dispersão de sementes como fator influente da fenologia reprodutiva de espécies arbóreas em áreas de Cerrado que apresentam sazonalidade do clima.

Dessa maneira, segundo Batalha e Mantovani (2000), para as espécies anemocóricas a estação seca tem destacada importância, pois a baixa umidade do ar propicia a abertura dos frutos e a ausência de chuvas possibilita a dispersão mais eficiente das sementes anemocóricas. Nesse contexto, a estação chuvosa possui relevância para as espécies zoocóricas, pois a alta umidade do ar contribui para a manutenção de frutos atrativos para a fauna por mais tempo, aumentando a eficiência do processo. E para que esses processos possam ocorrer de maneira adequada, os indivíduos vegetais devem coordenar as outras fenofases (vegetativas e reprodutivas) ao longo do ano (Batalha e Martins, 2004; Oliveira, 2008).

Assim, Morellato et al. (2000) afirmam que os estudos fenológicos são fundamentais para a caracterização de áreas naturais e fornecem importantes informações a respeito da regeneração natural dessas áreas.

\section{HIPÓTESE}

As espécies arbóreas analisadas apresentam características fenológicas relacionadas à duração e intensidade de seus ciclos reprodutivos típicos às respectivas espécies, repetindo padrões já observados em outras áreas de cerrado stricto sensu. Dessa forma, sua contribuição no fornecimento de propágulos para a manutenção das populações vegetais no fragmento ocorre conforme esperado. 


\section{OBJETIVOS ESPECÍFICOS}

- Acompanhar a fenologia de seis espécies lenhosas de cerrado, relacionando as fenofases e suas intensidades com fatores climáticos.

- Analisar as implicações das fenofases e suas intensidades na contribuição da regeneração natural no fragmento analisado.

\section{MATERIAL E MÉTODOS}

O estudo foi desenvolvido no fragmento de cerrado stricto sensu da Fazenda Santa Cecília, localizada no município de Patrocínio Paulista - SP, durante 18 meses (julho de 2015 a dezembro de 2016) e envolveu uma análise climática dos anos 2015 e 2016, abordando características básicas (temperatura e precipitação); o acompanhamento fenológico de seis espécies arbóreas; e a análise de correlação entre as fenofases e as características climáticas. Segue detalhamento da metodologia utilizada em cada atividade.

\subsection{Análise climática}

A análise climática foi realizada com dados compilados de dois sites disponíveis na internet. No site do Instituto Nacional de Meteorologia (INMET, 2017) foram coletados os dados históricos de precipitação e temperaturas máximas e mínimas. No site Banco de Dados Meteorológicos para Ensino e Pesquisa (BDMEP, 2017) foram obtidas as médias mensais de precipitação e temperaturas máximas e mínimas dos anos 2015 e 2016. Importante destacar que os dados indicados foram coletados da estação meteorológica localizada no município de Franca, limítrofe ao município de Patrocínio Paulista. Esse procedimento foi necessário pois não existem estações de coleta de dados meteorológicos no município de Patrocínio Paulista, segundo funcionários do Departamento Autônomo de Água e Esgotos (DAAE) do município.

Os dados coletados foram plotados em gráficos para melhor visualização e análise.

\subsection{Espécies estudadas}

Para o acompanhamento fenológico foram escolhidas seis espécies arbóreas com base no índice de importância obtido por Teixeira et al. (2004) em investigação prévia no fragmento. Além disso, as espécies escolhidas pertencem ao rol das espécies destacadas em várias investigações como importantes elementos da flora e estrutura do cerrado. As espécies 
são: Copaifera langsdorffii Desf., Dalbergia miscolobium Benth., Pterodon emarginatus Vogel., Qualea grandiflora Mart., Qualea multiflora Mart. e Xylopia aromatica (Lam) Mart. Informações ecológicas das espécies (síndrome de dispersão, grupo ecológico, síndrome de polinização e padrão de floração) são apresentadas na Tabela 1.

Tabela 1 - Classificação quanto a síndrome de dispersão e grupo ecológico das espécies vegetais amostradas no cerrado stricto sensu na Fazenda Santa Cecília, Patrocínio Paulista, SP. SP: síndrome de polinização; Z: zoofilia; SD: síndrome de dispersão; ZOO: zoocórica; ANE: anemocórica; GE: grupo ecológico; P: pioneira, SI: secundário inicial, ST: secundária tardia; PF: padrão de floração; 1: anual; 2: supra anual.

\begin{tabular}{lcccc}
\hline FAMÍLIA/ Espécie & SP & SD & GE & PF \\
\hline ANNONACEAE & & & & \\
Xylopia aromatica (Lam.) Mart. & Z & ZOO & P & 1 \\
FABACEAE & & & & \\
Copaifera langsdorffii Desf. & Z & ZOO & ST & 2 \\
Dalbergia miscolobium Benth. & Z & ANE & P & 1 \\
Pterodon emarginatus Vogel & Z & ANE & SI & 1 \\
VOCHYSIACEAE & & & & \\
Qualea grandiflora Mart. & Z & ANE & P & 1 \\
Qualea multiflora Mart. & Z & ANE & ST & 1 \\
\hline
\end{tabular}

\subsection{Coleta e análise dos dados}

Para as observações foram marcados cinco indivíduos de cada espécie, seguindo o método proposto por Fournier e Charpantier (1975). Os indivíduos foram observados mensalmente de julho de 2015 a dezembro de 2016, totalizando 18 meses de observação, utilizando-se binóculo e a olho nu.

Os eventos fenológicos observados foram: estado vegetativo, queda foliar, brotamento foliar, floração, frutos imaturos, frutos maduros e dispersão. Os estados fenológicos foram classificados em uma escala de intensidade, como proposto por Fournier (1974), conforme Tabela 2. Esta escala de intensidade de Fournier apresenta uma estimativa quantitativa do estado fenológico (Bencke e Morellato 2002), caracterizando-o de maneira mais completa. 
Tabela 2 - Escala de intensidade dos estados fenológicos. Baseado em Bencke e Morellato (2002).

\begin{tabular}{cc}
\hline Escala de intensidade & \% de ocorrência (copa) \\
\hline 1 & $1-25$ \\
2 & $26-50$ \\
3 & $51-75$ \\
4 & $76-100$ \\
\hline
\end{tabular}

Para cada espécie, em cada mês, foi calculado o percentual de intensidade de Fournier somando-se os valores individuais das escalas de intensidade de todos os indivíduos em cada fenofase, dividindo este valor por 20 (número total de indivíduos multiplicado por quatro) e multiplicando o valor obtido por 100 para se obter resultados em porcentagem, de acordo com a fórmula (Fournier 1974):

$$
I F=\left(\frac{\Sigma E I}{20}\right) \times 100
$$

onde:

$\Sigma$ El: somatório das escalas de intensidade de Fournier

Para verificar se houve influência dos fatores climáticos (temperatura e precipitação) nos eventos fenológicos os dados foram analisados por meio do coeficiente de correlação de Spearman $(\rho)(Z a r, 1999)$ com o uso do software PSPP (GNU, 2017).

$O$ valor do Coeficiente de Spearman encontra-se no intervalo entre -1 e +1 , sendo que quanto mais próximo desses valores, mais forte a correlação. Quanto mais próximo os valores estiverem de 0 (zero), mais fraca é a associação. Valores positivos indicam uma correlação diretamente proporcional, isto é, quando o valor de uma variável cresce a outra variável acompanha este crescimento. Valores negativos são próprios de uma correlação inversamente proporcional, isto é, quando os valores de uma variável aumentam os valores da outra variável diminuem.

Para interpretar a força da correlação foi utilizada a Tabela 3, disponível em Shimakura (2017). 
Tabela 3 - Interpretação dos valores de correlação de Spearman, conforme Shimakura (2017).

\begin{tabular}{cc}
\hline Valor de $\rho$ (+ ou - ) & Interpretação \\
\hline 0,00 a 0,19 & Correlação muito fraca \\
0,20 a 0,39 & Correlação fraca \\
0,40 a 0,69 & Correlação moderada \\
0,70 a 0,89 & Correlação forte \\
0,90 a 1,00 & Correlação muito forte \\
\hline
\end{tabular}

Considerando evento fenológico assincrônico: menos de $20 \%$ dos indivíduos da população apresentando a fenofase; pouco sincrônico 20 - 60\% dos indivíduos; e muito sincrônico mais de 60\% de indivíduos (Bencke e Morellato, 2002).

\section{RESULTADOS}

\subsection{Análise climática}

Os dados históricos obtidos para a região indicam um clima estacional com duas estações bem delimitadas: uma que se estende de abril a setembro, caracterizada pelo baixo volume de precipitação e temperaturas médias mais amenas, e outra de outubro a março, com elevados índices pluviométricos e temperaturas médias mais altas (Figura 1). De acordo com Silva et al. (2008) essas características são esperadas para áreas do Domínio do Cerrado, sendo definido como um clima Tropical Estacional, isto é, com duas estações do ano bem marcadas.

Nos anos de 2015 e 2016 percebem-se algumas alterações relacionadas, principalmente, à precipitação (Figura 2).

Em 2015, percebe-se que a estação seca teve uma duração sensivelmente menor do que a esperada, com os meses de abril e maio com chuvas além do esperado. Em contrapartida, os meses de julho e agosto foram mais secos do que a média histórica. As médias de temperatura acompanharam as normais climáticas de cada mês, com pequenas oscilações, naturais para uma variável tão dinâmica quanto a temperatura.

Já em 2016, a sazonalidade da precipitação ficou extremamente bem definida, sendo que nos meses de abril a setembro houve baixos índices pluviométricos e no primeiro e último trimestres do ano a precipitação atingiu valores mais altos, conforme previsto. 
Figura 1 - Normais climáticas do município de Patrocínio Paulista - SP. Valores de temperatura máxima e mínima apresentados correspondem à média do mês entre os anos 1961-1990.

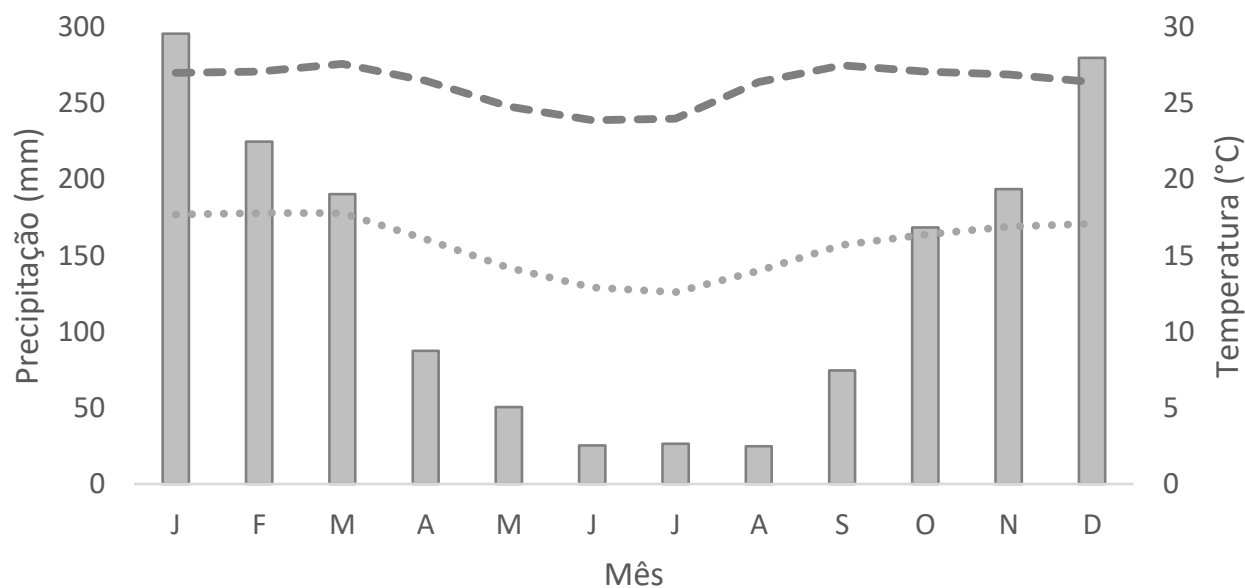

$\square$ Precipitação $\quad$ - Temperatura máxima $\quad$ - T... Temperatura mínima

Figura 2 - Dados climáticos do município de Patrocínio Paulista - SP. A: 2015; B: 2016.

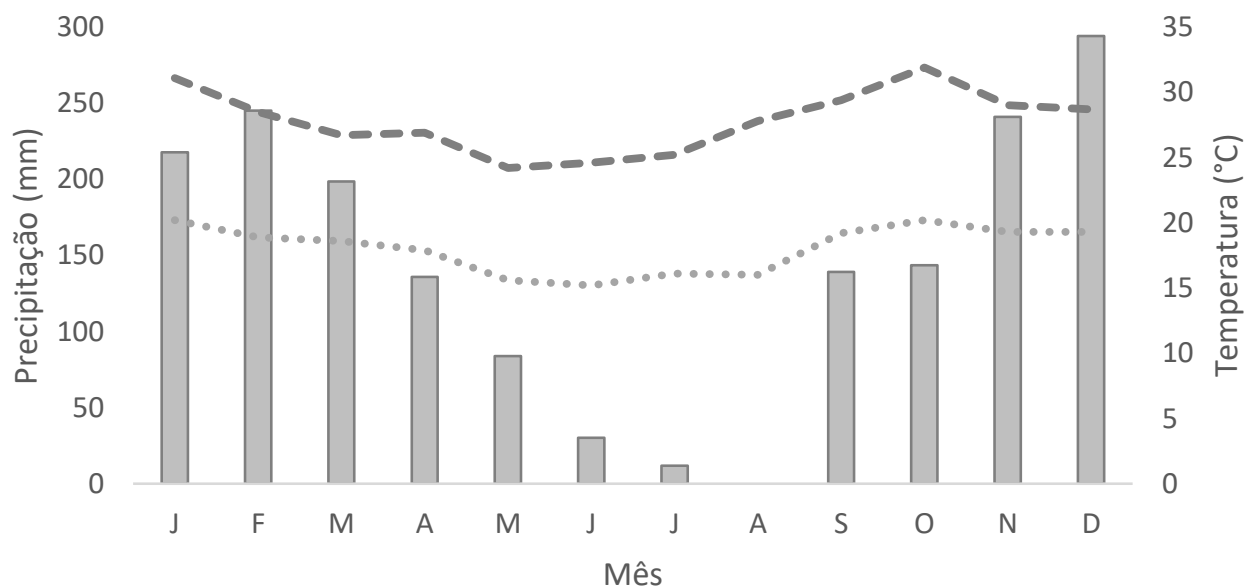

$\square$ Precipitação $\quad-$ Temperatura máxima $\quad \ldots$. Temperatura mínima

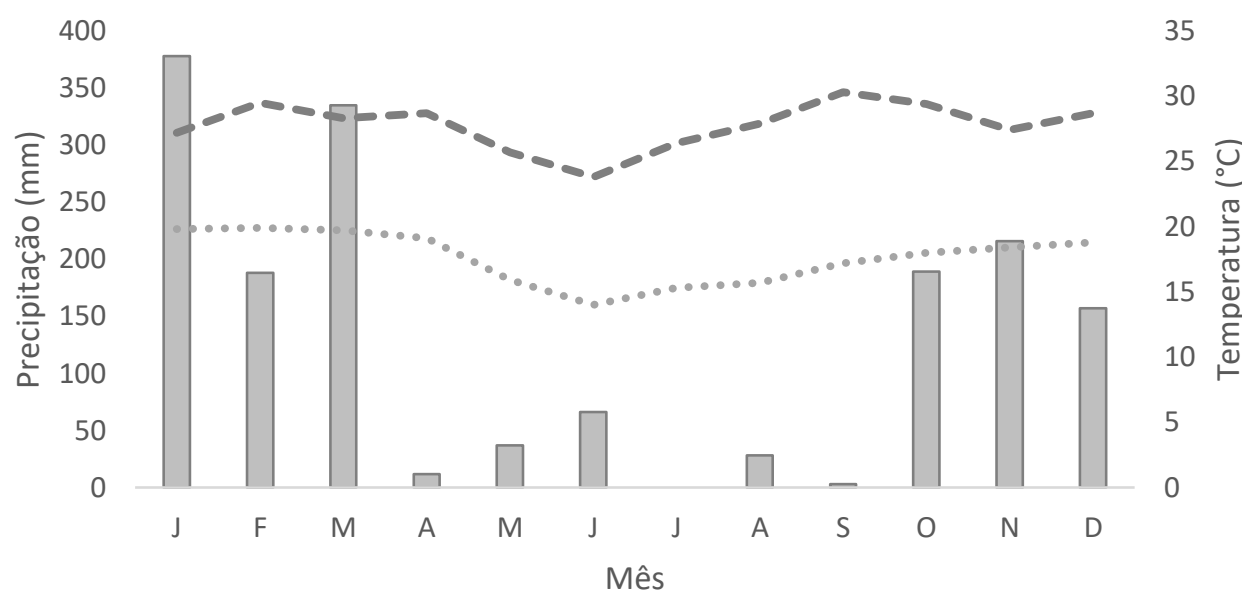

Precipitação $\quad-$ Temperatura máxima $\quad \ldots .$. Temperatura mínima 
Apesar dessas oscilações, considera-se que tais diferenças são naturais e confirmam a sazonalidade do clima conforme esperado para a região.

\subsection{Fenologia}

Os resultados das observações fenológicas são apresentados por espécie.

\subsubsection{Xylopia aromatica (Lam.) Mart.}

Nos indivíduos observados da espécie Xylopia aromatica nota-se uma baixa sincronicidade nos eventos, sendo que apenas no mês de março de 2016 todos os indivíduos apresentaram a mesma fenofase (estado vegetativo). Importante destacar que o estado vegetativo foi encontrado durante a estação chuvosa.

A floração e a presença de frutos imaturos foram registradas em muitos meses (oito e nove registros, respectivamente) com intensidade variável, atingindo um máximo de 50\%, indicando uma ausência de sincronicidade nestes eventos.

A presença de frutos maduros foi registrada apenas nos últimos três meses de observação, com uma intensidade aproximada de $60 \%$. Não foram observados os eventos de queda foliar, brotamento foliar e dispersão de frutos.

A Figura 3 apresenta a ocorrência das fenofases nos indivíduos de Xylopia aromatica no período de observação, assim como as suas intensidades.

Figura 3 - Eventos fenológicos e suas respectivas intensidades mensais de Xylopia aromatica em fragmento de cerrado stricto sensu em Patrocínio Paulista - SP. ( O ) estado vegetativo; $(\square)$ queda foliar; $(\diamond)$ brotamento foliar; $(x)$ floração; $(\Delta)$ frutos imaturos; $(\bullet)$ frutos maduros.

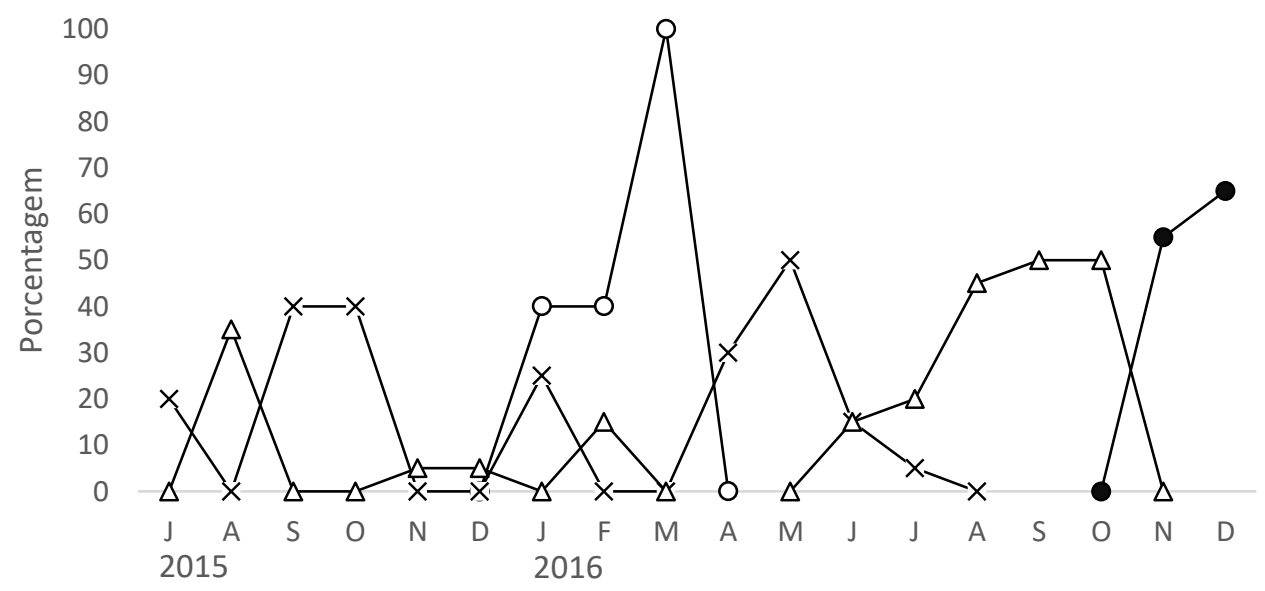




\subsubsection{Copaifera langsdorffii Desf.}

Os indivíduos de Copaifera langsdorffii mantiveram-se em estado vegetativo durante todo o período de coleta de dados, sem manifestar as outras fenofases.

A Figura 4 apresenta a ocorrência das fenofases nos indivíduos de Copaifera langsdorffii no período de observação, assim como as suas intensidades.

Figura 4 - Eventos fenológicos e suas respectivas intensidades mensais de Copaifera langsdorffii em fragmento de cerrado stricto sensu em Patrocínio Paulista - SP. ( o ) estado vegetativo.

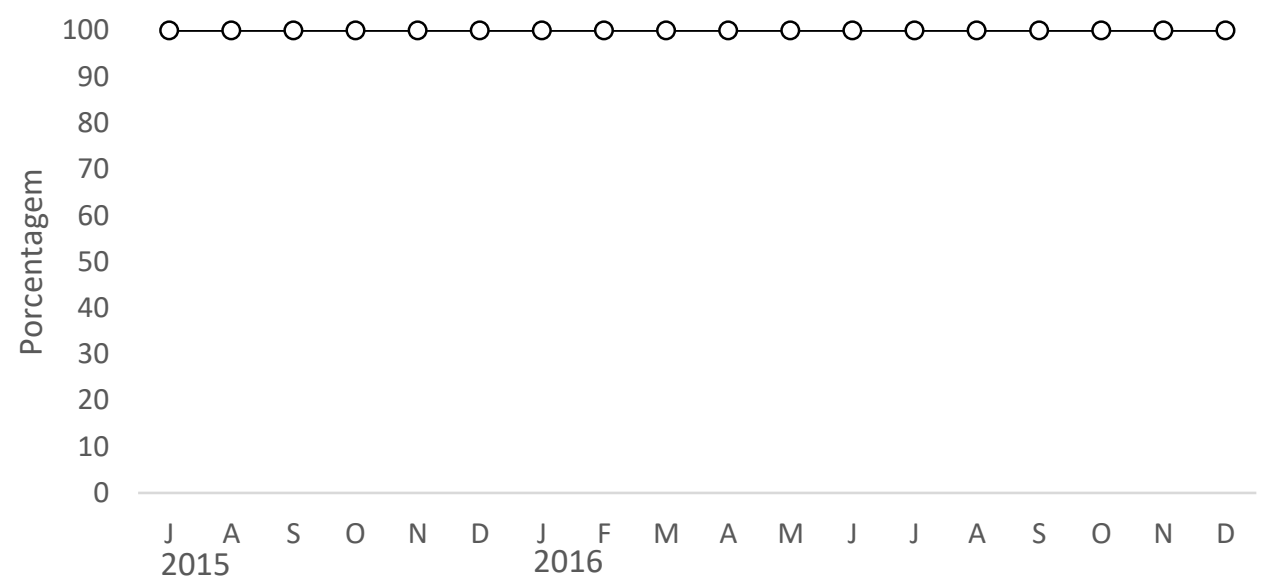

\subsubsection{Dalbergia miscolobium Benth.}

A análise da fenologia dos indivíduos de Dalbergia miscolobium indicam uma nítida estacionalidade entre os estados vegetativos e reprodutivos, sendo que nos meses chuvosos os indivíduos estão, na sua maioria, em estado vegetativo, e durante a época mais seca do ano realizam atividades reprodutivas.

Importante destacar que as atividades reprodutivas (floração, frutos imaturos, frutos maduros) sempre ocorreram abaixo de $50 \%$ do potencial máximo observado, indicando uma baixa taxa reprodutiva.

Não foi identificado, claramente, um período de dispersão das sementes. Em virtude da síndrome de dispersão anemocórica dessa espécie, o processo pode não ter sido observado ou, ainda, devido à baixa intensidade na produção de frutos, a dispersão ocorreu entre o intervalo das etapas de observação.

A Figura 5 apresenta a ocorrência das fenofases nos indivíduos de Dalbergia miscolobium no período de observação, assim como as suas intensidades. 
Figura 5 - Eventos fenológicos e suas respectivas intensidades mensais de Dalbergia miscolobium em fragmento de cerrado stricto sensu em Patrocínio Paulista - SP. ( o ) estado vegetativo; $(\square)$ queda foliar; $(\diamond)$ brotamento foliar; $(x)$ floração; $(\Delta)$ frutos imaturos; $(\bullet$ ) frutos maduros.

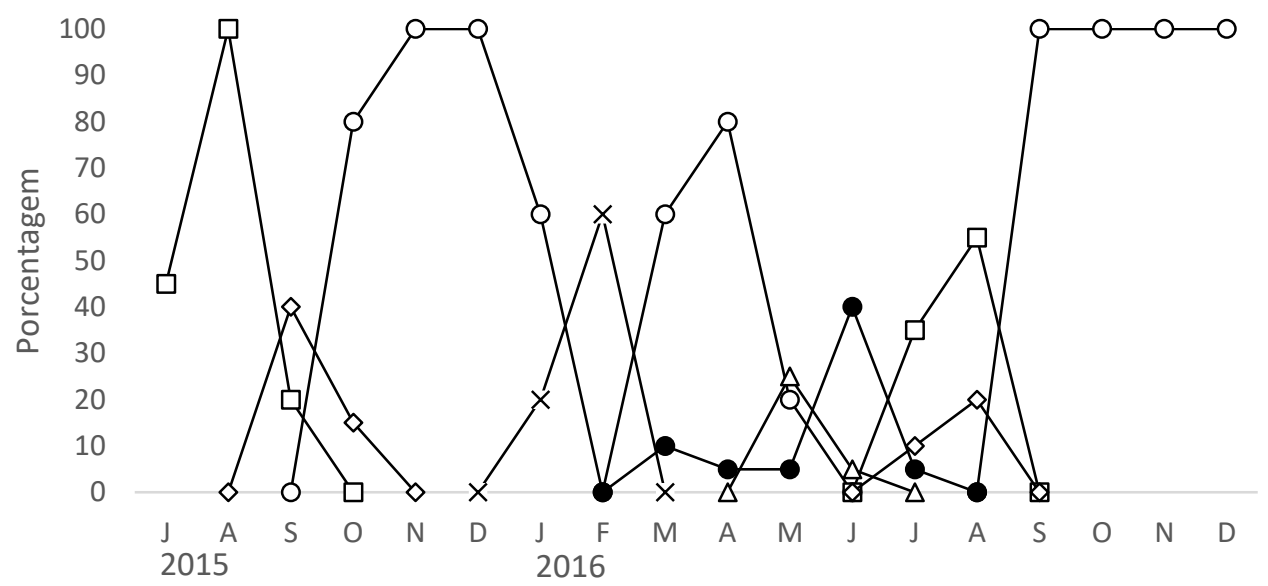

\subsubsection{Pterodon emarginatus Vogel}

Os indivíduos amostrados de Pterodon emarginatus apresentaram um ciclo fenológico semelhante aquele encontrado em Dalbergia miscolobium, com a prevalência do estado vegetativo na estação chuvosa e o estado reprodutivo na estação seca.

Também seguindo a tendência observada em Dalbergia miscolobium, as atividades reprodutivas de Pterodon emarginatus apresentaram-se com baixa intensidade, apresentando um máximo de $25 \%$, sendo que tanto a produção de frutos quanto a dispersão de sementes não ultrapassaram $20 \%$.

A Figura 6 apresenta a ocorrência das fenofases nos indivíduos de Pterodon emarginatus no período de observação, assim como as suas intensidades. 
Figura 6 - Eventos fenológicos e suas respectivas intensidades mensais de Pterodon emarginatus em fragmento de cerrado stricto sensu em Patrocínio Paulista - SP. ( o ) estado vegetativo; $(\square)$ queda foliar; $(\diamond)$ brotamento foliar; $(x)$ floração; $(\Delta)$ frutos imaturos; $(\bullet$ ) frutos maduros; ( + ) dispersão.

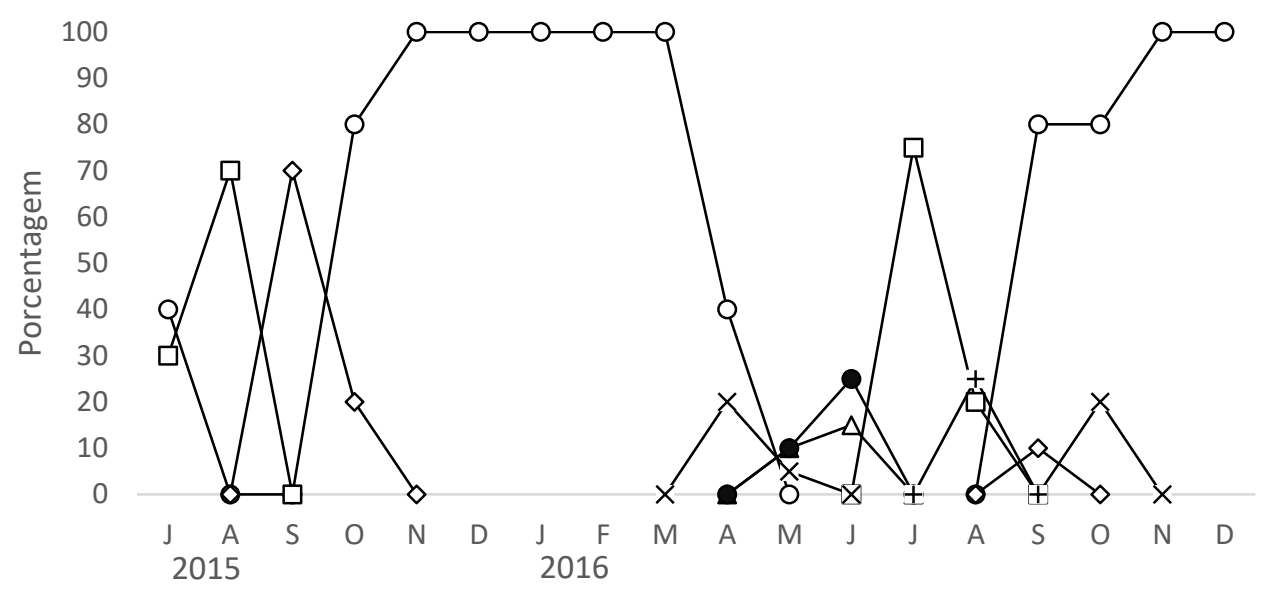

\subsubsection{Qualea grandiflora Mart.}

Os indivíduos de Qualea grandiflora não apresentaram uma estacionalidade, sendo que as fases fenotípicas, tanto vegetativa quanto reprodutivas, distribuíram-se ao longo do período de observação.

Uma sincronicidade foi registrada apenas nos meses de fevereiro e março (final da estação chuvosa) de 2016 , onde o estado vegetativo atingiu $90 \%$ e $100 \%$, respectivamente. Para essa espécie também foi percebida uma baixa taxa reprodutiva, sendo que o máximo foi 40\% na fase de frutos maduros no mês de agosto de 2015 (final da estação seca).

Importante destacar a alta incidência registrada de dispersão. Alguns indivíduos reprodutivos, após a dispersão de suas sementes, realizada por anemocoria, mantem os frutos secos em suas copas após a finalização do evento reprodutivo. Assim, estes frutos de épocas anteriores podem dificultar as observações do evento atual.

A Figura 7 apresenta a ocorrência das fenofases nos indivíduos de Qualea grandiflora no período de observação, assim como as suas intensidades. 
Figura 7 - Eventos fenológicos e suas respectivas intensidades mensais de Qualea grandiflora em fragmento de cerrado stricto sensu em Patrocínio Paulista - SP. ( o ) estado vegetativo; $(\square)$ queda foliar; $(\diamond)$ brotamento foliar; $(x)$ floração; $(\Delta)$ frutos imaturos; $(\bullet)$ frutos maduros; $\quad(+)$ dispersão.

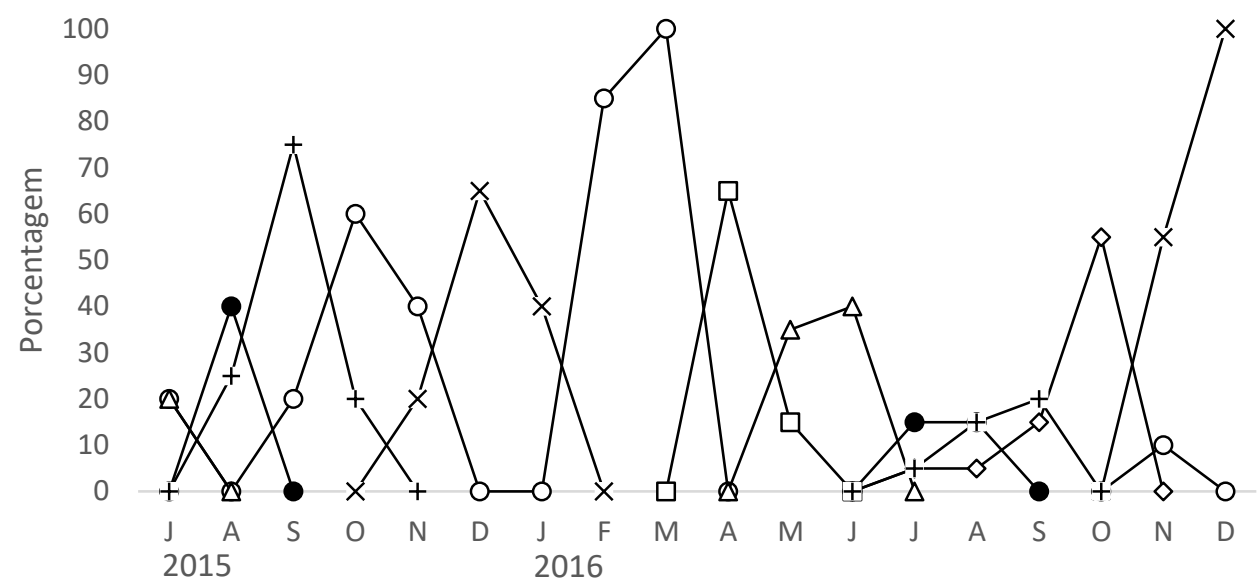

\subsubsection{Qualea multiflora Mart.}

No período observado, não foi identificado um padrão nítido para Qualea multiflora. Dois eventos fenológicos tiveram sincronicidade: entre agosto e outubro de 2015 os indivíduos da espécie apresentaram queda foliar, evento que não se repetiu na mesma época de 2016, e no período entre janeiro e abril de 2016 os indivíduos estavam em estado vegetativo.

Entre julho e outubro de 2016 (estação seca) houve uma baixa intensidade de ocorrência de eventos fenológicos relacionados à reprodução, com uma taxa, em média, de $20 \%$.

A Figura 8 apresenta a ocorrência das fenofases nos indivíduos de Qualea multiflora no período de observação, assim como as suas intensidades. 
Figura 8 - Eventos fenológicos e suas respectivas intensidades mensais de Qualea multiflora em fragmento de cerrado stricto sensu em Patrocínio Paulista - SP. ( ० ) estado vegetativo; ( $\square$ ) queda foliar; $(\diamond)$ brotamento foliar; $(x)$ floração; $(\Delta)$ frutos imaturos; $(\bullet)$ frutos maduros; (+) dispersão.

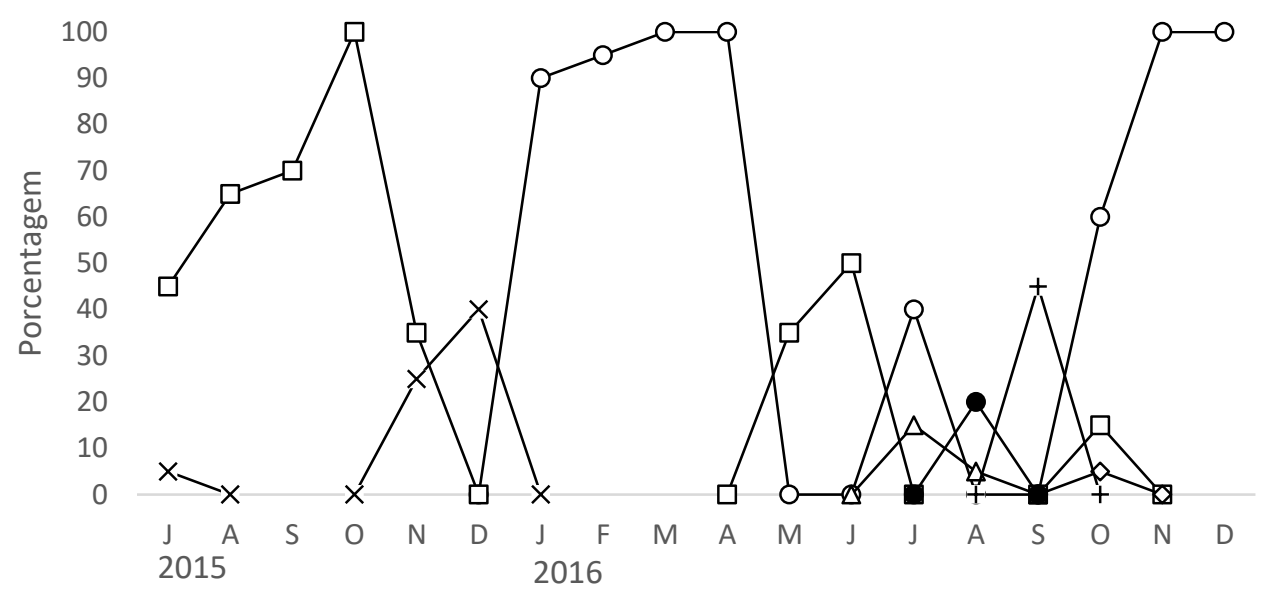

A Figura 9 apresenta as fases fenológicas considerando sua presença ou ausência. Isso possibilita sintetizar os dados fenológicos e realizar comparações das fenofases vegetativas e reprodutivas entre as espécies amostradas.

Figura 9. Presença e ausência das fenofases nos meses de observação para seis espécies localizadas no fragmento de cerrado stricto sensu da Fazenda Santa Cecília, Patrocínio Paulista - SP. fenofases reprodutivas; fenofases vegetativas.

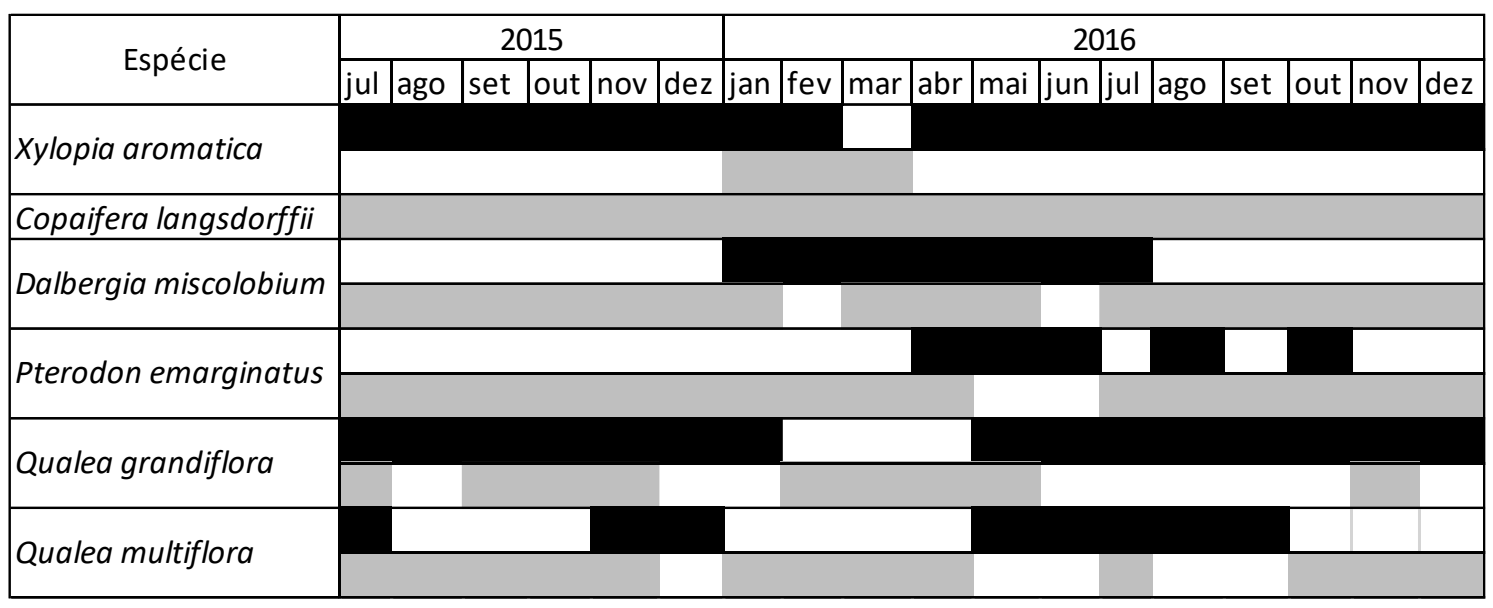

\section{3 Índice de Correlação de Spearman}

\subsubsection{Temperatura}

A análise da correlação entre a temperatura e os eventos fenológicos indicaram uma correlação muito fraca em todas as espécies analisadas (Tabela 4). Isto indica que as variações 
de temperatura registradas para a região não interferiram significativamente nos eventos fenológicos.

Tabela 4 - Correlações de Spearman entre temperatura e eventos fenológicos das seis espécies analisadas.

\begin{tabular}{lcc}
\hline Espécie & Índice de Spearman & Correlação \\
\hline Xylopia aromatica & $-0,11$ & muito fraca \\
Copaifera langsdorffii & $-0,02$ & muito fraca \\
Dalbergia miscolobium & $-0,17$ & muito fraca \\
Pterodon emarginatus & $-0,32$ & fraca \\
Qualea grandiflora & $-0,13$ & muito fraca \\
Qualea multiflora & 0,02 & muito fraca \\
\hline
\end{tabular}

\subsubsection{Precipitação}

Os resultados obtidos da correlação de Spearman entre os dados de precipitação e os eventos fenológicos das seis espécies arbóreas analisadas também indicam uma correlação pouco significativa, embora quando comparado com os resultados da temperatura, a precipitação apresentou correlação mais forte (Tabela 5).

Tabela 5 - Correlações de Spearman entre precipitação e eventos fenológicos das seis espécies analisadas.

\begin{tabular}{lcc}
\hline Espécie & Índice de Spearman & Correlação \\
\hline Xylopia aromatica & 0,07 & muito fraca \\
Copaifera langsdorffii & 0,08 & muito fraca \\
Dalbergia miscolobium & $-0,25$ & fraca \\
Pterodon emarginatus & $-0,52$ & moderada \\
Qualea grandiflora & $-0,34$ & fraca \\
Qualea multiflora & $-0,34$ & fraca \\
\hline
\end{tabular}

\section{DISCUSSÃO}

Antes de iniciar a discussão do presente capítulo é necessária uma contextualização. Sabe-se que estudos fenológicos fazem o acompanhamento dos indivíduos por, aproximadamente, 36 meses, tempo hábil para se identificar flutuações e periodicidades naturais das fenofases nas épocas do ano, tempo muito superior aos 18 meses de coleta de dados deste estudo. Assim, este estudo não pretende apresentar uma análise fenológica completa das espécies observadas, mas verificar características básicas da intensidade e 
duração das fenofases reprodutivas das espécies vegetais selecionadas, estimando a sua contribuição no processo de regeneração natural no fragmento de cerrado.

$\mathrm{Na}$ análise do climograma dos anos de 2015 e 2016, comparando-se com as médias históricas, percebe-se que, apesar de oscilações e diferenças naturais esperadas, os dois anos apresentaram características de temperaturas médias e precipitação de acordo com as normais climáticas para a região, com uma sazonalidade de precipitação bem destacada, aspecto comum para áreas de cerrado (Silva et al., 2008). Essa constatação é fundamental para descartar as influências de fatores ambientais nos resultados fenológicos.

Analisando-se os resultados do Índice de Correlação de Spearman pode-se perceber uma fraca relação entre os atributos climáticos e as fenofases. Isto indica que as características fenotípicas não estão sendo influenciadas pela temperatura ou precipitação, fato já identificado historicamente (Sarmiento e Monasterio, 1983; Mantovani e Martins, 1988). Entretanto, outros autores identificaram uma forte relação entre aspectos climáticos e fenofases de espécies do Cerrado (Morellato et al., 2000; Stevenson et al., 2008). Apesar disso, como Borchert (1980) afirma, as fases de desenvolvimento vegetativo ou reprodução de algumas espécies vegetais tropicais são definidas, primariamente, por características fisiológicas de cada espécie e apenas de maneira secundária pelo clima. Assim, assume-se que as espécies observadas estão sob efeito de outros aspectos não observados, climáticos ou fisiológicos, necessitando um acompanhamento mais prolongado e abrangente de diferentes espécies do fragmento de cerrado stricto sensu observado.

Partindo para a análise das fenofases reprodutivas das espécies observadas pode-se classificá-las em dois grupos: o primeiro, formado por Xylopia aromatica e Qualea grandiflora, onde as fenofases reprodutivas puderam ser observadas durante praticamente todo o ano, e o segundo grupo, formado por Copaifera langsdorffii, Dalbergia miscolobium, Pterodon emarginatus e Qualea multiflora, no qual as fenofases reprodutivas tiveram baixa intensidade e duração, quando não foram ausentes.

Considerando-se as características ecológicas das espécies, o grupo formado por $X$. aromatica e $Q$. grandiflora, possui como característica comum o grupo ecológico (pioneiras). Sabe que espécies pioneiras são caracterizadas, dentre outros aspectos, pela alta intensidade reprodutiva, visando a ocupação de território (Kageyama e Castro, 1989). Assim, essa característica ecológica poderia justificar a maior duração e intensidade das fenofases reprodutivas encontradas nas duas espécies. Vale destacar que Dalbergia miscolobium também é considerada espécie pioneira e não apresentou reprodução abundante. Este fato reforça a hipótese da influência de outros aspectos, bióticos ou abióticos, interferindo de maneira diversa sobre as espécies. 
Tratando especificamente da espécie Xylopia aromatica, Silva (2016) também verificou que a espécie apresentou suas fenofases reprodutivas bem distribuídas durante todo o ano, mas em baixas intensidades. Esse potencial reprodutivo da espécie poderia justificar sua ampla ocupação em áreas de Cerrado (Ratter et al., 1997; Rizzini, 1997; Almeida et al., 1998; Saporetti JR et al., 2003; Gimenez e Godoy, 2007; Maas et al., 2010; Güntzel et al., 2011), já que espécies que tenham maior intensidade reprodutiva tem uma maior possibilidade de contribuir com o processo de regeneração, oferecendo mais propágulos para germinação. Mas essa afirmação deve ser interpretada com cautela, pois Locardi (2011) afirma que $X$. aromatica apresenta variações fenológicas de acordo com a região estudada e, dada a sua ampla distribuição geográfica, as características das suas fenofases podem ser bem distintas, e Cardoso-Leite et al. (2004) indica que a expressiva abundância de espécies do gênero pode indicar uma resposta à intensa pressão antrópica na área, com subsequentes alterações na dinâmica natural do remanescente.

Ao verificar as fenofases reprodutivas das espécies classificadas como de baixa intensidade, percebe-se que as taxas de intensidade são menores do que $50 \%$, ficando em torno de $20-40 \%$, com exceção de $C$. langsdorffii, espécie para qual foi registrada apenas a fenofase vegetativa. Ressalva importante deve ser feita, pois alguns autores afirmam que 0 padrão de floração dessa espécie é bianual (Pedroni et al., 2002). Dessa maneira, devido ao tempo de observação do presente estudo (18 meses), deve-se considerar a hipótese de que as fenofases reprodutivas não foram registradas devido ao período de coleta de dados em campo.

As baixas intensidades de produção de sementes observadas podem ter significativo impacto nos processos de regeneração natural do fragmento analisado. Sabe-se que a etapa de produção e dispersão de sementes são fundamentais para a manutenção das populações das espécies vegetais (Jordano, 1993; Martínez-Ramos e Soto-Castro, 1993), pois estas etapas afetam diretamente o recrutamento de novos indivíduos. Jordano et al. (2004) chamou de gargalo demográfico qualquer fator que diminua a possibilidade de manutenção de uma população em uma área. Assim, a baixa taxa de produção de sementes poderia ser considerada um gargalo demográfico.

A baixa intensidade da produção de sementes pode ser resultado de vários processos, indo desde os aspectos endógenos das espécies (Janzen, 1967; Rathke e Lacey, 1985; Talora e Morellato, 2000), influência de aspectos abióticos e, na situação analisada, é possível a diminuição ou ausência de animais polinizadores, já que todas as espécies observadas possuem síndrome de polinização zoocórica. Determinar as relações entre as espécies vegetais e seus agentes polinizadores e/ou dispersores locais e seu grau de especificidade é muito 
importante para entender os motivos dessa baixa produção de sementes mas, de acordo com Muller-Landau et al. (2008), identificar esses padrões ainda é um desafio para os estudos ecológicos.

Münzbergová e Herben (2005) afirmam que em uma comunidade vegetal onde as espécies apresentam limitação na produção de sementes, em médio e longo prazo, resultaria em um desequilíbrio ecológico e uma diminuição da biodiversidade, pois quanto mais propágulos, há mais chances de sucesso na germinação e estabelecimento de um novo indivíduo. Importante destacar, também, que o desenvolvimento de um novo indivíduo depende de tentativas de germinação, pois uma pequena parcela das sementes germinadas alcançará o estágio adulto (Janzen, 1971; Schupp, 1995). Assim, quanto menos sementes disponíveis, menor será o número de tentativas de germinação e, dessa maneira, aumenta a possibilidade de raleamento da comunidade vegetal.

Dessa forma, percebe-se a importância e participação de indivíduos e espécies isoladamente no complexo processo de regeneração natural, afetando a estrutura espacial e temporal da comunidade.

\section{CONCLUSÃO}

De acordo com os dados coletados e análises realizadas para seis espécies arbóreas presentes no fragmento de cerrado stricto sensu da Fazenda Santa Cecília, pode-se perceber que parte desse conjunto apresentou uma baixa intensidade de fenofases reprodutivas. Essa baixa intensidade poderá refletir diretamente na dinâmica populacional, afetando o recrutamento de indivíduos em médio e longo prazo. Se essa tendência persistir e for identificada para outras espécies vegetais do fragmento, a tendência de diminuição da biodiversidade vegetal se torna ainda mais real, havendo necessidade de medidas de enriquecimento para evitar possíveis extinções locais.

Dessa forma, a hipótese inicial foi refutada, pois a análise dos dados indicou significativas mudanças nas fenofases reprodutivas das espécies analisadas.

\section{REFERÊNCIAS BIBLIOGRÁFICAS}

ALMEIDA, S. P.; PROENÇA, C. E. B.; SANO, S. M.; RIBEIRO, J. F. 1998. Cerrado: espécies vegetais úteis. Planaltina: Embrapa, $464 \mathrm{p}$.

BATALHA, M. A.; MARTINS, F. R. 2004. Reproductive phenology of the cerrado plant community in Emas National Park (central Brazil). Australian Journal of Botany 52, 149-16. 
BATALHA, M.A.; MANTOVANI, W. 2000. Reproductive phenology patterns of cerrado plant species at the Pé-de-Gigante Reserve (Santa Rita do Passa Quatro, SP, Brazil): a comparison between the herbaceous and woody flora. Revista Brasileira de Biologia 60 (1), 129-145.

BDMEP. Banco de Dados Meteorológicos para Ensino e Pesquisa. Acesso ao BDMEP. Disponível em: <http://www.inmet.gov.br/projetos/rede/pesquisa/>. Acesso em: 12 mar. 2017.

BENCKE, C. S. C.; MORELLATO, L. P. C. 2002. Comparação de dois métodos de avaliação da fenologia de plantas, sua interpretação e representação. Revista Brasileira de Botânica 25 (3), 269-275.

BORCHERT, R. 1980. Phenology and ecology of a tropical tree Erythryna poeppigiana O. F. Cook. Ecology 61, 1065-1074.

CARDOSO-LEITE, E.; COVRE, T. B.; OMETTO, R. G.; CAVALCANTI, D. C.; PAGANI, M. I. 2004. Fitossociologia e caracterização sucessional de um fragmento de mata ciliar em Rio Claro/SP, como subsídio à recuperação da área. Revista do Instituto Florestal 16 (1), p.3141.

FERNANDES-BULHÃO, C.; FIGUEIREDO P. S. 2002. Fenologia das leguminosas arbóreas em uma área de cerrado marginal no nordeste do Maranhão. Revista Brasileira de Botânica 25 (3), 361-369.

FOURNIER, L. A. 1974. Un método cuantitativo para la medición de características fenológicas en árboles. Turrialba 24 (4), 422-423.

FOURNIER, L. A.; CHARPANTIER, C. 1975. El tamaño de la muestra y la frequencia de las observaciones en el estudio de las caracteristicas fenológicas de los arbores tropicales. Turrialba 25 (1), 45-48.

FRANCO, A. C.; BUSTAMANTE, M.; CALDAS, L. S.; GOLDSTEIN, G.; MEINZER, F. C.; KOZOVITS, A. R.; RUNDEL, P.; CORADIN, V. T. R. 2005. Leaf functional traits of Neotropical savanna trees in relation to seasonal water deficit. Trees 19, 326-335.

GIMENEZ, V. M. M.; GODOY, S. A. P. 2007. Diversidade da Vegetação Regenerante de um Cerrado após Plantio de Exóticas em Luiz Antônio (SP). Revista Brasileira de Biociências 5 (2), p.729-731.

GNU. Boston: Free Software Foundation, 2011. Disponível em: <http://www.gnu.org/software/pspp/pspp.html>. Acesso em: 27 out. 2016.

GÜNTZEL, A. M.; DIAS, N. R.; COERTJENS, C. M.; SILVA, G. C.; VIEIRA, E. A. 2011. Análise fitossociológica de um remanescente de vegetação na microbacia do Córrego Criminoso (Bacia do Rio Taquari, Coxim, MS, Brasil): subsídios para a recomposição da vegetação. Acta Botanica Brasilica 25 (3), 586-592.

INMET. Instituto Nacional de Meteorologia. Normais climatológicas do Brasil 1961 - 1990. Disponível em: <http://www.inmet.gov.br/portal/index.php?r=clima/normaisClimatologicas>. Acesso em: 12 mar. 2017. 
JANZEN, D.H. 1967. Synchronization of sexual reproduction of trees within the dry season in Central America. Evolution 21, 237-260.

JANZEN, D. H. 1971. Seed predation by animals. Annual Review of Ecology and Systematics 2, 465-492.

JORDANO, P. 1993. Fruits and Frugivory. In: FENNER, M. (Ed.). Seeds: the ecology of regeneration in plan communities. Cambridge: CAB Internacional, p.105- 156.

JORDANO, P.; PULIDO, F.; ARROYO, J.; GARCÍA-CASTAÑO, J. L.; GARCÍAFAYOS, P. 2004. Procesos de limitación demográfica. In: VALLADARES, F. (Ed.). Ecología del bosque mediterráneo en un mundo cambiante. Madrid: EGRAF, p.229-248.

KAGEYAMA, P. Y.; CASTRO, C. F. A. 1989. Sucessão secundária, estrutura genética e plantações de espécies arbóreas nativas. IPEF 41/42, 83-93.

LENZA, E.; KLINK, C. A. 2006 Comportamento fenológico de espécies lenhosas em um cerrado sentido restrito de Brasília, DF. Revista Brasileira de Botânica 29 (4), 627-638.

LIETH, H. 1974. Purpose of a phenology book. In: LIETH, H. (Ed.). Phenology and seasonality modeling. Berlin: Springer, 3-19.

LOCARDI, B. 2011. Influência da variação sazonal da temperatura e umidade do solo na germinação de sementes de espécies do cerrado: Xylopia aromatica (Lam.) Mart. (Annonaceae), Banisteriopsis variabilis B. Gates (Malpighiaceae) e Vochysia tucanorum Mart. (Vochysiaceae). Dissertação de Mestrado em Ciências Biológicas, Universidade de Rio Claro, São Paulo, 111 p.

MAAS, P. J. M.; RAINER, H.; LOBÃO, A. Q. 2010. Annonaceae. In: FORZZA, R.C. et al. (Orgs.). Catálogo de plantas e fungos do Brasil. Rio de Janeiro: Jardim Botânico do Rio de Janeiro, p. 602-614.

MANTOVANI, W. MARTINS, F. R. 1988. Variações fenológicas das espécies do cerrado da Reserva Biológica de Mogi-Guaçu, estado de São Paulo. Revista Brasileira de Botânica 11, 101-112.

MARTÍNEZ-RAMOS, M.; SOTO-CASTRO, A. 1993. Seed rain and advanced regeneration in a tropical rain forest. Plant ecology 107-108, 299-318.

MORELLATO, L. P. C.; ROMERA, E. C.; TALORA, D. C.; TAKASHI, A.; BENCKE, C. C., ZIPARRO, V. B. 2000. Phenology of Atlantic rain forest trees: a comparative study. Biotropica 32 (4b), 811-823.

MÜLLER-LANDAU, H. C.; WRIGHT, S. J.; CALDERÓN, O.; CONDIT, R.; HUBBELL, S. P. 2008. Interspecific variation in primary seed dispersal in a tropical forest. Journal of Ecology 96, 653-667.

MUNHOZ, C. R. B.; FELFILI, J. M. 2007. Reproductive phenology of an herbaceous-subshrub layer of a Savannah (Campo Sujo) in the Cerrado Biosphere Reserve I. Brazil. Brazillian Journal of Biology 67 (2), 299-307. 
MÜNZBERGOVA, Z.; HERBEN, T. 2005. Seed, dispersal, microsite, habitat and recruitment limitation: identification of terms and concepts in studies of limitations. Oecologia 14, 1-8.

OLIVEIRA, P. E. A. M. 2008. Fenologia e Biologia Reprodutiva das Espécies de Cerrado. In: SANO, S.M.; ALMEIDA, S.P.; RIBEIRO, J.F. (Ed). Cerrado: ecologia e flora. Brasília: EMBRAPA, p. 275-290.

OLIVEIRA, R. S.; BEZERRA, L.; DAVIDSON, E. A.; PINTO, F.; KLINK, C. A.; NEPSTAD, D. C.; MOREIRA, A. 2005. Deep root function in soil water dynamics in cerrado savannas of central Brazil. Functional Ecology 19 (4), 574-581.

PEDRONI, F.; SANCHEZ, M.; SANTOS, F. A. M. 2002. Fenologia da copaíba (Copaifera langsdorffii Desf. - Leguminosae, Caesalpinioideae) em uma floresta semidecídua no sudeste do Brasil. Revista Brasileira de Botânica 25 (2), 183-194.

RATHKE, B.; LACEY, E. P. 1985. Phenological patterns of terrestrial plants. Annual Review of Ecology and Systematics 16, 179-214.

RATTER, J. A.; RIBEIRO, J. F.; BRIDGEWATER, S. 1997. The Brazilian cerrado vegetation and threats to its biodiversity. Annals of Botany 80 (3), 223-230.

RIZZINI, C. T. 1997. Tratado de fitogeografia do Brasil. Rio de Janeiro: Âmbito Cultural Edições Ltda, $747 \mathrm{p}$.

SAPORETTI JR., A. W.; MEIRA NETO, J. A. A.; ALMADO, R. P. 2003. Fitossociologia de cerrado sensu stricto no município de Abaeté - MG. Revista Árvore 27 (3), 413-419.

SARMIENTO, G.; MONASTERIO, M. 1983. Life forms and phenology. In: BOULIERE, F. (Ed.). Ecosystems of he world: tropical savannas. Amsterdan: Elsevier, p. 79-108.

SCHUPP, E.W. 1995. Seed-seedling conflicts, habitat choise, and patterns of plant recruitment. American Journal of Botany 82, 399-400.

SHIMAKURA, S. E. Interpretação do coeficiente de correlação. Disponível em: <http://leg.ufpr.br/ silvia/CE003/node74.html>. Acesso em: 09 mar. 2017.

SILVA, P. O. 2016. Estratégias fenológicas reprodutivas de Xylopia aromatica (Lam.) Mart. (Annonaceae) em área de cerrado. CERNE 22 (1), 129-136.

SILVA, F. A. M.; ASSAD, E. D.; EVANGELISTA, B. A. 2008. Caracterização Climática do Bioma Cerrado. In: SANO, S. M; ALMEIDA, S. P.; RIBEIRO, J. F. (Eds). Cerrado: ecologia e flora. Brasília: Embrapa, 69-88.

STEVENSON, P. R.; CASTELLANOS, M. C.; CORTÉS, A. I.; LINK, A. 2008. Flowering patterns in a seasonal tropical lowland forest in western Amazonia. Biotropica 40 (5), 559-567.

TALORA, D. C.; MORELLATO, L. P. C. 2000. Fenologia de espécies arbóreas em floresta de planície litorânea do sudeste do Brasil. Revista Brasileira de Botânica 23, 13-26.

TEIXEIRA, M. I. J. G.; ARAUJO, A. R. B.; VALERI, S. V.; RODRIGUES, R. R. 2004. Florística e fitossociologia de área de Cerrado s.s. no município de Patrocínio Paulista, nordeste do estado de São Paulo. Bragantia 63 (1), 1-11. 
WARMING, E. 1908. Lagoa Santa: contribuição para a geographia phytobiologica. Belo Horizonte: Imprensa Oficial do Estado de Minas Gerais, 278 p.

ZAR, J. H. 1999. Biostatistical analysis. 4aed. New Jersey: Prentice-Hall, 663 p. 


\section{CAPÍTULO V}

Dinâmica de regeneração de um remanescente de cerrado stricto sensu localizado em Patrocínio

Paulista - SP 


\section{RESUMO}

O ciclo de vida da maioria das espécies vegetais caracteriza-se pela chegada da semente, germinação, desenvolvimento de um novo indivíduo até a fase reprodutiva, finalizando com a geração e dispersão de novas sementes. A realização desse processo com sucesso garante a manutenção das populações de espécies vegetais e, quando consideradas as diversas populações vegetais, trata-se de regeneração natural. Esse processo é essencial para a manutenção ou restauração da biodiversidade vegetal de uma área. Em virtude do alto grau de antropização de áreas de cerrado stricto sensu é necessário saber se a regeneração natural está ocorrendo de maneira adequada. Dessa forma, o objetivo desse estudo foi comparar a estrutura e composição entre diferentes estratos (adulto, regeneração, banco/chuva de sementes) da vegetação do fragmento de cerrado stricto sensu localizado na Fazenda Santa Cecília, Patrocínio Paulista - SP, em um contexto de dinâmica da regeneração natural. Para isso foi verificada a similaridade florística entre os estratos do fragmento analisado utilizandose o Índice de Sorensen calculado com o software Past. Também se comparou os índices de diversidade dos estratos, incluindo nessa comparação um trabalho realizado na área em 2004 que realizaram estudo fitossociológico do fragmento de cerrado analisado no presente estudo. Calculou-se a Taxa de Regeneração Natural (TRN) com dados de abundância das espécies nos diferentes estratos, comparando-os dois a dois. A análise da similaridade florística indicou, claramente, a composição de três grupos distintos: estrato adulto em 2004, estrato adulto deste estudo e o estrato juvenil mais a chuva de sementes. Esse resultado é derivado de grupos distintos de espécies em cada componente, com uma nítida diminuição da riqueza durante este período. Analisando-se as TRNs percebe-se uma intensa diminuição da biodiversidade vegetal com a extinção local de muitas espécies arbóreas. A interpretação destes resultados permite-nos afirmar que, de acordo com os dados coletados, está ocorrendo uma rápida mudança na composição florística do fragmento analisado, com um intenso decréscimo da biodiversidade e subsequente homogeneização da comunidade vegetal. Estudos específicos sobre a comunidade de espécies polinizadoras e dispersoras, assim como outras análises de indicadores de qualidade ambiental, devem ser realizadas na área visando compreender os fatores que estão provocando a rápida extinção local de espécies lenhosas.

Palavras-chave: taxa de regeneração natural, dinâmica sucessional, diminuição da biodiversidade.

\section{INTRODUÇÃO}

A estrutura da comunidade vegetal de uma área pode ser caracterizada de diferentes maneiras e avaliar a abundância e a distribuição dos indivíduos das espécies no espaço e no tempo é uma possibilidade. A dinâmica das distintas populações de espécies vegetais é responsável, em linhas gerais, pela manutenção de uma população em tamanho viável (Connell et al., 1984) e da biodiversidade em determinada região. Outra característica relevante da dinâmica de uma comunidade vegetal, é o aumento da complexidade estrutural e dos processos ecológicos ao longo do tempo (Chazdon, 2012).

$\mathrm{Na}$ dinâmica vegetal, o fluxo de propágulos inicia todo o processo, determinando as espécies potenciais que ocuparão determinado espaço (Harper, 1977). Martínez-Ramos e Soto-Castro (1993) afirmam que toda a longa sequência de eventos envolvida desde a chegada 
da semente, sua germinação, desenvolvimento de um novo indivíduo até a fase reprodutiva, culminando com a geração e dispersão de novas sementes caracteriza todo o ciclo de vida da maioria das espécies vegetais. Ainda segundo os autores, se realizado com sucesso, esse processo garante a sobrevivência da população e a manutenção de suas características básicas.

O tamanho populacional em cada fase do ciclo de vida é um importante indicativo da possibilidade de substituição de indivíduos (Harper, 1977). Por exemplo, uma população só pode ser mantida em uma região quando existem indivíduos jovens aptos a substituir indivíduos adultos que morram.

Para cada fase de desenvolvimento de uma população existem diferentes condições, bióticas e abióticas, que direcionam a sobrevivência dos indivíduos, afetando diretamente suas taxas de desenvolvimento (Negrelle, 2006; Scherer et al., 2007). É importante destacar que, aliada às condições ambientais, as diferentes fases do ciclo vegetal também possuem diferentes condições fisiológicas e morfológicas. Por exemplo, é bem documentado que a fase inicial do desenvolvimento vegetal (plântula) é uma fase que apresenta alta mortalidade dos indivíduos (Harper, 1977), pois os indivíduos recém germinados são muito influenciados por características ambientais, como a luminosidade e umidade, além de características bióticas relacionadas, basicamente, à densidade populacional (Tabarelli e Mantovani, 1999; Guariguata e Ostertag, 2001).

Os processos descritos até este ponto consideram as espécies de forma isolada. Quando se analisa estes aspectos para várias espécies de uma mesma região em um intervalo de tempo determinado, trata-se da regeneração natural. Pode-se compreender a regeneração natural como o processo de perpetuação das espécies vegetais em uma determinada área, com o intuito de restaurar ou manter a biodiversidade da comunidade vegetal, por meio da dispersão de sementes e do desenvolvimento de indivíduos jovens (Inoue, 1979).

$\mathrm{O}$ conceito regeneração natural pode ter duas interpretações de acordo com Rollet (1978): a primeira indica um componente estrutural do ambiente, um conceito estático que se refere aos estratos jovens (plântulas e juvenis), com tamanho inferior ao estrato adulto; a segunda apresenta um dinamismo, ao significar o processo natural de estabelecimento de novos indivíduos.

Historicamente, o conceito de regeneração natural é bem recente e no início dos estudos dessa área o conceito adotado era o estático. Em 1971, Finol definiu que regeneração natural são todos os indivíduos vegetais arbóreos com até $10 \mathrm{~cm}$ de altura. Outros autores consideram o diâmetro a altura do peito (DAP) como principal característica, considerando os indivíduos com DAP menor do que $5 \mathrm{~cm}$ (Rollet, 1978). Rollet ainda faz uma importante 
ressalva, aumentando o escopo dessa definição, afirmando que a regeneração natural engloba todos os indivíduos juvenis, sendo que os indivíduos com menor DAP são os precursores dos indivíduos de maior DAP, já incluindo uma característica dinâmica ao conceito.

Atualmente, a regeneração natural também é chamada de dinâmica sucessional, valorizando mais o aspecto dinâmico do conceito. Assim, assume-se a pertinência do sistema fonte-escoadouro, onde a fonte é um habitat que, em virtude de suas características naturais, é capaz de produzir um excesso de indivíduos aptos a colonizar outras áreas, e escoadouro, em contrapartida, é o habitat que possui uma menor capacidade em manter uma população em equilíbrio e, dessa forma, há um déficit demográfico. Como não é viável identificar as características ambientais ótimas para cada espécie, individualmente, a abordagem populacional se mostra mais adequada, com análise da variação da densidade de espécies, identificação de novas espécies na área ou a sua extinção (Paglia et al., 2006).

As pesquisas sobre os processos de regeneração natural são fundamentais e possuem aplicabilidade em diversas áreas, como o manejo sustentável, a conservação ou exploração de determinada área natural (Rodrigues et al., 2004). Ao analisar as diferentes fases de desenvolvimento de indivíduos vegetais, iniciando na dispersão de sementes (chuva de sementes), os indivíduos jovens estabelecidos e os indivíduos adultos, pode-se determinar importantes características da área, com a indicação de tendências ou possibilidades referentes, principalmente, à composição florística futura (Carvalho, 1999).

Para qualquer espécie, a produção de descendentes em quantidade e condições viáveis para a sua sobrevivência garante a permanência da espécie no ambiente. Qualquer modificação nesta etapa do ciclo reprodutivo refletirá nas características populacionais básicas, como densidade e riqueza (Begon et al., 2006). A dificuldade ou impossibilidade de se acompanhar uma área natural durante um período de tempo suficiente para detectar mudanças significativas na sua composição e estrutura vegetacional aumenta a importância do estudo do estrato jovem e do banco de sementes (Miyazaki, 2009). Ao se estudar a dinâmica populacional presente em uma área busca-se entender como a dinâmica sucessional está ocorrendo, ou seja, quais as principais mudanças estão ocorrendo ao longo do tempo. Para isso, é fundamental a análise de três processos: ingresso de novos indivíduos e/ou espécies; taxas de mortalidade de indivíduos e/ou espécies; e desenvolvimento dos indivíduos já estabelecidos (Solomon, 1980).

Pode-se compreender ingresso como a quantidade de árvores que surgem em determinada área (Condit et al., 1994) e do ponto de vista da regeneração natural este processo é muito importante pois é ele que vai manter uma população em tamanho adequado para a sua manutenção e equilíbrio (Solomon, 1980). Já a diminuição da população, que em 
grau mais avançado pode resultar na extinção da espécie, indica a mortalidade dos indivíduos daquela população (Odum, 1983). Em áreas preservadas, onde os distúrbios antrópicos não estão presentes, a dinâmica da regeneração é direcionada por características próprias do bioma ou da região específica definidos, basicamente, pela estrutura e interação entre as espécies vegetais e animais (Glenn-Lewin et al., 1992). Entretanto, atualmente poucas áreas se mantem livres de influência antrópica direta ou indireta, ainda mais se tratando de áreas de Cerrado (Myers et al., 2000).

Os dados da flutuação populacional são importantes indicadores do estado de conservação de uma área, destacando-se a mortalidade, pois sabe-se que além das características genéticas e fisiológicas próprias da espécie, aspectos ambientais influenciam diretamente na definição da taxa de mortalidade. Em áreas antropizadas, ainda não se sabe de forma completa como a interação entre fatores genéticos e fisiológicos ocorre após o estabelecimento de novas características ambientais geradas após uma alteração (Brokaw, 1982), sendo uma importante área de estudos conservacionistas. Em áreas sob influência antrópica, as características básicas da dinâmica da regeneração natural serão modificadas de acordo com o tipo e a extensão das perturbações realizadas, pois sabe-se que as alterações antrópicas em ambientes naturais tem uma série de efeitos bióticos, como alterações na produção de propágulos, diminuição de agentes dispersores, aumento da predação de plântulas, dentre outros (Toriola et al., 1998), além das modificações em condições abióticas, como aspectos microclimáticos e condições físico-químicas do solo (Sorreano, 2002).

Os biomas tropicais, devido à sua complexidade, são desafiantes para a ciência atual, mesmo com todos os avanços metodológicos disponíveis. Assim, há sempre a necessidade de mais informações sobre estes ambientes, ainda mais no Brasil, onde grande parte das áreas naturais remanescentes estão inseridas em uma matriz antropizada com diferentes níveis de perturbação e sem preocupação quanto à sua conservação (Santos e Jardim, 2012).

Para dificultar a identificação dos diferentes processos ecológicos presentes em remanescentes naturais, além do processo de sucessão natural secundária, há aspectos relacionados à fragmentação e impactos ambientais, todos agindo em sinergia. Assim, é fundamental conhecer com mais clareza como os processos relacionados à regeneração natural estão acontecendo nessas áreas (Souza et al., 2002). Atualmente, sabe-se que as características ecofisiológicas das espécies vegetais apresenta íntima relação com as modificações na composição vegetacional dos fragmentos, pois estas características definirão os limites ambientais nos quais determinada espécie consegue sobreviver (Jardim et al., 1993). Assim, as alterações antrópicas provocadas em áreas naturais, sua intensidade e frequência, 
alterando aspectos ambientais nas áreas fragmentadas, tornam-se forças seletivas, determinando a direção da sucessão natural (Araújo et al., 2001).

Dessa forma, dado o atual estado de fragmentação de áreas naturais, assim como as pressões antrópicas em fragmentos, é fundamental conhecer a composição dos diferentes estratos dessas áreas, oferecendo uma perspectiva da sucessão natural ao longo do tempo. Essas informações são fundamentais para subsidiar ações de planejamento para a conservação ou recuperação de áreas naturais fragmentadas (Rodrigues, 1999; Paglia et al., 2006).

\section{HIPÓTESE}

As espécies vegetais lenhosas no fragmento estão obtendo sucesso no seu ciclo reprodutivo, mantendo a quantidade de espécies relativamente estável ao longo do tempo já que o fragmento analisado possui área suficiente para manter tais processos e não é alvo de ações antrópicas de forma direta.

\section{OBJETIVOS ESPECÍFICOS}

Comparar a estrutura e composição entre diferentes estratos (adulto, regeneração, banco/chuva de sementes) da vegetação do fragmento de cerrado stricto sensu localizado na Fazenda Santa Cecília, Patrocínio Paulista - SP, em um contexto de dinâmica da regeneração natural.

\section{MATERIAL E MÉTODOS}

\subsection{Similaridade florística entre estratos}

Para se verificar a semelhança da composição florística entre os diversos estratos do fragmento de cerrado analisado foi realizada uma análise de similaridade utilizando-se o Índice de Sorensen com o software Past (Hammer, 2001) e elaborado um dendrograma com agrupamento por média de grupo. Para esta análise foram considerados os dados da chuva de sementes, estrato de regeneração, estrato adulto do presente estudo e, para aumentar a escala temporal da análise, utilizou-se o trabalho de Teixeira et al. (2004), único estudo fitossociológico realizado anteriormente no fragmento de cerrado stricto sensu da Fazenda Santa Cecília. 
Para enriquecer a comparação entre os estratos, também se comparou os valores das medidas de diversidade utilizando-se o índice de diversidade de Shannon e Weaver $\left(\mathrm{H}^{\prime}\right)$, índice de concentração de Simpson e o índice de equabilidade de Pielou (Magurran, 1988). Como Teixeira et al. (2004) apenas apresentou o valor de $\mathrm{H}^{\prime}$, este foi a única medida de diversidade utilizada na comparação com esse estudo.

Também comparou-se a distribuição das espécies de cada estrato nas síndromes de dispersão de sementes (autocoria, barocoria ou zoocoria) e seu grupo ecológico (pioneira, secundária inicial, secundária tardia, clímax e sub-bosque), visando caracterizar importantes aspectos ecológicos do fragmento e que fornecem importantes informações sobre o processo de regeneração.

\subsection{Taxa de regeneração natural}

O comportamento da regeneração natural foi verificado pela determinação da Taxa de Regeneração Natural (TRN) com o uso de cálculo proposto por Mory (2000), utilizando dados de abundância das espécies nos diferentes estratos, de acordo com a equação abaixo:

$$
T R N \%=\frac{\left(A_{2}-A_{1}\right)}{\left(A_{2}+A_{1}\right)} \times 100
$$

Em que:

TRN = taxa de regeneração natural;

$\mathrm{A}_{1}=$ abundância absoluta no estrato 1 ;

$\mathrm{A}_{2}=$ abundância absoluta no estrato 2 .

Para isso, comparou-se os estratos estudados neste estudo dois a dois (estrato adulto amostrado por Teixeira et al. (2004) e estrato adulto deste estudo; e estrato adulto deste estudo com estrato de regeneração. Os dados referentes à chuva de sementes e fenologia serão considerados para complementar a análise, indicando possíveis tendências e/ou gargalos demográficos. Estas análises permitem identificar se as espécies apresentam um comportamento regenerativo de estabilidade, diminuição ou aumento populacional.

De acordo com Jardim (1987), espécies com valores da taxa de regeneração natural positivos indicam que a população está aumentando; valores negativos indicam diminuição da população; e valores igual a zero indicam estabilidade populacional. 
Para as análises da taxa de regeneração não foram utilizados dados relacionados à chuva de sementes, pois as sementes podem ser consideradas indivíduos potenciais, ainda não pertencentes ao processo de regeneração efetivamente. Assim, a chuva de sementes, assim como os dados fenológicos, serão utilizados como indicadores do processo de regeneração natural.

\section{RESULTADOS}

\subsection{Similaridade florística entre estratos}

A análise da similaridade florística indicou, claramente, a composição de três grupos distintos: estrato adulto em 2004, estrato adulto deste estudo e o estrato de regeneração mais a chuva de sementes (Figura 1). O grupo formado pelo estrato adulto amostrado por Teixeira et al. (2004) apresenta-se bem distinto do estrato adulto do presente estudo, fato demonstrado pela distância entre os dois componentes (primeiro nó do dendrograma). 0 segundo grupo, formado pelo estrato adulto deste estudo apresenta uma baixa similaridade com o estrato regenerativo, conforme nos indica a distância apresentada no dendrograma. Já o estrato de regeneração e a chuva de sementes formam um único grupo, apresentando uma similaridade florística mais forte.

A interpretação destes resultados permite-nos afirmar que, de acordo com os dados coletados, está ocorrendo uma rápida mudança na composição florística do fragmento analisado. Em uma década o componente adulto apresentou mudanças tão significativas que, de acordo com a análise realizada, permite-nos afirmar que se tratam de duas áreas distintas quando, na realidade, os estudos foram realizados no mesmo fragmento. Essa tendência de modificação temporal da composição florística é confirmada quando se inclui os componentes de regeneração na análise, já que o estrato regenerativo apresenta uma composição florística distinta do atual estrato adulto. 
Figura 1 - Dendrograma dos índices de similaridade de Sorensen dos diferentes estratos do fragmento de cerrado stricto sensu da Fazenda Santa Cecília, Patrocínio Paulista - SP.

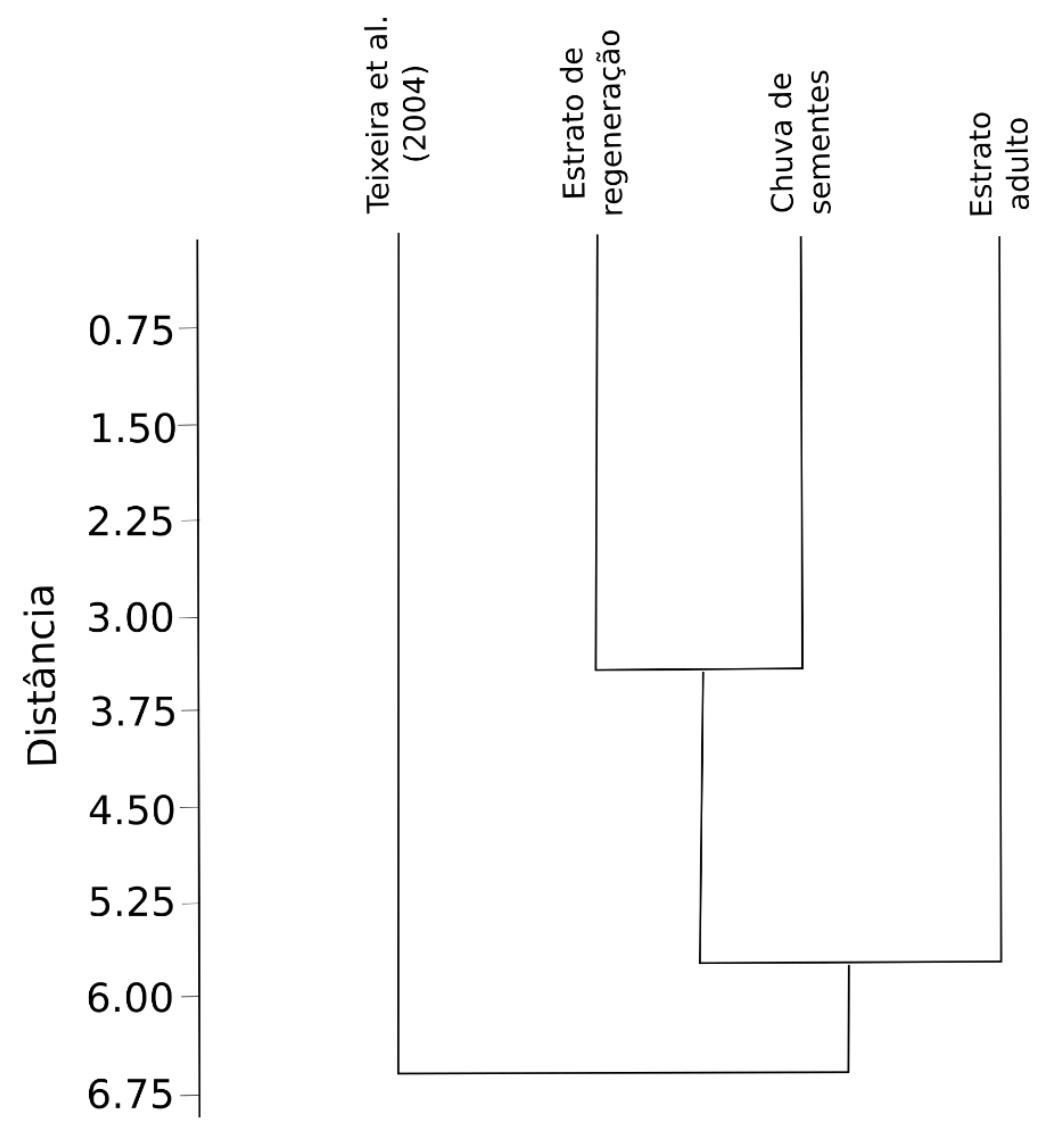

As espécies amostradas em cada um dos estratos mencionados, suas características ecológicas, e respectivos valores de importância no estrato adulto em 2004 e 2014 podem ser encontradas na Tabela 1.

Tabela 1 - Espécies e respectivas famílias amostradas no cerrado stricto sensu na Fazenda Santa Cecília, Patrocínio Paulista - SP. 1: espécie amostrado no estrato adulto por Teixeira et al. (2004). 2: espécie amostrado no estrato adulto neste estudo. 3: espécie amostrada no estrato de regeneração. 4: espécie amostrada na chuva de sementes. SD: síndrome de dispersão; ZOO: zoocórica; ANE: anemocórica, AUT: autocórica; GE: grupo ecológico; P: pioneira, SI: secundário inicial, ST: secundária tardia, C: clímax; SB: sub-bosque. $\mathrm{VI}^{1}$ : Valor de Importância para o estrato adulto encontrado em Teixeira et al. (2004). VI²: Valor de Importância para o estrato adulto encontrado neste estudo.

\begin{tabular}{lccccc}
\hline \multicolumn{1}{c}{ FAMÍLIA / Espécie } & Amostras & SD & GE & VI $^{1}$ & VI $^{2}$ \\
\hline ANACARDIACEAE & 1,2 & ZOO & ST & 1,47 & 2,37 \\
$\begin{array}{l}\text { Tapirira guianensis Aubl. } \\
\text { ANNONACEAE }\end{array}$ & 1 & ZOO & $\mathrm{P}$ & 1,83 & - \\
$\begin{array}{l}\text { Annona crassiflora Mart. } \\
\text { Xylopia aromatica (Lam.) Mart. }\end{array}$ & $1,2,3,4$ & ZOO & P & 1,21 & 45,12 \\
\hline
\end{tabular}




\begin{tabular}{|c|c|c|c|c|c|}
\hline FAMíLIA / Espécie & Amostras & SD & GE & $V \mathbf{I}^{1}$ & $\mathrm{VI}^{2}$ \\
\hline $\begin{array}{l}\text { Xylopia sericea A.St.-Hil. } \\
\text { APOCYNACEAE }\end{array}$ & $1,2,3,4$ & ZOO & $\mathrm{SI}$ & 1,18 & 23,53 \\
\hline $\begin{array}{l}\text { Aspidosperma tomentosum Mart. } \\
\text { ASTERACEAE }\end{array}$ & 1,2 & ANE & $\mathrm{C}$ & 0,59 & 2,94 \\
\hline $\begin{array}{l}\text { Gochnatia polymorpha (Less.) Cabrera } \\
\text { BIGNONIACEAE }\end{array}$ & 1 & ANE & $P$ & 2,20 & - \\
\hline $\begin{array}{l}\text { Tabebuia ochracea (Cham.) Standl. } \\
\text { CAESALPINIACEAE }\end{array}$ & 1 & ANE & $P$ & 0,59 & - \\
\hline $\begin{array}{l}\text { Bauhinia rufa (Bng.) Steud. } \\
\text { CARYOCARACEAE }\end{array}$ & 1 & AUTO & $\mathrm{SI}$ & 0,59 & - \\
\hline $\begin{array}{l}\text { Caryocar brasiliense A.St.-Hil. } \\
\text { CELASTRACEAE }\end{array}$ & 1,2 & ZOO & ST & 1,72 & 2,24 \\
\hline $\begin{array}{l}\text { Austroplenckia populnea (Reiss.) Lund } \\
\text { CHRYSOBALANACEAE }\end{array}$ & 1 & ANE & $\mathrm{SI}$ & 0,72 & - \\
\hline $\begin{array}{l}\text { Hirtella glandulosa Spreng. } \\
\text { CLUSIACEAE }\end{array}$ & 2,3 & ZOO & $\mathrm{C}$ & - & 1,56 \\
\hline $\begin{array}{l}\text { Clusia sp } \\
\text { CONNARACEAE }\end{array}$ & 2 & - & - & - & 0,75 \\
\hline $\begin{array}{l}\text { Connarus suberosus Planch. } \\
\text { EBENACEAE }\end{array}$ & 1 & ZOO & $\mathrm{P}$ & 0,61 & - \\
\hline $\begin{array}{l}\text { Diospyros hispida A.DC. } \\
\text { ERYTHROXYLACAEAE }\end{array}$ & 1,2 & ZOO & $\mathrm{SI}$ & 1,22 & 1,32 \\
\hline Erythroxylum suberosum A.St.-Hil. & 1,2 & ZOO & SB & 1,29 & 0,7 \\
\hline $\begin{array}{l}\text { Erythroxylum tortuosum Mart. } \\
\text { FABACEAE }\end{array}$ & 1 & ZOO & $P$ & 1,23 & - \\
\hline Acosmium dasycarpum (Vogel) Yakovlev & $1,2,3$ & ANE & $\mathrm{SI}$ & 3,36 & 0,62 \\
\hline Acosmium subelegans (Mohlenbr.) & 1,2 & ANE & $P$ & 4,08 & 0,61 \\
\hline Andira humilis Mart. ex Benth. & 2,3 & ZOO & SB & - & 0,57 \\
\hline Bowdichia virgilioides Kunth & 1,2 & AUT & ST & 9,79 & 3,13 \\
\hline Copaifera langsdorffii Desf. & $1,2,3$ & ZOO & ST & 4,82 & 14,87 \\
\hline Dalbergia miscolobium Benth. & $1,2,3$ & ANE & $P$ & 22,24 & 11,6 \\
\hline Dimorphandra mollis Benth. & 1,2 & ANE & $P$ & 3,66 & 2,91 \\
\hline Machaerium villosum Vogel & 1 & ANE & ST & 0,64 & - \\
\hline Platypodium elegans Vogel & 1 & ANE & $\mathrm{P}$ & 1,96 & - \\
\hline Pterocarpus violaceus Vogel & 2 & ANE & $\mathrm{SI}$ & - & 1,28 \\
\hline Pterodon emarginatus Vogel & $1,2,3$ & ANE & $\mathrm{SI}$ & 4,11 & 20,64 \\
\hline Senna rugosa (G. Don) H.S.Irwin e Barneby & 2,3 & AUT & SB & - & 1,27 \\
\hline Stryphnodendron adstringens (Mart.) Coville & 1,2 & AUT & ST & 3,30 & 0,57 \\
\hline $\begin{array}{l}\text { Stryphnodendron polyphyllum Mart. } \\
\text { FLACOURTIACEAE }\end{array}$ & 2 & AUT & $\mathrm{SI}$ & - & 0,58 \\
\hline $\begin{array}{l}\text { Casearia sylvestris Sw. } \\
\text { LAURACEAE }\end{array}$ & 1 & ZOO & $P$ & 0,63 & - \\
\hline Ocotea corymbosa (Meisn.) Mez & $1,2,3$ & ZOO & ST & 18,02 & 2,6 \\
\hline $\begin{array}{l}\text { Ocotea pulchella (Nees e Mart.) Mez } \\
\text { MALPIGHIACEAE }\end{array}$ & 1,2 & ZOO & ST & 3,04 & 1,65 \\
\hline Byrsonima coccolobifolia Kunth. & 1 & ZOO & $\mathrm{C}$ & 2,33 & - \\
\hline $\begin{array}{l}\text { Byrsonima intermedia A. Juss. } \\
\text { MALVACEAE }\end{array}$ & 1,2 & ZOO & SB & 2,08 & 0,58 \\
\hline Eriotheca gracilipes (K.Schum.) A.Robyns & 2 & ANE & SI & - & 0,63 \\
\hline
\end{tabular}




\begin{tabular}{|c|c|c|c|c|c|}
\hline FAMÍLIA / Espécie & Amostras & SD & GE & $V I^{1}$ & $\mathrm{VI}^{2}$ \\
\hline \multicolumn{6}{|l|}{ MELASTOMATACEAE } \\
\hline Miconia albicans (Sw.) Steud. & $1,2,3,4$ & ZOO & SB & 0,59 & 4,13 \\
\hline $\begin{array}{l}\text { Miconia ligustroides (DC.) Naud. } \\
\text { MONIMIACEAE }\end{array}$ & 1 & ZOO & $P$ & 1,20 & - \\
\hline $\begin{array}{l}\text { Siparuna guianensis Aubl. } \\
\text { MORACEAE }\end{array}$ & 1 & ZOO & SB & 0,87 & - \\
\hline $\begin{array}{l}\text { Brosimum gaudichaudii Trécul } \\
\text { MYRISTICACEAE }\end{array}$ & 2 & ZOO & $P$ & - & 0,61 \\
\hline $\begin{array}{l}\text { Virola sebifera Aubl. } \\
\text { MYRSINACEAE }\end{array}$ & $1,2,3,4$ & ZOO & $P$ & 5,88 & 6,95 \\
\hline $\begin{array}{l}\text { Rapanea guianensis Aubl. } \\
\text { MYRTACEAE }\end{array}$ & 1 & ZOO & $P$ & 1,62 & - \\
\hline Myrcia bella Cambess. & 1 & ZOO & $P$ & 5,43 & - \\
\hline Myrcia lasiantha DC. & 1,2 & ZOO & ST & 3,31 & 1,37 \\
\hline Myrcia rostrata DC. & 1 & ZOO & $\mathrm{P}$ & 7,54 & - \\
\hline Myrcia tomentosa (Aubl.) DC. & 1 & ZOO & ST & 2,70 & - \\
\hline $\begin{array}{l}\text { Myrcia variabilis (Mart.) ex DC. } \\
\text { NYCTAGINACEAE }\end{array}$ & 1,2 & ZOO & ST & 5,11 & 0,58 \\
\hline $\begin{array}{l}\text { Guapira noxia (Netto) Lundell } \\
\text { OCHNACEAE }\end{array}$ & 1,2 & ZOO & SI & 0,61 & 0,66 \\
\hline $\begin{array}{l}\text { Ouratea spectabilis (Mart. ex Engl.) Engl. } \\
\text { PERACEAE }\end{array}$ & 1,2 & ZOO & ST & 5,32 & 3,13 \\
\hline $\begin{array}{l}\text { Pera glabrata (Schott) Poepp. ex Baill. } \\
\text { PRIMULACEAE }\end{array}$ & 2 & ZOO & $\mathrm{P}$ & - & 2,21 \\
\hline $\begin{array}{l}\text { Myrsine guianensis (Aubl.) Kuntz } \\
\text { RUBIACEAE }\end{array}$ & 2 & ZOO & $P$ & - & 0,61 \\
\hline Alibertia sessilis (Cham.) K. Schum. & 1 & ZOO & SB & 0,70 & - \\
\hline $\begin{array}{l}\text { Cordiera sessilis (Vell.) Kuntze } \\
\text { RUTACEAE }\end{array}$ & 2 & ZOO & $\mathrm{SI}$ & - & 0,6 \\
\hline $\begin{array}{l}\text { Zanthoxylum rhoifolium Lam. } \\
\text { SAPINDACEAE }\end{array}$ & 1 & ZOO & SI & 0,60 & - \\
\hline $\begin{array}{l}\text { Cupania vernalis Cambess } \\
\text { STYRACACEAE }\end{array}$ & 2,3 & ZOO & SI & - & 0,65 \\
\hline Styrax camporum Pohl & 1,2 & ZOO & ST & 21,86 & 2,52 \\
\hline Styrax ferrugineus Nees e Mart. & $1,2,3$ & ZOO & ST & 0,61 & 2,09 \\
\hline Styrax pohlii A.DC. & 2,3 & ZOO & ST & - & 1,34 \\
\hline SYMPLOCACEAE & & & & & \\
\hline $\begin{array}{l}\text { Symplocos pubescens KI. ex Benth. } \\
\text { THEACEAE }\end{array}$ & 1 & AUTO & $\mathrm{SI}$ & 0,89 & - \\
\hline Kielmeyera coriacea (Spreng.) Mart. & 1 & ANE & $\mathrm{C}$ & 3,20 & - \\
\hline $\begin{array}{l}\text { Kielmeyera variabilis Mart. } \\
\text { VERBENACEAE }\end{array}$ & 1 & ANE & SI & 2,10 & - \\
\hline $\begin{array}{l}\text { Aegiphila Ihotskiana Cham. } \\
\text { VOCHYSIACEAE }\end{array}$ & 1 & ZOO & SB & 6,49 & - \\
\hline Qualea cordata Spreng. & 1 & ANE & $\mathrm{P}$ & 8,33 & - \\
\hline Qualea grandiflora Mart. & $1,2,3,4$ & ANE & $P$ & 62,38 & 48,34 \\
\hline Qualea jundiahy Warm. & 2,4 & ANE & ST & - & 34,32 \\
\hline Qualea multiflora Mart. & $1,2,4$ & ANE & ST & 11,46 & 6,84 \\
\hline Qualea parviflora Mart. & $1,2,3,4$ & ANE & ST & 14,97 & 3,78 \\
\hline
\end{tabular}


Comparando as características populacionais quantitativas do estrato adulto amostrado por Teixeira et al. (2004) com os dados do presente estudo há indicativo de uma alteração na diversidade vegetal (Tabela 2 ).

Tabela 2 - Características populacionais quantitativas do estrato adulto amostrado por Teixeira et al. (2004) e pelo presente estudo.

\begin{tabular}{lcc}
\hline Característica populacional & $\begin{array}{c}\text { Teixeira et al. } \\
\text { (2004) }\end{array}$ & presente estudo \\
\hline Número de indivíduos & 511 & 729 \\
Número de espécies & 53 & 44 \\
Número de gêneros & 38 & 34 \\
Número de famílias & 30 & 24 \\
\hline
\end{tabular}

Considerando os dois estudos, foram amostradas na área 67 espécies, distribuídas em 36 famílias, sendo que o número de espécies em cada levantamento variou de 53, em 2004, para 44 espécies em 2014. Além da diferença quantitativa na diversidade, a composição e importância das espécies também foram alteradas, destacando-se as famílias com maior riqueza. Em Teixeira et al. (2004) a família Fabaceae apresentou a maior riqueza, composta por sete espécies, Myrtaceae cinco espécies e Vochysiaceae quatro espécies. No presente estudo a família Fabaceae apresentou 12 espécies, Myrtaceae apenas duas espécies e Vochysiaceae quatro espécies, destacando-se Qualea grandiflora como a espécie mais frequente nos dois estudos. Esse cenário resultou em uma baixa similaridade florística entre os estudos, situação não esperada para estudos realizados em um mesmo fragmento com um intervalo de tempo de apenas uma década.

A diminuição da biodiversidade vegetal e da similaridade florística é nítida quando comparamos a composição do atual estrato adulto com o estrato de regeneração. Como apresentado anteriormente, o estrato adulto atual possui 44 espécies, enquanto o estrato de regeneração 17 espécies. Na análise de similaridade florística, o estrato de regeneração foi mais relacionado com a chuva de sementes do que com o estrato adulto. Para completar a análise da diversidade, na chuva de sementes foram identificadas apenas 8 espécies. A Figura 2, construída com o valor absoluto de espécies amostradas em cada estrato, demonstra claramente a diminuição da biodiversidade no fragmento de cerrado stricto sensu analisado. 
Figura 2 - Quantidade de espécies lenhosas em diferentes estratos em fragmento de cerrado stricto sensu da Fazenda Santa Cecília, Patrocínio Paulista - SP.

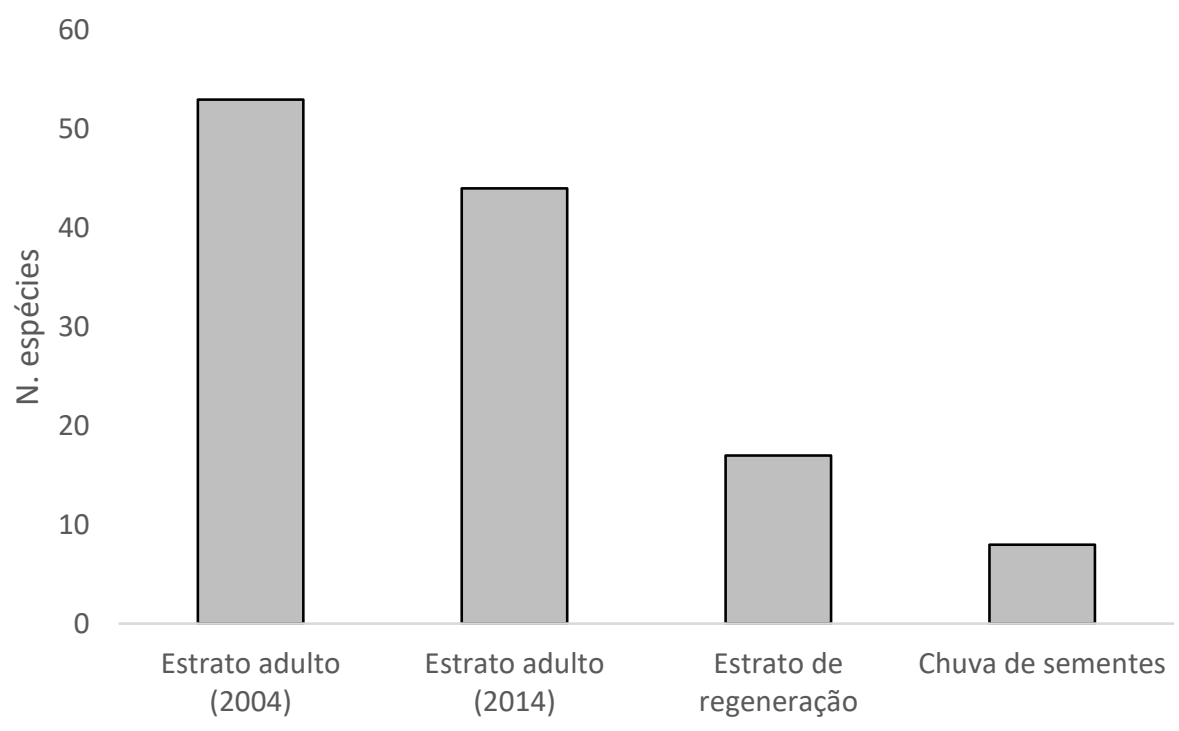

Quando analisadas as distribuições das espécies nas categorias de síndrome de dispersão e grupo ecológico temporalmente e entre os estratos atuais foram detectadas relevantes alterações (Tabela 3). Na comparação temporal (estratos adultos de 2004 e 2014) das síndromes de dispersão identificou-se discreta diminuição das proporções de espécies anemocóricas e zoocóricas e um aumento das espécies autocóricas. Seguindo a comparação temporal, foram identificadas uma clara diminuição das espécies pioneiras e um incremento das espécies secundárias (inicial e tardia). As alterações das proporções das espécies de subbosque e clímax foram pequenas.

Quando comparados os estratos adulto e de regeneração não se identifica uma tendência clara, pois no estrato de regeneração a distribuição das espécies pode ser considerada bem semelhante com aquela encontrada no estrato adulto com exceção das espécies secundárias tardias. Já na chuva de sementes há diferenças claras quando comparadas aos outros estratos, como o grande aumento de espécies anemocóricas em detrimento de espécies zoocóricas e o aumento de espécies pioneiras e secundária tardia.

A alteração da composição florística apontada pela análise de similaridade é confirmada quando se comparam as medidas de diversidade entre os estratos e temporalmente (utilizando o índice de Shannon e Weaver apresentado por Teixeira et al. 2004). Mais do que simplesmente confirmar a análise de similaridade, estes dados indicam uma diminuição da diversidade vegetal no fragmento de cerrado (Tabela 4). 
Tabela 3 - Distribuição das espécies amostradas segundo suas características ecológicas em cada componente da vegetação de fragmento de cerrado stricto sensu localizado no município de Patrocínio Paulista - SP.

\begin{tabular}{lcccc}
\hline $\begin{array}{c}\text { Aspecto } \\
\text { ecológico }\end{array}$ & $\begin{array}{c}\text { Estrato adulto } \\
\mathbf{2 0 0 4}(\%)\end{array}$ & $\begin{array}{c}\text { Estrato adulto } \\
\mathbf{2 0 1 4}(\%)\end{array}$ & $\begin{array}{c}\text { Estrato de } \\
\text { regeneração (\%) }\end{array}$ & $\begin{array}{c}\text { Chuva de } \\
\text { sementes (\%) }\end{array}$ \\
\hline Anemocoria & 32,7 & 29,3 & 29,4 & 50 \\
Autocoria & 5,8 & 9,8 & 5,9 & 0 \\
Zoocoria & 61,5 & 61,0 & 64,7 & 50 \\
Pioneira & 36,5 & 21,4 & 23,5 & 37,5 \\
Secundária inicial & 17,3 & 23,8 & 23,5 & 12,5 \\
Secundária tardia & 28,8 & 38,1 & 29,4 & 37,5 \\
Clímax & 5,8 & 4,8 & 5,9 & 0 \\
Sub-bosque & 11,5 & 11,9 & 17,6 & 12,5 \\
\hline
\end{tabular}

Tabela 4 - Valores dos índices de diversidade dos estratos adulto, de regeneração, chuva de sementes do presente estudo e do estrato adulto encontrado no trabalho de Teixeira et al. (2004). H': Índice de Shannon e Weaver.

\begin{tabular}{lcccc}
\hline $\begin{array}{c}\text { Índice de } \\
\text { diversidade }\end{array}$ & $\begin{array}{c}\text { Teixeira et al. } \\
(\mathbf{2 0 0 4 )}\end{array}$ & $\begin{array}{c}\text { Estrato } \\
\text { adulto }\end{array}$ & $\begin{array}{c}\text { Estrato de } \\
\text { regeneração }\end{array}$ & $\begin{array}{c}\text { Chuva de } \\
\text { sementes }\end{array}$ \\
\hline Shannon e Weaver & 3,05 & 2,54 & 2,27 & 1,60 \\
Simpson & - & 0,88 & 0,87 & 0,26 \\
Pielou & - & 0,67 & 0,78 & 0,77 \\
\hline
\end{tabular}

Analisando-se os índices de diversidade percebe-se o nítido decréscimo da biodiversidade entre os componentes analisados, o que nos permite afirmar que, se a situação se mantiver da mesma maneira, em poucos anos a diversidade local será drasticamente diminuída e haverá uma uniformização da biodiversidade, com poucas espécies apresentando uma grande quantidade de indivíduos.

Com relação à distribuição das espécies segundo o grupo ecológico no estrato adulto as espécies secundárias representam $61,9 \%$ das espécies amostradas, seguidas das pioneiras. No estrato de regeneração percebe-se uma diminuição das espécies secundárias (52,9\%) e um aumento das espécies de sub-bosque. Este aumento pode estar relacionado ao método utilizado na amostragem do estrato de regeneração que incluiu indivíduos com diâmetro de caule menor, quando comparado ao método de inclusão dos indivíduos do estrato adulto. Já na chuva de sementes há um equilíbrio entre espécies pioneiras e secundárias tardias, não sendo amostrada nenhuma espécie clímax. 


\subsection{Taxa de Regeneração Natural (TRN)}

Analisando-se as TRNs das espécies lenhosas amostradas no fragmento de cerrado stricto sensu da Fazenda Santa Cecília a tendência para a diminuição da diversidade indicada anteriormente, com a exclusão de muitas espécies, foi confirmada. A Tabela 5 apresenta os resultados das TRNs calculadas para duas situações: entre os estratos adultos amostrados por Teixeira et al. (2004) e este estudo; e entre os estratos adulto e de regeneração amostrados no presente estudo.

Tabela 5 - Taxas de Regeneração Natural (TRN), em porcentagem, de espécies lenhosas encontradas em um fragmento de cerrado stricto sensu localizado na Fazenda Santa Cecília, Patrocínio Paulista - SP. (1): TRN entre estrato adulto amostrado por Teixeira et al. (2004) e o estrato adulto do presente estudo; (2) TRN entre o estrato adulto do presente estudo e o estrato de regeneração; ( - ): espécie amostrada apenas em Teixeira et al. (2004).

\begin{tabular}{|c|c|c|}
\hline Família/Espécie & TRN\% (1) & TRN\% (2) \\
\hline \multicolumn{3}{|l|}{ ANACARDIACEAE } \\
\hline Tapirira guianensis & 33,3 & $-100,0$ \\
\hline \multicolumn{3}{|l|}{ ANNONACEAE } \\
\hline Annona crassiflora & $-100,0$ & - \\
\hline Xylopia aromatica & 97,6 & $-62,2$ \\
\hline Xylopia sericea & 94,4 & $-45,8$ \\
\hline \multicolumn{3}{|l|}{ APOCYNACEAE } \\
\hline Aspidosperma tomentosum & 33,3 & $-100,0$ \\
\hline \multicolumn{3}{|l|}{ ASTERACEAE } \\
\hline Gochnatia polymorpha & $-100,0$ & - \\
\hline \multicolumn{3}{|l|}{ BIGNONIACEAE } \\
\hline Tabebuia ochracea & $-100,0$ & - \\
\hline \multicolumn{3}{|l|}{ CAESALPINIACEAE } \\
\hline Bauhinia rufa & $-100,0$ & - \\
\hline \multicolumn{3}{|l|}{ CARYOCARACEAE } \\
\hline Caryocar brasiliense & 14,3 & $-100,0$ \\
\hline \multicolumn{3}{|l|}{ CELASTRACEAE } \\
\hline Austroplenckia populnea & $-100,0$ & - \\
\hline \multicolumn{3}{|l|}{ CHRYSOBALANACEAE } \\
\hline Hirtella glandulosa & 100,0 & 0,0 \\
\hline \multicolumn{3}{|l|}{ CLUSIACEAE } \\
\hline Clusia sp & 100,0 & $-100,0$ \\
\hline \multicolumn{3}{|l|}{ CONNARACEAE } \\
\hline Connarus suberosus & $-100,0$ & - \\
\hline \multicolumn{3}{|l|}{ EBENACEAE } \\
\hline Diospyros hispida & 0,0 & $-100,0$ \\
\hline
\end{tabular}




\begin{tabular}{|c|c|c|}
\hline Família/Espécie & TRN\% (1) & TRN\% (2) \\
\hline \multicolumn{3}{|l|}{ ERYTHROXYLACAEAE } \\
\hline Erythroxylum suberosum & $-33,3$ & $-100,0$ \\
\hline Erythroxylum tortuosum & $-100,0$ & - \\
\hline \multicolumn{3}{|l|}{ FABACEAE } \\
\hline Acosmium dasycarpum & $-71,4$ & 0,0 \\
\hline Acosmium subelegans & $-50,0$ & $-100,0$ \\
\hline Andira humilis & 100,0 & 33,3 \\
\hline Bowdichia virgilioides & $-14,3$ & $-100,0$ \\
\hline Copaifera langsdorffii & 69,2 & $-33,3$ \\
\hline Dalbergia miscolobium & $-47,4$ & $-76,5$ \\
\hline Dimorphandra mollis & 9,1 & $-100,0$ \\
\hline Machaerium villosum & $-100,0$ & - \\
\hline Platypodium elegans & $-100,0$ & - \\
\hline Pterocarpus violaceus & 100,0 & $-100,0$ \\
\hline Pterodon emarginatus & 66,7 & $-56,3$ \\
\hline Senna rugosa & 100,0 & $-50,0$ \\
\hline Sthyphnodendron adstringens & $-66,7$ & - \\
\hline Stryphnodendron polyphyllum & 100,0 & $-100,0$ \\
\hline \multicolumn{3}{|l|}{ FLACOURTIACEAE } \\
\hline Casearia sylvestris & $-100,0$ & - \\
\hline \multicolumn{3}{|l|}{ LAURACEAE } \\
\hline Ocotea corymbosa & $-72,4$ & $-60,0$ \\
\hline Ocotea pulchella & $-11,1$ & $-100,0$ \\
\hline \multicolumn{3}{|l|}{ MALPIGHIACEAE } \\
\hline Byrsonima coccolobifolia & $-100,0$ & - \\
\hline Byrsonima intermedia & $-60,0$ & $-100,0$ \\
\hline \multicolumn{3}{|l|}{ MALVACEAE } \\
\hline Eriotheca gracilipes & 100,0 & $-100,0$ \\
\hline \multicolumn{3}{|l|}{ MELASTOMATACEAE } \\
\hline Miconia albicans & 83,3 & 60,0 \\
\hline Miconia ligustroides & $-100,0$ & - \\
\hline \multicolumn{3}{|l|}{ MONIMIACEAE } \\
\hline Siparuna guianensis & $-100,0$ & - \\
\hline \multicolumn{3}{|l|}{ MORACEAE } \\
\hline Brosimum gaudichaudii & 100,0 & $-100,0$ \\
\hline \multicolumn{3}{|l|}{ MYRISTICACEAE } \\
\hline Virola sebifera & 18,5 & 23,8 \\
\hline \multicolumn{3}{|l|}{ MYRSINACEAE } \\
\hline Rapanea guianensis & $-100,0$ & - \\
\hline \multicolumn{3}{|l|}{ MYRTACEAE } \\
\hline Myrcia bella & $-100,0$ & - \\
\hline Myrcia lasiantha & $-25,0$ & $-100,0$ \\
\hline Myrcia rostrata & $-100,0$ & - \\
\hline
\end{tabular}




\begin{tabular}{|c|c|c|}
\hline Família/Espécie & TRN\% (1) & TRN\% (2) \\
\hline Myrcia tomentosa & $-100,0$ & - \\
\hline Myrcia variabilis & $-80,0$ & $-100,0$ \\
\hline \multicolumn{3}{|l|}{ NYCTAGINACEAE } \\
\hline Guapira noxia & 0,0 & $-100,0$ \\
\hline \multicolumn{3}{|l|}{ OCHNACEAE } \\
\hline Ouratea spectabilis & $-23,1$ & $-100,0$ \\
\hline \multicolumn{3}{|l|}{ PERACEAE } \\
\hline Pera glabrata & 100,0 & $-100,0$ \\
\hline \multicolumn{3}{|l|}{ PRIMULACEAE } \\
\hline Myrsine guianensis & 100,0 & $-100,0$ \\
\hline \multicolumn{3}{|l|}{ RUBIACEAE } \\
\hline Alibertia sessilis & 0,0 & $-100,0$ \\
\hline Cordiera sessilis & 100,0 & $-100,0$ \\
\hline \multicolumn{3}{|l|}{ RUTACEAE } \\
\hline Zanthoxylum rhoifolium & $-100,0$ & - \\
\hline \multicolumn{3}{|l|}{ SAPINDACEAE } \\
\hline Cupania vernalis & 100,0 & 0,0 \\
\hline \multicolumn{3}{|l|}{ STYRACACEAE } \\
\hline Styrax camporum & $-85,0$ & $-100,0$ \\
\hline Styrax ferrugineus & 50,0 & 50,0 \\
\hline Styrax pohlii & 100,0 & 0,0 \\
\hline \multicolumn{3}{|l|}{ SYMPLOCACEAE } \\
\hline Symplocos pubescens & $-100,0$ & - \\
\hline \multicolumn{3}{|l|}{ THEACEAE } \\
\hline Kielmeyera coriacea & $-100,0$ & - \\
\hline Kielmeyera variabilis & $-100,0$ & - \\
\hline \multicolumn{3}{|l|}{ VERBENACEAE } \\
\hline Aegiphila Ihotskiana & $-100,0$ & - \\
\hline \multicolumn{3}{|l|}{ VOCHYSIACEAE } \\
\hline Qualea cordata & $-100,0$ & - \\
\hline Qualea grandiflora & $-3,3$ & $-72,5$ \\
\hline Qualea jundiahy & 100,0 & $-100,0$ \\
\hline Qualea multiflora & $-29,4$ & $-100,0$ \\
\hline Qualea parviflora & $-51,4$ & $-80,0$ \\
\hline
\end{tabular}

Verificando-se as TRNs entre os estratos adultos amostrados por Teixeira et al. (2004) e o presente estudo, conforme ilustra a Figura $3-A, 40 \%$ das espécies apresentaram resultado positivo, indicando aumento populacional, 4,3\% tiveram resultado neutro, isto é, a população ficou estável, e 55,7\% das espécies apresentaram TRN negativa, o que significa a diminuição da sua população. Do total das espécies com TRN negativa, 59\% podem ser consideradas localmente extintas, pois indivíduos dessas espécies foram amostrados apenas em 2004. Quando analisadas as TRNs entre os estratos adulto e de regeneração amostrados neste 
estudo, a diminuição da diversidade é mais intensa: apenas $17 \%$ das espécies apresentaram TRN positiva, indicando crescimento populacional, 8,5\% das espécies tiveram TRN igual a zero, indicando uma estabilidade no tamanho populacional, e 74,5\% das espécies apresentaram TRN negativa, indicando uma diminuição da população (Figura 3-B). Do total das espécies que indicaram uma diminuição da população, $74,3 \%$ podem ser consideradas localmente extintas, ou seja, não possuem indivíduos no estrato de regeneração.

Figura 3 - Distribuição das espécies de acordo com Taxa de Regeneração Natural (TRN). A: estrato adulto atual comparado com o estrato adulto de 2004. B: estrato de regeneração comparado com o estrato adulto.

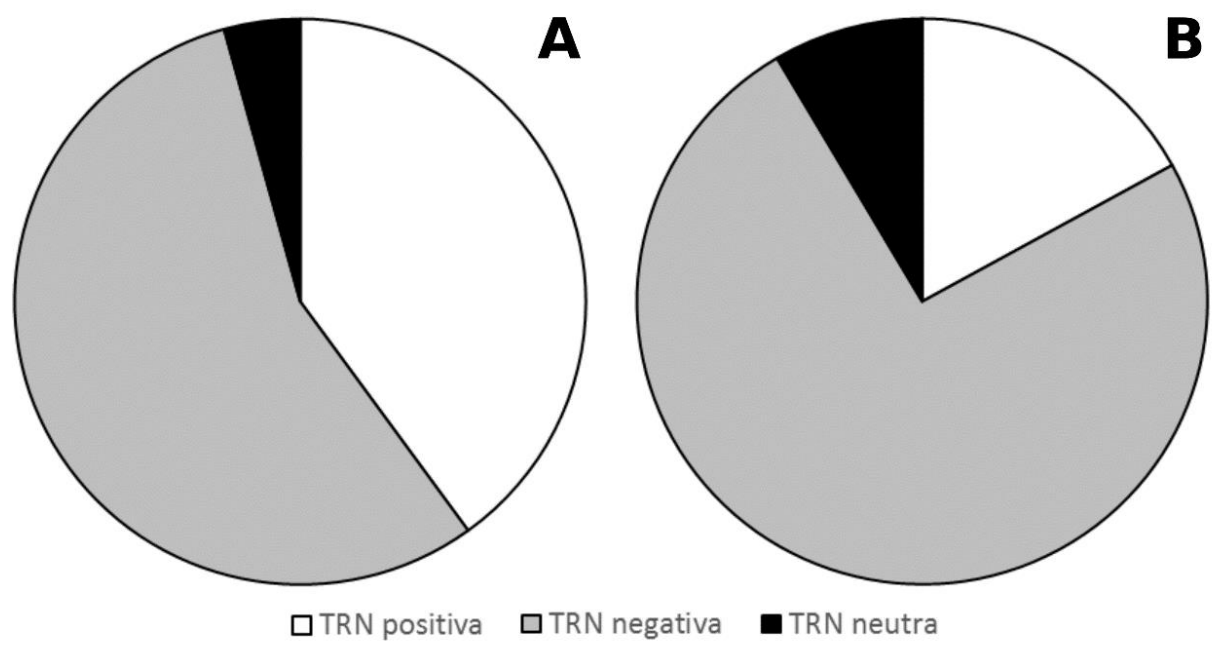

Verificando-se as espécies novas (14 espécies), ou seja, as espécies amostradas no estrato adulto em 2014 e não encontradas em 2004, 14,3\% são pioneiras e 85,7 \% são não pioneiras. Quando analisadas as síndromes de dispersão, 14,3\% são autocóricas, 21,4\% são anemocóricas e 64,3\% são zoocóricas (Figura 4-A). Quando verificadas as características ecológicas das espécies localmente extintas, isto é, aquelas encontradas no levantamento de 2004 e não amostradas em 2014 (23 espécies), 43,5\% são pioneiras e 56,5 \% são não pioneiras. Quando analisadas as síndromes de dispersão, 4,3\% são autocóricas, 30,4\% são anemocóricas e 65,3\% são zoocóricas (Figura 4-B). 
Figura 4 - Distribuição das espécies do estrato adulto do fragmento de cerrato stricto sensu da Fazenda Santa Cecília segundo suas características (grupo ecológico e síndrome de dispersão). A: espécies amostradas em 2014 e não amostradas em 2004. B: espécies amostradas em 2004 e não encontradas em 2014.
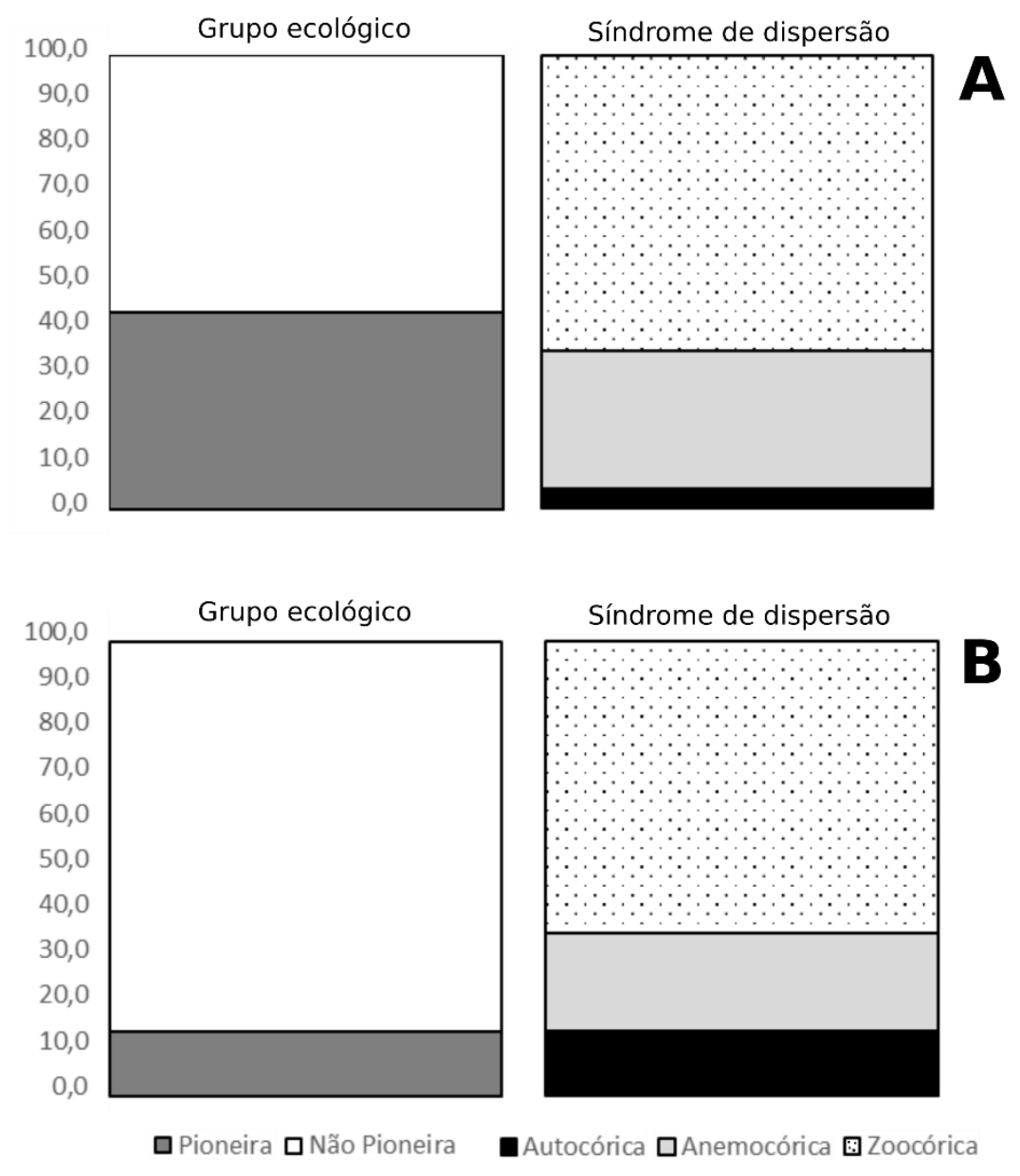

Quando verificadas as características ecológicas das espécies presentes no estrato adulto atual mas ausentes do estrato de regeneração, 3,8\% são pioneiras e $96,2 \%$ são não pioneiras. Com relação à síndrome de dispersão, 7,7\% das espécies são autocóricas, 26,9\% são anemocóricas e 65,4\% são zoocóricas (Figura 5). 
Figura 5 - Distribuição das espécies do estrato de regeneração do fragmento de cerrato stricto sensu da Fazenda Santa Cecília segundo suas características (grupo ecológico e síndrome de dispersão).

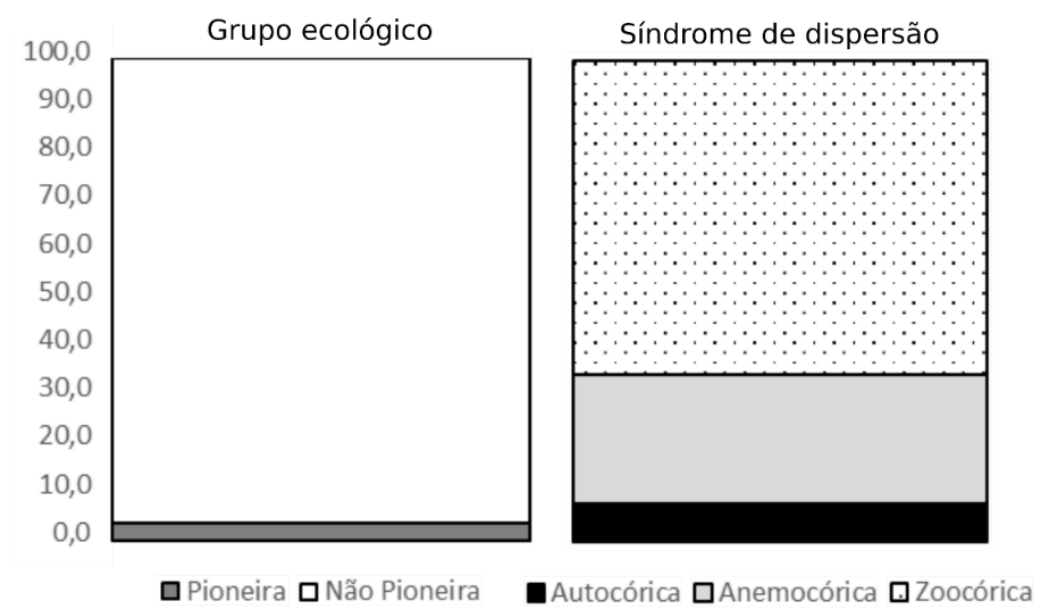

\section{DISCUSSÃO}

Para viabilizar o entendimento e aplicação de conceitos relacionados ao processo de regeneração natural em fragmentos naturais, na forma de medidas de conservação e manejo, é fundamental sintetizar o grande número de informações relacionadas sem, contudo, simplificar demasiadamente um processo naturalmente complexo, onde há muitas variáveis em ação (Rodrigues e Leitão-Filho, 2000; Engel e Parrota, 2003). Entretanto, apesar da grande complexidade deste processo e da necessidade crescente de subsídios para ações conservacionistas, ainda existem muitas lacunas sobre o entendimento do processo de regeneração natural em ecossistemas tropicais sujeitos a diferentes tipos e intensidades de pressão antrópica (Alves e Metzger, 2006). Dada a grande extensão de distribuição do Cerrado, do seu atual estado de fragmentação por ações antrópicas e da necessidade de recuperação de áreas degradadas (Klink e Moreira, 2002; Machado et al., 2004; Alho, 2005; Felfili et al., 2005; Ribeiro et al., 2005; Ratter et al., 2006), uma característica fundamental é conhecer o estado de conservação desses fragmentos, visando manter processos naturais e uma estrutura que represente, ao máximo, as características originais do bioma.

Uma das alternativas para a definição do estado de conservação de uma área natural é avaliar os processos relacionados à regeneração natural. Isso é possível por meio de estudos relacionados às alterações na estrutura e composição da vegetação dessas áreas ao longo do tempo (Guariguata e Ostertag, 2001). Esse tipo de estudo permite estimar os padrões de substituição de espécies vegetais, oferecendo importantes informações a respeito da dinâmica da biodiversidade vegetal (Williams-Linera, 2002). Nesta linha, conhecer as dificuldades ou 
entraves naturais que estão dificultando a regeneração natural, assim como suas origens (natural ou antrópica), são extremamente urgentes e necessárias (Engel e Parrota, 2003). Com esse intuito, conhecer o processo da dinâmica da regeneração natural secundária e identificar possíveis alterações na densidade e riqueza dos estratos mais jovens em áreas naturais podem se constituir em importantes indicadores (Faria et al., 2003).

Quando se aborda o estrato adulto da vegetação, a maioria dos trabalhos disponíveis são descritivos, sendo poucas as pesquisas que apresentam um foco relacionado à dinâmica populacional e/ou relação com impactos antrópicos. Devido à extrema complexidade e variedade dos resultados das atividades antrópicas em áreas naturais, o caráter processual de médio e longo prazos dessas ações e bibliografia disponível com diferentes graus de especificidade, é muito complicado determinar, de forma inequívoca, padrões ou resultados específicos. Assim, todos os resultados e implicações aqui apresentados, apesar de seguir os protocolos científicos adequados, devem ser interpretados com cautela.

Para viabilizar a discussão dos resultados de maneira clara e organizada, a mesma será organizada em tópicos. Entretanto, devido à sua característica processual, para um entendimento integral das ideias não se pode fazer uma interpretação pontual ou segmentada.

\subsection{Comparação entre estratos adultos: Teixeira et al. (2004) e presente estudo}

Os resultados das análises no aspecto temporal, considerando o estudo realizado por Teixeira et al. (2004) e o presente estudo, indica uma diminuição da diversidade vegetal e índices ecológicos. Entretanto, alguns autores, como Libano e Felfili (2006), também verificaram essa característica em outras áreas de Cerrado e consideraram essa diminuição dos índices como uma oscilação natural, relacionada à mudança temporal na composição da comunidade vegetal. Assim, a diminuição da biodiversidade verificada nos últimos 10 anos poderia ser uma oscilação natural.

Essa afirmação baseia-se na comparação da distribuição entre os grupos ecológicos, ou sucessionais, das espécies encontradas no presente estudo e em Teixeira et al. (2004), sugerindo um avanço de estágio seral, com a diminuição de espécies pioneiras e o aumento das secundárias, resultando em uma diminuição quantitativa das espécies encontradas, mas um aumento qualitativo. Esta alteração da composição e importância dos grupos ecológicos na estrutura da comunidade poderiam indicar que o fragmento está se estruturando em um estágio sucessional mais avançado (Finegan, 1992; Ivanauskas et al., 2002). Entretanto, a 
abundância de indivíduos do gênero Xylopia, assim como a ampla ocorrência de indivíduos mortos sugerem a hipótese de pressão antrópica no remanescente.

A baixa similaridade florística encontrada nos estudos com apenas uma década de intervalo é semelhante àquelas encontradas na comparação entre áreas de cerrado muito distantes geograficamente (Bridgewater et al., 2004; Balduino et al., 2005; Batalha e Martins, 2007). Entretanto, outros estudos realizados em áreas de cerrado próximas entre si já apontaram a tendência à grande diferença florística dessa formação (Felfili e Silva Júnior, 1993; Bridgewater et al., 2004).

Outro ponto relevante trata das espécies de sub-bosque, componente estrutural que compreende a vegetação arbustiva e subarbustiva dos ambientes florestais, elementos não amostrados especificamente no presente estudo ou em Teixeira et al. (2004), sendo que nestes estudos foram consideradas apenas arvoretas ou espécies lenhosas encontradas no sub-bosque. Saporetti Jr. et al. (2003) afirmam que as espécies de sub-bosque facilitam o estabelecimento e desenvolvimento de espécies dos outros estratos. Ainda segundo esses autores, um sub-bosque com baixa riqueza poderia resultar em uma diminuição da fauna dispersora de sementes, o que acarretaria em uma diminuição de espécies vegetais zoocóricas, fato não verificado no presente estudo, já que a diminuição das espécies de sub-bosque não foi acompanhada de uma diminuição na quantidade de espécies zoocóricas ao longo do tempo. Uma consideração importante que precisa ser feita é que este efeito pode estar em processo no presente, refletindo na diminuição da biodiversidade do estrato juvenil e da chuva de sementes, fatos identificados neste estudo. Importante destacar que a predominância da zoocoria em áreas de cerrado foi encontrada em outros estudos e é uma característica comum para este bioma (Gottsberger e Silberbauer-Gottsberger, 1983; Weiser e Godoy, 2001; Vieira et al., 2002).

Assim, a diminuição da riqueza verificada poderia ser resultado do conjunto entre mudanças sucessionais naturais e impactos antrópicos indiretos. Se analisados apenas os resultados quantitativos, encontramos uma diminuição geral nos índices de biodiversidade na última década, resultados típicos de áreas antropizadas. Em contrapartida, se considerados os resultados qualitativos (conjunto de espécies vegetais), verifica-se um aumento de espécies vegetais secundárias, em detrimento das pioneiras, e a prevalência de espécies zoocóricas, características de estágios sucessionais mais avançados. Assim, os dados temporais, isoladamente, não permitem um posicionamento definitivo sobre o estado de conservação do fragmento, podendo indicar uma fase de transição de um processo sucessional mais longo ou alterações na composição florística e estrutura da vegetação motivados por ações antrópicas no entorno. 
Entretanto, quando analisada a distribuição das espécies extintas entre os grupos ecológicos, uma tendência mais clara se apresenta. Do total de espécies consideradas extintas localmente (23), 43,5\% são pioneiras e 56,5\% são não-pioneiras. Em um processo de sucessão ecológica, é esperado que as espécies pioneiras sejam substituídas pelas espécies secundárias e clímax (não-pioneiras), mas isso não foi observado, já que um maior número de espécies não-pioneiras foi extinto localmente. Quando analisadas as espécies novas (14), percebe-se que $85,7 \%$ são não-pioneiras, aspecto mais coerente com o esperado em um processo de sucessão natural. Nesse caso, os dados quantitativos oferecem uma informação importante, pois há um número maior de espécies extintas do que novas indicando, assim, uma diminuição nos valores reais de espécies não-pioneiras.

Quando analisadas as distribuições das espécies extintas e novas com relação a síndrome de dispersão, o único resultado que merece destaque é o aumento de espécies autocóricas se estabelecendo no fragmento. A síndrome de dispersão autocórica acontece quando o próprio vegetal libera as suas sementes, independente da ação de um organismo dispersor. Assim, uma implicação do aumento das espécies com esta síndrome de dispersão poderia indicar uma vantagem competitiva na dispersão em comparação com espécies zoocóricas. Essa vantagem seria originada da reduzida comunidade de organismos dispersores presentes no fragmento e entorno.

De forma geral, considerando-se os estratos adultos nos anos de 2004 e 2014, percebese uma mudança na composição florística da vegetação do fragmento, com mais espécies extintas localmente do que a chegada de novas. Segundo Pinho e Pelicice (2017), quando uma espécie não é mais encontrada em determinada região é um indicativo que a mesma sofreu extinção local, prejudicando os processos ecológicos nos quais ela atuava, causando prejuízos ecossistêmicos. Ainda segundo os autores, alterações das características ambientais (estocasticidade ambiental), com destaque as modificações provocadas pelas ações antrópicas, provocam severas alterações locais que podem causar a extinção local de pequenas populações em um curto intervalo de tempo.

Dessa forma, aventa-se a hipótese de que o tamanho do fragmento, a matriz em que está inserido e consequentemente o seu isolamento, influências indiretas exercidas pela pressão humana, possam ser os complicantes para a sua conservação, modificando as suas características naturais, como propuseram Pivello e Coutinho (1996) para os remanescentes de Cerrado, sem desconsiderar a hipótese de eventos sucessionais naturais ocorrendo conjuntamente, dificultando, ainda mais, a identificação de padrões nítidos. 


\subsection{Comparação entre estrato adulto do presente estudo e estrato de regeneração}

Quando comparado o estrato de regeneração com o adulto, pode-se fazer considerações imediatas sobre a dinâmica da comunidade vegetal (Mendes, 2002), aplicadas em práticas relacionadas à conservação, preservação e recuperação de áreas naturais.

A diminuição da biodiversidade mundial é fato ocorrente e registrado nas últimas décadas, com destaque para ambientes tropicais, habitats altamente ameaçados pelas pressões antrópicas (Laurance et al., 2000). Apesar do ritmo acelerado de degradação, ainda não se conhecem, claramente, todos os efeitos dos impactos antrópicos em nível ecossistêmico (Lundberg e Moberg, 2003; Farwig et al., 2006).

No entanto, analisar apenas o estrato vegetal adulto pode não ser um indicador totalmente seguro, pois muitas espécies arbóreas apresentam longo ciclo de vida e as alterações ambientais podem, ainda, não ter se manifestado nesse estrato. De acordo com Janzen (1986) alguns indivíduos vegetais podem ser definidos como "mortos vivos" pois não conseguem se reproduzir de maneira a manter uma população viável em uma área em longo prazo. Dessa forma, para entender de maneira mais ampla o processo de regeneração natural em uma área é preciso considerar os estratos de regeneração, além do estrato adulto.

Devido à complexidade natural do processo reprodutivo vegetal, o processo de regeneração depende de vários atores além do indivíduo vegetal (Wang e Smith, 2002). A atuação de processos e/ou organismos polinizadores e dispersores de sementes se faz imprescindível para que processos fisiológicos e ecológicos intrínsecos a cada espécie se realize (Bleher et al., 2002; Ghazoul, 2005). Além da complexidade dos processos também deve-se considerar o fator tempo necessário para o desenvolvimento de um indivíduo arbóreo. Devido à impossibilidade de acompanhar individualmente o desenvolvimento de uma plântula até o seu estágio adulto, a composição do estrato juvenil já estabelecido é um indicador relevante da habilidade regenerativa de uma área natural (Babaasa et al., 2004).

Conforme apresentado, se em áreas naturais já são muitos os fatores que influenciam os processos relacionados à regeneração florestal, quando se consideram as alterações antrópicas e seus efeitos ainda, em parte, desconhecidos, torna-se ainda mais complicado definir os rumos da regeneração natural, sendo muitos os estudos desenvolvidos recentemente (Chapman e Chapman, 1997; Benitez-Malvido, 1998, Chapman et al., 1999; Cordeiro e Howe, 2001; Benitez-Malvido e Martinez-Ramos, 2003). Se já não bastasse, deve-se considerar também as diferentes respostas fisiológicas e ecológicas das espécies vegetais a essas novas condições, requerendo estudos aprofundados para determinar tendências e compreender as situações resultantes da interação de tantos fatores. 
A análise da regeneração natural considerando-se apenas o estrato adulto, conforme discutido no tópico anterior, permite duas considerações a respeito da diminuição da biodiversidade verificada: resultado do processo natural de sucessão florestal ou dos impactos antrópicos. Ao se aumentar a análise, considerando o estrato de regeneração (juvenil), fica claro que a diminuição da diversidade no estrato adulto é resultado direto da baixa diversidade do estrato de regeneração. Outros estudos já verificaram que as alterações antrópicas em habitats naturais, como a fragmentação e exploração seletiva, diminuíram significativamente a riqueza do estrato de regeneração (Chapman e Onderdonk, 1998; Cordeiro e Howe, 2001; Benitez-Malvido e Martinez-Ramos, 2003; Wang e Smith, 2002). Estes estudos afirmam que a redução da diversidade do estrato regenerativo pode ser decorrente da modificação de características ambientais (luz, umidade) ou das alterações nos componentes envolvidos nos processos de polinização ou de dispersão de sementes.

A pequena similaridade florística observada entre os estratos adulto e de regeneração pode ser justificado pelo caráter processual da regeneração natural de longo prazo. Assim, a composição do estrato adulto atual do fragmento de cerrado stricto sensu da Fazenda Santa Cecília refletiria fatores ambientais e bióticos presentes na área no momento do estabelecimento dos indivíduos (Oliveira-Filho et al. 1997; Schiavini et al. 2001). Seguindo essas considerações, as características ambientais e bióticas atuais estariam afetando, diretamente, a composição do estrato de regeneração (Oliveira e Felfili 2005).

A comparação entre os IVIs das espécies encontradas neste estudo e no estrato adulto permite notar uma clara modificação da importância das espécies entre os estratos. A espécie com maior valor de IVI no estrato regenerante foi Miconia albicans que só ocupa a 11 ำ posição no estrato adulto. Dentre a outras espécies com maior IVI no estrato de regeneração (Xylopia sericeae e Virola sebifera) elas ocupam a 5a e 9a posições, respectivamente, indicando espécies com alto poder de ocupação no fragmento analisado. Xylopia aromatica destaca-se nesta análise, ocupando a segunda posição de IVI nos estratos adulto e regenerante. $X$. aromatica é classificada como pioneira, sendo muito comum em áreas perturbadas (Miranda-Melo et al. 2007), sendo encontrada em mais de $50 \%$ dos estudos florísticos realizados em áreas de cerrado (Ratter et al. 1996). Assim, devido ao seu aumento populacional no fragmento analisado, pode-se assumir que a espécie está tendo sucesso reprodutivo, conforme afirmam Oliveira e Silva (1993) e, dessa maneira, assume-se que este é um importante indicador de desestabilização da comunidade vegetal.

A baixa similaridade florística detectada entre os estratos adulto e de regeneração pode indicar uma deficiência no processo regenerativo da comunidade, com uma pequena possibilidade de substituição de indivíduos e manutenção da biodiversidade. 


\subsection{Comparação entre estrato de regeneração e chuva de sementes}

Como apresentado no tópico anterior, os impactos antrópicos podem afetar a comunidade de organismos dispersores de sementes em fragmentos de áreas naturais, o que afeta diretamente o processo regenerativo. Entretanto, o presente estudo não avaliou os dispersores de sementes presentes na área. Em contrapartida, analisou-se a produção de sementes (fenologia) e o resultado da dispersão (chuva de sementes) e esses dados indicam que a baixa riqueza e quantidade de sementes produzidas e dispersadas estaria influenciando diretamente o estrato de regeneração, fato também observado por Schiavini et al. (2001) em outros habitats de regiões tropicais. Assim, de acordo com Muller-Landau et al. (2002), o processo de regeneração no fragmento analisado poderia estar sofrendo de limitação de recrutamento, ou seja, a diminuição da biodiversidade seria resultado da baixa quantidade de sementes (recrutas). Em uma situação como essa, ocorrendo em médio e longo prazo, haverá um desequilíbrio ecológico com significativa redução da biodiversidade (Münzbergová e Herben, 2005).

Para o estabelecimento de um novo indivíduo vegetal, alcançando o estágio juvenil, é preciso que várias sementes germinem, pois a fase de germinação e desenvolvimento da plântula apresenta a maior taxa de mortalidade do ciclo vegetal (Harper, 1977; Still, 1996). Com esse fato, o processo de dispersão ganha mais importância, com destaque para a zoocoria (Janzen e Vasquez-Yanes, 1991), devido a necessidade de muitas repetições no processo dispersivo para o estabelecimento de um indivíduo. Com os dados fenológicos e da chuva de sementes coletados no fragmento de cerrado da Fazenda Santa Cecília, detecta-se duas possibilidades para a limitação do processo de dispersão, segundo Jordano et al. (2006): a limitação de fonte (pequena produção de frutos e sementes) e a limitação de dispersão (pouca ação de animais dispersores).

A significativa similaridade florística entre o estrato de regeneração e a chuva de sementes, caracterizada basicamente pela baixíssima riqueza, indica um potencial regenerativo muito pequeno, com tendência a não manutenção da biodiversidade encontrada atualmente no estrato adulto.

Outro fato que merece destaque, e que tem implicações na dinâmica da regeneração natural, é a presença exclusiva de espécies autóctones ao fragmento na chuva de sementes, isto é, todas as espécies amostradas na chuva de sementes possuem indivíduos adultos na área analisada. Isto indica pode indicar um baixo sucesso do processo de dispersão, destacando-se a zoocoria, dificultando a chegada de sementes de espécies de áreas próximas. 
De acordo com o exposto até o momento, pode-se concluir que o ciclo reprodutivo de muitas espécies vegetais da área de cerrado stricto sensu não é concluído com sucesso há algum tempo, recrutando novos indivíduos. São necessários estudos específicos para se identificar qual é o processo ou componente deficiente: ausência de polinizadores ou dispersores; taxa de produção de sementes das espécies arbóreas; ou outros aspectos relacionados à fragmentação e isolamento de áreas naturais (Durigan et al., 2002).

\section{CONCLUSÃO}

A manutenção da cobertura vegetal de uma área é dependente da capacidade de conservação e desenvolvimento da comunidade, processo longo e extremamente complexo que pode ser entendido como regeneração natural. Assim, a ausência de um componente regenerativo robusto, representativo do estrato adulto, com uma diversidade esperada para o bioma, indica o fracasso no processo de regeneração no fragmento analisado. Assim, foi identificado um processo de diminuição da biodiversidade vegetal, podendo-se considerar a área como um escoadouro de biodiversidade, com a possibilidade de extinção local de muitas espécies arbóreas.

Compreendendo que todas as espécies em ambientes naturais estão sob um delicado equilíbrio, percebe-se a importância dos estratos regenerativos, indivíduos aptos a ocupar o espaço físico e o nicho ecológico dos indivíduos adultos quando estes completarem seu ciclo de vida. Indo além da importância natural (ecológica), é importante destacar que muitas espécies podem ser exploradas economicamente e conhecer os estoques de indivíduos regenerantes é fundamental para que o processo de uso das espécies seja baseado em conceitos sustentáveis. Vale destacar que os indivíduos regenerantes são plântulas ou juvenis que, reunidos, representam o depósito de riqueza da vegetação de uma área e quando esse componente não é representativo do estrato adulto, a morte dos indivíduos adultos significa a extinção local da espécie.

Assim, a hipótese inicial do presente estudo foi refutada, pois mesmo sem impactos antrópicos diretos a dinâmica de regeneração natural do fragmento de cerrado stricto sensu não está ocorrendo de maneira ecologicamente esperada, não sendo capaz de manter a diversidade e tamanho populacional das espécies lenhosas encontradas.

De acordo com a atual situação de degradação e sua intensa fragmentação, as pesquisas relacionadas a dinâmica de sucessão da vegetação do Cerrado em áreas antropizadas são fundamentais, pois tais ações antrópicas, com ênfase para a fragmentação de habitats, é um 
grande risco para a manutenção da biodiversidade, alterando drasticamente características relacionadas à dinâmica e estrutura da vegetação.

E dada a complexidade natural dos processos ecológicos é altamente recomendável o desenvolvimento de estudos sobre polinizadores e dispersores de sementes, além de estudos fenológicos prolongados e em larga escala com o intuito de conhecer detalhes da produção de sementes. Devido às possibilidades da presente pesquisa, esses componentes não foram devidamente abordados e o desenvolvimento dessas pesquisas promoveria importantes esclarecimentos de alguns resultados apresentados neste estudo.

\section{REFERÊNCIAS BIBLIOGRÁFICAS}

ALHO, C. J. R. 2005. Desafios para a conservação do Cerrado, em face das atuais tendências de uso e ocupação. In: SCARIOT, A.; SOUSA SILVA, J. C.; FELFILI, J. M. (Org.). Cerrado: ecologia, biodiversidade e conservação. Brasília: Ministério do Meio Ambiente, p. 367381.

ALVES, L. F.; METZGER, J. P. 2006. A regeneração florestal em áreas de floresta secundária na Reserva Florestal do Morro Grande, Cotia, SP. Biota Neotropica 6 (2), 1-26.

ARAÚJO, M. M.; OLIVEIRA, F. A. I. C. G.; BARROS, P. L. C.; LIMA, C. A. T. 2001. Densidade e composição florística do banco de sementes do solo de florestas sucessionais na região do Baixo Rio Guamá Amazônia Oriental. Scientia Forestalis 59 (12), 115 - 130.

BABAASA, D.; EILU, G.; KASANGAKI, A.; BITARIHO, R.; MCNEILAGE, A. 2004. Gap characteristics and regeneration in Bwindi Impenetrable National Park, Uganda. African Journal of Ecology 42, 217-224.

BALDUÍNO, A. P. C.; SOUZA, A. L.; NETO, J. A. A. M.; SILVA, A. F.; SILVA JÚNIOR, M. C. 2005. Fitossociologia e análise comparativa de composição florística do Cerrado na Floana de Paraopeba-MG. Revista Árvore 29 (1), 25-34.

BATALHA, M. A.; MARTINS, F. R. 2007. The vascular flora of the cerrado in Emas National Park (Central Brazil): a savanna flora summarized. Brazilian Archives of Biology and Techology 50, 269-277.

BEGON, M.; TOWNSEND, C. R.; HARPER, J. L. 2006. Ecology: from individuals to ecosystems. New Jersey: Blackwell Publishing, $738 \mathrm{p}$.

BENITEZ-MALVIDO, J. 1998. Impact of forest fragmentation on seedling abundance in a tropical rain forest. Conservation Biology 12, 380-389.

BENÍTEZ-MALVIDO, J.; MARTÍNEZ-RAMOS, M. 2003. Impact of forest fragmentation on understorey plant species richness in Amazonia. Conservation Biology 17 (2), 389- 400.

BLEHER, B.; OBERRATH, R.; BOHNING-GAESE, K. 2002. Seed dispersal, breeding system, tree density and the spatial pattern of trees - a simulation approach. Basic and Applied Ecology 3, 115-123. 
BRIDGEWATER, S.; RATTER, J. A.; RIBEIRO, J. F. 2004. Biogeographic patterns, b-diversity and dominance in the cerrado biome of Brazil. Biodiversity and Conservation 13, 2295-2318.

BROKAW, N. V. L. 1982. The definition of tree fall gap and its effect on measure of forests dynamics. Biotropica 14 (2), $156-160$.

CARVALHO, J. O. P.1999. Dinâmica de florestas naturais e sua implicação para o manejo florestal. In: Simpósio silvicultural na Amazônia Oriental: Contribuições do projeto EMBRAPA/DFID. Belém: EMBRAPA. p. 174 - 179.

CHAPMAN, C. A.; CHAPMAN, L. J. 1997. Forest regeneration in logged and unlogged forests of Kibale National Park, Uganda. Biotropica 29, 396-412.

CHAPMAN, C. A.; ONDERDONK, D. A. 1998. Forests Without Primates: Primate/Plant Codependency. American Journal of Primatology 45, 127-141.

CHAPMAN, C. A.; CHAPMAN, L. J.; KAUFMAN, L.; ZANNE, A. E. 1999. Potential causes of arrested sucession in Kibale National Park, Uganda: Growth and mortality of seedings. African Journal of Ecology 37, 81-92.

CHAZDON, R. 2012. Regeneração de florestas tropicais. Boletim Museu Paraense Emílio Goeldi 7 (3), 195-218.

CONDIT, R.; HUBBEL, S. P.; FOSTER, R. B. 1994. Density dependence in two understory tree species in a neotropical forest. Ecology Oxford 75 (3), 671 - 680.

CONNELL, J. H., TRACEY, J. G.; WEBB, L. J. 1984. Compensatory recruitment, growth, and mortality as factors maintaining rain forest tree diversity. Ecological Monographs 54, 141164.

CORDEIRO, N. J.; HOWE, H. F. 2001. Low recruitment of trees dispersed by animals in African forest fragments. Conservation Biology 15, 1733-1741.

DURIGAN, G.; NISHIKAWA, D. L. L.; ROCHA, E.; SILVEIRA, E. R.; PULITANO, F. M.; REGALADO, L. B.; CARVALHAES, M. A.; PARANAGUÁ, P. A.; RANIERI, V. E. L. 2002. Caracterização de dois estratos da vegetação em uma área de cerrado no município de Brotas, SP, Brasil. Acta Botanica Brasileira 16 (3), 251-262.

ENGEL, V. L.; PARROTA, J. A. 2003. Definindo a restauração ecológica: tendências e perspectivas mundiais. In: KAGEYAMA, P. Y.; OLIVEIRA, R. E.; MORAES, L. F. D.; ENGEL, V. L.; GANDARRA, F. B. (Ed.). Restauração ecológica de ecossistemas naturais. Botucatu: Fundação de Estudos e Pesquisas Agrícolas Florestais, p.1-26.

FARIA, M. B. B. C.; ALFANO, A. C. C.; ALVES, L. F.; FRANCO, G. A. D. C. 2003. Chuva de sementes em uma floresta tropical montana do planalto paulista. In: Anais do VI Congresso de Ecologia do Brasil, p.310-311.

FARWIG, N.; BOHNING-GAESE, K.; BLEHER, B. 2006. Enhanced seed dispersal of Prunus africana in fragmented and disturbed forests? Oecologia 147, 238-252.

FELFILI, J. M.; SILVA JÚNIOR, M. C. 1993. A comparative study of cerrado (stricto sensu) vegetation in Central Brazil. Journal of Tropical Ecology 9, 277-289. 
FELFILI, J. M.; SOUSA-SILVA, J. C.; SCARIOT, A. 2005. Biodiversidade, ecologia e conservação do Cerrado: avanços do conhecimento. In: SCARIOT, A.; SOUSA-SILVA, J. C.; FELFILI, J. M. (Org.). Cerrado: ecologia, biodiversidade e conservação. Brasília: Ministério do Meio Ambiente, p.25-44.

FINEGAN, B. 1992. The management potential of neotropical secondary lowland rain forest. Forest Ecology and Management 47 (1-4), 295-391.

FINOL, U. H. 1971. Nuevos parâmetros a considerarse em el analisis estructural de lãs selvas virgenes tropicales. Revista Venezolana 14 (21), 29-49.

GHAZOUL, J. 2005. Pollen and seed dispersal among dispersed plants. Biological Reviews 80, 413-443.

GLENN-LEWIN, D. C.; PEET, R. K.; VEBLEN, T. T. 1992. Plant Succession; theory and prediction. London: Chapman e Hall, $352 \mathrm{p}$.

GOTTSBERGER, G.; SILBERBAUER-GOTTSBERGER, I. 1983. Dispersal and distribution in the Cerrado vegetation of Brazil. Sonderbd Naturwiss ver Hamburg 7, 315-352.

GUARIGUATA, M. R. e OSTERTAG, R. 2001. Neotropical secondary succession: changes in structural and functional characteristics. Forest Ecology Management 148, 185-206.

HAMMER, O.; HARPER, D. A. T.; RYAN, P. D. 2001. PAST: Paleontological Statistics Software Package for Education and Data Analysis. Disponível em: <http://nhm2.uio.no/norlex/past/download.html>. Acesso em: 20 fev. 2017.

HARPER, J. L. 1977. Population biology of plants. London: Academic Press, 892 p.

INOUE, M. T. 1979. Regeneração natural: seus problemas e perspectivas para as florestas brasileiras. Curitiba: FUPEF, $23 \mathrm{p}$.

IVANAUSKAS, N. M.; RODRIGUES, R. R.; NAVE, A. G. 2002. Fitossociologia de um remanescente de Floresta Estacional Estacional Semidecidual em Itatinga-SP, para fins de restauração de áreas degradadas. Revista Árvore 26 (1), 43-57.

JANZEN, D. H. 1986. The future of tropical ecology. Annual Review of Ecology and Systematics $17,305-324$.

JANZEN, D. H.; VASQUEZ-YANES, C. 1991. Aspects of tropical seed ecology of relevance to management of tropical forested Wildlands. In: GOMEZ-POMPA, A.; WHITMORE, T.C.; HADLEY, M. (Ed.). Rainforest regeneration and management. Paris: UNESCO. p. 137-157.

JARDIM, F. C. S. 1987. Taxa de regeneração natural na floresta tropical úmida. Acta Amazonica 16/17, 401-410.

JARDIM, F. C. S.; VOLPATO, M. M. L.; SOUZA, A. L. 1993. Dinâmica de sucessão natural em clareiras de florestas tropicais. Viçosa: SIF, $60 \mathrm{p}$. 
JORDANO, P.; GALETTI, M.; PIZO, M. A.; SILVA, W. R. 2006. Ligando frugivoria e dispersão de sementes à Biologia da Conservação. In: ROCHA, C. F. D.; BERGALLO, H. G.; ALVES, M. A. S. S.; VAN SLUYS, M. (Org.). Biologia da Conservação: Essências. São Carlos: Editora RIMA. p. 411-436.

KLINK, C. A.; MOREIRA, A. 2002. Past and current human occupation, and land use. In: OLIVEIRA, P. S.; MARQUIS, R. J. (Ed.). Ecology and natural history of a Neotropical Savanna. New York: Columbia University Press, p. 69-88.

LAURANCE, W. F.; DELAMONICA, P.; LAURANCE, S. G.; VASCONCELOS, H. L.; LOVEJOY, T. E. 2000. Rainforest fragmentation kills big trees. Nature 404, 836.

LIBANO, A. M.; FELFILI, J. M. 2006. Mudanças temporais na composição florística e na diversidade de um cerrado sensu stricto do Brasil Central em um período de 18 anos. Acta Botanica Brasilica 20 (4), 927-936.

LUNDBERG, J.; MOBERG, F. 2003. Mobile link organisms and ecosystem functioning: Implications for ecosystem resilience and management. Ecosystems 6, 87-98.

MACHADO, R. B.; RAMOS NETO, M. B.; PEREIRA, P. G. P.; CALDAS, E. F.; GONÇALVES, D. A.; SANTOS, N. S.; TABOR, K.; STEININGER, M. 2004. Estimativas de perda da área do Cerrado brasileiro. Brasília: Conservação Internacional, 26 p. Disponível em: <http://cmbbc.cpac.embrapa.br/RelatDesmatamCerrado\%20CIBrasil\%20JUL2004.pdf>. Acesso em: 22 fev. 2017.

MAGURRAN, A. E. 1988. Ecological diversity and its measurement. New Jersey: Princeton University Press, $179 \mathrm{p}$.

MARTÍNEZ-RAMOS, M.; SOTO-CASTRO, A. 1993. Seed rain and advanced regeneration in a tropical rain forest. Plant ecology 107-108, 299-318.

MENDES, S. 2002. Comparação entre os estratos arbóreo e de regeneração na mata de galeria da Estação Ecológica do Panga, Uberlândia-MG. Dissertação de Mestrado: UFU, 76p.

MIRANDA-MELO, A. A.; MARTINS, F. R; SANTOS, F. A. M. 2007. Population structure of Xylopia aromatica (Lam.) Mart. and of Roupala montana Aubl. in "cerrado" fragments in São Paulo State. Revista Brasileira de Botânica 30 (3), 501-507.

MIYAZAKI, S. L. 2009. Análise de estrutura, chuva de sementes e regeneração natural de populações de plantas em floresta de restinga alta, São Vicente-SP. Tese de Doutorado apresentada ao Instituto de Botânica da Secretaria do Meio Ambiente, 107 p.

MORY, A. M. 2000. Comportamento de espécies arbóreas em diferentes níveis de desbaste por anelamento. Dissertação de Mestrado em Ciências Florestais, Belém: FCAP, 100 p.

MULLER-LANDAU, H. C.; WRIGHT, S. J.; CALDERÓN, O.; HUBBELL, S. P.; FOSTER, R. B. 2002. Assessing recruitment limitation: concepts, methods and case-studies from Tropical Forest. In: LEVEY, D. J.; SILVA, W. R.; GALETTI, M. (Ed). Seed dispersal and frugivory: ecology, evolution, and conservation. Wallingford: CABI Publishing, p. 35-53. 
MÜNZBERGOVÁ, Z.; HERBEN, T. 2005. Seed, dispersal, microsite, habitat and recruitment limitation: identifications of terms and concepts in studies of limitations. Oecologia 145, $1-8$.

MYeRS, N.; MITTERMEIER, R. A.; MitTeRMeIeR, C. G.; FONSECA, G. A. B.; KeNT, J. 2000. Biodiversity hotspots for conservation priorities. Nature 403, 853-858.

NEGRELLE, R. R. B. 2006. Composição florística e estrutura vertical de um trecho de Floresta Ombrófila Densa de Planície Quaternária. Hoehnea 33 (3), 261-289.

ODUM, E. P. 1983. Ecologia. Atlanta: University of Georgia, 434 p.

OLIVEIRA, E. C. L.; FELFILI, J. M. 2005. Estrutura e dinâmica da regeneração natural de uma mata de galeria no Distrito Federal, Brasil. Acta Botanica Brasílica 19, 801-811.

OLIVEIRA-FILHO, A.T.; MELLO, J.M. e SCOLFORO, J.R.S. 1997. Effects of past disturbance and edges on tree community structure and dynamics within a fragment of tropical semideciduous forest in south-eastern Brazil over a five-year period (1987-1992). Plant Ecology 131, 45-66.

OLIVEIRA, P. E.; SILVA, J. C. S. 1993. Reproductive biology of two species of Kielmeyera (Guttiferae) in the cerrados of central Brazil. Journal of Tropical Ecology 9, 67-79.

PAGLIA, A. P.; FERNANDEZ, F.A.S. e DE MARCO JR., P. 2006. Efeitos da fragmentação de habitats: Quantas espécies, quantas populações, quantos indivíduos, e serão eles suficientes?. In: ROCHA, C. F. D.; BERGALLO, H. G.; SLUYS, M. V.; ALVES, M. A. S. Biologia da Conservação: Essências. São Carlos: RIMA, p. 281-316.

PINHO, L. A.; PELICICE, F. M. Extinção. Disponível em: <http://nead.uesc.br/arquivos/Biologia/ modulo_8-bloco_1/uni_extincao/material_apoio/M8EBU3_Extincao_versao_web.pdf>. Acesso em: 04 abr. 2017.

PIVELLO, V. R.; COUTINHO, L. M. 1996. A qualitative successional model to assist in the management of Brazilian cerrados. Forest Ecology and Management 87 (1), 127-138.

RATTER, J. A.; BRIDGEWATER, S.; ATKINSON, R.; RIBEIRO, J. F. 1996. Analysis of the floristic composition of the brazilian cerrado vegetation II: Comparison of the woody vegetation of 98 areas. Edinburgh Journal of Botany 53 (2), 153-180.

RATTER, J. A.; BRIDGEWATER, S.; RIBEIRO, J. F. 2006. Biodiversity patterns of the woody vegetation of the Brazilian Cerrado. In: PENNINGTON, T.; LEWIS GWILYM, P.; RATTER, J. A. (Org.). Neotropical Savannas and dry forests: diversity, biogeography and conservation. Boca Raton: Taylor e Francis, p.31-66.

RIBEIRO, J. F.; BRIDGEWATER, S.; RATTER, J. A.; SOUSA-SILVA, J. C. 2005. Ocupação do bioma Cerrado e conservação da sua diversidade vegetal. In: SCARIOT, A.; SOUSA-SILVA, J. C.; FELFILI, J. M. (Org.). Cerrado: ecologia, biodiversidade e conservação. Brasília: Ministério do Meio Ambiente, p.383-399.

RODRIGUES, R. R.; LEITÃO-FILHO, H. F. 2000. Matas Ciliares - Conservação e recuperação. São Paulo: Edusp, $320 \mathrm{p}$. 
RODRIGUES, R. R. 1999. Colonização e enriquecimento de um fragmento florestal urbano após a ocorrência de fogo. Fazenda Santa Elisa, Campinas, SP: Avaliação temporal da regeneração natural (66 meses) e do crescimento (51 meses) de 30 espécies florestais plantadas em consórcios sucessionais. Piracicaba: Tese de Livre Docência - Escola Superior de Agricultura Luiz de Queiroz, Universidade de São Paulo, Piracicaba, 167 p.

RODRIGUES, R. R.; MARTINS, S. V.; BARROS, L. C. 2004. Tropical rainforest regeneration in an area degraded by mining in Mato Grosso State, Brazil. Forest Ecology and Management 190, $323-333$.

ROLLET, B. 1978. Arquitetura e crescimento das florestas tropicais. Belém: SUDAN, 22 p.

SANTOS, C. A. N.; JARDIM, F. C. S. 2012. Dinâmica da regeneração natural de Vouacapoua americana com diâmetro $<5 \mathrm{~cm}$, influenciada por clareiras, em Moju, Pará. Floresta 42 (3), 495-508.

SAPORETTI JR., A. W.; MEIRA NETO, J. A. A.; ALMADO, R. P. 2003. Fitossociologia de cerrado sensu stricto no município de Abaeté - MG. Revista Árvore 27 (3), 413-419.

SCHERER, A.; MARASCHIN-SILVA, F.; BAPTISTA, L. R. 2007. Regeneração arbórea num capão de restinga no Rio Grande do Sul, Brasil. Iheringia 62 (1-2), 89-98.

SCHIAVINI, I.; RESENDE, J. C. F.; AQUINO, F. G. 2001. Dinâmica de populações de espécies arbóreas em mata de galeria e mata mesófila na margem do ribeirão Panga, MG. In: RIBEIRO, J. F.; FONSECA, C. E. L.; SOUSA-SILVA, J. C. (Eds.). Cerrado: caracterização e recuperação de matas de galeria. Brasília: Embrapa Cerrados, p. 267-299.

SOLOMON, M. E. 1980. Dinâmica de populações. São Paulo: EPU, 78 p.

SOUZA, A. L.; SCHETTINO, S.; JESUS, R. M.; VALE, A. B. 2002. Dinâmica da regeneração natural em uma Floresta Ombrófila Densa Secundária após corte de cipós, Reserva Natural da Companhia Vale do Rio Doce S. A., estado do Espírito Santo, Brasil. Revista Árvore 26 (4), 411-419.

SORREANO, M. C. M. 2002. Avaliação de aspectos da dinâmica de florestas restauradas com diferentes idades. Dissertação de Mestrado em Engenharia Florestal - Escola Superior de Agricultura Luiz de Queiroz, Piracicaba, 153 p.

STILL, M. J. 1996. Rates of martality and growth in three groups of dipterocarp seedlings in Sabah, Malaysia. In: WAINE, M.D. The ecology of tropical forest tree seedlings. Paris: UNESCO and Parthenon Publishing Group, p. 315-331.

TABARELLI, M.; MANTOVANI, W. 1999. A regeneração de uma floresta tropical montana após corte e queima (São Paulo-Brasil). Revista Brasileira de Biologia 59 (2), 239-250.

TEIXEIRA, M. I. J. G.; ARAÚJO, A. R. B.; VALERI, S. V.; RODRIGUES, R. R. 2004. Florística e fitossociologia de área de Cerrado s.s. no município de Patrocínio Paulista, nordeste do estado de São Paulo. Bragantia 63 (1), 1-11.

TORIOLA, D.; CHAREYRE, P.; BUTTLER, A. 1998. Distribution of a primary forest plant species in a 18 ㅇy year old secondary forest in French Guiana. Journal of Tropical Ecology 14 (3), 323340. 
VIEIRA, D. L. M.; AQUINO, F. G.; BRITO, M. A.; FERNADES-BULHÃO, C.; HENRIQUES, R. P. B. 2002. Síndromes de dispersão de espécies arbustivo-arbóreas em Cerrado sensu stricto do Brasil Central e Savanas Amazônicas. Revista Brasileira de Botânica 25 (2), 215-220.

WANG, B. C.; SMITH, T. B. 2002. Closing the seed dispersal loop. Trends in Ecology and Evolution 17, 379-385.

WEISER, V. L.; GODOY, S. A. P. 2001. Florística em um hectare de cerrado stricto sensu na ARIECerrado Pé-de-Gigante, Santa Rita do Passa Quatro, SP. Acta Botanica Brasilica 15 (2), 201-212.

WILLIAMS-LINERA, G. 2002. Tree species richness complementarity, disturbance and fragmentation in a Mexican tropical montane cloud forest. Biodiversity Conservation 11, 1825-1843. 